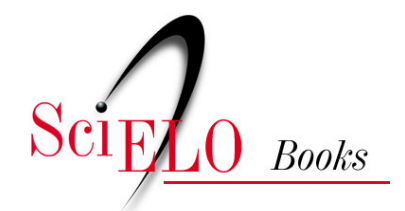

\title{
Epidemiologia, serviços e tecnologias em saúde
}

\author{
Maurício Lima Barreto \\ Naomar de Almeida Filho \\ Renato Peixoto Veras \\ Rita Barradas Barata \\ (orgs.)
}

BARRETO, ML., et al., orgs. Epidemiologia, serviços e tecnologias em saúde [online]. Rio de Janeiro: Editora FIOCRUZ, 1998. 235 p. EpidemioLógica series, nº 3. ISBN 85-85676-49-3. Available from SciELO Books <http://books.scielo.org>.

\section{(1) (1) (2)}

All the contents of this work, except where otherwise noted, is licensed under a Creative Commons Attribution-Non Commercial-ShareAlike 3.0 Unported.

Todo o conteúdo deste trabalho, exceto quando houver ressalva, é publicado sob a licença Creative Commons Atribuição Uso Não Comercial - Partilha nos Mesmos Termos 3.0 Não adaptada.

Todo el contenido de esta obra, excepto donde se indique lo contrario, está bajo licencia de la licencia Creative Commons Reconocimento-NoComercial-CompartirIgual 3.0 Unported. 


\section{EPIDEMIOLOGIA, SERVIÇOS E TECNOLOGIAS EM SAÚDE}

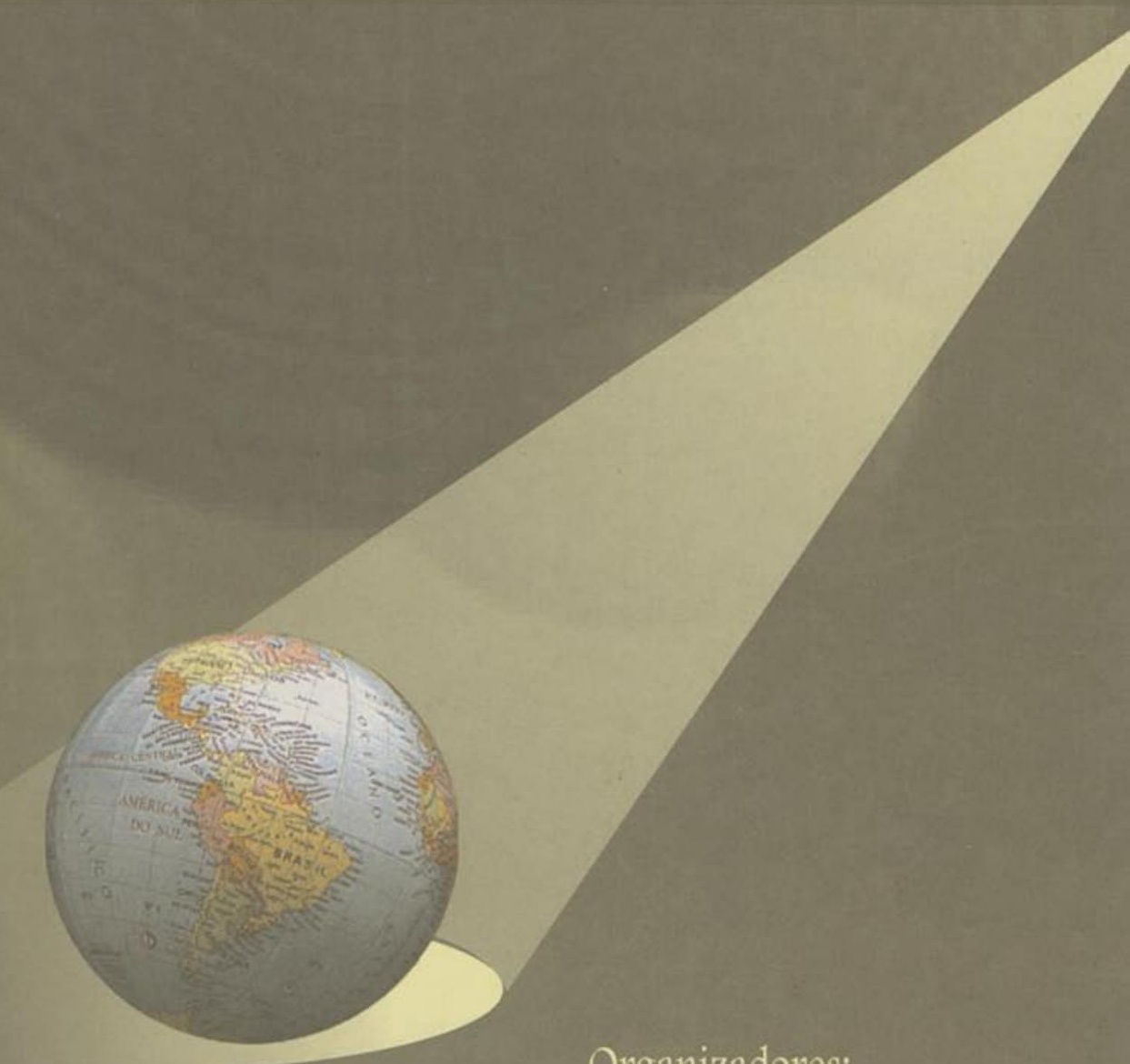

Organizadores:

Maurício Lima Barreto

Naomar de Almeida Filho

Renato Peixoto Veras

Rita Barradas Barata 


\section{EPIDEMIOLOGIA, SERVIÇOS E TECNOLOGIAS EM SAÚDE}




\section{FUNDAÇÃO OSWALDO CRUZ}

Presidente

Eloi de Souza Garcia

Vice-Presidente de Ambiente, Comunicação e Informação

Maria Cecilia de Souza Minayo

\section{EDITORA FIOCRUZ}

Coordenadora

Maria Cecilia de Souza Minayo

Conselho Editorial

Carlos E. A. Coimbra Jr.

Carolina M. Bori

Charles Pessanba

Hooman Momen

Jaime L. Bencbimol

José da Rocba Carvalbeiro

Luiz Fernando Ferreira

Miriam Struchiner

Paulo Amarante

Paulo Gadelha

Paulo Marchiori Buss

Vanize Macêdo

Zigman Brenner

Coordenador Executivo

João Carlos Canossa P. Mendes 


\title{
EPIDEMIOLOGIA, SERVIÇOS E TECNOLOGIAS EM SAÚDE
}

\author{
Organizadores \\ Maurício Lima Barreto \\ Naomar de Almeida Filho \\ Renato Peixoto Veras \\ Rita Barradas Barata
}

Série EpidemioLógica 3

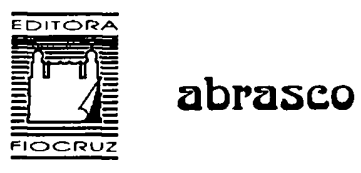


Copyright 1998 dos autores

Todos os direitos desta edição reservados à

FUNDAÇÃO OSWALDO CRUZ/EDITORA FIOCRUZ

ISBN 85-85676-49-3

Capa: Guilherme Asbton

Projeto gráfico: Guilberme Asbton e Carlos Fernando Reis da Costa

Editoração eletrônica: Carlos Fernando Reis da Costa

Copidesque: Jorge Luiz Moutinbo Lima

Revisào de provas: Fermanda Veneu

Supervisão editorial: M. Cecilia Gomes Barbosa Moreira

ESTA PUBLICAÇÃO FOI PARCIALMENTE PRODUZIDA COM RECURSOS PROVENIENTES DO CONVÊNIO 123/94 - ABRASCO/FUNDAÇÃO NACIONAL DE SAÚDE DO MINISTÉRIO DA SAÚDE

- COM O OBJETIVO DO DESENVOLVIMENTO DA EPIDEMIOLOGIA EM APOIO $\lambda S$ ESTRATÉGIAS DO SUS.

Catalogação-na-fonte

Centro de Informação Científica e Tecnológica

Biblioteca Lincoln de Freitas Filho

B273e Barreto, Maurício Lima (Org.)

Epidemiologia, serviços e tecnologias em saúde/Organizado por

Maurício Lima Barreto, Naomar de Almeida Filho, Renato Peixoto Veras e

Rita Barradas Barata. - Rio de Janeiro: Flocruz/ABrasCO, 1998.

235p., tab., graf., (Série EpidemioLógica 3)

1.Epidemiologia. 2. Tecnologia médica. 3. Países em desenvolvimento.

I. Almeida Filho, Naomar de. II. Veras, Renato Peixoto. III Barata, Rita Barradas.

CDD - 20ed. - 614.4

1998

EDITORA Fiocruz

Rua Leopoldo Bulhões, 1480 - Térreo - Manguinhos

21041-210 - Rio de Janeiro - RJ

Tel.: (021) 5903789 ramal 2009

Fax: (021) 2808194 


\title{
Autores
}

\author{
Andreu Segura
}

Institut Universitari de Salut Pública de Catalunya - Espanha

\section{Antonio F. C. Infantosi}

Coordenação de Programas de Pós-Graduação em Engenharia/Universidade Federal do Rio de Janeiro

\section{Chester Luiz Galvão Cesar}

Departamento de Epidemiologia da Faculdade de Saúde Pública/Universidade de São Paulo

\section{Ciro A. de Quadros}

Programa Especial de Vacinas e Imunização/Organização Pan-Americana da Saúde Washington, D.C.

\section{Cláudia Medina Coeli}

Departamento de Medicina Preventiva/Universidade Federal do Rio de Janeiro

\section{Dana P. Loomis}

Departamento de Epidemiologia e Centro de Pesquisa em Prevenção de Danos/Universidade da Carolina do Norte - EUA

\section{Edinilsa Ramos de Souza}

Centro Latino-Americano de Estudos sobre Violência e Saúde (CI.AvEs)/Escola Nacional de Saúde Pública/Fıccruz

\section{Eduardo Hage Carmo}

Instituto de Saúde Coletiva da Universidade Federal da Bahia

\section{Elena Matos}

International Agency for Research on Cancer - Lyon, França

\section{Elizabeth Barrett-Connor}

Departamento de Medicina Preventiva e Familiar/Universidade da Califórnia San Diego, EUA

\section{Evandro Coutinho}

Instituto de Medicina Social/Universidade do Estado do Rio de Janeiro e Escola Nacional de Saúde Pública/Fıocruz

$$
\text { G. Thériault }
$$

McGill University - Canadá

\section{Orozco Nodarse}

National Health Screening Service - Oslo, Noruega 


\section{Luiz Augusto Facchini}

Departamento de Medicina Social/Universidade Federal de Pelotas

\section{Manolis Kogevinas}

International Agency for Research on Cancer - Lyon, França

\section{Marcos Drumond Júnior}

Programa de Aprimoramento das Informações de Mortalidade/Secretaria Municipal da Saúde da Prefeitura do Município de São Paulo

\section{Miguel Carrasco Asenjo}

Centro Universitário de Saúde Pública/Universidade Autônoma de Madri - Espanha

\section{Neil Pearce}

Wellington School of Medicine - Wellington, Nova Zelândia e International Agency for Research on Cancer - Lyon, França

\section{Paolo Boffeta}

International Agency for Research on Cancer - Lyon, França

\section{Renan Moritz V. R. Almeida}

Coordenação de Programas de Pós-Graduação em Engenharia/Universidade Federal do Rio de Janeiro

\section{Renato Peixoto Veras}

Instituto de Medicina Social e Universidade Aberta da Terceira Idade/Universidade Estadual do Rio de Janeiro

S. Graff-Iversen

National Health Screening Service - Oslo, Noruega

\section{Organizadores}

\section{Mauricio Lima Barreto}

Instituto de Saúde Coletiva/Universidade Federal da Bahia

\section{Naomar de Almeida Filho}

Instituto de Saúde Coletiva/Universidade Federal da Bahia

\section{Renato Peixoto Veras}

Instituto de Medicina Social e Universidade Aberta da Terceira Idade/Universidade

Estadual do Rio de Janeiro

\section{Rita Barradas Barata}

Departamento de Medicina Social/Faculdade de Ciências Médicas da Santa Casa de São Paulo 


\section{Sumário}

1. A Avaliação Epidemiológica do Efeito das Intervenções Sanitárias Andreu Segura

2. Avaliação de Tecnologia em Saúde: uma metodologia para países em desenvolvimento

Renan Moritz. V. R. Almeida \& Antonio F. C. Infantosi 25

3. Avaliação dos Efeitos de Vacinas: mudanças na suscetibilidade, infectividade, contatos e efeitos diretos e indiretos

M. Elizabeth Halloran \& Claudio J. Strucbiner

4. A Infecção Hospitalar como Parâmetro da Qualidade

Miguel Carrasco Asenjo

5. Terapia de Substituição Hormonal

Elizabeth Barrett-Connor

6. Consumo de Hormônios e Fatores de Risco Cardiovascular em Mulheres

S. Graff-Iversen \& L Orozco Nodarse

7. O 'Enfoque de Risco’ em Saúde Pública

Chester Luiz Galvão Cesar

8. Vigilância da Morte Evitável: acesso rápido e descentralização das informações Marcos Drumond Júnior

9. Erradicação de Doenças: lições aprendidas, desafios a enfrentar

Ciro A. de Quadros

10. Construção de Novos Pressupostos para o Controle de Endemias Eduardo Hage Carmo

11. Câncer Ocupacional nos Países em Desenvolvimento Neil Pearce, Paolo Boffeta, Manolis Kogevinas \& Elena Matos 
12. Câncer Ocupacional e Mecanismos Carcinogênicos

G. Thériault

13. Epidemiologia da Violência em Locais de Trabalho nos EUA

Dana P. Loomis

14. Trabalho Materno e Nutrição Infantil: situação atual e perspectivas

Luir. Augusto Facchini

15. Mortalidade por Homicídios na Década de 80: Brasil e capitais de regiões metropolitanas

Edinilsa Ramos de Souza

16. Epidemiologia dos Transtornos Mentais em Idosos: um estudo comunitário e hospitalar

Renato Peixoto Veras, Evandro Coutinho \& Cláudia Medina Coeli 207 


\section{APRESENTAÇÃO}

A epidemiologia tem se mostrado, ao longo de sua história, um importante e potente instrumento para identificar e solucionar os problemas de saúde das populações. Fazem parte deste movimento a definição de necessidades, o planejamento e a avaliação dos serviços de saúde. Todo este esforço de organizar serviços e desenvolver novas tecnologias pode ser entendido como a forma encontrada pelas sociedades para compreender suas doenças e montar as estratégias para enfrentá-las. Os serviços de saúde devem ser vistos como um conjunto de esforços socialmente organizados para enfrentar os fatores geradores das doenças ou, pelo menos, minimizar seus males. Entretanto, ao longo da história, acumula-se um profícuo debate sobre o verdadeiro resultado destes esforços $\mathrm{cm}$, efetivamente, modificar as condições de saúde das populações. Hoje está claro que parte das atividades realizadas no sistema de saúde tem baixa ou nenhuma efetividade (quando não efeitos negativos). Outra parte, ainda que possa ser efetiva, necessita de permanentes adequações para amplificar os seus efeitos.

O sistema de saúde é um complexo que inclui intensos esforços de desenvolvimento científico e tecnológico, passando pelo processo de produção industrial e, por fim, pela organização dos seus produtos em unidades 
(simples ou complexas) prestadoras de serviços às sociedades. Na perspectiva epidemiológica, deve ser entendido como um potencial modificador das condições de saúde da população. Apesar de buscar sempre efeitos benéficos, não raras vezes gera efeitos indesejáveis. Neste contexto, a função da epidemiologia pode ser dividida em duas grandes perspectivas: contribuir para os ajustes internos do sistema - atuando na seleção de tecnologias e processos com maior efetividade, ajudando, também, a ampliá-la - e auxiliar na compreensão de problemas e necessidades de saúde que este sistema deve priorizar, medindo seu impacto sobre a saúde global das populações.

Umas das críticas à epidemiologia está calcada em suas relações com as práticas da saúde publica. Verificou-se que parte do conhecimento produzido sobre as populações é inadequado, invalidando as proposições de prevenção dele derivadas. Apesar de desempenhar um papel primordial na pesquisa sobre saúde da população, a epidemiologia nem sempre foi alicerce para desenvolver os conhecimentos necessários para fundamentar as práticas de promoção a saúde, tampouco para conduzir mudanças necessárias na organização dos serviços de saúde (Dean \& Kuster, 1996).

No campo da avaliação, as contribuições da epidemiologia, apesar de relevantes, têm ainda muitas limitações. A capacidade de produzir e colocar em uso novas tecnologias voltadas para o cuidado à saúde (drogas, aparelhos, procedimentos e sistemas organizacionais para a atenção à saúde) tem crescido exponencialmente. Ao lado do potencial de cura ou de prevenção (nem sempre confirmado) e dos efeitos indesejáveis destas tecnologias estão seus altos e crescentes custos, razão de preocupação de todos aqueles com alguma responsabilidade sobre a saúde dos indivíduos ou das populações. Há, na visão de progresso social, a idéia equivocada de que ele seja conseqüência da assimilação de novas tecnologias, deixando-se de lado, inclusive, os seus efeitos diretos como geradoras de doenças.

No campo da saúde, pairam grandes dúvidas sobre a importância destas tecnologias como modificadoras das condições de saúde das populações. Têm-se buscado várias estratégias para demonstrar o quanto as tecnologias, ações e serviços de saúde podem ser eficazes ou efetivas. Porém, há evidências de que parte importante delas, apesar de em uso corrente, não foi adequadamente avaliada. Os fatores que contribuem para isto são: a imensa e exponencialmente crescente quantidade de tecnologi- 
as disponíveis, altos custos de um adequado processo de avaliação, falta de interesse dos produtores, incertezas sobre a extrapolação dos estudos de eficácia para outras populações e insuficiências de ordem metodológicas como a falta de desenhos que permitam avaliações objetivas de certas tecnologias (United States, 1994). Os ensaios aleatorizados, a mais elaborada avaliação disponível (Power, Tunis \& Wagner, 1994) - para alguns, o modelo de referência na investigação epidemiológica - apresentam, com freqüência, resultados discordantes, mesmo quando têm como base desenhos e tamanhos amostrais que lhes garantiriam confiabilidade. Metódos observacionais e os quase-experimentos disponíveis nem sempre conseguem responder às questões apresentadas.

Mesmo com todo o esforço de avaliação, ainda não foi possível superar os problemas inerentes à definição da eficácia das tecnologias. As limitações relativas à avaliação da efetividade são ainda maiores. Mesmo tendo níveis aceitáveis de eficácia, quando analisadas isoladamente, muitas das tecnologias são pouco efetivas quando utilizadas como parte rotineira de ações, programas e serviços de saúde.

A questão torna-se mais complexa e real, embora menos aparente, quando nos deparamos com o problema da efetividade dos programas e serviços de saúde. São estruturas organizacionais que agregam uma ou mais tecnologias e que, em seu conjunto, formam o complexo prestador de serviços de saúde. Este complexo atua de acordo com regras de mercado, nem está sempre sujeito a normas reguladoras e ao controle social, e dificilmente poderá vir a ser globalmente avaliado. Entretanto, avaliar a eficácia e a efetividade de, pelo menos, parte das tecnologias, ações ou programas direcionados à cura ou prevenção em saúde é uma tarefa para a qual a epidemiologia dispõe de recursos. A documentação da baixa efetividade de muitas dessas intervenções e o alto custo dos seus limitados benefícios são contribuições científica e socialmente relevantes da epidemiologia para melhorar da qualidade e o controle de custos da assistência e da prevenção em saúde.

A identificação e priorização dos nossos problemas de saúde passam pela forma como conseguimos compreendê-los e definimos as suas relações com os potenciais fatores causais ou protetores. Os modelos quantitativos de estimativas de risco têm explicado apenas parte dos determinantes dos problemas de saúde que afligem as populações. Muitas vezes, fatores que 
não são - nem podem vir a ser detectados por esta estratégia de investigação - respondem por parte substancial do risco. Em conseqüência, podem ocorrer grandes frustrações relacionadas à efetividade de medidas preventivas derivadas de estimativas de riscos - que explicam uma parte menor do processo causal (Evans, 1994). Qualquer intervenção é derivada da maneira de compreender a estrutura causal de determinado fenômeno. Portanto, na perspectiva epidemiológica, a sua avaliação está sujeita às abordagens da investigação epidemiológica, em geral.

Nos artigos desta coletânea, relata-se um conjunto relevante de experiências, relacionando diferentes problemas, utilizando-se metodologias distintas e com diversos graus de profundidade. São temas como avaliação, controle de doenças, fatores determinantes, informação, trabalho; alguns em torno de questões muito específicas, outros com maior grau de generalidade. Em comum, têm o fato de serem contribuições apresentadas no curso dos Congressos de Epidemiologia de Salvador (III Brasileiro/II Ibero-Americano/I Latino-Americano). Em conjunto, constituem uma amostra representativa das preocupações e potencialidades contemporâneas da construção de uma epidemiologia da saúde coletiva - na qual a preocupação central deve ser enfrentar o complexo de problemas de saúde existentes e potenciais que afligem a humanidade.

O leitor deve ter como pressuposto a idéia de que a epidemiologia do presente deve transitar entre as definições e usos tradicionais e uma série de novos conceitos continuamente decodificados e assimilados. Deve dialogar com as experiências inovadoras, a fim de que elas contribuam para fortalecer os vínculos da epidemiologia com seus propósitos fundamentais e com a saúde coletiva. Deve utilizar todas as possíveis fontes de dados e informaçõcs existentes; participar da construção das novas bases conceituais e metodológicas que irão permitir o desenvolvimento de conhecimentos e novas possibilidades de prevenir os eventos mórbidos e amenizar os sofrimentos humanos. Neste caminho, talvez possamos romper em definitivo com a idéia de que a epidemiologia é apenas um método ou um conjunto de técnicas, como alguns quiseram nos incutir. E, indo além, talvez possamos reafirmar a epidemiologia como a disciplina encarregada de sintetizar as elaborações sobre a compreensão de nossa saúde e doenças que, de forma permanente e dinâmica, construímos (Barreto, no prelo). 


\section{REFERÊNCIAS BIBLIOGRÁFICAS}

DEAN, K. \& HUNTER, D. New directions for health: towards a knowledge for public health action. Social Science and Medicine, 42:745-750, 1996.

UNITED STATES. US Congress Office Technol. Assess. Identifying Health Technologies that Work. Searching for Evidence. Washington, D.C: US GPO, 1994.

POWER, E. J.; TUNIS, S.R. \& WAGNER, J. L. Tecnology assessment and public health. Annual Review of Public Health, 15:561-579, 1994.

EVANS, R. \& STODDART, G. Introduction. In: EVANS, R.; BARER, M. \& MARMOR, T. (Eds.) Why are some people bealthy and others not? The determinants of health of populations. New York: Aldine de Gruyter, 1994.

BARRETO, M. L. Por uma epidemiologia da saúde coletiva. Revista Brasileira de Epidemiologia (no prelo). 


\section{A AVALIAÇÃO EPIDEMIOLÓGICA \\ DO EFEITO DAS \\ INTERVENÇÕES SANITÁRIAS*}

Andreu Segura

Entre as diversas possibilidades de aplicação da epidemiologia à gestão dos serviços da saúde, destaca-se, como um dos aspectos básicos, o da avaliação das conseqüências de atividades e intervenções sanitárias. Estas conseqüências têm diversas dimensões, entre as quais costuma-se considerar como as mais importantes, a partir da perspectiva dos serviços sanitários, a eqüidade, a satisfação e a saúde propriamente dita, que seria a conseqüência mais genuinamente sanitária.

Apesar da ausência de análises empíricas acerca da importância relativa da finalidade avaliação em face da finalidade etiológica com relação à produtividade dos estudos epidemiológicos, admite-se geralmente que as análises referentes à avaliação são menos freqüentes que as investigações de causas e fatores de risco de problemas da saúdc. Admitindo csta formulação, a presente exposição pretende analisar os diversos fatores que podem explicar esta situação.

\footnotetext{
'Tradução: Claudia Bastos
} 
Com essa finalidade, consideraremos as particularidades diferenciais dos dois tipos de objetivos epidemiológicos em investigações causais, o papel dos gestores na demanda potencial de informação epidemiológica sobre o efeito das intervenções $\epsilon$ as atitudes dos epidemiologistas no que diz respeito à sua implicação na gestão. Mesmo no caso de a assunção inicial não ser válida, a análise da influência desses fatores e as possíveis medidas de correção propostas poderiam, todavia, preservar seu interesse no sentido de incrementar as aplicações da epidemiologia à gestão dos serviços e dos programas sanitários.

A epidemiologia como disciplina científica tem desenvolvido procedimentos para contrastar hipóteses de associação causal que, apesar de basicamente utilizados em investigações etiológicas, são passíveis de aplicação em investigações de avaliação. Em ambos os casos, trata-se de obter evidências razoavelmente convincentes de modo a atribuir a um determinado fator o papel de uma variável explicativa. Assim, enquanto o descobrimento de uma causa ou de um fator de risco permite formular sua prevenção ou seu tratamento, quando se dispõe de uma intervenção, um serviço ou uma terapêutica trata-se de avaliar a eficácia e a efetividade, de modo a colocá-lo em prática ou, caso seja necessário, substituí-lo por uma alternativa melhor.

Ainda que as aplicações à investigação etiológica e à avaliação compartilhem de um mesmo planejamento metodológico, a diferença nos respectivos objetivos e em suas repercussões práticas exige que consideremos algumas particularidades. Entre elas cabe mencionar, por exemplo, a utilização dos diferentes desenhos de estudos com relação à evidência necessária para tomar decisões de intervenção. Supõe-se que os desenhos experimentais - e dentre eles os ensaios controlados aleatórios - podem proporcionar a evidência mais convincente no âmbito da investigação de avaliação, o que torna conveniente o estímulo à prática desse tipo de investigações. Sem dúvida, a utilidade principal dessa forma de estudos se refere à demonstração da eficácia, e no campo da gestão é pelo menos tão importante a demonstração da efetividade que, conseqüentemente, se revestem de grande interesse os desenhos de estudos de intervenção não estritamente experimentais. De outro lado, os desenhos observacionais também podem buscar informações que sirvam de orientação relativa à utilidade - sobretudo os estudos de caso-controle que são mais rápidos e econômicos. Decorre dai a conveniência de adaptar esses recursos me- 
todológicos da epidemiologia às necessidades de informação dos gestores, de modo a racionalizar as atividades dos serviços sanitários (Selby, 1994).

Por outro lado ainda, deve-se considerar a aplicabilidade dos estudos ecológicos e de base individual a partir de dados administrativos. Apesar das limitações desse tipo de desenho no sentido de avaliar o efeito na saúde, mostram-se eles pertinentes para analisar a eqüidade segundo variáveis estratégicas como o local de residência, o gênero, a idade, o nível de renda etc.

Outro aspecto diferente é que, enquanto a verificação de hipóteses etiológicas objetiva a refutação da hipótese nula - razão pela qual interessa sobretudo quantificar a probabilidade de erro alfa ou de tipo I -, na verificação de hipóteses de avaliação pode ser muito importante estabelecer a probabilidade de erro beta ou do tipo II, visto que, de modo geral, trata-se de comparar duas ou mais intervenções, e nos interessa de modo idêntico saber se existem diferenças ou se elas inexistem - isto é, quantificar o erro que assumimos ao aceitar a hipótese nula. Mas a ausência de tábuas de valores de probabilidade de erro beta com relação às leis de probabilidade mais freqüentemente utilizadas na prática da inferência estatística supõe uma limitação prática na aceitação de hipóteses nulas.

Também devem-se levar em consideração as dificuldades que supõem a escolha das variáveis dependentes que refletem as mudanças na saúde das pessoas que são objeto de intervenção. No caso da sobrevida, dispomos de indicadores relativamente simples e de procedimentos adequados para sua análise, mas quando se trata de medir variações na qualidade de vida associada à saúde, explicitam-se complicações metodológicas sérias. $\mathrm{O}$ uso de índices como os Anos de Vida Ajustados por Qualidade (AvAQs), ou os anos de vida equivalentes em saúde, constituem possibilidades conceitualmente muito sugestivas ainda que seu cálculo implique certas restrições, fazendo com que persistam problemas metodológicos e práticos por resolver. $\mathrm{O}$ mesmo poderíamos dizer quanto aos perfis da saúde que têm sido desenvolvidos para aplicação à população geral - como o Nottingham Health Profile - ou em populações de pacientes - como o Sickness Impact Profile.

Neste sentido, é relevante recordar que as críticas de McKeown e de Cochrane (Alvarez-Dardet \& Ruiz, 1993) à falta de influência das intervenções médicas sobre a saúde têm sido de modo geral utilizadas como um álibi por aqueles que defendem políticas restritivas do gasto sanitário e que, por 
extensão, criticam o modelo de estado do bem-estar (welfare state). Portanto, se se pretende que os serviços sanitários sejam os maiores responsáveis pelo aumento da esperança de vida ou da melhora de outros indicadores globais da saúde, é natural que, em vista das evidências negativas, alguns políticos defendam que não vale a pena aumentar os gastos deste setor. Mas trata-se de demonstrar que as intervenções sanitárias propostas têm um efeito positivo. $\mathrm{E}$, com isto, comprovar que tal efeito se produz.

Daí o interesse em desenvolver medidas sensíveis da influência das intervenções sobre a saúde e a qualidade de vida associada à saúde. Mas, enquanto se elabora esse tipo de medidas, parece factível selecionar indicadores simples, a partir dos dados recolhidos nos prontuários clínico-administrativos, que se mostrem aplicáveis de forma sistemática, ainda que somente visando a orientar as análises. Naturalmente, ao mesmo tempo, devem-se levar adiante estudos epidemiológicos que permitam avaliar a efetividade dos procedimentos e das intervenções praticadas.

Devem-se ainda considerar as avaliações denominadas custo/efetividade ou custo/utilidade. Sobretudo porque o estudo da eficiência representa um campo de grande interesse para os gestores - ainda que na maioria dos casos esses trabalhos sejam, em realidade, análises de custo/eficácia, generalizadas a condições de aplicação real pouco conhecidas. Sem dúvida, deve-se alertar acerca das limitações que implicam passar da eficácia à efetividade sem uma base empírica, o que não anula o interesse de tais avaliações, mas sim diminui em parte sua aplicabilidade, uma vez que a gestão sanitária deve se preocupar com a efetividade, na mesma medida em que se preocupa com a eficácia.

É inquestionável o caráter legitimador de muitas dessas avaliações secundário à sua finalidade comercial. Daí tornar-se esclarecedor o fato de que são os departamentos comerciais das empresas farmacêuticas, mais do que os departamentos de pesquisa e desenvolvimento, os que quase sempre levam a cabo ou estimulam essas investigações. Exige-se, pois, um estímulo complementar que promova o estudo da efetividade - estímulo esse que deve emanar do próprio sistema sanitário, já que é ele, em tese, o maior interessado em aumentar a eficiência (a relação entre o custo e a efetividade ou utilidade) de suas atividades.

As dificuldades secundárias às peculiaridades da investigação epidemiológica avaliatória provavelmente refletem mais a falta de tradição do que um 
obstáculo particularmente insuperável. De fato, o desenvolvimento dos métodos epidemiológicos na investigação etiológica tem se defrontado também com problemas e dificuldades que estão sendo superados, em função da insistência e da dedicação. Sem dúvida, a história da epidemiologia não é alheia ao estudo de avaliação. Vale a pena recordar o trabalho de Bernouilli (1971) acerca da sobrevida de crianças submetidas à 'variolização', ou o de Semmelweis (1988) sobre as diversas taxas de mortalidade materna nas duas maternidades de Viena. Mas se aceitarmos que as aplicações epidemiológicas à avaliação de serviços mostram-se de pequena monta, provavelmente será útil procurar alguma explicação nos modelos de serviços sanitários atuais como instituições.

Em primeiro lugar, cabe perguntar quais são as preocupações básicas dos responsáveis pelos serviços sanitários. E se, para além da retórica, a saúde ocupa algum lugar entre elas. Por quê? Como prestar contas à sociedade no que diz respeito aos benefícios obtidos com relação à saúde ou à qualidade de vida associada à saúde, atribuíveis a suas instituições e atividades? Quem solicita as contas e como o faz?

Talvez dever-se-iam também fazer as mesmas perguntas aos clínicos e, de modo geral, a qualquer sanitarista. Isto porque, pelo menos desde Cochrane, sabemos que eficácia é um conceito análogo ao de valor para os militares, concepção que supomos estar popularizada em demasia. De qualquer modo, as respostas a essas perguntas são provavelmente tributárias da definição de objetivos mensuráveis em termos da saúde, que possam ser atribuídos de forma razoável às intervenções. Neste sentido, a iniciativa da Saúde para Todos, da Organização Mundial da Saúde, talvez se revele útil. Sempre que, como é natural, os objetivos se convertam em compromissos explícitos das instituições e comportem, conseqüentemente, a adoção de incentivos e sanções.

A gestão dos serviços sanitários não cobre toda a responsabilidade da direção, mas constitui um elemento muito importante, já que o papel do gestor é conseguir que a instituição, o serviço ou o programa funcione. Novamente cabe perguntar: até que ponto o efeito das intervenções na saúde preocupa o gestor? Isto é, que vantagens procura o gestor que se preocupa com o impacto na saúde das atividades do serviço? A quem ele presta contas acerca desses aspectos?

A adoção de técnicas empresariais na gestão dos serviços sanitários é absolutamente inevitável, em função da complexidade das organizações, mas 
a empresa sanitária, apesar de compartilhar muitas das características das empresas de serviços, tem especificidades no sentido em que lida com a saúde dos pacientes. E, como ocorre em qualquer outra empresa, a produtividade $\mathrm{e}$ a eficiência são simplesmente instrumentos para alcançar a finalidade que lhes é própria - em nosso caso, melhorar a saúde e a qualidade de vida associada à saúde das pessoas atendidas. E, como se deduz da definição de eficiência, não é possível melhorá-la, nem somente quantificá-la, senão com base na eficácia ou na efetividade. Para ser eficiente, a atividade sanitária tem que ser eficaz ou efetiva. Ela poderá ser mais ou menos custosa, mas não mais ou menos barata. Desse modo, a gestão deve ser uma ferramenta, uma forma de proceder, de modo a alcançar os objetivos da instituição. Para tanto, deve existir uma instância que os estabeleça, e pelo menos alguns deles devem ser definidos em termos de impacto sobre a saúde e a qualidade de vida das pessoas atendidas. Essa instância deveria ser a direção geral da empresa sanitária.

Fixar os objetivos constitui a fase prévia de um processo que continua com o estabelecimento de prioridades. Porque atender às necessidades ou demandas crescentes com recursos limitados exige sempre optar entre distintas alternativas. E é evidente que o volume e a natureza das demandas de serviços da saúde não têm limites, ao menos perceptíveis na atualidade. De um lado, as mudanças no padrão epidemiológico, em que cada vez são mais importantes os problemas da saúde e as enfermidades crônicas sem uma terapêutica resolutiva, fazem com que não somente não se reduza a prevalência de problemas, como, de fato, a incrementem. Por outro lado, a idéia cada vez mais difundida de que a saúde e os serviços sanitários são um direito da população, e de que tais serviços são desejáveis, determina também uma tendência ao aumento da demanda.

Por isso, devem-se estabelecer prioridades, que não consistem simplesmente na expressão de boas intenções, mas que devem levar em consideração os recursos disponíveis e as estratégias para utilizá-los, o que supõe se defrontar com os conflitos de interesses que inevitavelmente ocorrem. A formalização das decisões de escolha, baseada, por exemplo, na importância dos problemas e em sua vulnerabilidade face às intervenções, permite a racionalização dessas decisões. Daí decorre que, caso não se formalizem as prioridades, carece de sentido analisar a importância dos problemas da saúde e a suscetibilidade destes às intervenções preventivas, curativas reabilitadoras, ou de promoção da saúde. 
Assim, pois, para que as instituições sanitárias tenham interesse no desenvolvimento da epidemiologia de avaliação, faz-se necessário prestar contas no que diz respeito à sua influência sobre a saúde das pessoas e das populações sob seu cuidado. A iniciativa que alguns sistemas sanitários têm tomado, de separar o financiamento da provisão dos serviços sanitários, pode ter repercussões positivas nesse sentido, sempre que nos contratos que se estabeleçam entre financiadores e produtores esteja incluída a avaliação do efeito sobre a saúde de suas atividades. E que cssa avaliação tenha conseqüências na forma de incentivos positivos e negativos.

Porém, a medida do impacto na saúde das intervenções não é simples, devido ao fato de o produto 'saúde' - ou 'qualidade de vida associada à saúde' - de muitos serviços sanitários ser distinguido com dificuldade da 'saúde’ como resultante de muitas outras influências que não as estritamente sanitárias. Influências essas que têm relação com o grau de riqueza, com a cultura ou com a exposição a fatores do ambiente físico, familiar ou social com impacto positivo ou negativo sobre a saúde.

Por isso, pode ser adequado aproveitar o interesse e os esforços que os gestores dedicam no sentido de medir e avaliar as atividades dos serviços que gerenciam. O que levam a cabo, inclusive, com certo grau de sofisticação, como se evidencia na utilização de indicadores de consumo de recursos como os Diagnostic Related Groups (DRGs) ou, mais recentemente, os PMCs. Trata-se, pois, de introduzir paulatinamente medidas simples de impacto na saúde - como as taxas de mortalidade ajustadas pela casuística atendida, a proporção de reinternações por complicações, ou a simples percepção subjetiva da saúde e, neste âmbito, a redução da ansiedade, dos sintomas, a melhora da dor e do mal-estar, ou a limitação de atividades (Ellis \& Whittington, 1993) - medidas que se poderão associar às atividades e aos procedimentos dos serviços sanitários.

Outras conseqüências das intervenções sanitárias que merecem atenção são a satisfação dos usuários e dos profissionais e a eqüidade no acesso aos serviços sanitários e no seu consumo. Ainda que as contribuições potenciais da cpidemiologia na análise dessas conseqüências não sejam tão específicas como o que ocorre na análise do efeito na saúde, é conveniente que nossa disciplina colabore em scu estudo. E isto por duas razões: a primeira, porque esta ć uma necessidade particularmente importante do sistema sanitário, que até agora não 
tem sido adequadamente satisfeita; a segunda, porque tanto a satisfação como a eqüidade interagem com a saúde e com a qualidade de vida associada à saúde. Alćm disso, tanto uma quanto outra permitem abordagens similares à da epidemiologia. Assim, a medida da satisfação formula problemas parecidos com aqueles com que nos defrontamos quando pretendemos avaliar a percepção da saúde por parte das pessoas atendidas, o que também ocorre no caso da eqüidade. Vale a pena recordar as propostas de Dever (1984) de utilizar índices de 'compromisso' (commitment) e de 'relevância' (relevance) para avaliar o uso de scrviços sanitários em territórios definidos e, inclusive, para estudar a variabilidade na freqüência das intervenções médicas e sanitárias.

Finalmente, devem-se considerar nossas próprias atitudes como epidemiologistas na linha de frente com relação à promoção das aplicações da epidemiologia à investigação avaliatória e à colaboração na gestão dos scrviços sanitários. Provavelmente, este ten sido um campo de nossa atividade relativamente descuidado, talvez em conseqüência do fato de que os pólos mais importantes de atração intelectual de boa parte dos epidemiologistas mais tradicionais sejam, em minha opinião, o acadêmico - interessado sobretudo no desenvolvimento de modelos teóricos e na sofisticação da análise, particularmente estatística - e o político-social - preocupado com a ideologia. (Os debates sobre a prática da epidemiologia clínica ilustram esta polarização, de modo que, para alguns ilustres colegas, a epidemiologia clínica não mereceria este nome. Sem dúvida, ignorar, sem mais nem menos, o desenvolvimento crescente desta área não evita os eventuais erros ou insuficiências de sua prática, deixando simplesmente o campo livre aos que aceitam sc engajar.

Ao menos em potência, a epidemiologia possui todos os ingredientes necessários para se converter em uma linguagem comum para clínicos (e sanitaristas), de um lado, e gestores de (e responsáveis por) scrviços da saúde, por outro. Daí decorre ser necessário empenhar-se na gestão, ainda que isto pressuponha, inevitavelmente, se expor e cometer alguns erros que não têm lugar, por exemplo, na segurança de um departamento universitário. Mas não fazêlo implica abandonar grande parte das possibilidades de atuação. 


\section{REFERÊNCIAS BIBLIOGRÁFICAS}

ALVAREZ-DARDET, C. \& RUIZ, M. T. Thomas McKeown and Archibald Cochrane: a journey through the diffusion of their ideas. British Medical Journal, 306:1.252-1.255, 1993.

BERNOULLI, D. Mathematical and physical memoirs, taken from the registers of Royal Academy of Sciences for the year 1760: an attempt at a new analysis of mortality caused by smallpox and of advantages of inoculation to prevent it. In: BRADLEY, L. Smallpox Inoculation: an eighteenth century mathematical controversy. Nottingham: University of Nottingham, 1971.

DEVER, A. G. E. Epidemiology in Health Services Management. Rockville: Aspen Publications, 1984.

ELLIS, R. \& WHITTINGTON, D. Quality Assurance in Health Care. London: Edward Arnold, 1993.

SELBY, Joe V. Case-control evaluations of treatment program efficacy. Epidemiological Reviews, 16:90-101, 1994.

SEMMELWEIS, J. I. Etiologia, concepto y profilaxis de la fiebre puerperal. In: BUCK, C. et al. (Ed.) El Desafio de la Epidemiologia. Washington: OPS, 1988. 


\section{A AVALIAÇÃO DE TECNOLOGIA EM SAÚDE: UMA METODOLOGIA PARA PAÍSES EM DESENVOLVIMENTO}

Renan Moritz. V.R. Almeida \& Antonio F. C. Infantosi

\section{INTRODUÇÃO}

Avaliação de Tecnologia em Saúde (ATS) pode ser entendida como o procedimento sistemático que permite avaliar os impactos de uma tecnologia sobre uma população no que concerne a aspectos como segurança, eficácia, efetividade, custo-efetividade e implicações éticas e sociais. Nessa definição, tecnologia refere-se tanto a produtos biotecnológicos, drogas e equipamentos médicos, quanto a procedimentos terapêuticos e sistemas de apoio à decisão (Clifford, 1994).

O objetivo fundamental da ATS é prover informações confiáveis a planejadores, auxiliando a formulação de políticas da saúde, por meio de uma compreensão mais elaborada do desenvolvimento, da difusão e do uso apropriado da tecnologia em saúde (Clifford, 1994; Panerai \& Peña-Mohr, 1989). A ATS tem-se preocupado, principalmente, com os efeitos indiretos, colaterais ou não esperados, ocasionados pela disseminação do uso de uma 
tecnologia em uma população. $\mathrm{Na}$ avaliação desses efeitos, os procedimentos e desenhos de estudo tradicionais da epidemiologia são utilizados pela ATS. Da mesma forma, problemas metodológicos similares aos da epidemiologia ocorrem também em estudos de ATS (por exemplo, na obtenção de indicadores com validade conceitual adequada e no estabelecimento de grupos de comparação-controle válidos).

A atividade de ATS ganhou grande impulso na década de 60 , com o desenvolvimento da percepção de que numerosas tecnologias em saúde caracterizavam-se por alto custo, rápida evolução e obsolescência acelerada. Apesar da enorme expectativa por ocasião de sua introdução, constatou-se que o impacto dessas tecnologias não era tão benéfico como o esperado e que sua demanda era, freqüentemente, desnecessária, artificialmente induzida e, muitas vezes, contraproducente (Panerai \& Peña-Mohr, 1989).

Os desenhos de estudo em ATS preocupam-se com três conceitos fundamentais: a efetividade, a segurança e o custo-efetividade de uma tecnologia. A efetividade é a capacidade de uma tecnologia ser utilizada sob condições reais (médias de uso), em oposição à sua funcionalidade sob condições idealizadas (eficácia). A segurança preocupa-se com a probabilidade de efeitos adversos para o paciente, decorrentes do uso de uma nova tecnologia. Já o custo-efetividade de uma tecnologia visa a avaliar alternativas tecnológicas, de forma a identificar aquelas que apresentem impactos positivos maiores em relação a determinado problema, para um mesmo risco e custo.

\section{ATS em Países em Desenvolvimento}

\section{AdMINISTRAÇÃo LOCAL}

A forma como a ATS se articula aos sistemas da saúde e sua administração global é essencial para sua execução adequada, pois ela não pode ser desvinculada das condições de implementação de uma tecnologia, em particular da forma como o sistema da saúde se estrutura. Isso é de fundamental importância para países em desenvolvimento, nos quais a organização do 
sistema da saúde ainda não está consolidada. No Brasil, nota-se uma forte tendência à regionalização da administração na saúde, decorrente da implantação do Sistema Único de Saúde (SUS). Novas questões são então impostas à ATS, como, por exemplo, se é viável a constituição de centros nacionais de Avaliação de Tecnologia em Saúde, inseridos em um sistema cuja administração é altamente descentralizada (Panerai, 1994).

\section{Ciclo de Vida Tecnológico}

Outro conceito de grande importância para a ATS é o de ciclo de vida tecnológico. O processo de aceitação de uma tecnologia (seu ciclo de vida) é classicamente descrito como constituído das fases de inovação, difusão, incorporação, utilização plena e eventual 'abandono' (Brorsson \& Wall, 1989; Mosteller, 1989). Tradicionalmente, recomenda-se também que a avaliação tecnológica seja empreendida o mais próximo possível da fase de difusão. No entanto, em países em desenvolvimento, não se pode falar em um ciclo tecnológico como o descrito, já que as fases de 'inovação', 'difusão' e 'incorporação' são na verdade resumidas em uma única fase, a de 'absorção'. Isso sintetiza o fato de que a produção da tecnologia já se processou em seu país de origem, o que permitiria uma economia de esforços, se a transferência tecnológica se desse por completo (o que normalmente não é o caso).

Tecnologias introduzidas em países desenvolvidos contam com processos de avaliação tecnológica bastante elaborados, devido à atuação de órgãos como o FDA (Food and Drug Administration) e o OHTA (Office of Health Technology Assessment). Portanto, na presença de um processo de transferência tecnológica completa, a prioridade para países em desenvolvimento se tornaria investigar questões referentes à efetividade da tecnologia e sua prioridade epidemiológica, uma vez que o problema de sua comparação com tecnologias existentes já se encontratia delineado. 


\section{NormatizaÇão E Regulação}

Uma etapa inicial e da maior importância na ATS para países em desenvolvimento é a efetiva 'normatização' tecnológica. Tal processo se refere à constituição de regras e parâmetros claros e acessíveis que permitam o julgamento de seu estado de funcionamento. Esse aspecto é fundamental, já que a efetividade de tecnologias em paises em desenvolvimento tem sido frustrada por problemas como a falta de infra-estrutura e treinamento. No Brasil, a regulação e a normatização de tecnologias em saúde apresentam uma série de deficiências, como a descontinuidade administrativa e a falta de definições sobre a responsabilidade de implementação e fiscalização de normas e regulamentos, combinando-se à falta de vontade política e çonscientização da importância desses procedimentos (Brasil, 1994).

\section{CONCLUSÃO}

A ATS preocupa-se com impactos reais que se refiram a grupos de pacientes ou pessoas. Sua aplicação deve contar, portanto, com resultados confiáveis sobre o emprego de tecnologias, que permitam diferenciar efeitos reais de vantagens 'propagandeadas'.

Para países em desenvolvimento, uma fase crucial neste processo de avaliação é a de normatização do uso tecnológico, sem a qual se torna difícil a realização de estudos de ATS clássicos, tais como de custo-efetividade. Nessas condições, a ATS, além de estar voltada para estudos de efetividade, deve buscar a melhoria da coleta de informações e, principalmente, o estabelecimento de indicadores e normas tecnológicas úteis aos serviços da saúde. 


\section{REFERÊNCIAS BIBLIOGRÁfICAS}

BRASIL. Ministério da Saúde. In: X FÓRUM NACIONAL EM CIÊNCIA E TECNOLOGIA. Anais. Brasília, 1994.

BRORSSON, B. \& WALL, S. Assessing Medical Technology: problems and methods. Sweeden: MFR, 1989.

CLIFFORD, G. Ten trends in health technology assessment affecting the development and difusion of advanced health care technologies. In: WORLD CONGRESS ON BIOMEDICAL ENGINEERING AND MEDICAL PHYSICS. Rio de Janeiro, 1994. MOSTELLER, F. Assessing Medical Technology. New York: Academic Press, 1989.

PANERAI, R. B. \& PEÑA-MOHR, J. Health Technology Assesment Methodologies for Developing Countries. Washington: PAHO, 1989.

PANERAI, R. B. Health care technology assesment and the planning of local health systems. In: WORLD CONGRESS ON BIOMEDICAL ENGINEERING AND MEDICAL PHYSICS. Rio de Janeiro, 1994. 


\section{AVALIAÇÃO DOS EFEITOS DE VACINAS: MUDANÇAS NA SUSCETIBILIDADE, INFECTIVIDADE, CONTATOS E EFEITOS DIRETOS E INDIRETOS}

M. Elizabeth Halloran \& Claudio J. Strucbiner

\section{INTRODUÇÃO}

A eficácia de uma vacina é avaliada, geralmente, a partir do cálculo de 1 (um) menos alguma medida de risco relativo na comparação do grupo vacinado com o grupo não-vacinado:

$$
V E=1-R R
$$

Portanto, a eficácia de uma vacina se apresenta sob a forma da fração de prevenção no exposto. Neste caso, a exposição significa ser vacinado. A família de parâmetros da fração de prevenção ou atribuível a doenças não-infecciosas foi tratada por Greenland e Robins (1988; Robins \& Greenland, 1989). Esta família inclui a fração de prevenção com base na razão do taxa de incidência e na razão da proporção de incidência. As vacinas, no entanto, podem ter muitos tipos diferentes de efeitos, tanto nas pessoas vacinadas quanto nas populações submetidas a programas de 
vacinação. Isto se deve aos acontecimentos dependentes em doenças infecciosas (Ross, 1916). Assim, precisamos expandir a família dos parâmetros da fração de prevenção a fim de avaliar a diversidade de efeitos característicos a intervenções em doenças infecciosas.

Apresentamos os métodos de avaliação de diferentes efeitos de vacinas, incluindo redução na suscetibilidade, na infecciosidade e os efeitos dirctos versus indiretos, levando em conta a estrutura do acontecimento dependente das ocorrências em doenças infecciosas. Generalizamos as medidas comuns dos efeitos, a razão da taxa de incidência e a razão de proporção de incidência cm duas dimensões diferentes.

A primeira generaliza a razão de probabilidade de transmissão, parâmetro especifico a doenças infecciosas, que condiciona à exposição à infecção). Esta medida pode estimar o cfeito de uma vacina em reduzir suscetibilidade ou infecciosidade ou ambas, dependendo do status vacinal dos infectados ou suscetíveis que fazem contatos nos grupos de comparação. Os diferentes parâmetros de efeito constituem uma hierarquia baseada na quantidade de informação utilizada na análisc.

A segunda dimensão amplia a opção de população de comparação, de modo que a unidade de intervenção torne-se a população inteira, a fim de se estimarem os efeitos diretos, indirctos, totais e globais de intervenções e os programas de intervenção.

Considerando as difcrentes extensões de eficácia de uma vacina como variantes da fração de prevenção, essa expansão amplia também os parâmetros causais de família de fração atribuível, discutida por Greenland e Robins (1988; Robins \& Greenland, 1989), em duas dimensões. Isto proporciona uma definição sistemática dos muitos tipos diferentes de fração de prevenção, de acordo com acontecimentos dependentes em doenças infecciosas. Tratamos, também, da eficácia comportamental e de exposição de intervenções que, com freqüência, resultam por meio de mudanças nos contatos. Essses métodos são aplicáveis a fatores de risco outros que não vacinas. Enfatizamos a importância de distinguir fatores de risco para a exposição à infecção de fatores de tisco para suscetibilidade. 


\section{Probabilidade de Transmissão}

Referindo-nos à Tabela 1, primeiro expandimos a família de parâmetros para eficácia de vacina, ou para a fração de prevenção no exposto, ao incluir um parâmetro condicionado à exposição à infecção. Este tipo de parâmetro é específico de doenças infecciosas (Halloran \& Struchiner, 1995). A probabilidade de transmissão é a probabilidade condicional a um contato entre uma fonte infecciosa e um hospedeiro suscetível de ocorrer com sucesso a transferência do parasito. A probabilidade de transmissão depende das características da fonte infecciosa, do agente infeccioso, do hospedeiro suscetível e do tipo e da definição de contato. Assim, na Tabela 1, temos na parte superior a relação de parâmetros baseada na probabilidade de transmissão, enquanto embaixo estão os parâmetros usuais para estimar a fração de prevenção no exposto. Isto inclui a densidade de incidência, a taxa de casualidade e a incidência cumulativa. A incidência cumulativa também é chamada de proporção de incidência ou, em doenças infecciosas, a taxa de ataque. Estes parâmetros são comuns nos estudos sobre doenças não-infecciosas, bem como nas doenças infecciosas. Não é necessário condicionar à exposição à infecção para estimá-los.

A probabilidade de transmissão é estimada de duas maneiras principais. O primeiro método, chamado taxa de ataque secundário, ou método de taxa de contato-caso, é usado desde a década de 30 para estimar a eficácia de vacina. Também é utilizado para estimar transmissão na tuberculose. Neste método, as pessoas que entraram em contato com pessoas infectadas são identificadas. A proporção das pessoas contactadas que se tornaram infectadas é a 'taxa de ataque secundário'. A medida de eficácia de vacina pode ser baseada nas taxas de ataque secundário nos contactados vacinados em comparação com os não-vacinados. Isto é um exemplo de uma medida condicional de eficácia de vacina, ou fração de prevenção condicional em expostos. Outro método para estimar a probabilidade de transmissão é aquele baseado no modelo binominal. Neste caso, acompanhamos as pessoas suscetíveis e contamos o número de contatos que elas fazem com os infectados. Isto é utilizado, comumente, nos estudos de doenças transmissíveis sexualmente ou HIV. 
A idéia básica, aqui, é de que há parâmetros que condicionam à exposição à infecção e outros que não condicionam à exposição à infecção. Os primeiros são específicos a doenças infecciosas e usualmente representam alguma forma da probabilidade de transmissão.

\section{Tabela 1 - Parâmetros para medir diferentes efeitos de vacinas}

\begin{tabular}{|c|c|c|c|c|}
\hline $\begin{array}{c}\text { Alternativa de } \\
\text { parâmetro }\end{array}$ & $\begin{array}{l}\text { Efeito } \\
\text { direto }\end{array}$ & $\begin{array}{l}\text { Eifeito } \\
\text { indireto }\end{array}$ & TOTAI & GLOBAL \\
\hline \multicolumn{5}{|l|}{$\begin{array}{l}\text { Condicional à } \\
\text { exposição à } \\
\text { infecção }\end{array}$} \\
\hline $\begin{array}{l}\text { Probabilidade } \\
\text { de transmissão, } \\
\text { indices } p\end{array}$ & $\begin{array}{c}p_{(0)} / p_{(x)} \\
\text { suscetibilidade }\end{array}$ & $\begin{array}{c}p_{01} / p_{(x)} \\
\text { infecciosidade }\end{array}$ & $\begin{array}{c}p_{11} / p_{1 x} \\
\text { mudanças } \\
\text { combinadas cm } \\
\text { suscetibilidade e } \\
\text { infecciosidade }\end{array}$ & $\begin{array}{l}\text { Média ponderada sobre o } \\
\text { número de contatos entre } \\
\text { tratados e não-tratados }\end{array}$ \\
\hline
\end{tabular}

Desenho de estudo

I IIA IIB III

\begin{tabular}{|c|c|c|c|c|}
\hline \multicolumn{5}{|l|}{ Incondicional } \\
\hline $\begin{array}{l}\text { Densidade de } \\
\text { incidência, ID }\end{array}$ & $\mathrm{ID}_{1 N} / \mathrm{ID}_{0,1}$ & $\mathrm{ID}_{1 \mathrm{~N}} / \mathrm{ID}_{\mathrm{UH}}$ & $\mathrm{ID}_{1 \mathrm{~A}} / \mathrm{ID}_{1 \mathrm{BB}}$ & {$\left[f \mathrm{ID}_{1 \mathrm{~A}}+(1-f) \mathrm{ID}_{(1,1}\right] / \mathrm{ID}_{(\mathfrak{B})}$} \\
\hline $\begin{array}{c}\text { Casualidade, }{ }^{*} \lambda \\
\text { Incidência }\end{array}$ & $\lambda_{1 \mathrm{~A}} / \lambda_{\mathrm{NA}}$ & $\lambda_{1 N_{i}} / \lambda_{1, B}$ & $\lambda_{\mathrm{AN}} / \lambda_{1, \mathrm{~B}}$ & {$\left[f \lambda_{1 A}+(1-f) \lambda_{(1, \lambda}\right] \lambda_{1 B B}$} \\
\hline acumulada, $\mathrm{Cl}$ & $\mathrm{CI}_{1 \Lambda} / \mathrm{CI}_{n A}$ & $C \mathrm{I}_{\mathrm{HA}} / \mathrm{CI}_{\mathrm{HB}}$ & $\mathrm{Cl}_{1 A} / \mathrm{CI}_{11 B}$ & {$\left[f \mathrm{Cl}_{1.1}+(1-\not f) \mathrm{CI}_{(1,1}\right] \mathrm{CI}_{1 \mathrm{BB}}$} \\
\hline Observações: & $\begin{array}{l}\text { Parâmetros- } \\
\text { padrão; } \\
\text { podem ser } \\
\text { influenciados } \\
\text { por efeitos } \\
\text { indiretos }\end{array}$ & $\begin{array}{c}\text { Medida } \\
\text { incondicional } \\
\text { de mudança de } \\
\text { exposição c } \\
\text { infecciosidade } \\
\text { na população }\end{array}$ & $\begin{array}{l}\text { Utilizado para } \\
\text { estimar número } \\
\text { de casos } \\
\text { prevenidos pelo } \\
\text { programa }\end{array}$ & \\
\hline
\end{tabular}

* Hazurd no original (N. T.). 


\section{Efeito Vacinal na Suscetibilidade}

Para se estimar o efeito da vacina na redução da suscetibilidade, os grupos de comparação vacinados e não-vacinados têm de ser igualmente expostos à infecção. No caso dos parâmetros condicionais, tal como a probabilidade de transmissão, isto é parcialmente realizado ao condicionar à exposição ao infectado e a quaisquer covariáveis (covariates) relevantes dos infectados ou do tipo de contato. Nos parâmetros incondicionais, isto é realizado presumindo-se idêntica exposição, ou estratificando-se por indicadores do grau de exposição à infecção. A randomização em testes de vacina é feita com a esperança de se balancear a exposição à infecção nos grupos de comparação (Struchiner et al., 1994). A eficácia de vacina baseada na probabilidade de transmissão pode ser interpretada como a redução proporcional na suscetibilidade. Aos parâmetros incondicionais, somente pode-se dar interpretação biológica sob certa suposição de como a vacina atua e como se dá a distribuição de seus efeitos na população.

Na primeira coluna da Tabela 1 , vemos que os parâmetros condicionais e incondicionais podem ser divididos em uma hierarquia de parâmetros com base em quanta informação está disponível a respeito do sistema de transmissão e como as ocorrências se desdobram no tempo (Rhodes, Halloran \& Longini, 1994). Já fizemos a distinção entre a probabilidade de transmissão e os parâmetros incondicionais. A probabilidade de transmissão requer o máximo de informação para sua estimativa. Precisamos saber quem é o infectado, quando e quem ele contacta e como.

Para a densidade de incidência, ou taxa de casualidade (hazard rate), apenas precisamos saber há quanto tempo as pessoas estão sob estudo e quando as ocorrências se dão. $\mathrm{Na}$ doença infecciosa, por causa da natureza do acontecimento dependente das ocorrências, a densidade de incidência ou casualidade pode ser pensada como uma função do processo de transmissão subjacente, mesmo se não medirmos os componentes. Os componentes incluem a taxa de contatos na população, a probabilidade que um contato entre um infectado e um suscetível resulte em transmissão, e a probabilidade de que qualquer contato que um suscetível faça seja com um infectado. Assim, vemos que a densidade de incidência, ou taxa de casualidade, depende da probabilidade 
de transmissão, ainda que não estimemos a probabilidade de transmissão quando estamos estimando a eficácia da vacina com base em dados de duração da ocorrência. Portanto, este parâmetro é um degrau abaixo na hierarquia. Se cé o índice de contato, $p$ a probabilidade de transmissão e $P(t)$ a prevalência de infecção no tempo $t$, a casualidade ou densidade de incidência $\lambda(t)$ pode ser expressa como $\lambda(t)=c p P(t)$. Esta simples expressão presume mistura ao acaso dentro da população.

Para estimar a eficácia vacinal com base na incidência acumulada, precisa-se apenas saber que uma ocorrência se deu entre o começo da observação e algum tempo subseqüente $T$. Assim, esta estimativa requer até mesmo menos informação, posicionando-se mais abaixo na hierarquia de parâmetros. A incidência acumulada, no entanto, é uma função da taxa de casualidade no intervalo de observação e, portanto, também uma função da probabilidade de transmissão e do processo de transmissão e contato subjacente.

A probabilidade de transmissão pode ser utilizada para estimar o efeito vacinal na redução da infecciosidade. Na parte superior da Tabela 1, medimos diferentes tipos de efeitos vacinais usando a probabilidade de transmissão conforme alternativas diferentes para o status vacinal de infectados e suscetiveis (Halloran \& Struchiner, 1995). Para estimar o efeito vacinal na redução da infecciosidade, comparamos as probabilidades de transmissão dos infectados vacinados e não-vacinados para os suscetíveis não-vacinados. O efeito combinado da vacina na redução da suscetibilidade e da infecciosidade é estimado através da comparação entre a probabilidade de transmissão quando ambos os grupos no contato são vacinados com a probabilidade de transmissão quando ambos os grupos são não-vacinados.

Como exemplo, considere-se um estudo de eficácia de uma vacina de coqueluche com base na taxa de ataque secundário domiciliar em que a condição de vacinação de cada caso catalogado foi registrada. As taxas de ataque secundário domiciliares de casos não-vacinados para suscetíveis não-vacinados e vacinados foram de $S A R_{100}=0,85$ e $S A R_{10}=0,15$, respectivamente; e de casos vacinados para suscetíveis não-vacinados e vacinados foram de $S A R_{01}=$ 0,50 e $S A R_{11}=0,89$, respectivamente. Deste modo, o efeito da vacina na redução da suscetibilidade, da infecciosidade e de efeitos combinados em ambos é estimado por: 


$$
\begin{aligned}
& V E_{\mathrm{s}}=1-S A \mathrm{R}_{10} / S A \mathrm{R}_{00}=0,82 ; \\
& V E_{\mathrm{i}}=1-S A \mathrm{R}_{01} / S A \mathrm{R}_{00}=0,41 ; \\
& V E_{\mathrm{t}}=1-S A \mathrm{R}_{11} / S A \mathrm{R}_{00}=0,89 .
\end{aligned}
$$

Interpreta-se, assim, que a vacina reduz a suscetibilidade em $82 \%$ e a infecciosidade condicionada em tornar-se infeccioso em $41 \%$; e que a redução combinada na suscetibilidade e na infecciosidade é de $89 \%$.

A mudança global na probabilidade de transmissão na população é a média ponderada dos diferentes tipos de pares de contatos na população e depende da fração $f$ vacinada.

\section{Desenhos de Estudo para Acontecimentos Dependentes}

Nos avaliadores incondicionais da primeira coluna da Tabela 1, assumiu-se que os grupos de comparação têm idêntica exposição à infecção. Esta abordagem, no entanto, não nos garante uma medida dos efeitos indiretos ou globais de um programa de intervenção em uma população submetida a acontecimentos dependentes (Halloran et al., 1991). Esses tipos diferentes de efeitos são medidos utilizando-se os estimadores incondicionais com diferentes alternativas de população de comparação. Os efeitos incondicionais indiretos, totais e globais são definidos dentro do contexto de um programa de intervenção específico em uma população. Estamos interessados, aqui, em comparar os resultados de um programa de vacinação com os resultados caso não tenha havido programa de vacinação.

Assim, assume-se que há duas populações, uma chamada população $\mathrm{A}$ e outra população $B$, e que ambas estão separadas de todo modo que seja relevante para a transmissão da infecção sob estudo. A separação poderia ser geográfica, cultural ou temporal. Poderíamos comparar com vilarejos vizinhos ou centros de atendimento a crianças com diferentes intervenções. 
A população A poderia corresponder à população pré-intervenção, ao passo que a $\mathrm{B}$ poderia corresponder à população pós-intervenção. Assume-se que um programa de vacinação seja submetido à população $\mathrm{A}$ de modo que alguns, mas não necessariamente todos os indivíduos, sejam vacinados. Struchiner et al. (1990) e Halloran \& Struchiner (1991) descrevem quatro tipos de desenhos de estudo que dependem da alternativa da população de comparação e de estarmos medindo os efeitos diretos, indiretos, totais e globais do programa de intervenção. Os desenhos de estudo do tipo I utilizando os parâmetros incondicionais de efeito são aqueles descritos anteriormente. Assume-se que os grupos vacinados e não-vacinados têm idêntica exposição à infecção e que o parâmetro de eficácia de vacina mede o efeito incondicional direto.

O efeito incondicional indireto de um programa de vacinação é definido como o resultado em um indivíduo que não recebeu a vacina diretamente, mas está na população $A$ que recebeu o programa de vacinação, comparado com o resultado que teria sido obervado no indivíduo caso a população não tivesse recebido o programa de vacinação. A comparação é entre os indivíduos não-vacinados da população A com os não-vacinados da população B. Estes são desenhos de estudo do tipo IIA, representados pela coluna 2 da Tabela 1 . Uma importante diferença entre a probabilidade de transmissão como medida de infecciosidade reduzida e os efeitos incondicionais indiretos é que o efeito incondicional indireto resulta do decréscimo de exposição à infecção tanto das pessoas que não se tornaram infectadas quanto daquelas que se tornaram infectadas, mas eram menos infecciosas. A redução na probabilidade de transmissão devido à infecciosidade reduzida, entretanto, não leva em conta as pessoas que não se infectaram, porque se requer que um contato entre uma pessoa infectada e uma suscetível aconteça. Assim, obtemos, com a probabilidade de transmissão, uma estimativa truncada da redução na infecciosidade.

Os efeitos incondicionais totais são análogos aos efeitos indiretos, exceto que agora estamos interessados nos efeitos protetores combinados da vacina em um indivíduo que a recebe e o programa de vacinação na população $A$. O efeito é medido comparando-se o resultado nas pessoas vacinadas da população A com a população não-vacinada $B$. Isto está representado na terceira coluna da Tabela 1. 
Nas doenças não-infecciosas, a fração de prevenção, ou de excesso na 'população' seria supostamente dependente da fração na população que teve a covariável (covariate) de interesse. No contexto dos acontecimentos dependentes, a fração de prevenção, ou de excesso nos expostos pode depender, também, da fração da população vacinada. Assim, a fração de prevenção nos expostos (vacinados) multiplicado pelo número de pessoas expostas (vacinadas) não produzirá uma estimativa direta do número de casos que foram prevenidos pela vacina, visto que a grandeza a ser comparada, o número de casos nos não-vacinados, não representa o número de casos que teria ocorrido na população não-vacinada se o programa de vacinação não tivesse acontecido. A proporção de incidência no grupo não-vacinado poderia depender da fração vacinada e, em geral, será menor na presença de um programa de vacinação do que se ninguém tivesse sido vacinado. Portanto, a fração de prevenção nos expostos subestimará, geralmente, o número verdadeiro de casos prevenidos pela vacina no grupo vacinado se calculado utilizando-se métodos para doenças não-infecciosas, tal como no desenho de estudo I. A comparação precisa ser feita entre a proporção de incidência no grupo vacinado e o que a proporção de incidência teria sido no grupo não-vacinado se nenhuma vacinação tivesse ocorrido, tal como no desenho de estudo IIB. Não é possível, comumente, saber o que a proporção de incidência teria sido na falta do programa de intervenção. Se as estimativas são realizadas sob essas circunstâncias, é importante notar que elas foram obtidas ignorando-se possíveis efeitos indiretos.

O benefício global para a saúde pública de um programa de vacinação, comparado à ausência desta, é a média ponderada dos eventos nas pessoas em risco, vacinadas e não-vacinadas, da população A comparado com os eventos nas pessoas em risco da população B. Ele depende da fração $f$ de quem é vacinado na população $A$. Estes desenhos de estudo de tipo III estão representados pela quarta coluna da Tabela 1 . 


\section{TAXas de Contato \\ E EFICÁCIA DA EXPOSIÇÃO}

Os padrões de contato em uma população representam um papel central na determinação da transmissão e da exposição à infecção. Uma intervenção poderia alterar as taxas de contato ou o padrão de contato em uma pessoa ou população vacinada. A 'eficácia da taxa de contato' significa a mudança relativa nas taxas de contato devido a uma intervenção. 'Eficácia comportamental ou de exposição' significa o acréscimo ou o decréscimo relativo na exposição à infecção na pessoa vacinada, ou a mudança pertinente na taxa de infecção ou doença devido à alteração na exposição ao agente infeccioso, dependendo da medida de freqüência de evento (Halloran et al., 1994). A mudança na exposição à infecção pode ocorrer em estudos randomizados quer como o objetivo primário da intervenção, quer secundário, acreditando-se na eficácia profilática de uma medida. Nos estudos de eficácia vacinal, os parâmetros incondicionais são mais sensíveis ao vício por exposição desigual à infecção devido a diferenças nos índices de contato. Alguém poderia argumentar que o efeito de interesse na saúde pública é a ação combinada de eficácia biológica e comportamental, porque um aumento no índice de contato poderia ter mais valor do que qualquer proteção biológica conferida pela vacina. Portanto, uma vacina biologicamente eficaz poderia ter efeitos prejudiciais na saúde pública. Esses tipos muito diferentes de efeitos são a motivação para essa sistemática de parâmetros de eficácia. Em geral, é importante diferenciar fatores de risco para exposição à infecção de fatores de risco para suscetibilidade.

\section{Número Reprodutivo BÁsico $R_{0}$}

Apesar de não incluídas na Tabela 1, muitas outras medidas de freqüência de evento poderiam ser utilizadas para se estimarem os efeitos de uma vacina ou de um programa de vacinação. Isto inclui idade média da primeira infecção e duração da ocorrência, ambas significando variações da taxa de incidência. Outro importante parâmetro em doenças infecciosas é o número 
reprodutivo básico $R_{0}$. Em agentes infecciosos microparasíticos, tais como bactérias, vírus e pequenos parasitos, este é o número de novos casos infecciosos produzidos por um caso infeccioso, durante seu período de infecciosidade, em uma população totalmente suscetível. Este parâmetro também pode ser influenciado por programas de intervenção e ser utilizado como medida da eficácia dos programas, dependendo da escolha das populações a serem comparadas.

\section{CONCLUSÃO}

As vacinas podem afetar tanto a suscetibilidade quanto a infecciosidade das pessoas que são vacinadas. Os programas de vacinação podem ter cfeitos diretos ou indiretos nas populações tanto através da mudança do número de pessoas tornando-se infectadas e infecciosas quanto através da produção de mudanças nas taxas e nos padrões de contato. Apresentamos uma sistemática para generalizar os parâmetros usuais para a fração previnível no exposto utilizado em doenças não-infecciosas, a fim de descrever os parâmetros para se medirem os diferentes efeitos diretos de vacinas e efeitos indiretos de programas de vacinação. Esta abordagem permite uma definição e uma avaliação mais precisas das vacinas e dos programas de vacinação. 


\section{REFERÊNCIAS BIBLIOGRÁFICAS}

GREENLAND, S. \& ROBINS, J. M. Conceptual problems in the definition and interpretation of attributable fraction. American Journal of Epidemiology, 128:1.1851.197, 1988.

HALLORAN, M. E. et al. Direct indirect effects in vaccine field efficacy and effectiveness. American Journal of Epidemiology, 133:323-331, 1991.

HALLORAN, M. E. et al. Exposure efficacy and change in contact rates in evaluating prophylactic HIV vaccines in the field. Statistics in Medicine, 13:357-377, 1994.

HALLORAN, M. E. \& STRUCHINER, C. J. Study designs for dependent happenings. Epidemiology, 2:331-338, 1991.

HALLORAN, M. E. \& STRUCHINER, C. J. Causal inference for infectious diseases. Epidemiology, 6:142-151, 1995.

RHODES, P. H.; HALLORAN, M. E. \& LONGINI, I. M. Counting process models for differentiating exposure to infection and susceptibility. Technical Report 94-1. Division of Biostatistics, Emory University School of Public Health, 1994.

ROBINS, J. M. \& GREENLAND, S. Estimability and estimation of excess and etiologic fraction. Statistics in Medicine, 8:845-859, 1989.

ROSS, R. An application of the theory of probabilities to the study of a priori pathometry, part 1. Procedings of the Reyal Society - Series A, 92:204-230, 1916.

STRUCHINER, C. J. et al. The behavior of common measures of association used to assess a vaccination program under complex disease transmission patterns: a computer simulation study of malaria vaccines. International Journal of Epidemiology, 19:187-196, 1990.

STRUCHINER, C. J. et al. Malaria vaccines: lessons from field trials. Cadernos de Saúde Pública, 10(suppl. 2):310-326, 1994. 


\section{A INFECÇÃO HOSPITALAR \\ COMO PARÂMETRO \\ DA QUALIDADE*}

Miguel Carrasco Asenjo

\section{INTRODUÇÃO: A QUALIDADE NOS HOSPITAIS}

Não é difícil prever o futuro da epidemiologia hospitalar relacionada à prevenção e ao controle da Infecção Nosocomial (IN). Segundo Kunin (1988), ocorrerá um crescimento importante devido ao previsível incremento dos gastos decorrentes dela e, simultaneamente, haverá maior necessidade de controle do gasto e melhora da qualidade hospitalar.

As gerências e as direções dos hospitais têm se mostrado interessadas em nosso trabalho quando se demonstra que a presença de um bom Sistema de Vigilância e Controle das Infecções Nosocomiais (SVCIN) associa-se a uma diminuição de $32 \%$ das infecções; ao contrário, observa-se um incremento de $18 \%$ das mesmas quando o sistema não está implantado ou se encontra pouco - ou não adquadamente - desenvolvido (Haley et al., 1985).

\footnotetext{
- Tradução: Claudia Bastos
} 
Progressivamente, vimos obtendo reconhecimento ao comprovarmos que nossos esforços servem para controlar e diminuir custos e riscos para o hospital. Os SVCIN têm demonstrado sua eficiência ao encurtar permanências no sentido de prevenir a infecção, diminuir os gastos com equipamentos, insumos c medicamentos, ao melhorar as condições do meio ambicnte (ar, água, resíduos etc.) $\mathrm{c}$ ao diminuir os riscos de contágio entre os profissionais. Além desses aspectos, todos relacionados à qualidade, deve-se mencionar a contribuição proporcionada à assistência dispensada aos pacientes, ao propiciar procedimentos assépticos.

Nos últimos anos tem se transferido ao hospital a necessidade de melhorar a qualidade dos serviços, como fator essencial da cstratégia de otimizar seus produtos. A qualidade nos serviços deve estar orientada para a satisfação do cliente/usuário, tanto externo (pacientc) como interno. Trata-se de conhecer suas necessidades e adotar as medidas que impliquem a sua satisfação (Yaetano, 1994).

Os Planos de Qualidade Total devem conter a análise das questões relacionadas à estrutura e ao processo assistencial hospitalar, ter objetivos c padrões de qualidade, assim como uma planificação das ações de aprimoramento e o desenho de um Sistema de Acompanhamento da Qualidade (avaliação continuada) que permita conhecer a cvolução desta por meio de indicadorcs objetivos e da obscrvação. É imprescindível a difusão da informação - comunicar os objetivos e os resultados a todos os integrantes do grupo, envolvendo todos os ocupantes de cargos dirigentes no processo de comunicação.

Diversas estratégias têm sido propostas no sentido de elevar a qualidade nos hospitais, mas pode-se dizer que todas elas incorporam o que classicamente é definido como vigilância: a compilação e o registro dos dados que retratam a realidade observada; a análise desses dados; e uma difusão adequada da informação obtida, de modo a propiciar uma intervenção corretiva (Langmuir, 1963). Por outro lado, Donabedian (1990) definiu a monitoração da qualidade assistencial como uma revisão periódica ou contínua da qualidade dos cuidados, mediante a obtenção de dados, análise, interpretação, intervenções corretivas e verificação da efetividade das ações.

Como se pode comprovar, é bastante fácil ver suas similitudes c a utilidade da vigilância como ferramenta dos programas de qualidade (JCAHO, 1992). Mesmo que o objeto imediato do estudo se modifique, os conceitos e 
as técnicas utilizadas são essencialmente similares. E ainda que a vigilância esteja orientada pela epidemiologia para a identificação dos aspectos causais e as possíveis ações de prevenção e controle dos problemas da saúde, as atividades relativas à qualidade assistencial são guiadas pelos princípios de administração e gestão dos serviços da saúde.

A experiência obtida pelos epidemiologistas nos SVCIN proporciona-lhes uma preparação básica para contribuir nos Programas de Melhora da Qualidade Hospitalar, já que estão acostumados a manejar os sistemas de vigilância - isto é, são peritos em sistemas de informações úteis para a toma$\mathrm{da}$ de decisões. Dominam métodos para mensurar o impacto positivo ou adverso de determinados eventos hospitalares, para a identificação de fatores de risco e para a avaliação da efetividade de medidas preventivas (casos e controles, coortes, ensaios clínicos, análises de séries temporais etc.). Por essas razões, alguns autores afirmam que o SVCIN se constituiu, desde seu advento, em um programa pioneiro de controle de qualidade nos hospitais (Wenzel \& Pfaller, 1991).

\section{Da VigilânCIA ao Aprimoramento Contínuo da Qualidade Hospitalar}

Os SVCIN foram úteis, em seu momento, para os Programas de Controle da Qualidade. Eles serviram à busca de problemas e numeradores que identificaram a 'banda podre da maçã' (Scheckler, 1992), com a finalidade de assinalar departamentos ou profissionais que deviam ser recusados ou aceitos segundo algum padrão preestabelecido (Berwick, 1989).

Não obstante, os SVCIN baseados na ativa, contínua e sistemática Observação-Análise-Intervenção-Avaliação aproximam-se mais do ciclo Plan-DoChec-Act de Deming (1982), que enfatiza mais a incorporação da qualidade ao processo do que a inspeção dos erros ao final deste mesmo processo.

Trata-se de compreender os fatos ocorridos no contexto de uma população (numeradores e denominadores). Os dados coletados pelos SVCIN e os 
cálculos de prevalência ou incidência são muito similares aos dados requeridos pelas equipes de Melhora Contínua da Qualidade (MCC) com relação às análises dos processos. A MCC quer um processo estatístico de mensuração, de controle.

Por sua capacidade de observar não somente as tendências e a distribuição das IN, mas também as mudanças nas circunstâncias que determinam os riscos (hipóteses causais), o SVCIN permite identificar os 'desvios' ou as 'variações' que se produzem sobre o esperado. Isto é, põe-nos em posição de investigar as relações existentes entre as características básicas do processo assistencial e suas possíveis modificações a partir das eventuais variações observadas nos resultados (Decker, 1992).

O fato estudado pode se expressar de duas maneiras. De um lado, é possível observar uma variação que se distingue marcadamente do esperado e que normalmente se deve a circunstâncias causais especiais e esporádicas, isto é, uma 'situação epidérmica'. Por outro lado, podemos observar uma variação relativamente escassa ou nula que surge de circunstâncias habituais inerentes ao próprio processo, isto é, uma 'situação endêmica', que pode ser mais ou menos elevada de forma isolada, em função da qualidade deste processo.

A estratégia da MCC se baseia no questionamento constante acerca do porquê dos fatos. Essencialmente, esta é a razão de ser da epidemiologia. Trata-se de melhorar a qualidade do processo, o que supõe trabalhar os problemas habitualmente a ele vinculados, o que, segundo Deming (1982), constitui $85 \%$ dos componentes que determinam um resultado; mais relevantes do que o papel referente aos fatos casuais ou especiais, cuja presença poderia ser quantificada em $15 \%$ dos eventos.

Como conclusão, os SVCIN aportam informação fundamental para a MCC da assistência hospitalar, auxiliando na tomada de decisões no que se refere a:

- projeto/redesenho dos processos;

- distribuição de recursos;

- práticas de assepsia;

- investigação;

- educação continuada;

- credibilidade nos programas de qualidade. 
A ampla aceitação e o êxito dos SVCIN (Crede \& Hierholzer Jr., 1989) devem-se fundamentalmente ao fato de que:

- permitem a prevenção de resultados adversos (mortalidade, morbidade, custos);

- estudam um problema hospitalar bem definido, permitindo a localização da informação necessária à identificação da sua presença. Donabedian (1986) define esta característica como 'registrabilidade';

- buscam impulsionar, melhorar e ensinar a metodologia que torna possível vigiar e controlar o próprio sistema;

- têm demonstrado sua efetividade em aspectos concretos de suas intervenções preventivas e de controle.

\section{A INFECÇÃo Nosocomial COMO INDICADOR DE QUALIDADE}

Um indicador não é uma medida direta da qualidade; o que ele de fato faz é dirigir a atenção para aqueles componentes do processo assistencial que devem ser revisados ou aperfeiçoados, devido ao seu potencial de melhorar a qualidade assistencial.

A IN como complicação de um resultado esperado ou resultado adverso é uma medida quantitativa que pode ser utilizada como guia para monitorar e avaliar a qualidade dos cuidados e dos serviços prestados aos pacientes (Quality Review Bulletin, 1989). De qualquer modo, devemos ter em mente que a presença deste 'resultado adverso' nem sempre pode ser associada a um determinado processo.

A utilização da IN como Indicador de Qualidade (IQ) baseia-se no cumprimento de atributos mínimos que todo indicador deve possuir (Crede \& Hierholzer, 1990), tais como:

- ter um problema, que é objeto de estudo;

- estabelecer definições e critérios; 
- ter aplicabilidade funcional;

- estabelecer sua utilidade e eficácia (sensibilidade, especificidade).

É possível pensar, naquilo que se refere ao cumprimento destes atributos, em qualquer uma das taxas utilizadas quanto à IN, como, por exemplo, a endometrite pós-parto por cesárea.

\section{Problema Objeto de Estudo}

É necessário que o fenômeno estudado, neste caso a cesárea, permita relacioná-lo à significação clínica do processo assistencial, seja pela indicação, pelo impacto ou pelas complicações de uma determinada intervenção sobre o paciente.

Neste caso, a IN diz respeito a um fracasso da intervenção de grande importância clínica, tanto pela gravidade como pela magnitude de sua freqüência. Pode ser investigada e associada a um componente do processo assistencial. E existem razões para crer que, mudando esse componente, seja possível reduzir sua presença ou gravidade em futuras pacientes.

\section{Definição de Critérios}

Muitos dos indicadores de qualidade podem ser expressos por meio de taxas ou proporções, já que, com freqüência, busca-se a expressão da relação existente entre a indicação ou não de uma determinada intervenção, ou o êxito ou o fracasso que se obteve com a mesma etc. A utilização de proporções ou taxas como indicadores de qualidade requer duas condições: uma, definir o indicador primário; e outra, estabelecer o indicador secundário.

Definir o Indicador Primário supõe construir o numerador e o denominador. Nesta tarefa, deve-se levar em conta que: 
- a precisão da definição do numerador pode ter efcitos importantes na taxa de deteç̧ão ou incidência do evento;

- a precisão na definição do denominador reveste-se de grande importância (ao especificar o nível de risco dos pacientes expostos), especialmente quando as taxas são utilizadas para comparar indivíduos e instituições (CDC, 1991);

- a facilidade para captar os dados que figurarão no numerador ou no denominador também influencia as taxas.

O Indicador Secundário pode ser definido como uma espécie de limiar, a partir do qual uma taxa superior ou inferior indica a necessidade de revisar o processo. Uma vez que se estabelece o Indicador Secundário mediante o limiar máximo c mínimo, temos critérios para atuar depois da revisão. Entretanto, resta ainda um problema: saber quem estabelece o limiar e com que objetivo ele é cstabelecido.

\section{Aplicabilidade FunCIONAL}

Esta é fornecida por sua capacidade de determinar nas pacientes que fizeram cesárea, no exemplo em questão, possíveis aumentos na incidência de endometrite, que indiquem problemas potenciais da qualidade assistencial.

Dada a baixa incidência de infecções específicas, demonstrada em muitos estudos, a principal função da IN como IQ é similar aos diagnósticos por filtragem. Isto é, usaremos estes indicadores para selecionar potenciais casos-problema e, posteriormente, realizaremos uma revisão secundária que exige mais tempo e custos, de modo a verificar a hipótese.

\section{UTILIDADE DO INDICADOR}

É dada pela possibilidade que tem o indicador de discriminar - no caso da endometrite pós-cesárea - o que é atribuível a deficiências do processo ou da estrutura e, portanto, solucionável, c o que constitui fatores 
de risco intrínsecos aos pacientes, não abordáveis através de programas próprios da SVCIN.

Para que possamos determinar o grau de eficácia do indicador, é necessário dispor do correspondente ao Indicador Secundário no que se refere a requisitos de cuidados padronizados e resultados esperados correspondentes - o que é muito difícil.

O Indicador Primário atua como um teste diagnóstico que, resultando em um determinado valor, serve para indicar se ultrapassamos o limiar estabelecido. Diante desta quantidade, deve-se perguntar qual é a sua utilidade em termos de especificidade, sensibilidade e valor preditivo do sistema de vigilância que capta o dado. Levando em conta que esses valores referem-se à presença da infecção (capacidade do SVCIN para captar o dado correto), seria necessário aplicar ainda uma vez um teste diagnóstico similar, de modo a saber em que proporção esse indicador está fornecendo mensagens de falta de qualidade nos cuidados e, portanto, qual seria a prevenção potencial se as coisas fossem levadas a bom termo.

Ao menos dois fatores, não ligados diretamente à qualidade dos cuidados, têm relação com a magnitude das taxas de infecção: o primeiro associa-se aos fatores de risco intrínsecos ao próprio paciente (idade, patologia crônica, gravidade etc.); o segundo refere-se à variabilidade dos instrumentos destinados a medir a magnitude do problema (critérios de infecção, métodos de vigilância, cálculo de taxas etc.).

Por conseguinte, não devemos ignorar a existência de fatores que influenciem a magnitude das taxas de IN que são independentes da qualidade dos cuidados. Esta limitação pode ser incrementada ou dissimulada, de acordo com o caso, caso se controlem ou não as práticas de vigilância e caso se necessite ou não do Indicador Primário, sobretudo no que se refere a indicadores que buscam evitar as taxas brutas ou globais. Devemos levar em consideração que, para que as taxas de IN possam ser consideradas como IQ, os problemas têm de estar equacionados, como o que se expõe no Quadro 1 (Larson, Oram \& Hedrick, 1988).

À guisa de conclusão, é necessário considerar com muito cuidado o indicador escolhido, não somente no que se refere à utilidade ou eficácia, mas também no que diz respeito à capacidade do instrumento utilizado na mensuração do problema e de sua precisão para descrevê-lo. 
Trata-se, definitivamente, de garantir a qualidade da informação, já que alguns indicadores que carecem das características mencionadas anulariam qualquer tipo de conclusão elaborada mediante a sua utilização.

\section{Quadro 1 - Problemas que devem estar resolvidos antes de se utilizarem as taxas de Infecção Nosocomial (IN) como Indicador de Qualidade (IQ)}

\begin{tabular}{|l|l|}
\hline Problema & Informação necessária \\
\hline $\begin{array}{l}\text { Poder comparar, entre instituições, riscos } \\
\text { intrínsecos dos pacientes }\end{array}$ & $\begin{array}{l}\text { Métodos adequados para medir a gravidade } \\
\text { da enfermidade de base e outros fatores de } \\
\text { risco }\end{array}$ \\
\hline $\begin{array}{l}\text { Necessidade de um sistema de vigilância } \\
\text { global, ativo e continuo }\end{array}$ & $\begin{array}{l}\text { Valoração de sensibilidade, especificidade e } \\
\text { valor preditivo do sistema }\end{array}$ \\
\hline $\begin{array}{l}\text { Variações nas definições de infecções } \\
\text { entre centros }\end{array}$ & $\begin{array}{l}\text { Padronizar definições de infecções por } \\
\text { localização }\end{array}$ \\
\hline $\begin{array}{l}\text { Diferentes modos de calcular as taxas e } \\
\text { não inclusão das infecções que se } \\
\text { manifestam depois da alta }\end{array}$ & $\begin{array}{l}\text { Utilizar denominadores de uso universal } \\
\text { (melhor: os mais precisos enquanto se } \\
\text { mantém o risco). Desenvolver sistemas de } \\
\text { acompanhamento das altas }\end{array}$ \\
\hline $\begin{array}{l}\text { Nivel de esforço distinto entre os centros } \\
\text { no sentido de medir as taxas de IN }\end{array}$ & $\begin{array}{l}\text { Sistema prospectivo de monitoração para } \\
\text { avaliar o cumprimento do processo de } \\
\text { vigilância }\end{array}$ \\
\hline $\begin{array}{l}\text { Variações em formação, técnicas e } \\
\text { conhecimentos do pessoal encarregado } \\
\text { do sistema de vigilância }\end{array}$ & \begin{tabular}{l} 
Treinamento padronizado \\
\hline
\end{tabular}
\end{tabular}

Fonte: Larson, Oram \& Hedrick (1988). 


\section{RELAÇÃo DE QuALIDADE E INFECÇÃO: APRESENTAÇÃO DE UM ESTUDO'}

\section{O Ambiente}

Trata-se de um hospital geral (Insalud), que atende a uma população de referência de âmbito provincial com cerca de 150 mil habitantes. É um hospital de primeiro nível. Assim, as patologias médico-cirúrgicas especiais são referidas a centros hospitalares de segundo e terceiro níveis.

O hospital possui 406 leitos de hospitalização, agrupados em postos de enfermagem que controlam 28 leitos cada, distribuídos em quartos duplos ou individuais.

O quadro de pessoal conta com 900 pessoas: 100 médicos, 250 enfermeiros(as), 220 auxiliares de enfermagem e 320 profissionais fora da área da saúde. Em cada posto de enfermagem trabalham, em cada turno, três ou quatro pessoas (duas enfermeiras e dois auxiliares).

\section{APRESENTAÇÃO DO SVCIN}

Seu modelo corresponde à definição de 'vigilância contínua, global e ativa' e tem por objeto detectar e analisar todas as infecções nosocomiais que ocorram em qualquer paciente hospitalizado, em qualquer período de tempo. Ele possibilita conhecer as tendências e descobrir os 'surtos' infecciosos de forma precoce, caso tenham sido previamente estabelecidos os 'mecanismos de alarme' correspondentes.

Suas características assemelham-se, fundamentalmente, ao esboçado e avaliado pelos Centers for Disease Control and Prevention (CDCs) de Atlanta e utilizado no National Nosocomial Infections Surveillance System (NNIS) (CDC, 1970; Emori et al., 1991).

\footnotetext{
${ }^{1}$ Carrasco (1993).
} 
A Unidade de Medicina Preventiva é responsável, perante a direção do hospital, pela prevenção e pelo controle da infeção hospitalar (Carrasco et al., 1987), contando especificamente para isto com uma planilha corrente que se compõe de:

- um médico epidemiologista,

- uma enfermeira supervisora de higiene e saneamento,

- duas enfermeiras para a vigilância epidemiológica, e

- uma auxiliar de clínica.

Dispõe-se dos recursos mais importantes para o controle da infecção hospitalar, tais como:

- comissão clínica de infecções,

- sistema de vigilância e controle da infecção, e

- sistema informatizado de gestão de pacientes.

As atividades são realizadas de acordo com os pontos assinalados por Fossaert, Llopes \& Tigre (1974) para os SVCIN, que são:

- identificação das fontes e compilação sistemática de seus dados,

- tabulação e registro dos dados,

- análises, avaliação e interpretação dos dados,

- elaboração de programas a serem realizados,

- disseminação da informação, e

- avaliação dos programas de vigilância e controle.

A avaliação do SVCIN, no que se refere aos atributos de pertinência, aceitabilidade, flexibilidade, sensibilidade, representatividade, oportunidade e efetividade (CDC, 1988; Joint Comission on Accreditation of Hospitals, 1987; Haley et al., 1980), tem superado de modo satisfatório as avaliações valorativas a que vem sendo submetida, destacando-se como características principais: 
- o equilíbrio entre os esforços de vigilância e controle,

- a sensibilidade (80\%) e a especificidade (95\%) do sistema para diagnosticar a IN,

- a aplicação funcional e a utilidade proporcionada pela informação elaborada,

- a dotação de recursos,

- as normas escritas de assepsia e anti-sepsia,

- o funcionamento da comissão de infecções,

- a difusão da informação, e

- a formação/capacitação do pessoal e dos usuários.

\section{RESULTADOS}

Os dados estudados foram compilados de março de 1982 até dezembro de 1990. A incidência de IN se apresenta como Incidência Acumulada Mensal (IAM) expressa em percentagens (Carrasco et al., 1990).

A Incidência Acumulada para todo o período do estudo foi de 5,43\%, tendo-se detectado um total de 5.025 infecções nosocomiais. A série revela a existência de quatro períodos distintos (Gráfico 1):

- período de treinamento e controle - coincide com a implantação e o desenvolvimento do SVCIN de 1982 até 1984. Este período corresponde à realização de um programa especial para a prevenção e o controle da 'infecção do trato urinário';

- período de menor incidência - de janeiro de 1984 até maio de 1987, corresponde a um período de estabilização com um mínimo de infecção;

- greves médicas - observa-se um incremento da incidência, coincidindo com uma greve dos médicos, na qual estiveram envolvidos $99 \%$ dos profissionais, atingindo-se $10,16 \%$, em maio de 1987 , e percentuais de $8,86 \mathrm{e}$ 8,41 , respectivamente, durante os meses subseqüentes;

- mudança de nível - observamos que a série mantém um nível constante após a greve, porém mais elevado do que o relativo ao periodo que a antecedeu. 


\section{Gráfico 1 - Incidência acumulada mensal de infecções. 1982-1990*}

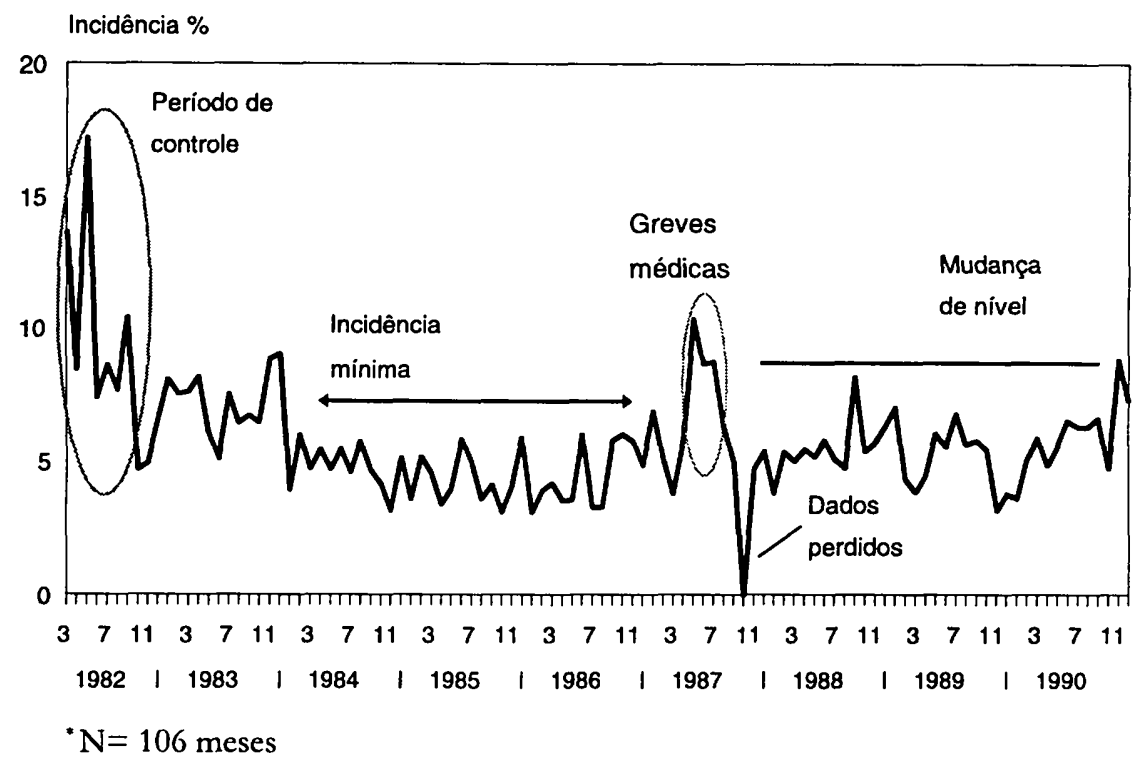

O desenho da curva do Gráfico 2, elaborado a partir de um 'alisamento’, mediante a técnica de médias móveis de períodos de 12 , revela que o nível inicial da série, antes de se iniciar o SVCIN, situava-se em uma incidência de $7,28 \%$, passando a uma situação de mínima incidência com $4,19 \%$, com uma diferença entre as duas de $3,63 \%$, o que significa uma redução superior em $40 \%$ à incidência inicial.

A série temporal é estudada 'modelizando' a curva, utilizando modelos ARIMA e mediante a análise de intervenção e regressão dinâmica.

Os resultados relativos à estimação dos parâmetros do modelo são os seguintes:

- após a implantação do SVCIN, o nível mínimo de infecção situou-se em torno de 4,19\% de incidência,

- o efeito proporcional dos dias de greve foi de $4,34 \%$,

- a mudança do nível de incidência no período posterior à greve situa-se em torno de $0,68 \%$, 
- há uma variação sazonal da incidência de IN, observando-se elevações de $0,75 \%$ em julho, $0,75 \%$ em setembro e $1,12 \%$ em dezembro,

- há uma relação positiva entre o número de contratações de novas enfermeiras e o aumento da incidência de IN. O parâmetro obtido foi de $0,16 \%$ de incremento a cada nova contratação. Demonstrou-se, assim, que o número de infecções eleva-se quando aumenta o número de novas contratações.

Gráfico 2-Modelização do período de controle e desenvolvimento do SVCIN

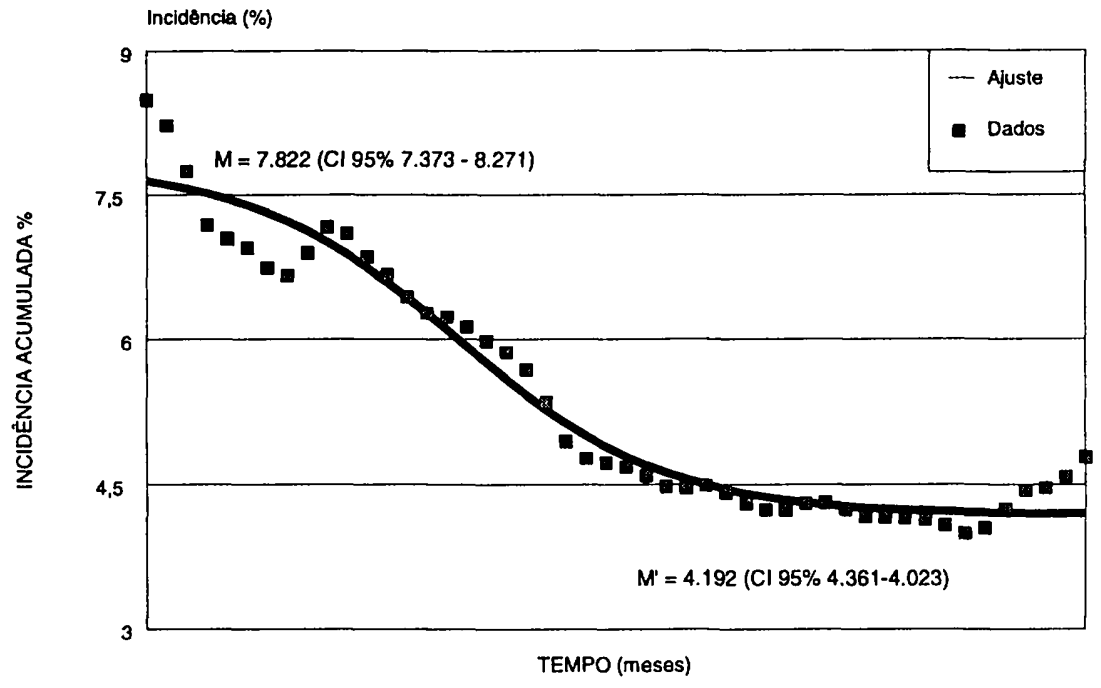

Descrição do Programa de Prevenção e Controle da INFECÇÃO DO TRATO URINÁRIO

O programa iniciou-se em setembro de 1982 e consistiu na realização de três subprogramas simultâneos:

- Subprograma 1 - busca de insumos adequados: comprar, pelo serviço de fornecimento, bolsas de circuito fechado para a recoleta de urina nos pacientes com sonda vesical; 
- Subprograma 2-possibilitar técnicas assépticas mediante desenho, preparação e fornecimento pela central de esterilização de um equipamento estéril para a realização de sondagem vesical;

- Subprograma 3 - formação continuada e supervisão: visitas aos postos de enfermagem para verificar a o cumprimento das instruções dadas a esse respeito e a formação pessoa-a-pessoa. Tudo isto finalizado com um programa especial de educação continuada para os diferentes grupos de profissionais.

Os componentes de qualidade dessa intervenção são evidentes. Relacionam-se à melhora dos recursos técnicos, através da formação continuada dos recursos humanos e do estabelecimento de protocolos normatizados no processo.

\section{Estudo do Período de Greve Médica}

Para documentar o ocorrido durante o período do conflito médico, realizou-se um estudo retrospectivo com três indicadores de Qualidade Assistencial. Observou-se o comportamento destes no periodo conflitante, comparando-o com o registrado em outro período livre de conflito. Em ambos os momentos, o comportamento dos IQAs esteve relacionado ao nível de incidência de IN encontrado neles.

Os indicadores escolhidos foram:

- número de dias que um paciente permanece com sonda vesical,

- proporção de cirurgias urgentes e programadas, e

- avaliação valorativa da terapêutica profilática antimicrobiana no período de sua utilização.

Foram revisadas, selecionadas mediante processo de amostragem aleatória simples, 95 histórias clínicas de pacientes que ingressaram no período do conflito (abril, maio e junho de 1987) e 106 de pacientes que ingressaram no período de controle (abril, maio e junho de 1986).

Uma vez realizado o trabalho retrospectivo comparativo, encontrouse o seguinte: 
- a média de permanência das sondagens vesicais aumentou aproximadamente em quatro dias no período de greve, chegando-se a uma média de 10,33 (dp cinco dias) para 6 (dp quatro dias) do período de controle $(\mathrm{p}<0,01)$,

- trinta e sete por cento das profilaxias antimicrobianas foram inadequadas ( $>$ duração) para 17\% do período de controle $(p<0,05)$,

- a proporção de cirurgias programadas e de urgência se inverteu, passando a ser mais freqüente a intervenção de urgência no período de greve.

\section{ConClusões}

Verificou-se a efetividade do SVCIN, em decorrência da tendência a um mínimo de infecção quando se alcança o desenvolvimento do programa, comprovando-se o seguinte:

- a redução da incidência de $\mathrm{IN}$,

- o máximo impacto foi obtido mediante a prevenção e o controle do problema mais freqüente e vulnerável: a infecção do trato urinário,

- a deterioração da qualidade assistencial durante uma greve médica determinou um incremento da incidência de IN em todas as suas localizações e em todos os serviços hospitalares, e

- as mudanças na Qualidade Assistencial foram detectadas e relacionadas facilmente aos níveis de incidência, mediante os sistemas e métodos de análise do SVCIN. 


\section{REFERÊNCIAS BiBLIOGRÁFICAS}

BERWICK, D. M. Continuous improvement as an ideal in health carc. Nen Fingland Journal Medical, 320(1):53-56, 1989.

CARRASCO, M. ct al. El control de la infección hospitalaria en un hospital de 400 camas. Enfermidades Infecciosas y Microbiologia Clinica, 5:603-608, 1987.

CARRASCO, M. et al. Vigilancia epidemiológica de la infección hospitalaria: análisis preliminar de una serie de cinco años. Medicina Clínica (Barcelona), 95:201-206, 199).

CARRASCO, M. El Control de la Infección Hospitalaria: evaluación de un modelo de sistema de rigilancia, 1993. Tese de Doutorado, Alcala de Henares: Universidad de Alcala de Henares.

CENTERS FOR DISEASE CONTROL. (CDCs). Outline for Surveillance and Control of Nosocomial lnfections. Atlanta: 1970.

CENTERS FOR DISEASE CONTROL (CDCs). Guidelines for evaluating surveillance systems. Morbidity and Mortality Weekley Report, 37(suppl. S-5):1-23, 1988.

CENTERS FOR DISEASE CONTROL (CDC). Nosocomial infecction rates for interhospital comparison limitations and possible solutions. Infection Control and Hospital Epidemiology, 12:609-621, 1991.

CREDE, W. \& HIERHOLZER JR., W. J. Surveillance for quality assessment: I. Surveillance in infection control success reviewed. Infection Control and Hospital Epidemiology, 10:470-474, 1989.

CREDE, W. \& HIERHOLZER JR., W. J. Surveillance for quality assessment: III. The critical assessment of quality indicators. Infection Control and Hospital Epideminology, 11(4):197-201, 1990.

DECKER, M. D. Continuous quality improvement. Infection Control and Hospital Epidemiology, 13:165-169, 1992.

DEMING, W. E. Out of the Crisis. Cambridge, Massachusetts: MIT Center for Advanced Enginecring Study, 1982.

DONABEDIAN, $A$. Criteria and standards for quality assessment and monitoring. Quality Revien Bulletin, 12:99-108, 1986.

DONABEDIAN, A. Contributions of epidemiology to quality assessment and monitoring. Infection Control and Hospital Epidemiology, 11:117-121, 1990.

EMORI, T. G. et al. National Nosocomial Infections Surveillance System (NNIS): description of surveillance methods. American Journal of Obstetrics and Cinnecology, 1):19-35, 1991. 
FOSSAERT, M.; LLOPES, A. \& TIGRE, M. Sistema de vigilancia epidemiológica. Boletin de la Oficina Sanitaria Panamericana, jun.1974. p. 512-528.

HALEY, R. W. et al. Design of the preliminary screening questionary and specifications for computing indexes for surveillance and control. (Appendix B). Preliminary Screening Questionary (PSQ) survey form (Appendix C). In: THE SENIC PROJECT: study on the efficacy of nosocomial infection control. Summary of study design. American Journal of Epidemiology, 11:613-627, 1980.

HALEY, R. W. et al. The efficacy of infection surveillance and control programs in preventing nosocomial infection in U.S. hospitals. American Journal of Epidemiology, 121:182-205, 1985.

JOINT COMISSION ON ACCREDITATION OF HEALTHCARE ORGANIZATIONS (JCAHO). An overview of quality improvement tools. How to Acbieve Quality and Accreditation in an Infection Control Program. Illinois, 1992.

JOINT COMISSION ON ACCREDITATION OF HOSPITALS (JCAH). Infection control. Accreditation Manual for Hospitals. Chicago, 1987.

KUNIN, C. M. The future of hospital epidemiology. Infection Control and Hospital Epidemiology, 10:276-279, 1988.

LANGMUIR, A. D. The surveillance of comunicable diseases of national importance. New England Journal Medical, 268:182-192, 1963.

LARSON, E.; ORAM, L. \& HEDRICK, E. Nosocomial infection rates as an indicator of quality. Medical Care, 26:676-684, 1988.

QUALITY REVIEW BULLETIN. Characteristics of clinical indicator.. 15:330-339, 1989. (anônimo).

SCHECKLER, W. E. Continuous quality improvement in a hospital system: implications for hospital epidemiology. Infection Control and Hospital Epidemiology, 13:288292, 1992.

WENZEL, R. P. \& PFALLER, M. A. Infection control: the premier Quality Assessment Program in United States hospitals. American Journal of Medicine, 91 (suppl.3b):27s-31s, 1991.

YAETANO, J. La mejora de la calidad hospitalaria. Medicina Clinica (Barcelona), 103:780781, 1994. 


\section{TERAPIA DE \\ SUBSTITUIÇÃO \\ HORMONAL}

Elizabeth Barrett-Connor

Como já assinalado em outros trabalhos (Barrett-Connor \& Bush, 1991), estudos realizados no início da década de 50 mostraram que o estrogênio prevenia a arteriosclerose em modelos animais, aumentava os níveis de colesterol HDL e diminuía os níveis de colesterol LDL em humanos, e que mulheres prematuramente oforectomizadas tinham excesso de arteriosclerose coronária. Oliver \& Boyd (1959) propuseram "a prescrição de um pouco de estrogênio para a vida" de modo a prevenir doenças de coração em mulheres na pós-menopausa. Tikkanen (1978) indicou o uso de estrogênio como agente diminuidor de lipídios para mulheres com hipercolesterolemia.

No entanto, uma vasta experiência clínica - chamada Projetos de Medicamentos Coronários - de quatro medicamentos para diminuição de lipídios, incluindo dois regimes de estrogênio, foi conduzida em homens. Doses muito altas de estrogênio ( 5 ou $2,5 \mathrm{mg}$ de Premarin) eram ministradas diariamente. Os regimes foram escolhidos deliberadamente de modo a fazer da ginecomastia um indicador de 'feminização' bem-sucedida. Não surpreende que, em retrospecto, essas doses não-fisiológicas também tenham causado impotência 
e trombose, levando ao abandono dos estudos e à descontinuação desses instrumentos de tratamento (The Coronary Drug Project Research Group, 1973).

Desafortunadamente, reporta-se apenas uma pequena experiência clínica com eliminação de doenças cardíacas em mulheres. Nachtigall et al. (1979) registraram uma experiência aleatória com estrogênio mais uma progesterona cíclica em 168 mulheres internadas, que foram observadas por dez anos. Foram poucos os eventos cardiovasculares, e o risco relativo de 0,33 não era estatisticamente significante. No mesmo ano, Hammond et al. (1979) registraram um vasto estudo de observação mostrando significativas reduções de doenças cardíacas e diabetes em mulheres tratadas com estrogênio em comparação às não-tratadas.

$\mathrm{Na}$ década de 80 , o tema estrogênio-doença cardíaca foi redescoberto. Cerca de vinte estudos de controle de casos e coorte foram publicados, quase todos baseados em estrogênio eqüino oral conjugado não-antagonizado ministrado sem um progestínico. Uma metanálise desses estudos elaborada por Stampfer \& Colditz (1991) encontrou uma redução de risco global de aproximadamente $50 \%$. Estudos de mulheres submetidas a angiografia coronária também encontraram menos arteriosclerose em mulheres sob tratamento de estrogênio (Barrett-Connor \& Bush, 1991).

Cardioproteção induzida por estrogênio é biologicamente plausível. Tanto o Estudo Clínico de Pesquisas sobre Lipídios (Bush et al., 1987) quanto um estudo sobre mulheres com doenças da artéria angiográfica coronária, realizado por Gruchow et al. (1988) sugerem que os mais altos níveis de colesterol HDL encontrados em usuários de hormônios situam-se entre 25 e $50 \%$ de proteção. Esse mecanismo é sugerido porque a introdução de colesterol HDL no modelo analítico reduziu a associação independente inversa de estrogênio ao risco de doenças cardíacas. Algumas das aparentes proteções associadas ao estrogênio são perdidas quando a terapia de substituição de hormônio é interrompida (Criqui, 1988), sugerindo assim que o estrogênio tem um efeito dinâmico em vasos sangüíneos, além de reduzir a arteriosclerose. Um estudo controlado por placebo mostrou que um pequeno número de mulheres com angina pectoris apresentava aumentos significativos durante $o$ tempo de exercise-treadmill subseqüente a uma dose farmacológica de etinil estradiol sublingual (Rosano et al., 1992). Outros efeitos conhecidos do estrogênio no coração ou em fatores de risco para doenças cardíacas também são 
favoráveis, e incluem atividade antioxidante e de bloqueio de canais de cálcio, bem como efeitos sobre a hiper-homocisteinemia (Barrett-Connor \& Bush, 1991). Muitos concluíram que esses resultados eram suficientemente consistentes e coerentes para recomendar estrogênio a quase todas as mulheres na pós-menopausa. Tivesse ele sido aplicado, esta seria a primeira vez na história que uma droga foi recomendada para 'prevenir' doenças cardíacas em uma população inteira definida apenas com base em idade e sexo.

Apesar de evidência sugerindo que a substituição de hormônio previne doenças coronárias cardíacas e é biologicamente plausível, os 'benefícios' verificados nos estudos de observação, como regra geral, são consideravelmente mais largos do que aqueles observados em experiências randômicas, controladas por placebo e duplo-cego. Os verdadeiros riscos e benefícios do estrogênio podem ser avaliados apenas por meio de tais estudos. Isto porque muitos dos aparentes benefícios podem refletir tendências. Mulheres sob tratamento de estrogênio tendem a ser de baixo risco desde o início, pois pertencem, na média, às classes sociais mais altas, mais educadas, mais esbeltas e com níveis de fatores de risco de doenças cardíacas mais baixos do que em mulheres nãotratadas. Mulheres que tomam estrogênio por um período de tempo extenso representam menos da metade de todas as mulheres às quais se prescreve estrogênio; em experiências clínicas, submissão ao placebo pode reduzir o risco de doença cardíaca em $50 \%$.

Há também evidência de tendências para prevenção: mulheres tomando estrogênio têm cuidado médico regular, que freqüentemente inclui medição (e controle) de pressão sangüínea e de colesterol, além de outros acompanhamentos médicos (Barrett-Connor, 1991). Como regra geral, experiências clínicas randomizadas são necessárias para estabelecer qualquer recomendação preventiva que não seja uma restauração da norma evolucionária. Desse modo, pode-se recomendar abstinência de fumo ou mais atividades físicas sem a exigência de prova dos benefícios ou ausência de risco. Seguindo essa orientação, podem-se recomendar estrogênio e progesterona, que são drogas ministradas em doses não-fisiológicas para o controle da menopausa, condição que não é uma doença.

Experiências clínicas com terapia de estrogênio na pós-menopausa foram por fim realizadas. Os resultados de um primeiro e vasto estudo multicentros, a experiência Postmenopausal Estrogen/Progestin Interventions (PEPI), foram reporta- 
dos em janeiro de 1995 (The Writing Group for the PEPI Trial, 1995). Esse estudo randômico, controlado por placebo, envolveu a comparação entre 875 mulheres submetidas somente a estrogênio ou ao estrogênio ministrado juntamente com um dos três regimes de progesterona. Mulheres tratadas com estrogênio eqüino oral conjugado não-antagonizado tiveram as mais favoráveis mudanças no colesterol HDL e na glicose plasmática 2 horas pós-prandial; mulheres tratadas com estrogênio e progesterona cíclica micronizada tiveram mudanças similares. Com respeito ao colesterol LDL e ao fibrinogênio, todos os tratamentos ativos, incluindo um regime cíclico contínuo de baixa dose de acetato medroxyprogesterona, produziram efeitos similares e melhores que o placebo. Os tratamentos não tinham efeito em pressão sangüínea, insulina ou peso de ganho. Após três anos, teve-se que suspender o tratamento de apenas um terço das mulheres com útero submetidas a estrogênio não-antagonizado, porque haviam desenvolvido adenomatos ou hiperplasia endometrial atípica. Não houve outras diferenças significativas em eventos adversos pelo tratamento.

O estudo PEPI não examinou o fluxo sangüineo e não era suficientemente abrangente para encontrar diferenças na interrupção de doenças cardíacas, porém os resultados são úteis para escolher o mais adequado regime para melhorar fatores selecionados de risco de doenças cardíacas. Os pesquisadores da PEPI concluíram que mulheres sem útero deviam receber estrogênio sem progesterona, mas que a maioria das mulheres com útero na pósmenopausa e que escolheram tomar estrogênio necessitaria também de uma progesterona, a qual - no contexto dos fatores de risco das doenças cardíacas estudadas - deveria ser micronizada.

Três estudos estão em andamento nos EUA para examinar manifestações de doenças cardiovasculares. Um estudo multicentro de cinco anos terminou de recrutar mais de 2.750 mulheres acometidas de doenças cardíacas, para comparar o efeito do estrogênio e do acetato medroxyprogesterona continuado contra o placebo em taxas de recorrência. Um segundo estudo multicentro (ainda em fase de recrutamento) irá submeter randomicamente 25 mil mulheres a estrogênio puro (se tiverem tido uma histerectomia) ou a estrogênio mais acetato medroxyprogesterona (se tiverem útero) ou placebo, para então acompanhá-las por nove anos, atentando para doenças cardíacas, fraturas de osteoporose e câncer de mama. Um terceiro estudo controlado por placebo, que está apenas se iniciando, foi projetado para examinar o efeito da substituição de hormônio em doenças da artéria carótida extracranial, avaliada por ultra-som. 
Até que esses estudos estejam terminados, as mulheres terão de tomar decisões sobre o uso de hormônios na prevenção de doenças cardíacas com base nos resultados obtidos até o momento, no seu status quanto aos fatores de risco pessoais e suas preocupações. Se o estrogênio é cardioprotetor como sugerem os estudos de observação, a relação risco-benefício seria maior para mulheres já acometidas por doenças cardíacas ou que tenham dislipidemia (Grady et al., 1992). Mulheres com colesterol total alto e baixo colesterol HDL podem ser candidatas particularmente boas para a terapia hormonal de prevenção de doenças cardíacas.

\section{REFERÊNCIAS BIBLIOGRÁFICAS}

BARRETT-CONNOR, E. \& BUSH, T. L. Estrogen and coronary heart disease in women. Journal American Association, 265:1.861-1.867, 1991.

BARRETT-CONNOR, E. Postmenopausal estrogen and prevention bias. Annals of Internal Medicine, 115:954-963, 1991.

BUSH, T. L. et al. Cardiovascular disease mortality in women: results from the Lipid Research Clinics Follow-up Study. In: BAKER, E. D. et al. (Ed.) Coronary Heart Disease in Women. Nova York: Haymarket Doyma, Inc., 1987.

CRIQUI, M. H. et al. Postmenopausal estrogen use and mortality: results from a prospective study in a defined, homogenous community. American Journal of Epidemiology, 128:606-614, 1988.

GRADY, D. et al. Hormone therapy to prevent disease and prolong life in postmenopausal women. Annals Internal Medicine, 117:1.016-1.037, 1992.

GRUCHOW, H. W. et al. Postmenopausal use of estrogen and occlusion of coronary arteries. American Heart Journal, 115:954-963, 1988.

HAMMOND, C. V. et al. Effects of long-term estrogen replacement therapy, I: metabolic effects. American Journal Obstetrics and Gynecology, 133:525-536, 1979.

NACHTIGALL, L. E. et al. Estrogen replacement therapy II: a prospective study in the relationship to carcinoma, cardiovascular disease, and metabolic problems. Obstetric Gynecology, 54:74-79, 1979. 
OLIVER, M. F. \& BOYD, G. S. Effect of bilateral ovariectomy on coronary-artery disease and serum-lipid levels. Lancet, 2:690-694, 1959.

ROSANO, G. M. et al. Beneficial effects of estrogen on exercise-induced myocardial ischemia in women with coronary artery disease. Lancet, 342:133-136, 1992.

STAMPFER, M. J. \& COLDITZ, G. A. Estrogen replacement therapy and coronary disease: a quantitative assessment of the epidemiological evidence. Preventive Medicine, 20:47-63, 1991.

THE CORONARY DRUG PROJECT RESEARCH GROUP. The Coronary Drug Project: findings leading to discontinuation of the $2,5 \mathrm{mg} /$ day estrogen group. Journal of American Medical Association, 226:652-657, 1973.

THE WRITING GROUP FOR THE PEPI TRIAL. Effects of estrogen or estrogen/progestin regimens on heart disease risk factors in postmenopausal women: the Postmenopausal Estrogen/Progestin Interventions (PEPI) Trial. Journal of American Medical Association, 273:199-208, 1995.

TIKKANEN, M. J. Natural estrogen as an effective treatment for type-II hyperlipoproteinaemia in postmenopausal women. Lancet, 2:490-491, 1978. 


\section{CONSUMO DE HORMÔNIOS E FATORES DE RISCO CARDIOVASCULAR EM MULHERES*}

S. Graff-Iversen \& L. Orozco Nodarse

\section{INTRODUÇÃO}

Estudos observacionais mostram uma redução de risco da ordem de $50 \%$ de ocorrer um evento coronário em mulheres no período de pós-menopausa que utilizam terapia de reposição com estrogênio de boa absorção (Barrett-Connor \& Bush, 1991). Uma intervenção randômica, duplo-cega e controlada com a utilização de placebo, o Ensaio Clínico Pós-Menopausa de Intervenções com Estrogênio/Progesterona (Postmenopausal Estrogen/Progestin Interventions Trial) indica, fortemente, existir um benefício cardioprotetor secundário aos tratamentos ativos de reposição hormonal - efeito mais acentuado em mulheres que recebem somente estrogênio (Writing Group for the PEPI Trial, 1995). Os resultados desses estudos de observação não

\footnotetext{
*Tradução: Erick Felinto
} 
se mostram, contudo, necessariamente válidos na população norueguesa, e os resultados de ensaios clínicos controlados nem sempre se reproduzem na prática médica corrente.

No presente trabalho analisamos dados obtidos a partir de uma ampla pesquisa desenvolvida na Noruega, de modo a investigar fatores de risco coronários em mulheres norueguesas que utilizam terapia hormonal de reposição. Primeiramente, identificamos subamostras relativas a configurações específicas, em função de distintos modos de utilização e diferentes tipos de hormônios empregados, e então testamos hipóteses como a seguinte: mulheres recebendo estrogênio de fácil absorção possuem um padrão mais favorável de lipídios séricos e menor pressão arterial se comparadas a mulheres não-usuárias e usuárias de esquemas terapêuticos que empregam estrogênio/progesterona.

\section{DESENHO}

A hipótese foi testada pela comparação, ajustada por idade, de valores médios de colesterol total (TC), triglicerídeos (TG) - colhidos sem estar em jejum (non-fasting triglycerides) -, colesterol de lipoproteína de alta densidade (hdl-c), a razão TC/hdl-c, a pressão arterial sistólica (SBP), a pressão arterial diastólica (DBP) e os batimentos cardíacos (HR) em usuárias não-grávidas de: apenas estrogênio; terapia de reposição hormonal combinada com estrogênio/progesterona; e não-utilização de hormônios sexuais femininos em mulheres que participavam de uma pesquisa sobre saúde.

\section{Sujeitos E MÉTodos}

Este estudo seccional baseia-se em dados obtidos a partir de uma pesquisa sobre saúde realizado em três comarcas norueguesas, durante os anos 1985-1988. O objetivo principal foi oferecer à população um programa de prevenção de doenças em função das altas taxas de mortalidade por doenças coronárias e cardiovasculares. Todas as mulheres e os homens na faixa etária 
de 40-54 anos - e amostras compreendendo $10 \%$ da população nas faixas entre 20-39 e 55-63 anos - foram convidados a tomar parte. $O$ índice de participação entre as mulheres foi de $87 \%$.

$\mathrm{Na}$ presente análise, utilizamos dados de 33.880 mulheres não-grávidas com idades entre 20 e 63 anos, das quais 24.529 se situavam na faixa etária 40 54 . Duzentas e dezoito $(0,6 \%)$ utilizaram somente estrogênio (a maioria delas 17-beta-estradiol cíclico na posologia de 1-2 mg por dia); 405 (1,2\%) utilizaram terapia de reposição de estrogênio/progesterona (a maioria delas 17-betaestradiol cíclico $171-2 \mathrm{mg}$, combinado a noretisteronacetato $1 \mathrm{mg}$ ou levonorgestrel $0,25 \mathrm{mg}$ dez dias por mês); $130(0,4 \%)$ usaram somente progesterona (a maioria noretisterona $0,35 \mathrm{mg}$ ou linestrenol $0,5 \mathrm{mg}$ diariamente); $614(1,8 \%)$ serviram-se de contraceptivos orais combinados (em sua maioria etinil estradiol $0,03 \mathrm{mg}$ com levonorgestrel $0,05-0,125 \mathrm{mg}$ ou $0,150 \mathrm{mg}$ em 21 de cada 28 dias); 288 (0,8\%) utilizaram outras formulações ou formulações não-especificadas de hormônios; e 32.225 (95,1\%) eram não-usuárias. Neste trabalho, apresentamos os resultados relativos às usuárias de terapia de reposição hormonal e não-usuárias de hormônios sexuais femininos.

Uma descrição dos procedimentos empregados na pesquisa pode ser obtida em Bjartveit et al. (1985). As participantes preencheram um questionário, versando principalmente sobre saúde cardiovascular, fatores de risco cardiovasculares conhecidos e fatores sociais relacionados ao risco cardiovascular. Informações sobre menstruação, gravidez e uso corrente de contraceptivos ou terapia de reposição hormonal foram igualmente coletadas, por meio de uma entrevista de breve duração realizada por uma enfermeira. Peso, altura, batimentos cardíacos, pressão arterial diastólica e sistólica foram avaliados, e amostras de sangue após ingestão de alimento (non-fasting) foram extraídas para análise de TC e TG no soro (método enzimático, auto-analisador Technicon). $O$ hdl-c foi avaliado em 25.157 mulheres, em duas das três comarcas.

Visando a comparar a distribuição de fatores relacionados à saúde que constavam do questionário, utilizamos testes Qui-quadrado, e para a comparação de valores médios usamos o teste $T$. Cada um dos grupos de tratamento de reposição foi comparado com as não-usuárias. Para o cálculo de valores médios ajustados, utilizamos o procedimento MANOVA/SPSS. Verificamos as diferenças intergrupais nos dados ajustados por meio de testes $T$ de Bonferroni. Quando testamos diferenças nos níveis de TG, utilizamos dados 'logtransfor- 
mados' (logtransformed). As covariantes, além da idade, foram: comarcas de residência, hábito diário de fumar e índice de massa corporal (BMI, $\mathrm{kg} / \mathrm{m}^{2}$ ) - cada um deles em adição à idade, e todos combinados.

\section{Resultados: Amostra SaÚdAVEl?}

A Tabela 1 mostra proporções dentre os entrevistados com hábitos saudáveis, de acordo com informações do questionário. Com exceção do uso menos freqüente de gordura saturada no pão por parte das usuárias de estrogênio, não encontramos diferenças significativas entre os diferentes grupos de usuárias da terapia de reposição hormonal e não-usuárias.

Tabela 1 - Indicadores de um estilo de vida saudável distribuidos por uso de terapia de reposição hormonal

\begin{tabular}{|l|c|c|c|}
\hline & $\begin{array}{c}\text { Estrogênio } \\
\mathrm{n}=218\end{array}$ & $\begin{array}{c}\text { Estrogênio/progesterona } \\
\mathrm{n}=405\end{array}$ & $\begin{array}{c}\text { Não-usuárias } \\
\mathrm{n}=32.225\end{array}$ \\
\hline Não usam gordura no pão, \% & $31,2^{*}$ & 23,5 & 23,1 \\
Têm gorduras leves em casa, \% & 38,5 & 40,5 & 37,8 \\
Nunca adicionam sal às refeições, \% & 73,9 & 70,5 & 74,4 \\
Atividade fisica, \% & 9,6 & 9,2 & 10,9 \\
Nunca tomam café, \% & 7,8 & 7,9 & 6,3 \\
Não-fumantes, \% & 61,9 & 59,0 & 62,4 \\
\hline
\end{tabular}

* Estatisticamente significativo (Teste Qui-quadrado, $\mathrm{p}<0,05$ ).

A Tabela 2 mostra alguns indicadores da saúde geral e cardiovascular versus uso da terapia de reposição hormonal. Comparadas às não-usuárias, as mulheres em terapia de reposição eram mais velhas, algo mais altas $(p=0,053)$ e com um menor BMI. Quando ajustado por idade, o BMI era significativamente inferior em ambos os grupos de usuárias de hormônios de reposição. Fatores como pensão por invalidez, dispensas por enfermidade e doenças coronarianas em parentes revelaram-se prevalentes entre as usuárias de reposição hormonal. 
Tabela 2 - Indicadores da saúde versus uso de terapia de reposição hormonal

\begin{tabular}{|l|c|c|c|}
\hline & $\begin{array}{c}\text { Estrogênio } \\
\mathrm{n}=218\end{array}$ & $\begin{array}{c}\text { Estrogênio/progesterona } \\
\mathrm{n}=405\end{array}$ & $\begin{array}{c}\text { Não-usuárias } \\
\mathrm{n}=32.225\end{array}$ \\
\hline Idade, anos, média (DP) & $49,4(5,2)^{*}$ & $49,1(4,4)^{*}$ & $46,2(7,9)$ \\
Altura, cm, média (DP) & $163,3(5,9)$ & $164,2(5,8)$ & $163,6(6,2)$ \\
BMI, kg/m², média (DP) & $24,9(3,8)$ & $24,5(3,5)^{*}$ & $25,0(4,3)$ \\
Anti-hipertensivos, \% & 6,9 & 7,2 & 8,7 \\
D. coronária ou AVE, \% & 2,2 & 0,7 & 1,4 \\
Diabetes mellitus, \% & 0,9 & 1,0 & 1,0 \\
D. coron. em parentes, \% & 41,7 & $45,6^{*}$ & 37,9 \\
Pensão por invalidez, \% & $15,6^{*}$ & 10,4 & 9,7 \\
Dispensas por enfermidade, \% & $9,6^{*}$ & $8,9 *$ & 6,0 \\
\hline
\end{tabular}

* Estatisticamente significativo $(\mathrm{p}<0,05)$.

A Tabela 3 mostra alguns indicadores de situação social, trabalho e emprego. Quando comparadas às não-usuárias, constatou-se que as mulheres submetidas à terapia de reposição com estrogênio/progesterona recebiam seguro-desemprego menos freqüentemente. Um número menor residia na região norte da Noruega, e menos comumente as atividades domésticas constituiam sua ocupação principal. Aquelas que utilizavam somente estrogênio relatavam menos freqüentemente trabalho manual ou deambulação freqüente durante o trabalho. 
Tabela 3 - Indicadores de situação social versus uso de terapia de reposição hormonal

\begin{tabular}{|l|c|c|c|}
\hline & $\begin{array}{c}\text { Estrogênio } \\
\mathrm{n}=218\end{array}$ & $\begin{array}{c}\text { Estrogênio/progesterona } \\
\mathrm{n}=405\end{array}$ & $\begin{array}{c}\text { Não-usuárias } \\
\mathrm{n}=32.225\end{array}$ \\
\hline Desemprego registrado, \% & 3,7 & $2,2^{*}$ & 4,0 \\
Trabalho noturno ou em escala,\% & 11,0 & 11,9 & 11,0 \\
Trabalho manual/deambulação, \% & $67,4^{*}$ & 75,1 & 77,6 \\
Do norte da Noruega, \% & 21,1 & $12,8^{*}$ & 25,9 \\
Casadas, \% & 83,9 & 83,0 & 81,6 \\
Trabalho doméstico, \% & 40,4 & $32,6^{*}$ & 44,0 \\
\hline
\end{tabular}

* Estatisticamente significativo (Qui-quadrado, $\mathrm{p}<0,05$ ).

\section{Lipídios SÉrICOS}

A Tabela 4 mostra que mulheres que utilizavam esquemas terapêuticos de estrogênio/progesterona tinham médias mais baixas de TC, ajustadas por idade, menor razão de TC/hdl-c e médias mais altas de TG e hdl-c, se comparadas às não-usuárias. As que utilizavam somente estrogênio tinham o valor médio mais elevado de hdl-c. A razão média de TC/hdl-c em usuárias de esquemas terapêuticos de estrogênio/progesterona não era significativamente diferente, estatisticamente, daquela referente às mulheres que utilizavam somente estrogênio. Aquelas que usavam èstrogênio de fácil absorção apresentavam valores médios de TG mais elevados, enquanto as usuárias de estrogênio/progesterona apresentavam valores médios mais baixos de TG do que as não-usuárias. 


\section{Tabela 4 - Valores médios de lipídios séricos versus utilização de terapia de reposição hormonal. Ajustado por idade}

\begin{tabular}{|l|c|c|c|}
\hline & $\begin{array}{c}\text { Estrogênio } \\
\mathrm{n}=218\end{array}$ & $\begin{array}{c}\text { Estrogênio/progesterona } \\
\mathrm{n}=405\end{array}$ & $\begin{array}{c}\text { Não-usuárias } \\
\mathrm{n}=32.225\end{array}$ \\
\hline Colesterol total, $\mathrm{nmol} / 1$ & $6,03^{*}$ & $5,72^{*}$ & 6,07 \\
Hdl-c, nmol/1 & $1,63^{* \#}$ & $1,56^{*}$ & 1,52 \\
Razão total/hdl-c & 3,91 & $3,79^{*}$ & 4,13 \\
Triglicerídeos, nmol/1 & $1,48^{* \#}$ & $1,34^{*}$ & 1,44 \\
\hline
\end{tabular}

* Diferença estatisticamente significativa, se comparada com não-usuárias $(p<0,05)$.

* Diferença estatisticamente significativa, comparada com usuárias de estrogênio/ progesterona $(\mathrm{p}<0,05)$.

Ao se adicionar comarca de residência, BMI e fumo como covariantes, a diferença de $\mathrm{TC}$ entre não-usuárias e usuárias de estrogênio/progesterona reduziu-se em $0,06 \mathrm{mmol} / 1$. A diferença entre médias para TG entre usuárias de apenas estrogênio e não-usuárias aumentou em $0,03 \mathrm{mmol} / \mathrm{l}$. Para hdl-c e a razão $\mathrm{TC} / \mathrm{hdl}-\mathrm{c}$, as diferenças foram minimamente reduzidas.

\section{Pressão Arterial e Batimentos Cardíacos}

A Tabela 5 mostra que as usuárias de estrogênio possuíam a mais baixa SBP ajustada por idade, e que ambos os grupos de usuárias de terapia hormonal de reposição tinham SBP mais baixa do que as não-usuárias. Os níveis de DBP foram não-significativamente menores em ambas as usuárias de terapia hormonal de reposição do que entre as não-usuárias $(p<0,1)$. Ao adicionarmos BMI, comarca de residência e fumo à idade como covariantes, reduzemse as diferenças quanto à SBP entre usuárias de estrogênio e não-usuárias entre $5,8 \mathrm{mmHg}$ e $5 \mathrm{mmHg}$, enquanto a diferença relativa à DBP reduziu-se entre $1,3 \mathrm{mmHg}$ e $0,8 \mathrm{mmHg}$. De modo correspondente, as diferenças entre não-usuárias e usuárias de esquemas de reposição com estrogênio/progesterona reduziram-se de $3,3 \mathrm{mmHg}$ a $2,0 \mathrm{mmHg}$ para a SBP e de $0,9 \mathrm{mmHg}$ a 
$0,1 \mathrm{mmHg}$ para a DBP, respectivamente. Aquelas que utilizaram apenas o estrogênio apresentaram o mais baixo HR ajustado por idade. Em termos de dados brutos, a diferença mostrou-se mais acentuada, com valores médios de 73,6 batidas/min em usuárias de estrogênio puro, 76,8 batidas/min em usuárias de estrogênio/progesterona e 77,5 batidas/min em não-usuárias.

\section{Tabela 5 - Valores médios de pressão arterial sistólica e diastólica e batimentos cardiacos versus uso de terapia de reposição hormonal. Ajustado por idade}

\begin{tabular}{|l|c|c|c|}
\hline & $\begin{array}{c}\text { Estrogênio } \\
\mathrm{n}=218\end{array}$ & $\begin{array}{c}\text { Estrogênio/progesterona } \\
\mathrm{n}=405\end{array}$ & $\begin{array}{c}\text { Não-usuárias } \\
\mathrm{n}=32.225\end{array}$ \\
\hline P. arterial sistólica, $\mathrm{mmHg}$ & $121,9^{* *}$ & $124,4^{*}$ & 127,7 \\
P. arterial diastólica, $\mathrm{mmHg}$ & 76,2 & 76,6 & 77,5 \\
Freq. cardiaca, freq./min. & $74,3^{*}$ & 77,4 & 77,8 \\
\hline
\end{tabular}

* Diferença estatisticamente significativa, se comparada a não-usuárias $(\mathrm{p}<0,05)$.

** Diferença estatisticamente significativa, se comparada com usuárias de estrogênio/ progesterona $(p<0,05)$.

\section{DISCUSSÃO}

A hipótese de que as usuárias de terapia de reposição hormonal constituam uma coorte saudável ou uma amostra selecionada entre os saudáveis não encontrou apoio no presente estudo. Isto revelou-se surpreendente, porque a maioria dos autores tem encontrado, ou sugerido, um vício de seleção de mulheres saudáveis e de baixo risco quanto ao tratamento de reposição hormonal ao longo dos anos 70 e 80 (Vandenbroucke, 1995). Acreditou-se, até fins da década de 80 , que o estrogênio aumentava o risco coronariano, determinando provavelmente um viés nos padrões de prescrição. $O$ presente estudo, no entanto, sugere mesmo a possibilidade de uma seleção não-saudável quanto à terapia hormonal. Consultas médicas podem constituir um fator de risco para mulheres em idade de menopausa, no sentido de receber uma pres- 
crição, bem como um reforço social no sentido da manutenção do uso dos hormônios de reposição. De forma menos surpreendente, este estudo sugere que mulheres que utilizam estrogênio/progesterona foram recrutadas de estratos de nível socioeconômico relativamente alto. A altura é um indicador de nutrição durante a infância ou a juventude, quando se comparam grupos dentro de uma população geneticamente homogênea. O peso corporal algo mais elevado, o BMI mais baixo, o menor índice de desemprego, a menor proporção de envolvimento com atividades domésticas como ocupação principal e, talvez, a percentagem mais baixa de habitantes da região mais ao norte do país reforçam a hipótese de seleção de natureza socioeconômica.

No sentido de encontrar níveis de pressão arterial e lipídios séricos com parâmetros mais favoráveis em usuárias de estrogênio de fácil absorção, nossa hipótese vê-se reforçada pela descoberta de que esse grupo tinha os mais altos valores médios de hdl-c ajustados pela idade e a mais baixa SBP. Contudo, usuárias de esquema terapêutico de estrogênio/progesterona possuiam os mais baixos niveis de TC e TG. A razão total/hdl-c era favorável em usuárias de ambos os esquemas terapêuticos de reposição. Para aquelas que utilizavam estrogênio/progesterona, a seleção social pode, em alguma medida, explicar o perfil metabólico favorável. Os achados relativos ao hdl-c e TG nas usuárias estão em consonância com o estudo PEPI (Writing Group for the PEPI Trial, 1995). O hdl-c mais elevado em $0,11 \mathrm{mmol} / 1$ registrado em mulheres que utilizavam apenas estrogênio, se comparado às não-usuárias, tem importância clínica, uma vez que os estudos de observação demonstraram que um incremento de 0,1 a 0,13 mmol/hdl-c estava associado a um decréscimo de 20$25 \%$ no risco de doenças coronarianas (Gouldburt \& Medalie, 1979). Por outro lado, o hdl-c mais elevado em $0,04 \mathrm{mmol} / \mathrm{l} \mathrm{em}$ mulheres que utilizavam esquemas terapêuticos de estrogênio/progesterona, se comparado às não-usuárias, representa uma pequena diferença de um ponto de vista clínico. Nossos achados de SBP e HR significativamente (do ponto de vista estatístico) mais baixos em usuárias de estrogênio foram surpreendentes e necessitam de confirmação por meio de estudos controlados. As diferenças no nivel de triglicerídeos devido ao uso de hormônios não têm provavelmente significação clínica (Writing Group for the PEPI Trial, 1995).

Estudos seccionais nada permitem afirmar sobre causa e efeito, e sempre existem fatores de confusão (confounders). Há fatores de confusão que esca- 
pam à nossa atenção; aqueles de que pọdemos suspeitar, mas não avaliar; e aqueles que avaliamos de forma imprecisa. No presente estudo, o uso de álcool e a educação são exemplos de possíveis fatores de confusão não-avaliados, uma vez que a pesquisa não foi inicialmente planejada como um estudo sobre terapia de reposição hormonal. Por outro lado, pode-se ajustar demasiadamente, como talvez seja o caso ao se incluir o BMI como covariante. Existem argumentos para ajustar pelo BMI, o qual poderia ser menor em usuárias de estrogênio/progesterona do que em não-usuárias antes que a terapia hormonal se iniciasse. Mulheres magras podem desenvolver sintomas de deficiência hormonal - o que constituía a indicação mais comum para terapia hormonal nos anos 80 - com maior freqüência do que mulheres gordas. Mulheres que escolheram usar hormônios podem ser mais conscientes do seu peso do que as não-usuárias. Em ambos os casos, o BMI é um fator de confusão que deveríamos ajustar. Mas os hormônios sexuais femininos podem também influenciar o peso corporal e, neste caso, o ajuste para BMI significa ajuste para o efeito hormonal que desejamos estudar.

\section{CONCLUSÃO}

No presente estudo seccional, as usuárias de estrogênio puro tiveram os valores médios ajustados mais favoráveis de hdl e SBP, comparadas com nãousuárias e usuárias de outros esquemas terapêuticos. No entanto, usuárias de esquemas de reposição combinada de hormônios sexuais apresentaram TC mais baixo, razão TC/hdl idêntica e idêntico DBP, se comparadas a usuárias de estrogênio de fácil absorção. 


\section{REFERÊNCIAS BIBLIOGRÁFICAS}

BARRETT-CONNOR, E. \& BUSH, T. L. Estrogen and coronary heart disease in women. Journal of American Medical Association, 256:1.861-1.867, 1991.

BJARTVEIT, $K$. et al. The cardiovascular disease study in Norwegian countries: background and organization. Acta Medica Scandinava, (suppl.) 634:1-70, 1985.

GOULDBURT, U. \& MEDALIE, J. H. High density lipoprotein cholesterol and incidence of coronary heart disease: the Israeli ischemic heart disease study. American Journal of Epidemiology, 109:296-308, 1979.

VANDENBROUCKE, J. P. How much of the cardioprotective effect of postmenopausal estrogen is real? Epidemiology, 6:207-208, 1995.

WRITING GROUP FOR THE PEPI TRIAL. Effects of estrogen or estrogen/ progestin regimes on heart disease risk factors in postmenopausal women. Journal of American Medical Association, 273:199-208, 1995. 


\section{O 'ENFOQUE DE RISCO' EM SAÚDE PÚBLICA}

Chester Luiz Galvão Cesar

\section{INTRODUÇÃO}

Os serviços da saúde têm tradicionalmente dedicado atenção especial ao grupo materno-infantil, com programas específicos de assistência, sendo esta uma possível razão para a maior sistematização das ações da saúde voltadas ao grupo. O processo de gestação, o parto, o puerpério e o primeiro ano de vida da criança vêm sendo identificados como períodos do ciclo vital de maior vulnerabilidade, merecendo assim um acompanhamento cuidadoso. Esses programas da saúde, ao longo do seu desenvolvimento, passaram a utilizar critérios de diferenciação das gestantes e das crianças que permitissem identificar as de maior vulnerabilidade, surgindo assim os conceitos de risco gravídico, gravidez de alto risco, recém-nascido de risco e outros. Produziu-se uma vasta literatura sobre risco na área materno-infantil, inclusive com o desenvolvimento de escalas usadas em modelos preditivos.

$\mathrm{Na}$ década de 70, a Organização Mundial da Saúde (OMS) propôs, a partir do trabalho desenvolvido por um grupo-tarefa, uma metodologia de 
programação materno-infantil com 'enfoque de risco', divulgada através da publicação intitulada Método de Atención Sanitária de la Madre y el Niño Basado en el Concepto de Riesgo (OMS, 1978). Este trabalho foi seguido pela elaboração de material para treinamento, destinado ao desenvolvimento de programas da saúde materno-infantil, baseados na 'estratégia de risco'. $\mathrm{O}$ subtítulo desta mesma publicação já definia os objetivos do trabalho, pois referia-se a "uma estratégia de gerência para melhorar a cobertura e a qualidade dos serviços da saúde da mãe, da criança e do planejamento familiar, baseada na mensuração do risco individual e coletivo".

Durante a primeira metade da década de 80 , os esforços foram concentrados no treinamento de pessoal, particularmente dos profissionais ligados aos programas materno-infantis. O material de treinamento foi centrado em um banco de dados fictícios - Fictícia (Brasil, 1983) - guardando estreita semelhança com a realidade da saúde dos países em desenvolvimento. Este material permitia a discussão da proposta da 'estratégia de risco' em uma simulação prática, sendo o treinamento desenvolvido em seminários de uma ou duas semanas. Durante este período, a OMS publicou também uma bibliografia comentada (WHO, 1981) sobre o assunto, a qual incluía trabalhos publicados que, de alguma forma, usavam os conceitos envolvidos no enfoque de risco. Foram principalmente trabalhos da área de obstetrícia e pediatria que estudavam fatores de risco obstétrico e infantil, alguns deles utilizando escalas e modelos preditivos.

Em 1984 foi publicado um novo texto, de certa maneira uma revisão dos anteriores, intitulado "O enfoque de risco na assistência à saúde", com especial referência à saúde materno-infantil, inclusive planejamento familiat (Backett, Davies \& Petros-Barvazian, 1984). O material do treinamento, originalmente publicado em inglês, foi traduzido para o espanhol e o português. No Brasil, o Ministério da Saúde (MS), em conjunto com a Organização PanAmericana de Saúde (OpAS), coordenou a edição dos textos e a realização de seminários, treinando técnicos das Secretarias de Estado da Saúde, sendo que algumas delas, como a de São Paulo, reproduziram estes cursos (São Paulo, 1984), descentralizando o conhecimento sobre a proposta. A experiência brasileira e os textos em português foram utilizados em 1985 para um seminário em Maputo (Moçambique), que reuniu técnicos dos países africanos de língua portuguesa. 
No Brasil, as atividades ligadas à 'estratégia de risco' na área maternoinfantil ocorreram paralelamente aos programas estaduais e mesmo federal, não tendo sido incorporadas explicitamente como diretriz na organização dos serviços da saúde, desaparecendo paulatinamente com as mudanças das equipes técnicas, decorrentes das alternâncias políticas em âmbito federal $\mathrm{e}$ estadual. É difícil avaliar o quanto da estratégia foi incorporada nas práticas da saúde, principalmente nos programas de atenção materno-infantil. Duas experiências no estado de São Paulo se destacam por explicitarem̀ o uso da 'estratégia de risco' como base para programas materno-infantis. A primeira delas foi no município de Bauru, através da iniciativa intitulada Programa de Defesa da Vida dos Lactentes, que teve alguns de seus aspectos publicados pela Revista de Saúde Pública (Rumel et al., 1992). Recentemente, a Prefeitura de Santos vem desenvolvendo um programa semelhante, centrado na mesma estratégia.

O processo de descentralização do setor da saúde, particularmente a municipalização e a criação dos Distritos da Saúde, com a conseqüente criação de equipes locais para gerência e planejamento, vem aumentando a demanda por modelos de aplicação da epidemiologia em serviços da saúde, e a proposta da estratégia de risco voltou a ser discutida, havendo necessidade de uma análise crítica da metodologia proposta, bem como das experiências desenvolvidas.

\section{Fundamentos da Estratégia de Risco}

A estratégia de risco baseia-se em dois fatos fundamentais. O primeiro deles é a constatação de que há uma distribuição desigual dos 'danos' à saúde entre os diversos grupos populacionais, como decorrência de que alguns indivíduos apresentam características próprias ou estão sujeitos a determinadas circunstâncias, as quais fazem com que a probabilidade de ocorrência de um dano à saúde seja maior do que para outros indivíduos sem as mesmas características, ou não expostos às circunstâncias (fatores de risco). O segundo fato importante é que esses fatores de risco são observáveis ou identificáveis antes do evento a que estão associados. 
Segundo a estratégia de risco, a identificação dos fatores de risco a priori, isto é, antes do aparecimento do evento (dano) a que estão associados, abre uma ampla possibilidade operacional através dos seguintes aspectos: previsão do aparecimento do dano, tendo assim uma função preditiva; possível controle ou eliminação desses fatores, assim reduzindo a probabilidade de aparecimento do dano; e possível identificação dos grupos de alto risco que devam ser objeto de atenção especial por parte dos serviços da saúde, no sentido de 'compensar' esses riscos através de ações da saúde.

A partir dessas idéias, a estratégia de risco propõe que se analisem os serviços da saúde frente às prioridades da sua área de atuação e que eles redirecionem suas atividades para que, dispensando uma assistência básica a todos os indivíduos, concentrem esforços naqueles que pertençam aos grupos de risco.

Em seguida, são propostas algumas etapas para a reorganização dos serviços da saúde com enfoque de risco. A primeira etapa consiste no diagnóstico da saúde para identificação dos problemas (danos) prioritários, devendo-se aqui trabalhar com indicadores de morbi-mortalidade e com os critérios, já tradicionais, de estabelecimento de prioridades. A seguir devem-se identificar os fatores de risco para esses danos selecionados, podendo, segundo a proposta, ser feito de uma maneira relativamente simplificada, trabalhando-se com o conhecimento e a opinião dos agentes da saúde, ou com técnicas mais elaboradas, como o método Delphos, ou ainda com modelos epidemiológicos como estudos de caso-controle utilizando-se inclusive técnicas de análise multivariada (WHO, 1984). A utilização de técnicas mais elaboradas para identificação e seleção dos fatores de risco deve resultar em modelos preditivos de maior precisão.

A terceira etapa corresponde à identificação dos indivíduos (população) em risco, e o modelo propõe a criação de escalas para seleção dos indivíduos. Aqui também as alternativas vão desde escalas relativamente simples, nas quais se assinala a presença ou ausência de determinado fator de risco, até aquelas mais complexas que incorporam peso a cada fator de risco específico, geralmente proporcional aos valores do risco relativo. Estas escalas permitem, no seu uso, a opção por diferentes pontos de cortes, implicando um número maior ou menor de indivíduos identificados como de alto ou baixo risco.

A quarta etapa refere-se à análise da adequação dos serviços da saúde como resposta às necessidades dos indivíduos (populações) em risco, e a 
partir desta análise devem ser propostas as reformulações necessárias dos programas para adequá-los a essas necessidades identificadas.

Por último, deve ser mantido um esquema de acompanhamento e avaliação do desenvolvimento do programa, tanto quanto ao impacto em nível populacional como no processo de trabalho no que diz respeito à incorporação das estratégias de risco no funcionamento dos serviços. Neste processo de avaliação, devem ser analisados inclusive os próprios instrumentos de identificação dos grupos de risco, podendo-se reformulá-los no sentido de terem maior sensibilidade e especificidade.

Exemplo da estratégia de risco, ainda que parcial, foi publicado na Revista de Saúde Pública em 1990 (Cesar, 1990). Neste trabalho, a partir da constatação da importância da mortalidade infantil em uma área da região metropolitana de São Paulo (Cotia e Vargem Grande Paulista), foi desenvolvido um estudo de caso-controle para identificação dos fatores de risco associados à mortalidade no primeiro ano de vida. A partir dos resultados obtidos, foram elaboradas quatro escalas para identificação de grupos de risco que deveriam merecer uma assistência prioritária dos serviços da saúde. As escalas destinam-se a momentos diferentes do processo de gestação, parto e primeiro ano de vida. A primeira delas destina-se a identificar, durante o pré-natal, aquelas mães que, pelas suas características e condições de sobrevivência, teriam um risco aumentado de perda da criança no primeiro ano de vida. As três outras escalas, com o mesmo objetivo da primeira, foram elaboradas para uso na ocasião do parto, no período neonatal e no período pós-neonatal. As escalas levaram em conta o valor do odds ratio de cada fator de risco. Assim, por exemplo, a escala para uso em pré-natal (Tabela 1) incluiu dez variáveis, cada uma dicotomizada em risco e não-risco, correspondendo ao grupo risco o respectivo valor do odds ratio, e ao grupo não-risco o valor 1 .

A primeira variável que compõe a escala é a altura da mãe, e ela foi dicotomizada em altura inferior a $150 \mathrm{~cm}$ e em altura igual ou superior a $150 \mathrm{~cm}$. $O$ primeiro grupo corresponde ao de risco e foi ponderado em 2,15, valor do odds ratio. Se o valor da altura da mãe foi superior a $150 \mathrm{~cm}$, isto é, se ela pertence ao grupo não-risco, o valor computado foi 1 . O mesmo procedimento foi feito para as variáveis seguintes, computando-se para cada uma delas o respectivo valor do odds ratio quando se tratava de grupo de risco, ou o valor 1 , quando pertencia ao grupo de não-risco. Para compor o total de pontos para cada indivíduo, os diferentes valores encontrados foram então multiplicados. 


\section{Tabela 1 - Escala para identificar durante o período pré-natal grupos de risco para óbito infantil. Cotia e Vargem Grande Paulista - 1984-1985}

\begin{tabular}{|l|l|c|}
\hline Variáveis & & Valores dos odds ratios \\
\hline Altura das mães & abaixo de $150 \mathrm{~cm}$ & 2,15 \\
& $150 \mathrm{~cm}$ ou mais & 1,00 \\
\hline Número prévio de gestações & 4 ou mais & 2,15 \\
& até 3 & 1,00 \\
\hline Intervalo entre a data & até 18 meses & 2,29 \\
provável do parto e o parto anterior & 18 meses ou mais & 1,00 \\
\hline Intervalo interpartal médio & até 24 meses & 3,20 \\
& 24 meses ou mais & 1,00 \\
\hline História prévia de perda fetal & sim & 2,38 \\
& não & 1,00 \\
\hline História prévia de óbito de & sim & 3,83 \\
criança menor de 1 ano & não & 1,00 \\
\hline Cobertura das mães por & não & 1,96 \\
serviços da saúde & sim & 1,00 \\
\hline Migração recente & sim & 5,28 \\
& não & 1,00 \\
\hline Tempo morando com o & menos de 24 meses & 2,26 \\
companheiro & 24 meses ou mais & 1,00 \\
\hline Tipo de habitação & outros & 1,00 \\
\hline & casa ou apto. & 5,83 \\
\hline & & \\
\hline
\end{tabular}

Considere-se, por exemplo, determinada mãe que pertença aos grupos de risco para as variáveis 'número prévio de gestações' e 'migração recente' e que, para as demais, situe-se nos grupos de não-risco. Neste caso, ela teria para a variável 'número prévio de gestações' o valor do odds ratio de $2,15 \mathrm{e}$, para 'migração recente', de 5,28. Para as demais variáveis, os valores computados seriam iguais a 1. Esta mãe teria então o valor final dos seus pontos na 
escala de risco igual ao produto destes dois valores diferentes de 1 , ou seja, $11,35(2,15 \times 5,28)$. A Tabela 2 mostra os intervalos dos valores dos odds ratios para cada nível da escala de pré-natal.

Tabela 2 - Distribuição dos intervalos dos valores dos odds ratios segundo os graus da escala de pré-natal. Cotia e Vargem Grande Paulista - 1984-1985

\begin{tabular}{|c|c|}
\hline Graus da escala & Intervalo dos valores dos odds ratios \\
\hline 8 ou + & $60,0 \mathrm{e}+$ \\
7 & $25,0-60,0$ \\
6 & $15,0-25,0$ \\
5 & $10,0-15,0$ \\
4 & $5,0-10,0$ \\
3 & $2,5-5,0$ \\
2 & $2,0-2,5$ \\
1 & $1,1-2,0$ \\
0 & $<1,1$ \\
\hline
\end{tabular}

$\mathrm{Na}$ sua aplicação, as escalas permitem uma definição dos grupos de risco e não-risco a partir da decisão sobre os níveis dos pontos de corte nas escalas, que deverão indicar em que grupo será incluído um indivíduo em particular. Assim, ainda na escala de pré-natal (Tabela 2), se o nível 3 for o escolhido como ponto de corte, isto implicará que todas as mães cujo resultado final da multiplicação da razão dos seus produtos cruzados for igual ou superior a 2,5 serão consideradas de 'risco', e todas aquelas cujo resultado for abaixo de 2,5 serão consideradas de 'não-risco'. Na realidade, entre os indivíduos considerados de risco há aqueles que, na verdade, não o são, e denominam-se falsos positivos. Da mesma forma, entre os indivíduos do grupo 'nãorisco' há aqueles que de fato são de alto risco e, neste caso, denominam-se falsos negativos.

Utilizando-se esta escala de pré-natal no ponto de corte 3 para classificar os nascimentos ocorridos em 1984 (2.559) e os nascidos em 1984 que foram a óbito no primeiro ano de vida (90), teríamos do total de nascidos- 
vivos (NV) 940 classificados como de alto risco, e 1.619 como de baixo risco. Da mesma forma, este nível da escala selecionaria 57 das noventa mães que tiveram óbitos como de alto risco, e 33 como de baixo risco. Assim, entre os 940 nascidos-vivos de alto risco estariam incluídos 57 óbitos, significando um Coeficiente de Mortalidade Infantil (CMI) igual a 60,63/1.000 NV [(57/940) $x 1.000]$, e entre os 1.619 de baixo risco estariam incluídos 33 óbitos, traduzindo um CMI de 20,38/1.000 NV [(33/1.619) x 1.000] (Tabela 3).

\section{Tabela 3 - Aplicação da escala pré-natal, no ponto de corte 3, à população geral de nascidos-vivos em 1984}

\begin{tabular}{|c|c|c|c|}
\hline \multirow{2}{*}{ Classificação da escala } & \multicolumn{2}{|c|}{ Verdade } & \multirow{2}{*}{ TOT $\Lambda \mathrm{L}$} \\
\cline { 2 - 3 } & risco & não-risco & \\
\hline Risco & 57 & 883 & 940 \\
Não-risco & 33 & 1.586 & 1.619 \\
TOTAı. & 90 & 2.469 & 2.559 \\
\hline
\end{tabular}

Grupo de risco $=940(\mathrm{CMI}=60,63 / 1.000 \mathrm{NV})$

Grupo de não-risco $=1.619(\mathrm{CMI}=20,38 / 1.000 \mathrm{NV})$

A utilização do 'enfoque de risco' teria o significado de, ao se trabaIhar com essas duas populações, dar prioridade àquela de alto risco que apresenta mortalidade infantil três vezes maior que a de baixo risco sem, contudo, o que é óbvio, deixar de fornecer uma assistência básica a essa população de menor risco.

As escalas elaboradas visam tão-somente à identificação dos grupos que, por serem de alto risco, mereçam uma assistência especial. As características desta assistência deverão ser definidas pelos programas da saúde. Algumas famílias precisarão muito mais de orientação educativa e suporte social do que de assistência médica ou tratamento clínico. Por outro lado, para algumas mães será necessário um eficaz acompanhamento médico-laboratorial e provavelmente acesso a tecnologias mais sofisticadas para superarem seus fatores de risco. $\mathrm{Na}$ verdade, o que vai causar impacto em âmbito populacional é a qualidade e a eficiência dos programas da saúde. 


\section{Críticas e Limites da Proposta DE 'ENFoque De Risco'}

A proposta da OMS é objeto de críticas desde sua divulgação, e algumas delas são a seguir analisadas.

Uma das críticas formuladas (Alvarenga, 1987) diz respeito à questão do planejamento familiar, expressão incluída no próprio título de algumas das publicações de enfoque de risco. A este respeito, alertou-se quanto ao perigo de uma 'roupagem' técnica para uma questão freqüentemente ideológica, pois os fatores de risco sociais (englobados na 'pobreza') seriam uma justificativa 'técnica' para a anticoncepção nos grupos de baixo nível socioeconômico. Embora este fato possa ocorrer na prática, obviamente ele representaria uma grave distorção da proposta originalmente formulada, sendo importante, no entanto, que se mantenha alerta sobre a possibilidade de sua ocorrência.

Outro ponto importante referido por Alvarenga (1987) é que, pelo menos em parte da literatura, os trabalhos basearam-se em critérios subjetivos para a definição dos fatores de risco e conseqüentemente dos grupos de risco, afirmando que "em função da não-adoção de critérios metodológicos (teóricos e técnicos) mais adequados, estes instrumentos de medida de risco passam a ser construídos, na quase totalidade, em bases totalmente arbitrárias e isentas de validade". Possivelmente, os modelos que trabalham com critérios subjetivos apresentam menor eficácia no processo de identificação dos grupos de risco, e a forma de melhorar a precisão desses instrumentos seria trabalhar com a metodologia epidemiológica, incluindo análises estatísticas de maior complexidade, como aparece nas propostas originais da OMS. No entanto, é preciso ter cuidado quanto à incorporação de metodologias complexas em um programa a ser desenvolvido na rede básica da saúde, em que um dos critérios para sua viabilidade é ser facilmente aplicável, não necessitando de conhecimentos muito avançados de epidemiologia e estatística. Uma possível alternativa é trabalhar-se com modelos mais simples como triagem e, para o grupo selecionado, utilizarem-se modelos de análise mais complexa que possam inclusive incorporar variáveis clínicas e exames laboratoriais.

Outra crítica levantada tanto por Alvarenga (1987) como por Hayes (1991) é o tratamento dado às variáveis sociais. Alvarenga (1987) faz especial 
referência à introdução de variávcis sociais $\mathrm{cm}$ conjunto com as biológicas nos modelos preditivos, alertando para a forma fragmentada como são trabalhadas e para a "perda da sua verdadeira hierarquia de determinação no processo saúde doença". Hayes (1991) também critica o tratamento dado ao social, afirmando que a predição para os fenômenos sociais é muito mais complexa e menos precisa do que para os fenômenos naturais.

Estas são, scm dúvida, críticas importantes, já que é fundamental para quem trabalha com o enfoque de risco ter em mente o reducionismo dos modelos preditivos, principalmente no que diz respeito às variáveis sociais. No entanto, para os profissionais da saúde em geral, a incorporação da dimensão social nos modelos, anteriormente cxclusivamente biológicos, de risco gravídico ou mesmo na avaliação do recém-nascido (Escala de Apgar) significou um grande avanço, principalmente porque há muito tempo se enfatiza a importância da determinação social na saúde materno-infantil c principalmente na mortalidade infantil. Embora correndo o risco da simplificação apontada, a proposta do enfoque de risco pode ser vista como uma tentativa de ampliar para além do biológico a discussão das determinações, incorporando a dimensão social na organização dos serviços da saúde.

Ainda Hayes (1991), na sua análise crítica do modelo, levanta outras questões que, embora muito importantes, são provavelmente limites da epidemiologia e não exclusivas da estratégia de risco. São elas o pressuposto da regularidade dos fatos empíricos e a qualidade da relação entre os marcadores de risco e os resultados (efeitos).

Com relação à regularidade dos fatos empíricos, o autor considera que o modelo apresenta uma visão estática do processo que produz morbidade e que há um pressuposto de que a conjunção de eventos (fatores de risco precedendo um resultado específico) é generalizável através do espaço e mais ou menos invariável através do tempo. Na verdade, um aspecto inerente ao modelo de programação com enfoque de risco é a necessidade de conhecimento da realidade local, isto é, a proposta baseia-se em diagnóstico local da saúde para a identificação de problemas, fatores de risco e prioridades. Com isto, pressupõe, ao contrário da crítica levantada, uma variabilidade nas realidades locais (espaço) e em diferentes momentos (tempo).

Quanto à questão da relação entre fatores de risco e os resultados (cfeitos), é importante ressaltar que a proposta do cnfoque de risco trabalha tanto 
com fatorcs que apresentam uma relação provavelmente causal quanto com fatores que, embora não sejam parte da cadeia causal, sejam bons indicadorcs de risco. Isto porque um aspecto fundamental do modelo é a possibilidade de ações da saúde 'compensatórias' quando não for possível alterarem-se as possíveis causas. Este fato foi muito bem discutido por Plaut (1984): "Sem dúvi$\mathrm{d}$ a, todos os fatores de risco, inclusive os reconhecidamente não vinculados à trama causal, têm utilidade para o administrador de saúde porque podem ser usados como elementos capazes de predizer danos, com a condição de que sua relação com esses danos seja estreita."

Além dessas críticas acima descritas, é importante lembrar que a questão central da programação, com cnfoque de risco, refere-se à identificação dos grupos de alto risco que passam a ser alvo de uma assistência especial. $O$ rcsultado esperado, uma redução da morbidade e da mortalidade nesses grupos, vai depender basicamente de dois fatores. O primeiro deles é a eficácia do modelo preditivo utilizado, principalmente a sua sensibilidade para identificar os indivíduos de alto risco. O segundo é a eficácia do programa da saúde a eles destinado, que em última análise é o que deve controlar ou eliminar fatores de risco ou compensar, com ações específicas, os fatores não-elimináveis.

A eficácia do modelo preditivo pode ser alterada com técnicas epidemiológicas e estatísticas, conforme foi anteriormente citado, e depende fundamentalmente de os serviços da saúde estarem capacitados e optarem por modelos preditivos mais precisos.

A eficácia dos programas da saúde é talvez um problema de solução mais complexa. Se considerarmos o atual perfil epidemiológico da população materno-infantil em nosso meio, verificamos que parte do problema requer melhoria qualitativa do pré-natal e do parto, bem como o uso de tecnologias mais avançadas nos berçários, que permita reduzir ou compensar riscos biológicos. Por outro lado, uma parcela significativa deste perfil da saúde decorre de condições socioeconômicas pouco compensávcis a partir dos programas da própria saúde. Além disso, cssas condições socioeconômicas podem reduzir o possível impacto das ações da saúde. O grande grupo de gestantes adolescentes e com graves problemas sociais é um excmplo das dificuldades dos programas materno-infantis, principalmente considerando-se a quase ausência de políticas públicas de suporte social. 
İsscs fatos devem ser lembrados na avaliação dos programas desenvolvidos que, mesmo estando bem estruturados, podem apresentar um impacto aquém do csperado, devido a limitações que extrapolam sua árca de atuação.

Outra questão importante relativa aos programas com enfoque de risco diz respeito ao que Rose (1985) discutiu como 'indivíduos doentes' c 'populações doentes'. A programação com enfoque de risco, se desenvolvida a contento, isto é, se for utilizado um modelo preditivo eficaz e se houver um bom descmpenho dos scrviços da saúde no que diz respeito às ações desenvolvidas, deve reduzir a morbidade e a mortalidade dos grupos de alto risco sem quc, obrigatoriamente, o impacto na população materno-infantil em geral seja muito expressivo. Essa possibilidade decorre do fato de que o grupo de baixo risco é freqüentemente muito mais numeroso que o de alto risco, e os eventos indesejáveis que nele ocorrem, doença e óbito, podem ser em grande parte os responsávcis pela incidência encontrada. Rose (1985) exemplifica com a incidência da síndrome de Down e a idade materna, mostrando que, apesar de o risco aumentar com a idade materna, a maioria dos casos ocorre em mães jovens, por serem muito mais numerosas que as gestantes idosas.

As críticas que se apresentaram até aqui não significam que se deva invalidar a proposta de programação materno-infantil com enfoque de risco, mas representam alguns de seus limites, bem como alertam para cuidados a serem observados em seu desenvolvimento e avaliação.

\section{ConsideraÇões Finais}

A proposta de enfoque de risco na organização dos serviços da saúde representa um bom exemplo da articulação da epidemiologia com a gerência dos serviços da saúde. Em particular, ela possibilita o uso dos conceitos c dos métodos da cpidemiologia analítica na prática da saúde pública. Embora desenvolvida inicialmente para a área materno-infantil, ela não é exclusiva desta, sendo sua fundamentação aplicável a qualquer outra árca - recentcmente, tcm 
sido utilizada em outras situações, tais como programas de controle da malária (Castillo-Salgado, 1992).

As possibilidades de aplicação da proposta são amplas e devem ser adequadas às diferentes realidades da saúde. É possível trabalhar de maneira relativamente simples, em âmbito local e com instrumental técnico de pequena complexidade, ou pode-se, ainda, avançar na implantação de modelos mais complexos com análises epidemiológicas e estatísticas que permitam instrumentos mais precisos de identificação de grupos de risco.

É importante lembrar que o possível impacto da implantação de uma programação com enfoque de risco vai depender não somente da capacidade dos serviços em identificar os grupos de alto risco, mas principalmente das ações da saúde desenvolvidas.

Vários autores têm alertado para os limites da proposta, conforme já foi discutido, e é importante que os profissionais que trabalham com o enfoque de risco se mantenham alertas para essas questões - em particular o tratamento reducionista conferido às variáveis sociais.

Por último, continua havendo uma grande necessidade de avaliação dos programas desenvolvidos na pratica da saúde pública. Conforme comenta Hayes (1991), a literatura especializada indica raros trabalhos de avaliação.

\section{REFERÊNCIAS BIBLIOGRÁFICAS}

ALVARENGA, A. T. O enfoque de risco. In: II SEMINÁRIO ESTADUAL DE SAÚDE DA CRIANÇA. São Paulo, 1986. Anais. Governo do Estado de São Paulo, Secretaria de Estado da Saúde, 1987. p.19-24.

BACKETT, E. M.; DAVIES, A. M. \& PETROS-BARVAZIAN, A. The Risk Approach in Health Care. Geneva: World Health Organization, 1984. (WHO, Public Health Papers, 76).

BRASIL. Ministério da Saúde/Organização Pan-Americana da Saúde. Seminário Nacional de Aplicafão do Enfoque de Risco na Organização de Serviços da Saúde. Brasilia, 1983. 
CASTILLO-SALGADO, C. Epidemiological risk stratification of malaria in the Americas. Memórias do Instituto Oswaldo Cruq, 87(3):115-120, 1992.

CESAR, C. L. G. Fatores de risco associados à mortalidade infantil em duas áreas da região metropolitana de São Paulo (Brasil), 1984-1985: proposta de instrumentos preditivos. Revista de Saúde Pública, 24:300-310, 1990.

HAYES, M. V. The risk approach: unassailable logic? Sociology Science Medical, 33(1):55-70, 1991.

ORGANIZACIÓN MUNDIAL DE LA SALUD (OMS). Método de Atención Sanitária de la Madre y el Niño Basado en el Concepto de Riesgo. Geneva, 1978. (Publicación en offset $n^{20} 39$ ).

PLAUT, R. Analisis de riesgo: alcance y limitaciones para el administrador de salud. Boletin de la Oficina Sanitária Panamericana, 96(4):296-306, 1984.

ROSE, G. Indivíduos enfermos y poblaciones enfermas. Boletin Epdemiológico OPAS, 6(3):1-8, 1985.

RUMEL, D. et al. Acurácia dos indicadores de risco do Programa de Defesa da Vida do Lactente em região do estado de São Paulo, Brasil. Revista de Saúde Pública, 26:6-11, 1992 .

SÃO PAULO (Governo do Estado). Secretaria de Estado da Saúde. Seminário de Aplicasaão do Enfoque de Risco na Organizaf̧ão de Serviços da Saúde. Sorocaba, 1984.

WORLD HEALTH ORGANIZATION (WHO). Risk Approach for Maternal and Cbild Health: a selected, annotated bibliograpby. Geneva: Division of Family Health, 1981.

WORLD HEALTH ORGANIZATION (WHO). A Work Book or How to Plan and Carry Out Research on the Risk Approach in Maternal and Child Health Including Family Planning. Geneva: Division of Family Health, 1984. (Experimental edition FHE/MCH/RA 84.1.) 


\section{VIGILÂNCIA DA MORTE EVITÁVEL: ACESSO RÁPIDO E DESCENTRALIZAÇÃO DAS INFORMAÇÕES}

Marcos Drumond Júnior

Desde o século XVII, com John Graunt, na Inglaterra, as estatísticas vitais informam sobre os níveis e padrões de causas de morte e sua evolução temporal. Estudos de mortalidade têm contribuído na compreensão do processo saúde-doença em diversos locais e épocas, permitindo maior conhecimento das realidades e avaliação do efeito de intervenções na saúde das populações. O estabelecimento de relações entre as condições sociais e econômicas com os perfis de mortalidade vem tendo grande importância na revelação do acesso diferenciado a bens e serviços entre grupos sociais, gerando condições de vida, adoecimento e morte diferenciadas.

No Brasil, os estudos da mortalidade são mais recentes. As estatísticas vitais se estruturaram em todo o País só a partir de meados da década de 70 . Anteriormente, os estudos foram eventuais pela dificuldade de obtenção de dados e restritos a algumas unidades da Federação.

Uma das características predominantes dos estudos de mortalidade vem sendo a sua ampla base geográfica de abrangência. Países e cidades ou agregações dessas bases em regiões têm predominado em relação a estudos de áreas 
em menores níveis de agregação que procurem estabelecer índices, padrões e tendências da mortalidade em diferentes grupos populacionais de uma mesma localidade, definidos pelo espaço de moradia.

Outra característica desses estudos é o seu afastamento temporal em relação ao momento em que ocorreram as mortes. A disponibilidade de dados de mortalidade vem ocorrendo com atrasos de vários anos. No Brasil, as estatísticas de mortalidade do Ministério da Saúde têm sido publicadas com intervalos de 5-6 anos, sendo possível obter dados não publicados após 4-5 anos. No estado de São Paulo, o intervalo médio é de 2-3 anos para publicação e de seis meses a 1-2 anos para acesso ao dado não-publicado.

A base territorial em grandes áreas geográficas e o atraso em relação ao momento de ocorrência da morte têm dificultado a utilização efetiva dos dados de mortalidade para a atuação das equipes responsáveis pela atenção à saúde de populações concretas. $\mathrm{O}$ uso da mortalidade como elemento componente da análise da situação da saúde em áreas de planejamento e intervenção local, além de seu monitoramento com avaliação permanente, é limitado pelas características com que o sistema de informações de mortalidade está estruturado tradicionalmente no País.

Com o processo de construção e implementação do Sistema Único de Saúde (SUS) no Brasil, várias experiências iniciaram a produção de informações adequadas à atuação municipal, distrital e local. Vários municípios brasileiros implementaram formas de uso descentralizado e com acesso rápido às informações de mortalidade. Essas experiências indicaram a possibilidade da melhoria da qualidade da informação de mortalidade e o seu uso, de forma a subsidiar a atuação no enfrentamento de problemas concretos geradores de adoecimento e morte da população, inspirados em princípios e diretrizes da política da saúde.

\section{As MORTES EvitáveIs}

Esse olhar mais próximo da realidade de atuação das equipes da saúde permitiu a abordagem das mortes consideradas evitáveis. O conceito de morte evitável tem-se desenvolvido e modificado nos últimos anos. $\mathrm{Na}$ 
década de 70, Rutstein et al. (1976) propuseram um elenco de causas de mortes prematuras e desnecessárias como indicadores da qualidade da atenção à saúde, permitindo avaliar a adequação da intervenção médica preventiva ou curativa. Este trabalho gerou diversos aprofundamentos. Charlton et al. (1983) restringiram a lista a um grupo de 15 causas de morte com numerosidade suficiente para acompanhamento e indicativas da qualidade da atenção médica recebida. O conceito se desenvolveu posteriormente em Grupo de Trabalho da Comunidade Européia, passando a abarcar as causas de morte evitáveis por uma adequada política de prevenção primária (Westerling \& Smedby, 1992).

Paralelamente, foram propostas formas de operacionalização do acompanhamento visando à redução de mortes evitáveis através dos conceitos de mortes prematuras e excessivas (Plaut \& Roberts, 1989). O conceito de mortalidade prematura foi inicialmente proposto por Romeder \& McWhinnie (1977) como a morte que ocorre precocemente, utilizando para operacionalização uma determinada faixa etária como referência. Estes autores propuseram o indicador dos anos potenciais de vida perdidos. Definiu-se que as mortes que ocorreram precocemente, por exemplo antes de se alcançarem 65 anos, impediram que essas pessoas pudessem ter vivido esses anos potenciais. A escolha dos pontos de corte superior e inferior permitiam ressaltar aspectos diferenciados das mortes precoces. $O$ conceito de morte excessiva procurou relacionar as mortes por sexo e faixa etária, em determinado local e, tempo, com um padrão referencial com melhores níveis de saúde num mesmo local em outro momento (mínimo histórico) ou em local diferente no mesmo momento (mínimo corrente) (Uemura, 1989).

Ao desenvolvimento desses conceitos se agregou a discussão de intervenções a partir de eventos sentinela e condições traçadoras (Rutstein, 1976; Westerling \& Smedby, 1992; Plaut \& Roberts, 1989). A mortalidade por algumas causas evitáveis, tais como as relacionadas à gravidez, ao parto e ao pósparto afetando a mãe ou a criança e as infecções intestinais infantis agudas, informaria a qualidade da atuação dos serviços da saúde como sinais de alerta. A investigação das condições geradoras e contribuintes das mortes levantaria problemas nos diversos aspectos envolvidos, com a possibilidade de intervenções preventivas para evitar novas mortes semelhantes. 
A discussão da vigilância das condições de vida e saúde dos diferentes grupos populacionais trouxe novas propostas para diagnóstico e intervenção em problemas da saúde em nível descentralizado. $O$ acompanhamento das condições utilizando indicadores adequados ao seu monitoramento foi proposto, contribuindo para a análise da situação da saúde da população numa unidade, num distrito de saúde ou município dentro de um processo de planejamento estratégico. Os indicadores de mortalidade, entre outros, foram sendo utilizados (Castellanos, 1991). A vigilância da morte evitável foi se estruturando nesse processo de desenvolvimento de conceitos agregados à organização de serviços.

\section{A Estruturação dos Sistemas de INFORMAÇÃO DE Mortalidade Adequados à Vigilância da Morte Evitável: A ExPERIÊNCIA do Pro-Aim do Município de São Paulo}

As diversas experiências, em âmbito municipal/distrital/local, com o uso das informações de mortalidade, têm indicado que a natureza do dado necessário para essas atividades difere da forma tradicionalmente operada no País. O fluxo da declaração de óbito passando pelo cartório até a repartição de estatística de nível estadual ou federal é muito lento para seu uso na vigilância da morte evitável nos serviços da saúde.

Da mesma forma, o processamento normatizado do endereço do falecido pelo município de residência impossibilita o uso das informações para atuação concreta dos níveis distrital/local ou mesmo municipal, na perspectiva do diagnóstico diferenciado em suas áreas geográficas. Para a abordagem das mortes evitáveis visando a sua prevenção, tornam-se necessários acesso rápido e descentralização das informações, pois só assim o evento pode ser avaliado oportunamente.

Entre essas experiências municipais, o Programa de Aprimoramento das Informações de Mortalidade no Município de São Paulo (PRO-AIM) é 
um bom exemplo da possibilidade de vigilância e monitoramento a partir da construção de sistemas de informação de mortalidade com as características necessárias à atuação oportuna e adequada à realidade local. O PRO-AIM, executado pela Secretaria da Saúde, pelo Serviço Funerário e pela Companhia de Processamento de Dados do Município de São Paulo, recebe a declaração de óbito em média 24 horas após a morte, informa diariamente ao Centro de Vigilância Epidemiológica (SES/SP) as doenças de notificação compulsória, incluindo os acidentes de trabalho, e processa os documentos com o fechamento da base de dados mensal em cerca de 15 dias. A identificação do falecido e do serviço da saúde ou local de ocorrência da morte são processados para viabilizar a vigilância das mortes evitáveis.

O endereço do falecido é processado pelo código do logradouro e o número do imóvel, o que permite a seleção automática em duas diferentes subdivisões municipais em 58 distritos e subdistritos de paz e em 96 distritos administrativos, compatibilizando suas agregações com aquelas produzidas por outras instituições de diversos níveis e setores públicos e garantindo o acompanhamento da série histórica. A padronização da grafia permite que os niveis locais desenvolvam outras subdivisões adequadas à sua realidade e necessidade, tais como nos diagnósticos distritais por área de abrangência de unidades da saúde ou na construção de áreas homogêneas de risco de acordo com informações socioeconômicas e ambientais.

O alcance dos objetivos é garantido pela democratização do acesso às informações, produzidas em bases de dados abertas e gratuitas, fornecidas aos responsáveis pela condução de políticas sociais relativas à saúde nos diversos níveis e setores às universidades, à sociedade civil organizada e à imprensa. As informações disponíveis permitem a execução da vigilância das mortes evitáveis, a produção de novos conhecimentos sobre a sua distribuição e determinação, o subsídio à atuação da sociedade civil organizada e gestores urbanos na denúncia e na prevenção de situações de risco, além da divulgação ampla das tendências recentes de mudança em níveis e padrões de mortalidade.

Nas diversas experiências municipais no País, destaca-se a vigilância das Doenças de Notificação Compulsória (DNC), em especial a Síndrome de Imunodeficiência Adquirida (SID $/$ AIDS), das mortes infantis e das mortes maternas. No caso das DNC, o processamento municipal da mortalidade é 
um complemento dos sistemas de vigilância epidemiológica já existentes. As vigilâncias das mortes infantis e maternas têm se estruturado recentemente com a criação de comitês, comissões e programas específicos. Estes desenvolvem atividades de avaliação de serviços nos seus mais diversos aspectos, tais como o sistema de transporte e referência, a qualidade da atenção recebida, o acesso diferenciado à assistência e suas relações com as principais causas de morte. $\mathrm{O}$ aprofundamento nas determinações do adoecimento e da morte evitáveis permite intervenções visando a sua prevenção.

A vigilância da morte evitável, no entanto, se dá ainda pelo monitoramento de causas e circunstâncias de mortes que não eram tradicionalmente abordadas na condução das políticas sociais, ampliando a visão de intervenção na saúde pública. As mortes violentas, especialmente por homicídios e acidentes de trânsito, as doenças crônicas não-transmissíveis atingindo uma população em idade produtiva, a poluição atmosférica e os problemas respiratórios e as mortes intra-institucionais, entre outras, começam a ser acompanhadas.

Algumas possibilidades de vigilância e monitoramento com descentralização e acesso rápido às informações de mortalidade podem ser discutidas a partir da experiência do PRO-AIM. Como exemplos, serão relatadas algumas formas de acompanhamento a partir dos números absolutos de mortes e médias diárias e mensais que possam ser reproduzidas em unidades de menor área geográfica, tais como nas áreas de Distritos de Saúde e suas subdivisões (Gráficos 1 e 2). Nos Gráficos 1 e 2, podem-se observar as tendências recentes de 'periferização' e expansão da mortalidade pela Síndrome da Imunodeficiência Adquirida (SIDA/AIDS) em ambos os sexos com o deslocamento e a concentração das mortes nos grupos sociais residentes em áreas homogêneas de piores condições socioeconômico-ambientais do município de São Paulo. ${ }^{1}$ As implicações preventivas e assistenciais decorrentes dessa tendência são desafios colocados ao sistema da saúde municipal público.

\footnotetext{
${ }^{1} \mathrm{Na}$ construção das áreas homogêneas do município de São Paulo, o PRO-AIM utilizou indicadores de escolaridade, renda, cobertura de rede de esgotamento sanitário e proporção de mortes de menores de um ano em relação ao total das mortes nos distritos de paz do município. Essas áreas foram utilizadas originalmente para estudar a mortalidade de adultos por doenças cardiovasculares. A área homogênea 4 representa a de piores condições socioeconômico-ambientais.
} 
Gráfico 1 - Óbitos por AIDs segundo área homogênea de residência, sexo masculino. Município de São Paulo - 1991 a 1994

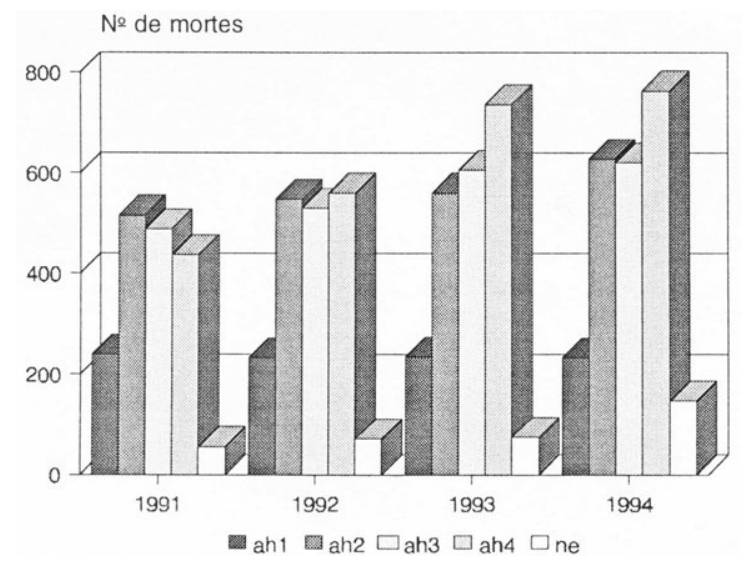

Fonte: PRO-AIM - Programa de Aprimoramento das Informações de Mortalidade - MSP.

Gráfico 2 - Óbitos por ArDs segundo área homogênea de tesidência, sexo feminino. Município de São Paulo - 1991 a 1994

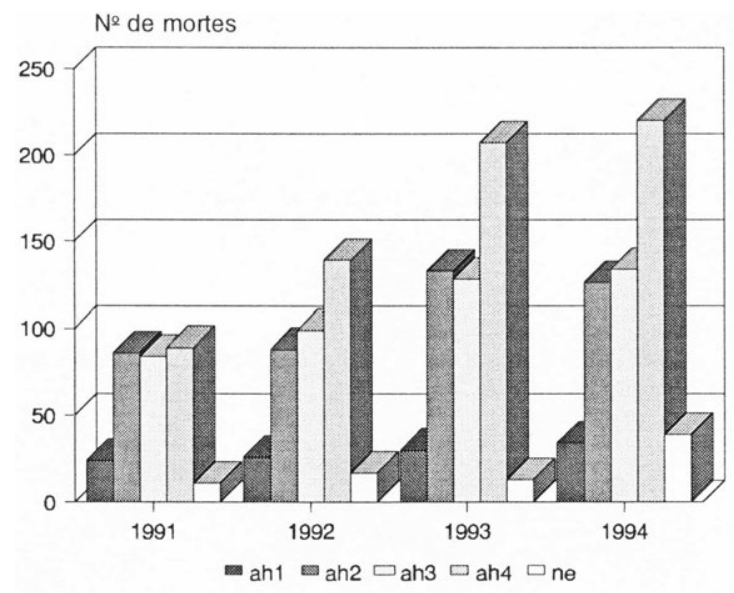

Fonte: PRO-AIM - Programa de Aprimoramento das Informações de Mortalidade - MSP. 
No Gráfico 3, observa-se a média mensal de homicídios no município de São Paulo de março de 1991 a fevereiro de 1995 com sua tendência crescente atingindo os maiores valores no final da série. $O$ Gráfico 4 mostra as tendências em áreas homogêneas do ponto de vista socioeconômico-ambiental, indicando que a tendência de aumento se explica pelos homicídios ocorridos na população residente nas áreas de piores condições socioambientais, enquanto nas outras áreas os níveis são estáveis. Estes dados sugerem que as formas de intervenção visando à contenção da violência têm sido ineficazes e inadequadas, em especial para os grupos sociais que vivem em áreas com maiores niveis de carência.

Gráfico 3 - Média mensal de homicídios. Municipio de São Paulo março/1991 a fevereiro/1995

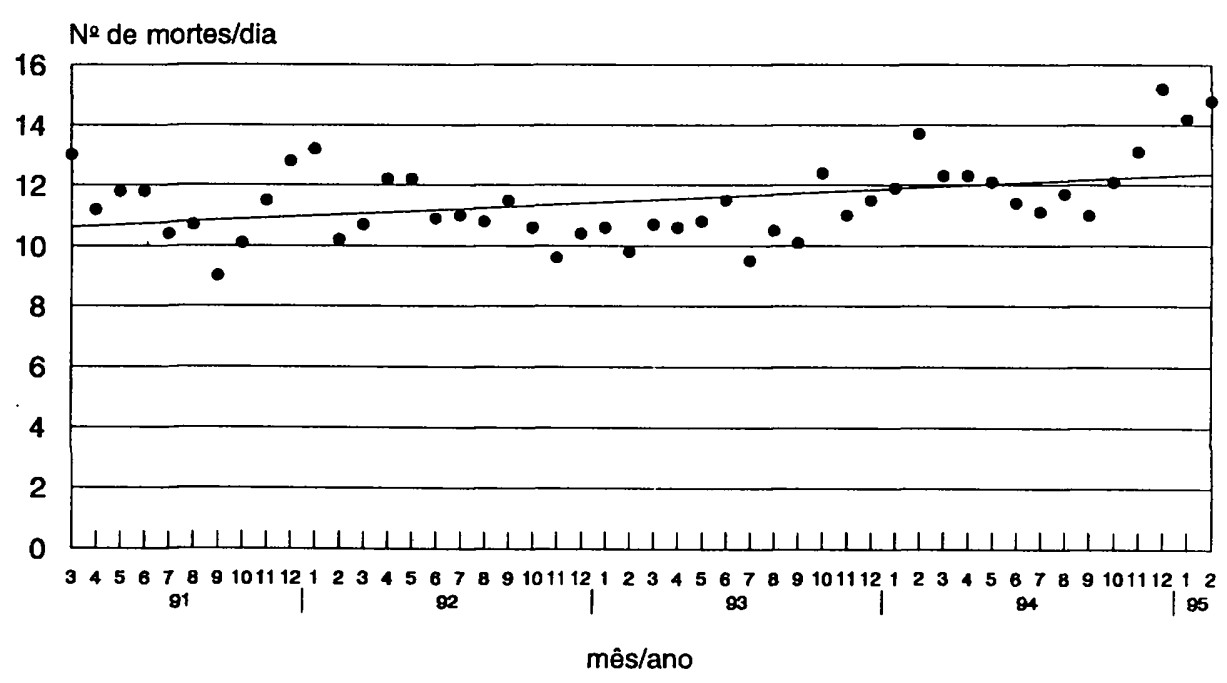

Fonte: PRO-AIM - Programa de Aprimoramento das Informações de Mortalidade - MSP. 
Gráfico 4 - Homicídios segundo área homogênea de residência. Município de São Paulo - março/1991 a fevereiro/1995

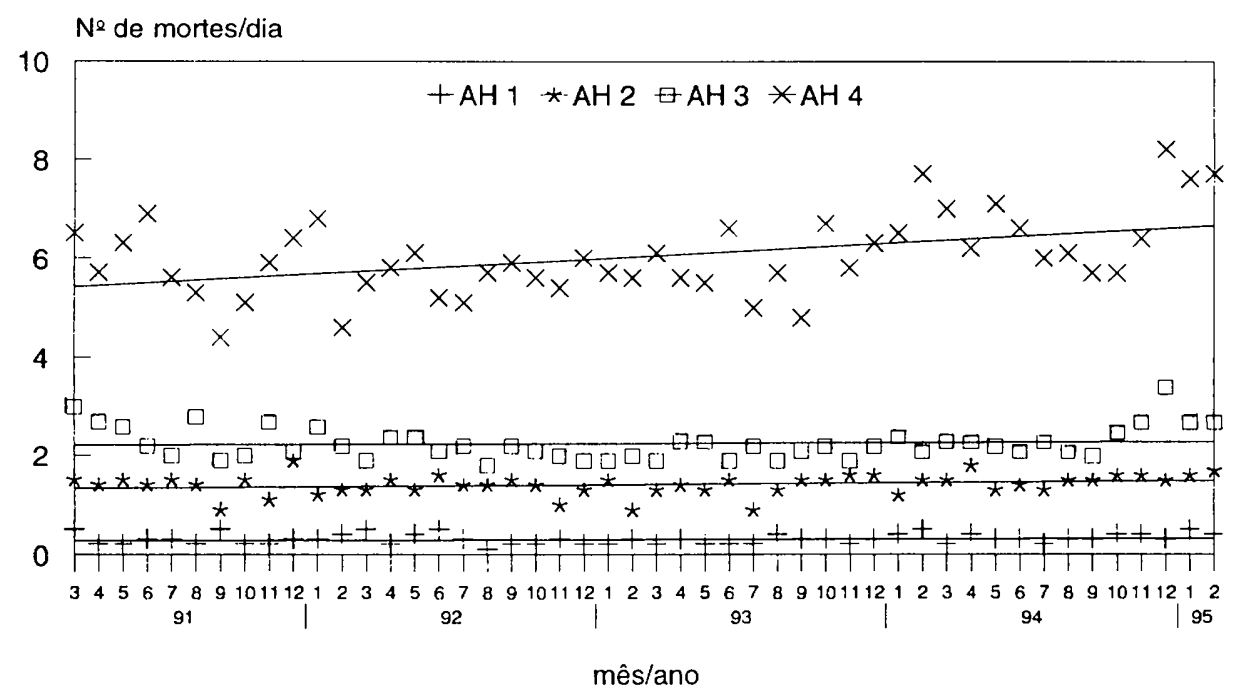

Fonte: PRO-AIM - Programa de Aprimoramento das Informações de Mortalidade - MSP.

No Gráfico 5, observam-se as médias de mortes por acidentes de trânsito no município de São Paulo nos meses de janeiro de 1994 a abril de 1995. A especificação dos atropelamentos como tipo de morte no trânsito foi introduzida recentemente na declaração de óbito, de forma que sua avaliação só pode ser feita a partir dos últimos meses do ano de 1994. Em novembro de 1994, foi decretado o uso obrigatório do cinto de segurança no município, com altos índices de adesão no mês seguinte. Em dezembro, verifica-se o maior número de mortes no trânsito da série considerada. Observa-se, no entanto, que o aumento deveu-se aos atropelamentos, responsáveis pela maior parte das mortes no trânsito, e que no final da série a média mensal total volta aos níveis semelhantes aos dos mesmos meses do ano anterior. Estes dados sugerem que a priorização do condutor como alvo das políticas de trânsito, sem se acompanhar da mesma priorização para o pedestre, pode anular os efeitos positivos do uso do cinto de segurança. 
Gráfico 5 - Mortes por acidentes de trânsito. Município de São Paulo janeiro/1994 a março/1995

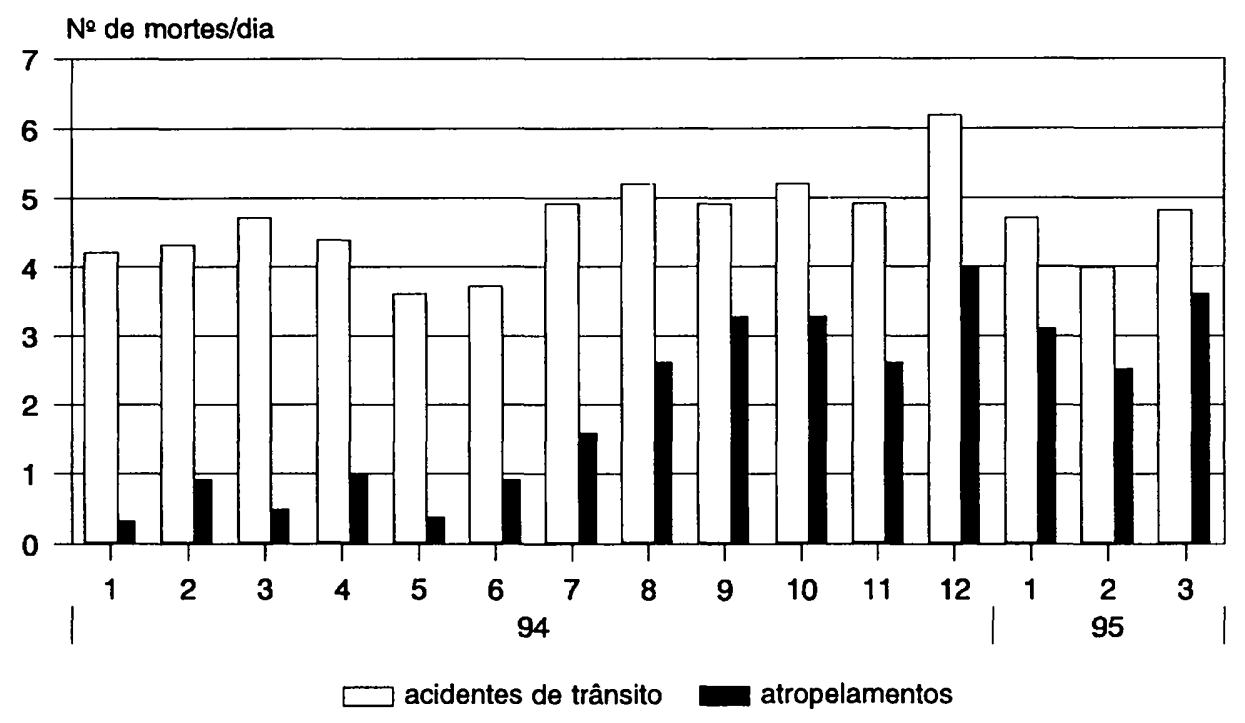

Fonte: PRO-AIM - Programa de Aprimoramento das Informações de Mortalidade - MSP.

O Gráfico 6 mostra a média mensal de mortes de idosos por problemas respiratórios no ano de 1994, em que observa-se que nos meses de inverno esta média chega a ser o dobro daquela dos meses de verão. Este indicador pode contribuir para o monitoramento dos efeitos do frio e da poluição ambiental na saúde da população em todas as áreas do município de São Paulo, permitindo uma discussão sobre os efeitos de aspectos da urbanização sobre a qualidade de vida da população, em especial daquela residente nas áreas periféricas. 
Gráfico 6 - Óbitos por doenças do aparelho respiratório em maiores de 64 anos. Município de São Paulo - janeiro a dezembro/1994

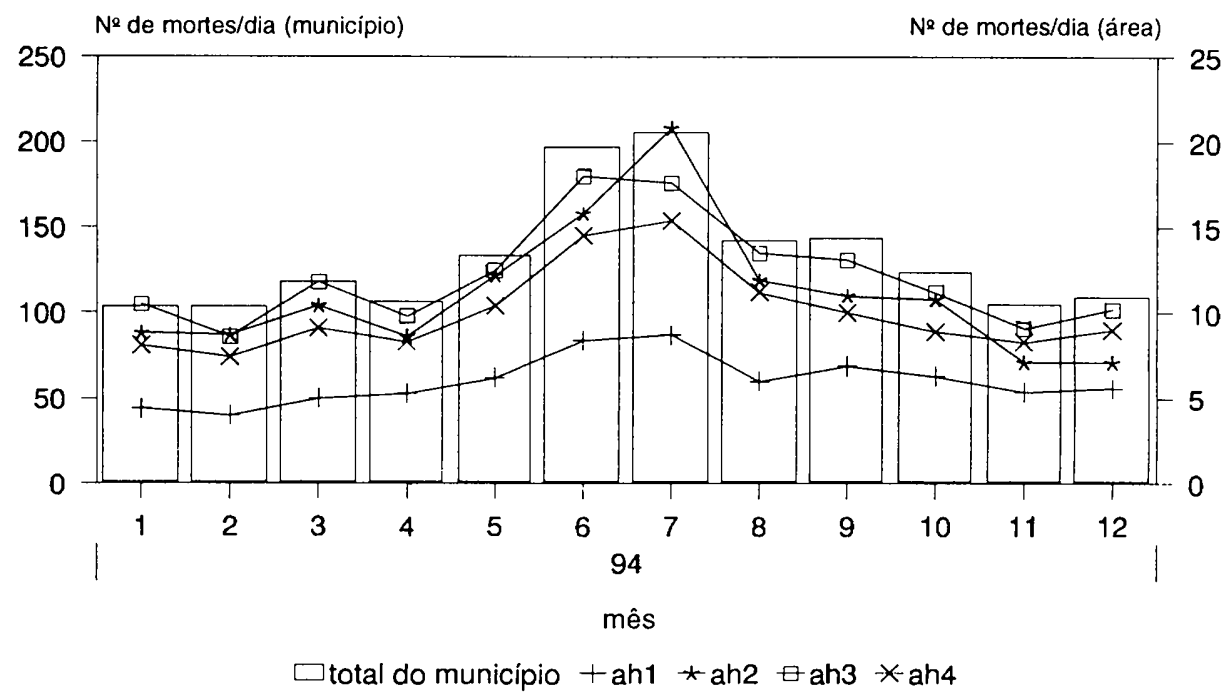

Fonte: PRO-AIM - Programa de Aprimoramento das Informações de Mortalidade - MSP.

Estudos do PRO-AIM já indicaram os riscos diferenciados de morte por doenças cardiovasculares em distritos do município de São Paulo no ano de 1991, mostrando que estes são maiores nas áreas de residência das populações em piores condições socioeconômico-ambientais (Prefeitura do município de São Paulo, 1993). O Gráfico 7 indica uma forma de monitorar esse fenômeno através do acompanhamento da precocidade das mortes por doenças vasculares cerebrais segundo áreas homogêneas. Aspectos ligados à prevalência dos fatores de risco e ao acesso ao controle e tratamento dessas doenças podem explicar esses perfis e necessitam de aprofundamento e adequação de políticas públicas em áreas prioritárias. 
Gráfico 7 - Óbitos por doenças do aparelho respiratório em maiores de 64 anos. Município de São Paulo - janeiro a dezembro/19 94

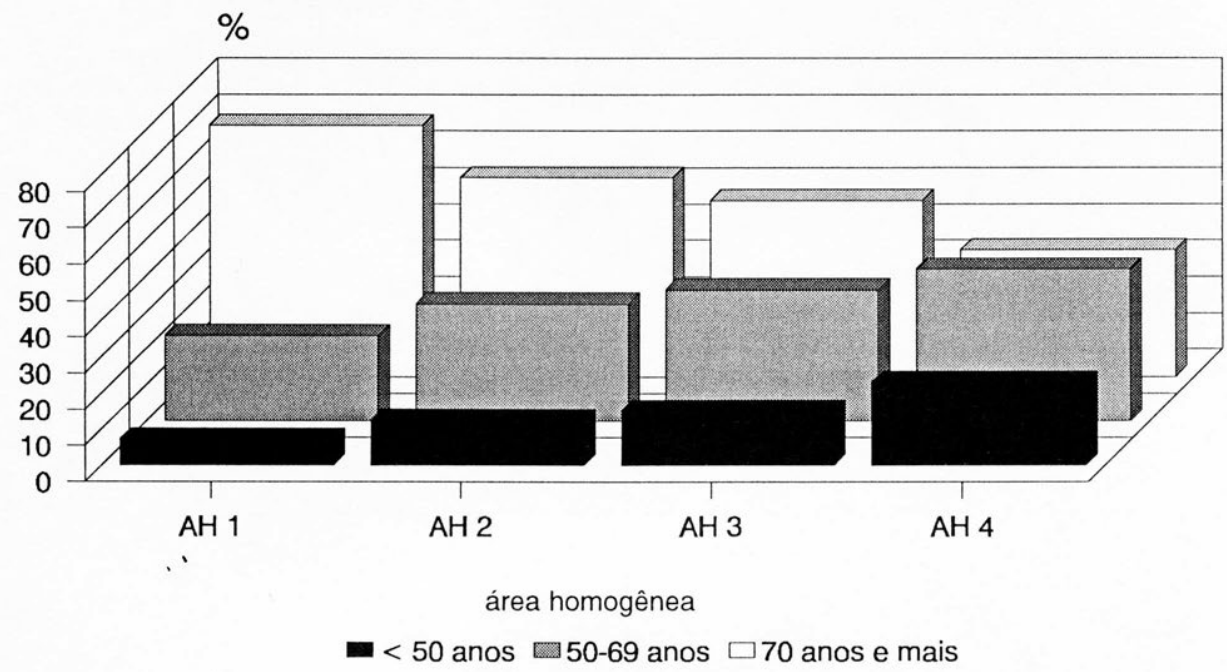

Fonte: PRO-AIM - Programa de Aprimoramento das Informações de Mortalidade - MSP.

\section{CONCLUSÃo}

O monitoramento e a vigilância das mortes evitáveis em diferentes grupos sociais c áreas geográficas nos sistemas de informação rotinizados e com acesso rápido podem contribuir para a melhoria da qualidade de vida da população. Tanto a abordagem das docnças infecciosas e das causas infantis c maternas quanto das doenças crônicas não-transmissíveis e da violência podem ser acompanhadas em sistemas de vigilância da morte evitável.

O monitoramento da cidade com o acompanhamento das condições de vida da população, a partir do envolvimento dos diversos setores dos poderes públicos, das instituições de ensino e pesquisa, da sociedade civil organizada c da imprensa, vai contribuir para denunciar e impedir que as políticas globais e setoriais produzam o aumento da desigualdade social, deixem de considerar princípios de ética pública na sua formulação e condução e não priorizem as necessidades da maioria da população. 


\section{REFERÊNCIAS BiBLIOGRÁfICAS}

CASTELLANOS, P. L. Sistemas nacionales de vigilância de la situación de salud segun condiciones de vida y del impacto de las acciones de salud y bienestar. OPS/ OMS, 1991. (Mimeo.)

CHARLTON, J. R. H. et al. Geographical variation in mortality from conditions amenable to medical intervention in England and Wales. Lancet, 1:691-696, 1983.

PLAUT, R. \& ROBERTS, E. Preventable mortality: indicator or target? Applications in developing countries. World Health Statistics Quartely, 42(1):4-15, 1989.

PREFEITURA DO MUNICÍPIO DE SÃO PAULO. Programa de Aprimoramento das Informações de Mortalidade. Boletim do PRO-AIM nº10, 1993.

ROMEDER, J. M. \& MCWHINNIE, J. R. Potencial years of life lost between ages 1 and 70: an indicator of premature mortality for health planning. International Journal of Epidemiology, 6:143-151, 1977.

RUTSTEIN, D. D. et al. Measuring the quality of medical care. New England Journal Medical, 294:582-588, 1976.

UEMURA, K. Excess mortality ratio with reference to the lowest age-sex-especific death rates among countries. World Health Statistics Quartely, 42(1):26-41, 1989.

WESTERLING, R. \& SMEDBY, B. The European Community 'Avoidable Death Indicators' in Sweden 1974-1985. International Journal of Epidemiology, 21(3):502-510, 1992. 



\section{ERRADICAÇÃO DE DOENÇAS: LIÇÕES APRENDIDAS, DESAFIOS A ENFRENTAR}

Ciro A. de Quadros

\section{INTRODUÇÃO}

O último caso confirmado de poliomielite paralítica causada por poliovirus selvagem nas Américas foi detectado num menino de dois anos em 23 de agosto de 1991, em Junin, Peru (ICCPE, 1995). A varíola é o último agente infeccioso a ser erradicado pela prática da vacinação, quase duzentos anos depois do desenvolvimento da vacina antivariólica por Edward Jenner. Passaram-se cerca de cinqüenta anos desde o desenvolvimento da vacina contra a poliomielite até a erradicação da doença no continente americano, numa considerável diminuição do intervalo entre a disponibilidade inicial da vacina e a erradicação da doença-alvo.

Após as bem-sucedidas experiências nas Américas, a Organização Mundial da Saúde (OMS) estabeleceu o alvo de erradicação mundial da poliomielite até o ano 2000. As estratégias postas em prática no resto do mundo são as que foram aperfeiçoadas nas Américas. 


\section{ESTRATÉGIAS DE ERRADICAÇÃO}

A questão básica foi a determinação da melhor estratégia para interromper a transmissão do poliovírus. O uso de Vacina Oral Antipólio (VOA) em experiências de promoção de Dias Nacionais de Imunização (DNI) no Brasil acusou um declínio espetacular do número de casos em um período de tempo muito curto (Gráfico 1).

Gráfico 1 - Casos de pólio por períodos de 4 semanas. Brasil - 1975-84

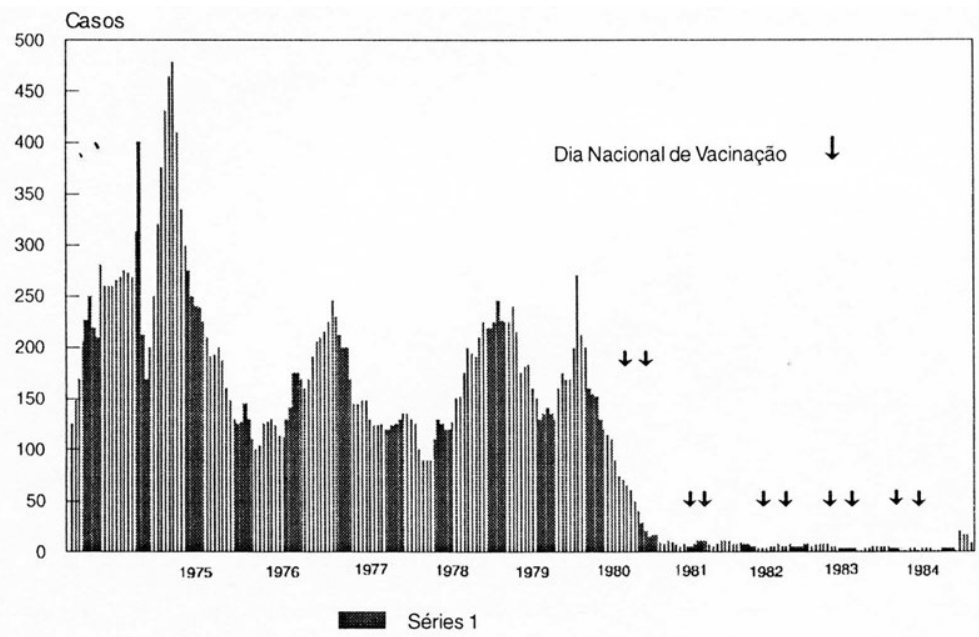

Fonte: DNE-Snabs, MS e OpAS.

Fonte: DNE-SNABS, MS e OPAS.

Os DNI eram, geralmente, promovidos duas vezes por ano, com intervalos de dois meses. Em cada um daqueles DNI, o Brasil pôde vacinar vinte milhões de crianças menores de cinco anos com VOA (Risi Jr., 1984). O uso de DNI com VOA ocorreu pela primeira vez em princípios da década de 60, em Cuba (Sabin, 1984), onde a transmissão foi interrompida em meados daquele decênio (Rodriguez Cruz, 1984). Utilizaram-se também estratégias semelhantes nos Estados Unidos, na Inglaterra e no Japão, assim como na antiga União Soviética e em outros países da Europa oriental. 
As observações feitas no Brasil mostraram que a estratégia era logisticamente viável num país daquele tamanho.

Recomendou-se, então, que os países onde a poliomielite era endêmica complementassem seus programas de imunização promovendo DNI, nos quais seriam aplicadas VOA e outras vacinas disponíveis (Quadros et al., 1992). Até 1987 , todos os países endêmicos estavam utilizando DNI como parte de suas estratégias de imunização.

Algum tempo depois, a estratégia passou a contar com outro componente, as operações de 'limpeza', que consistiam na vacinação de casa em casa, nos distritos onde persistia a transmissão após a implementação dos DNI.

\section{VIGILÂNCIA}

Foram adotadas definições uniformes de casos de poliomielite. 'Caso suspeito': qualquer caso de doença paralítica aguda em crianças menores de 15 anos. Quando se constatava 'Paralisia Flácida Aguda' (PFA), o caso era classificado como 'provável poliomielite' e se colhiam, com duras horas de intervalo, duas amostras de fezes que eram enviadas a um dos laboratórios da rede. Após dez semanas, o caso era classificado como 'poliomielite confirmada', quando se isolava poliovírus selvagem das amostras, ou quando o paciente morria dentro de sessenta dias do início da doença ou ela desaparecia. Do contrário, o caso era 'descartado'. Nas etapas finais, foi acrescentada à classificação outra categoria, 'compatível com poliomielite': o caso preenchia outros critérios de diagnóstico, mas não houvera adequada coleta de duas amostras de fezes. Tais casos representavam falhas da vigilância e não podiam ser descartados como doenças paralíticas devidas a outras causas.

A rede de notificação de casos de PFA, que a princípio incluía os serviços da saúde com mais probabilidades de observá-los, veio a ser ampliada, com pelo menos um serviço da saúde em cada distrito de todos os países, compreendendo mais de vinte mil instituições da saúde em toda a América Latina e no Caribe. Essa rede é hoje utilizada para notificação de outras doenças, como sarampo, tétano e cólera, em alguns países, e no futuro será ampliada, para incluir outras doenças transmissíveis. 


\section{RESUlTADOS}

Em abril de 1995, tinham-se passado quase quatro anos desde o histórico achado do caso de poliomielite no Peru. Desde então, foram testadas mais de trinta mil amostras de fezes de todas as partes das Américas, sem sequer uma detecção de poliovírus selvagem (Gráfico 2).

Gráfico 2 - Vigilância de poliovírus selvagem. Américas - 1986-1994

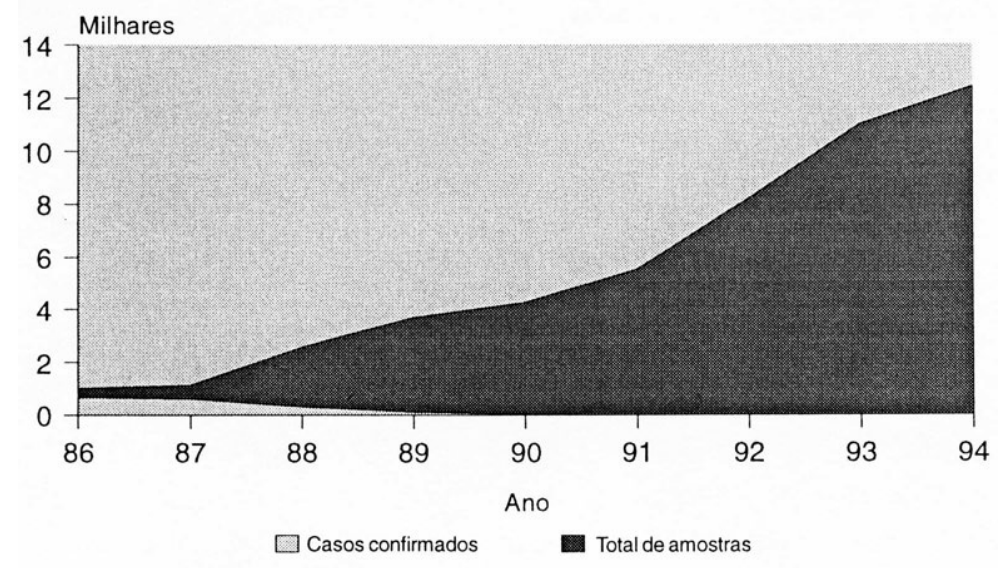

Fonte: PAI/OpAS.

A Comissão Internacional Encarregada de Certificação da Erradicação da Poliomielite (CICEP), criada pela Organização Pan-Americana da Saúde (OpAs), só considerava a possibilidade de certificação de um país quando este havia passado um período de pelo menos três anos sem poliomielite, em presença de uma vigilância adequada.

Para a vigilância da PFA, a Comissão determinou que cinco indicadores teriam de ser constatados: a) pelo menos $80 \%$ das unidades sanitárias da rede informante deveriam notificar semanalmente a ausência ou presença de PFA; b) a taxa de PFA deveria ser de pelo menos um caso por cem mil crianças menores de 15 anos; c) pelo menos $80 \%$ de todos os casos de PFA notificados deveriam ser investigados dentro de 48 horas da 
notificação; d) em pelo menos $80 \%$ de todos os casos de PFA, deveriam ser colhidas duas amostras de fezes para cultura do vírus dentro de duas semanas do início da paralisia; e) em pelo menos $80 \%$ de todos os casos de PFA dever-se-ia fazer o exame de fezes de pelo menos cinco contatos (PAHO, 1993). Para facilitar o processo de certificação, cada país organizou sua própria 'comissão nacional' para acompanhar e revisar o processo de certificação.

Em sua última reunião, realizada em setembro de 1994, em Washington, D.C., a CiceP, após revisão e análise dos dados apresentados pelas comissões nacionais, declarou: "Com base na convincente evidência apresentada, a Ciclip conclui que a transmissão do poliovírus selvagem foi interrompida nas Américas."

A Comissão acentuou que a transmissão ainda ocorre em outras partes do mundo e exortou todos os países das Américas a manter alta cobertura de vacinação com VOA e vigilância de $\mathrm{PFA}$, até que se efetive a erradicação mundial da poliomielite.

\section{ELIMINAÇÃO DO SARAMPO}

O sucesso na erradicação da poliomielite e o aumento da cobertura da imunização levaram as autoridades sanitárias a lançar outras iniciativas para a eliminação de doenças. Em 1988, os países de língua inglesa do Caribe estabeleceram a meta de eliminar a transmissão autóctone do sarampo até 1995. Com base num bem-sucedido esforço lançado por Cuba em 1986, eles acreditavam que isso era possível. Em maio de 1991, aqueles países promoveram campanhas de vacinação em massa de mais de $90 \%$ das crianças de nove meses a 14 anos de idade.

Posteriormente, todos os países das Américas, exceto o Canadá, os Estados Unidos e o Paraguai, realizaram essas campanhas de massa. No fim de 1994, mais de $90 \%$ das crianças da América Latina e do Caribe haviam recebido pelo menos uma dose de vacina contra o sarampo, e a incidência da doença atingira o seu nível mais baixo de todos os tempos (Gráfico 3). Em mais de três anos, não se registraram casos de sarampo confirmados por 
laboratório nos países anglófonos do Caribe (PAHO/EPI, 1993) e no Chile, e em dois anos em Cuba.

\section{Gráfico 3 - Número de casos de sarampo notificados e cobertura vacinal. Américas - 1960-1994}

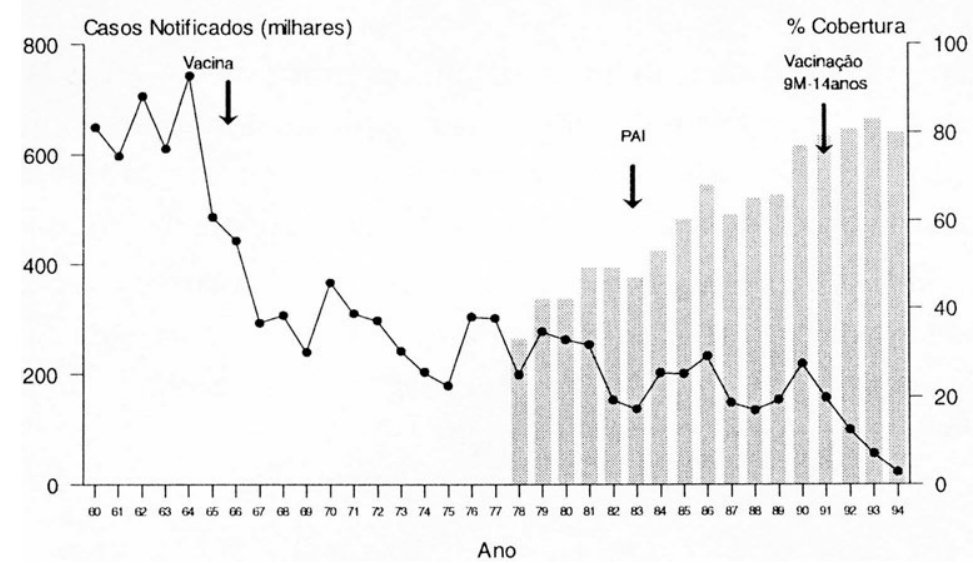

Fonte: PAI/OPAS.

A experiência adquirida mostra que a estratégia recomendada pela OPAs é eficaz na luta contra o sarampo (PAHO, 1992). Consiste em envidar, cm um mesmo momento, esforços para vacinar todas as crianças de nove meses a 14 anos de idade, mesmo que tenham sido antes vacinadas ou tido a doença, e em assegurar a manutenção de altas taxas de cobertura de vacinação contra o sarampo para cada nova coorte de recém-nascidos. Como a vacina contra o sarampo não é $100 \%$ eficaz e nem mesmo o melhor programa de imunização é capaz de dar cobertura a 100\% das crianças, haverá uma acumulação de suscetíveis na população jovem. Por isso, são necessárias campanhas de seguimento da vacinação, para captar as crianças que não foram vacinadas na idade recomendada ou nas quais a vacina falhou. Recomenda-se que essas campanhas de seguimento sejam realizadas a cada quatro ou cinco anos, tendo como alvos as crianças menores de cinco anos, entre as quais se acumulou a maioria desses suscetiveis.

Uma vez postas em prática cssas campanhas de massa, os sistemas de vigilância cxistentes terão de detectar quaisquer cadeias de transmissão rema- 
nescentes e fazer face aos casos importados. Esse sistema deve basear-se na notificação de rotina e no seguimento de pacientes com febre e erupções, que atuam como substitutos dos casos suspeitos de sarampo.

Apesar do progresso excepcional, continuam existindo problemas. Vários países ainda não atingiram taxas de cobertura de vacinação de $80 \%$, e muitos casos suspeitos ainda não são adequadamente investigados. Não se faz a coleta rotineira de informações epidemiológicas cruciais e de amostras de sangue para classificação precisa dos casos, e a rede de laboratórios ainda não está em condições de atender às necessidades do programa.

Se tais esforços forem coroados de êxito, as Américas estarão uma vez mais à frente do esforço global para erradicar essa doença, importante causadora de mortes.

\section{CONCLUSÃO}

Registraram-se ganhos substanciais na área da imunização e do controle/erradicação de doenças que podem ser prevenidas por vacinação. Acredita-se que o impacto dessas atividades contribuiu enormemente para o fortalecimento da infra-estrutura da saúde. Entre essas contribuições, destacam-se as seguintes:

- todos os países contam hoje com um quadro de epidemiologistas e virologistas bem preparados, com considerável experiência em vigilância epidemiológica, atividades de controle de doenças e pesquisa operacional;

- a capacidade de diagnóstico foi fortalecida com a transferência de tecnologias como os testes de ADN e a Reação em Cadeia de Polimerase (RCP) para as redes de laboratórios;

- todos os países melhoraram a sua capacidade de planejamento da saúde e apresentam em ciclos anuais e qüinqüenais planos de ação nacionais que expõem objetivos, atividades e resultados esperados, com identificação de custos e fontes de financiamento tanto nacionais como internacionais; 
- pela primeira vez na região das Américas, foi criado um Comitê Interagencial de Coordenação (CIC), com a participação de todos os organismos que colaboram nesse esforço. $\mathrm{O}$ CIC foi reproduzido em todos os países e, sob a liderança dos respectivos Ministérios da Saúde, esses comitês acompanham a implementação dos programas nacionais;

- a erradicação da poliomielite granjeou mais prestígio para o setor da saúde, com a conseqüente possibilidade de mobilização de mais recursos para fazer face a outros problemas da saúde;

- foi acionado o mais amplo sistema de vigilância da saúde humana já criado no hemisfério ocidental, com a participação de mais de vinte mil unidades da saúde (cobrindo $100 \%$ de todos os distritos e municípios da América Latina). Esse sistema está sendo agora ampliado, para incluir outras doenças evitáveis por vacinação;

- foi criado e vem operando há 16 anos um Fundo Rotatório para Aquisição de Vacinas. Esse fundo assegura a oportuna disponibilidade de vacinas de alta qualidade para os países interessados, os quais fazem reembolsos ao fundo em moeda local.

Uma grande ameaça a essas realizações e à erradicação global da transmissão autóctone do poliovírus selvagem, assim como à futura erradicação global do sarampo, será a atitude complacente que, muitas vezes, se observa quando uma doença se torna rara e os sistemas nacionais de vigilância tão meticulosamente organizados começam a se deteriorar.

A erradicação da poliomielite nas Américas, com a erradicação mundial da varíola, vem confirmar o alto coeficiente custo/benefício das vacinas e sua capacidade de melhorar a saúde humana. Esses exemplos devem constituir mais um lembrete dos possíveis benefícios que advirão para a humanidade com a disponibilidade de novas vacinas no futuro. 


\section{REFERÊNCIAS BIBLIOGRÁFICAS}

INTERNATIONAL COMMISSION FOR CERTIFICATION OF POLIOMYELITIS ERADICATION IN THE AMERICAS (ICCPE). Third Meeting of... Final Report. Washington, D.C., sept. 1995.

PAN AMERICAN HEALTH ORGANIZATION (PAHO). Field guide for measles control. PAHO, 1992.

PAN AMERICAN HEALTH ORGANIZATION (PAHO). Plan of Action for the Certification of Eradication of Wild Poliovirus from the Americas. PAHO: Washington, D. C., mar. 1993.

QUADROS et al. Polio Eradication from the Western hemisphere. Annual Review of Public Health, 13:239-252, 1992.

RISI JR., J. B. The control of poliomyelitis in Brazil. INTERNATIONAL SYMPOSIUM ON THE CONTROL OF POLIOMYELITIS. Washington, D. C., 14-17 mar. 1983. Reviews of Infectious Diseases, 6(suppl. 2):S400-S403, 1984.

RODRIGUEZ CRUZ, R. Cuba: mass-vacination against poliomyelitis. INTERNATIONALSYMPOSIUM ON THE CONTROL OF POLIOMYELITIS. Washington, D.C., 14-17 mar. 1983. Revienss of Infectious Diseases, 6(suppl. 2):S408S412, 1984.

SABIN, A. B. Strategies for the elimination of poliomyelitis in different parts of the world using OPV. INTERNATIONAL SYMPOSIUM ON THE CONTROL OF POLIOMYELITIS. Washington, D.C., 14-17 mar. 1983. Reviews of Infectious Diseases, 6(suppl. 2):S391-S396, 1984. 


\section{CONSTRUÇÃO DE NOVOS \\ PRESSUPOSTOS PARA O \\ CONTROLE DE ENDEMIAS}

Eduardo Hage Carmo

\section{INTRODUÇÃO}

O processo de descentralização no controle das endemias pode cumprir duas trajetórias distintas. A primeira delas, que tende a ser a trajetória predominante e efetivamente vem sendo cumprida na maioria das experiências em curso no nosso país, caracteriza-se pelo repasse da gestão das ações de controle dos níveis mais centrais para os níveis periféricos das instituições públicas da saúde. Esta vertente começa pelo aumento gradual da participação das gestões estaduais, municipais e locais no planejamento, na execução e, em algumas situações, na avaliação das ações, como é evidenciado pelas experiências atuais. A riqueza desse processo diz respeito ao fortalecimento dos mecanismos de parceria, à viabilização da participação de atores excluídos dos processos decisórios que, em âmbito local, estão mais habilitados a serem integrados. Outra vertente, além de incorporar o processo de descentralização gerencial das ações de controle e, portanto, do poder, aponta para uma 
redefinição dos pressupostos teóricos, com os desdobramentos metodológicos, que fundamentam a priorização de ações.

\section{ConcepçÃo do Processo Saúde-Doença e Definição de Medidas de Controle}

A despeito de todo o conhecimento acumulado no campo da epidemiologia, bem como das diversas experiências na execução das ações de controle, que têm continuamente apontado para a necessidade de uma redefinição das estratégias de controle de doenças, este não é ainda um caminho suficientemente percorrido.

Toda a discussão traçada hoje na busca de uma explicação para as profundas modificações nos padrões epidemiológicos das sociedades contemporâneas tende a apontar para uma aparente dicotomia: as modificações se deveram à utilização da tecnologia médica - para os adeptos da teoria da transição epidemiológica - ou à melhoria das condições de vida das populações - para os críticos da teoria (Barreto et al., 1993). Na situação do Brasil, caracterizada por uma superposição de redução na mortalidade por doenças infecciosas e manutenção no padrão de morbidade por essas doenças, com o acréscimo de problemas como dengue, cólera, Aids etc., tal quadro se torna mais complexo.

A despeito desses aspectos, as ações da saúde são voltadas para a utilização intensiva e exclusiva da tecnologia médica. No caso das doenças endêmicas, sejam transmitidas por vetores ou não, as ações priorizadas, em geral, são: quimioterapia (esquistossomose, hanseníase, tuberculose, cólera) e/ou utilização de inseticidas (doença de Chagas, malária, dengue). Tais medidas têm como base, na explicitação do processo saúde-doença, tanto uma concepção ontológica, que visualiza a doença entrando no homem, quanto a concepção ecológica, que incorpora a tríade agente-hospedeiro-meio. Assumem uma perspectiva focal, segundo a formulação de Pavlowsky na década de 30 (Pavlowsky, 1964), e uma dicotomia urbano-rural. 
Segundo essas concepções, a ocorrência de doenças transmissíveis é definida pela inserção do homem em um determinado ambiente, com condições favoráveis para a reprodução de vetores e agentes patogênicos, sem uma incorporação do processo de modificação desse ambiente pelo homem. No entendimento da disseminação para áreas urbanas, incorporam, quando muito, o papel exclusivo da migração, não como processo social, mas como um atributo individual. $O$ espaço sob o qual é compreendida a ocorrência do processo saúde-doença é um espaço possuidor de atributos, em geral físicos e com ênfase nos elementos do clima, e que pode ser esquadrinhado para qualquer nível de escala, definida pela forma de organização dos serviços.

O estudo da produção de doenças e sua articulação com formas específicas de organização do espaço, mediante o qual o papel da intervenção humana sobre o espaço é considerado como componente importante no processo de causalidade, tem sido desenvolvido por Sabroza, Toledo \& Osanai (1992), bem como por Silva (1985), em análise da distribuição da doença de Chagas no estado de São Paulo. No entanto, a incorporação dessas abordagens na discussão das medidas de controle das doenças endêmicas ainda é incipiente.

As conseqüências dessa dissociação entre a produção do conhecimento da epidemiologia e a definição de políticas da saúde se expressam seja na baixa efetividade das ações de controle, seja no controle limitado e temporário de alguma etapa do processo de transmissão. Como evidências da primeira forma de expressão, podem ser citadas as experiências no controle da hanseníase, $\mathrm{da}$ tuberculose, da malária e da leishmaniose visceral, as quais têm apresentado manutenção ou mesmo aumento na ocorrência de casos no País como um todo (Quadro 1). 


\section{Quadro 1 -Tendências em indicadores de morbidade para doenças endêmicas selecionadas. Brasil - 1980, 1991, 1992, 1993}

\begin{tabular}{|c|c|c|c|c|c|}
\hline \multirow[t]{2}{*}{ Doença } & \multirow[t]{2}{*}{ Indicador } & \multicolumn{4}{|c|}{ Ano } \\
\hline & & 1980 & 1991 & 1992 & 1993 \\
\hline Hanseníase & índice de detecção* & - & 20,59 & 23,12 & 21,71 \\
\hline $\begin{array}{l}\text { Tuberculose } \\
\text { pulmonar total }\end{array}$ & incidência* & 49,41 & 49,62 & 49,40 & - \\
\hline $\begin{array}{l}\text { Tuberculose } \\
\text { pulmonar pos. }\end{array}$ & incidência ${ }^{*}$ & 32,20 & 30,20 & 30,50 & - \\
\hline $\begin{array}{l}\text { Leishmaniose } \\
\text { visceral }\end{array}$ & incidência* & 0,14 & 1,03 & 1,25 & - \\
\hline Malária & lâminas positivas & 169.871 & 541.927 & 577.098 & - \\
\hline
\end{tabular}

* $1 / 100.000$ habitantes.

Fonte: Brasil, 1992a, 1992b, 1993.

Cabe ressaltar, no entanto, que tem sido observada uma tendência recente de redução da incidência de hanseníase em alguns estados. A manutenção no índice de detecção apresentada para os três anos referidos pode ser atribuída à melhoria no sistema de vigilância para este agravo no País como um todo.

$\mathrm{Na}$ segunda perspectiva, pode ser lembrada a doença de Chagas, para a qual vem-se obtendo controle na transmissão vetorial, particularmente por T. infestans após a utilização maciça de inseticida (Dias, 1992), enquanto a transmissão sangüínea segue ocorrendo em grandes áreas do nosso território. Outro exemplo é representado pela esquistossomose, na medida em que a redução da prevalência de infecção pelo $S$. mansoni é obtida com a utilização da quimioterapia específica por um período limitado de tempo (Santos \& Coura, 1986; Sleigh et al., 1981), enquanto a redução na morbidade e na mortalidade por formas graves da doença não tem sido verificada de forma consistente em nosso país (Carmo, Barreto \& Evangelista Filho, 1993a, 1993b). 
Ainda que possam ser visualizadas perspectivas de controle de algumas doenças particularmente transmitidas por vetores, também são apontadas as possibilidades de surgimento de novas moléstias ou reaparecimento de outras, constituindo um processo de substituição ou sobreposição de doenças.

\section{CONCLUSÕES}

Não se pretende assumir a dicotomia entre utilização ou não da tecnologia médica em larga escala. O exemplo da erradicação da poliomielite em nosso país e a significativa redução na incidência de sarampo levantam a possibilidade de resultados efetivos na utilização de tecnologia médica. $O$ que merece ser aprofundado é a adoção de medidas integradas, definidas pela dinâmica de transmissão das doenças. Tal integração pressupõe, além da incorporação de tecnologia com comprovada efetividade, investimento em infra-estrutura (do setor da saúde e fora dele) e disseminação do conhecimento sobre o processo de transmissão e possibilidade de controle. Extra-setorialmente, a integração implica a utilização do conhecimento epidemiológico nas instâncias de decisão (administração, planejamento, urbanismos etc.).

Tal discussão deve ter como base alguns conhecimentos que vêm sendo trabalhados pela epidemiologia, com o aporte de outras disciplinas. O primeiro deles diz respeito ao modelo de causalidade adotado na análise da ocorrência e da distribuição da doença. A não-aderência ao modelo unicausal (por exemplo, teoria microbiana) ou multicausal aponta para a incorporação de novos paradigmas (Tesh, 1988). Outro fator se refere ao espaço sobre o qual a doença ocorre na população. A utilização da categoria espaço social como definido pelo movimento da geografia crítica, na abordagem do processo saúde-doença, requer a explicitação da interação do homem com a natureza, na perspectiva do movimento de globalização da economia internacional (Santos, 1991).

Neste sentido, para o entendimento da dinâmica de transmissão de doenças, deve ser buscada uma apreensão dos mecanismos que incidem no nível local, que podem representar a constituição de um foco para algumas doenças, mas também a integração com os espaços diferenciados. Isto implica re- 
definir a unidade de análise, planejamento e execução das ações, bem como a recomposição do processo de informação sobre saúde, na perspectiva de permitir o desenho das situações da saúde.

Existe instrumental suficiente para o desenvolvimento contínuo do processo de avaliação das ações, incorporando a participação popular com o aporte de informações relevantes e de fácil acesso. Para tanto, torna-se fundamental uma redefinição dos indicadores necessários, não só para permitir a análise da situação da saúde, mas também a avaliação das ações de controle. Em muitas situações, serão necessários o aperfeiçoamento dos fluxos de informações, a simplificação de formulários etc.

Entendida, portanto, a descentralização das ações de controle das endemias como um processo que vem se desenvolvendo progressivamente em muitas instâncias, este constitui o momento adequado para o repensar das medidas que têm sido executadas. A efetivação deste processo, de forma que assegure qualidade, pode representar um fortalecimento da estratégia, conforme defendido nas várias instâncias de discussão.

\section{REFERÊNCIAS BIBLIOGRÁFICAS}

BARRETO, M. L. et al. Mudanças nos padrões de morbi-mortalidade: uma revisão crítica das abordagens epidemiológicas. Pbysis, 3(1):126-146, 1993.

BRASIL. Ministério da Saúde. Fundação Nacional da Saúde. Centro Nacional de Epidemiologia. Séries históricas de agravos e doenças transmissíveis. Informe Epidemiológico do SUS, 1(1):17-72, 1992a.

BRASIL. Ministério da Saúde. Fundação Nacional da Saúde. Centro Nacional de Epidemiologia. Doenças transmissiveis e acidentes por animais peçonhentos: taxas de incidência anual por unidade federada, Brasil 1980-1991. Informe Epidemiológico do SUS, 1(5):119-138, 1992b.

BRASIL. Ministério da Saúde. Fundação Nacional da Saúde. Centro Nacional de Epidemiologia. Casos e agravos de doenças infecciosas e parasitárias notificados em 1991, 1992 e 1993 por unidade federada. Informe Epidemiológico do SUS, 2(6):117-146, 1993. 
CARMO, E. H.; BARRETO, M. L. \& EVANGELISTA FILHO, D. Schistosomiasis control in Northeast Brazil and trends in related morbidity. In: IV SIMPÓSIO INTERNACIONAL DE ESQUISTOSSOMOSE. Rio de Janeiro, 1993a.

CARMO, E. H.; BARRETO, M. L. \& EVANGELISTA FILHO, D. Control of schistosomiasis and schistosomiasis-related mortality in Northeast Brazil. In: IV SIMPÓSIO INTERNACIONAL DE ESQUISTOSSOMOSE. Rio de Janeiro, 1993b.

DIAS, J. C. P. Doença de Chagas no Brasil: situação atual e perspectivas. Informe Epidemiológico do SUS, 1(4):17-25, 1992.

PAVLOWSKY, F. Natural Nidality of Transmissible Disease. Moscow: Peace Publishers, 1964.

SABROZA, P. C.; TOLEDO, L. M. \& OSANAI, C. H. A organização do espaço e os processos endêmicos-epidêmicos. In: LEAL, M. C. et al. (Org.) Saúde, Ambiente e Desenvolvimento: processos e conseqüências sobre as condiģôes de vida. v.2. São Paulo/Rio de Janeiro: Hucitec/Abrasco, 1992.

SANTOS, M. Metamorfoses do Espafo Habitado. São Paulo: Hucitec, 1991.

SANTOS, M. L. \& COURA J. R. Morbidade da esquistossomose no Brasil. IVEvolução em pacientes tratados e seus controles. Memórias do Instituto Oswaldo Crur, 81(1):53-60, 1986.

SILVA, L. J. Crescimento urbano e doença: a esquistossomose no município de São Paulo (Brasil). Revista de Saúde Pública, 19:1-7, 1985.

SLEIGH, A. C. et al. A three year follow-up of chemotherapy with oxamniquine in a Brazilian community with endemic schistosomiasis mansoni. Transactions of the Royal Society of Tropical Medicine and Hygiene, 75(2):234-238, 1981.

TESH, S. N. Hidden Arguments:political ideology and disease prevention policy. Londres: Rutgers University Press, 1988. 


\section{CÂNCER OCUPACIONAL NOS PAÍSES EM DESENVOLVIMENTO*}

Neil Pearce, Paolo Boffeta, Manolis Kogevinas \& Elena Matos

\section{INTRODUÇÃO}

Há uma necessidade crescente de informação sobre o problema do câncer ocupacional em países em desenvolvimento (Vainio et al., 1993), nos quais processos industriais importados, freqüentemente, colidem com uma infraestrutura institucional diferente e uma força de trabalho que pode se mostrar particularmente vulnerável, devido à saúde deficiente e à subnutrição. $O$ câncer ocupacional, contudo, é também um problema negligenciado em alguns países em desenvolvimento relativamente industrializados, nos quais a guerra e a subnutrição são incomuns. Esta situação é exacerbada pela ineficácia da segurança do trabalho e da legislação de saúde, o não-cumprimento de regulamentos, reduzida divulgação de informação, supervisão inadequada, processos de trabalho perigosos, tecnologia insegura e falta de roupas de proteção

- Tradução: Claudete Daflon dos Santos 
em climas quentes. Estes problemas vêm ocorrendo no contexto de um ágil processo de industrialização global e rápidas mudanças demográficas.

Os paises em desenvolvimento apresentam situações sociais, culturais e políticas heterogêneas. O próprio termo 'países em desenvolvimento' tem sido sujeito a muitas críticas (Sachs, 1990), porque as políticas de desenvolvimento vêm freqüentemente igualando desenvolvimento a crescimento econômico e, particularmente, à industrialização (Pearce \& Matos, 1994). Neste trabalho, o termo em pauta refere-se à África, Américas do Sul e Central, Ásia (excluindo Japão c a antiga URSS) e Oceania (excluindo Austrália c Nova Zelândia).

A maneira de encarar a industrialização nos países em desenvolvimento tem-se alterado em décadas recentes. Em muitos deles, a industrialização é tradicionalmente vista como uma solução para a modernização da sociedade e redução da dependência (Jeyaratnam, 1985). Assim, nos anos 70, a visão geral era de que a poluição industrial - preocupação significativa nos países desenvolvidos - não constituía uma preocupação fundamental nos países em desenvolvimento, que a miséria cra o principal poluidor e que a industrialização cra essencial para superar a pobreza c aumentar o padrão de vida (Tolba \& El-Kholy, 1992). Nos anos 80, as atitudes dos países industrializados e em desenvolvimento se aproximaram, em grande parte como resultado de experiências com problemas da poluição, doença ocupacional, instabilidade social e acidentes de trabalho em larga escala. Além disso, a crise da dívida do Terceiro Mundo durante os anos 80 e os programas de ajuste estrutural têm posto em perigo o progresso significante ocorrido na educação, na saúde e nas condições de trabalho durante os anos 60 e 70 (Kanji, Kanji \& Manji, 1991) e aumentado as pressões para a transferência da indústria de risco.

Dispõe-se de informação assistemática de muitos países, mas pouquíssimos estudos vêm sendo levados a cabo acerca de exposições a carcinógenos ocupacionais nos países em desenvolvimento, e menos ainda acerca dos efeitos na saúde de tais exposições (Boffetta ct al., 1994; Matos \& Boffetta, 1994). Existe, todavia, uma preocupação crescente de que o impacto das substâncias químicas utilizadas no mundo $\mathrm{cm}$ desenvolvimento sobre a saúde tenha sido subestimado. Neste trabalho, tentamos resumir a informação disponível até o momento sobre exposições a carcinógenos nos países em desenvolvimento, in- 
cluindo os achados de um recente levantamento do International Agency for Research on Cancer - IARC - (Matos \& Vainio, 1994).

\section{Exposição OCUPACIONAL a CARCINÓgENOS}

Não dispomos de cálculos precisos do número de trabalhadores expostos a carcinógenos ocupacionais nos países em desenvolvimento. Estatísticas oficiais sobre o número de trabalhadores em indústrias específicas (como aquelas publicadas pelas Nações Unidas) não são totalmente confiáveis, já que não podem abranger setores consideráveis da mão-de-obra, como os artesãos ou os trabalhadores da indústria de pequena escala e os trabalhadores migrantes ou ilegais. Além disso, a agricultura responde por uma grande proporção da força de trabalho em muitos países em desenvolvimento, mas diferenças na definição dos trabalhadores agrícolas tornam difícil a interpretação de comparações internacionais.

Pode-se obter uma estimativa indireta do número de trabalhadores empregados em indústrias específicas, a partir da análise de padrões e tendências temporais na produção de determinados bens. Por exemplo, o Gráfico 1 mostra a produção de asbesto no mundo, e em países em desenvolvimento selecionados, durante os anos de 1960 e 1970 . Os da região sul da África contribuíram em 1970 com cerca de $15 \%$ da produção mundial e algo em torno de $50 \%$ da produção fora do Canadá e da antiga URSS. A África do Sul é o maior produtor no mundo de minerais de asbestos anfibólios, e o Zimbábue é o terceiro maior produtor e fornecedor de asbesto crisotila, depois do Canadá e da antiga URSS (Baloyi, 1989). Também é digno de nota o rápido crescimento na produção de asbesto em países como o Brasil e a Índia, que não eram produtores tradicionais. 
Gráfico 1 - Produção de asbesto em países selecionados. 1973, 1981 e 1990

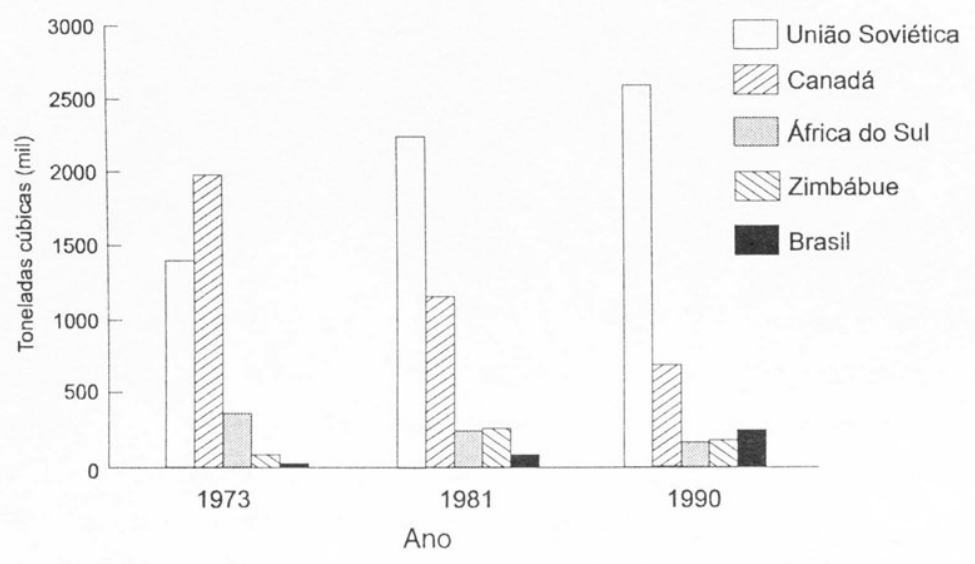

Fonte: Kogevinas, Boffetta \& Pearce (1994).

O Gráfico 2 mostra um quadro semelhante com relação à produção de pneumáticos, uma indústria que pode envolver riscos aumentados de leucemia e câncer de bexiga. Neste caso, grande crescimento na produção ocorreu nos países em desenvolvimento, enquanto a produção mundial cresceu menos de $10 \%$ durante os anos 80 .

Gráfico 2 - Produção de pneumáticos em países selecionados. 1961-1987

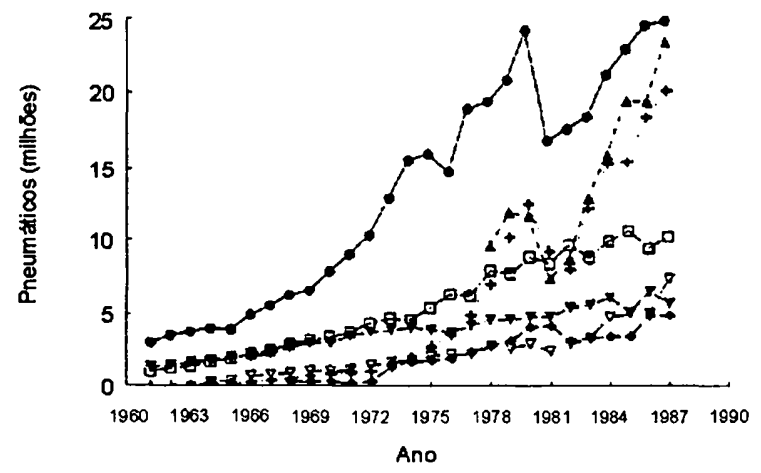

Fonte: Kogevinas, Boffetta \& Pearce (1994). 
Obteve-se informação adicional nos resultados do levantamento do IARC sobre câncer ocupacional nos países em desenvolvimento (Matos \& Vainio, 1994). A ocorrência de exposição a asbesto é relatada em quase todos os países que responderam à avaliação; a exposição a benzeno é também mencionada em alguns países, ao passo que o contato com outros carcinógenos como o níquel e o cloreto de vinil parece ser mais esporádico. Com exceção do Peru e de Chipre, as indústrias de borracha e de substâncias químicas estavam presentes em todos os países que responderam ao levantamento.

A maior evidência da falta de informação a respeito de exposições ocupacionais potencialmente perigosas é a exposição a pesticidas a longo prazo. $\mathrm{O}$ uso de tais substâncias tem aumentado dramaticamente nos países industrializados e naqueles em desenvolvimento durante as décadas mais recentes (Gráficos 3 e 4). Pesticidas são usados principalmente na agricultura, na horticultura e em programas de controle de vetor na saúde pública; eles são aplicados sobretudo no controle de cinco doenças transmitidas por vetor: malária, filariose, oncocercose, esquistossomose e tripanossomíase (Edwards, 1986). A venda, no mundo inteiro, de pesticidas usados na agricultura e no controle de doenças vetoriais cresceu de US $\$ 8,1$ bilhões em 1972 para US $\$ 12,8$ bilhões (dólares corrigidos) em 1983 (World Resources, 1986). O crescimento mais rápido foi observado nos países em desenvolvimento, onde cerca de $20 \%$ dos agroquímicos do mundo são usados.

O DDT foi um dos primeiros pesticidas a serem usados em larga escala. Ele é classificado pelo IARC como possivelmente carcinogênico para humanos (categoria 2B). Seu uso tem sido proibido ou severamente restringido em alguns países industrializados desde o início dos anos 70; contudo, é ainda vendido nos países em desenvolvimento, e sabe-se que cerca de 96 toneladas deste pesticida foram exportadas dos Estados Unidos em 1991 (FASE, 1993). O DDT foi introduzido na Índia para uso na saúde pública e na agricultura em 1948; desde então, estima-se que aproximadamente 250 mil toneladas foram utilizadas, incluindo 50 mil toneladas na agricultura (embora seu uso para fins agrícolas tenha sido proibido no país em 1989). No Iraque, as autoridades agrícolas utilizaram cerca de 12 mil toneladas entre 1960 e 1978. Já no Paquistão, o uso agrícola anual de DDT durante $1977-$ 1981 variou de 40 a 100 toneladas do ingrediente ativo. $\mathrm{Na}$ Indonésia, a aplicação anual do pesticida, entre 1952 e 1980, foi estimada em 1.400 toneladas, cifra elevada (IARC, 1991). 
Gráfico 3 - Vendas de pesticidas nas Filipinas com base no total de importações. 1983-1987

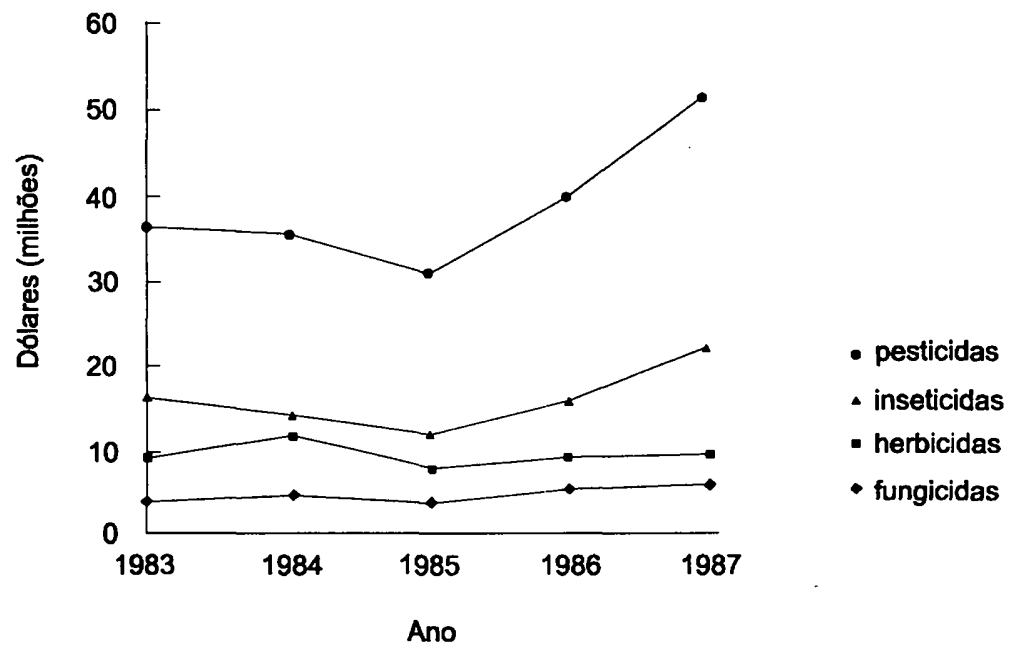

Fonte: Kogevinas, Boffetta \& Pearce (1994).

Gráfico 4 - Valores dos pesticidas importados para o Quênia. 1985-1987

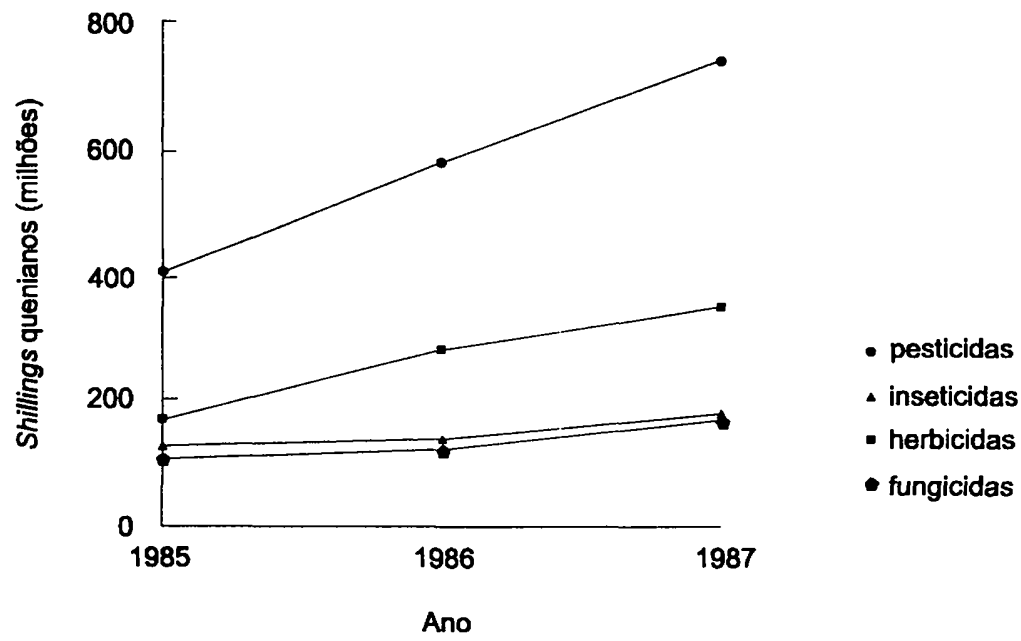

Fonte: Kogevinas, Boffetta \& Pearce (1994). 
Os pesticidas têm-se tornado, assim, importante mercadoria de exportação para países industrializados, e o valor da exportação mundial quase triplicou no período de 1970-1987. Em muitos casos, são proibidos ou duramente restringidos nos países industrializados. No entanto, é difícil obter um retrato cuidadoso das exportações para os países em desenvolvimento, devido a descrições incompletas ou ausentes dos produtos pesticidas exportados e das companhias que os embarcam (FASE, 1993). Embora pouca informação esteja disponível sobre exposições ocupacionais a longo prazo nos países em desenvolvimento, a possível extensão do problema é indicada por estimativas de que mais de dois milhões de incidentes de envenenamento agudo por pesticidas ocorrem anualmente no mundo, dos quais cerca de quarenta mil possivelmente fatais (Forget, 1991).

Em muitas publicações sobre câncer ocupacional nos países em desenvolvimento, a presença de exposições ocupacionais carcinogênicas é relatada sem qualquer informação quantitativa sobre os níveis de exposição (Kogevinas, Boffetta \& Pearce, 1994). Estas incluem carcinógenos reconhecidos, como a exposição ao éter clorometil durante sua produção e manipulação; os numerosos relatos sobre exposição a asbesto em diferentes indústrias; a exposição a benzeno entre fabricantes de sapato e na indústria de borracha; a exposição de trabalhadores em fornalhas de carvão; ${ }^{1}$ exposição a hidrocarbonetos aromáticos policíclicos em vários ambientes industriais; exposições na indústria de borracha, fabricantes de corante e usinas de aço; exposição dos mineiros de minas subterrâneas a produtos radioativos (radônio) em decaimento e exposições na indústria de couro. De fato, todas as substâncias químicas industriais, as profissões e os processos industriais classificados pelo IARC como carcinógenos grupo 1 e grupo $2 \mathrm{~A}$ têm sido descritos nos países em desenvolvimento, com exceção de um punhado de métodos de produção hoje apenas históricos.

Nas indústrias dos países em desenvolvimento onde vêm sendo realizadas medidas de exposição, os níveis de exposição são claramente superiores aos dos países desenvolvidos, e geralmente excedem os níveis de regulação propostos para países desenvolvidos (Kogevinas, Boffetta \& Pearce, 1994).

\footnotetext{
' Do original coke-oven; correspondendo coke a 'coque' em português, ou seja, carvão amorfo derivado do carvão mineral (N.T.).
} 
Por essa razão, parece razoável assumir que padrões semelhantes se aplicam àquelas indústrias e exposições para as quais medidas seguras não têm sido relatadas. Por outro lado, niveis médios de exposição a substâncias carcinogênicas como o asbesto e o benzeno parecem ter diminuído extraordinariamente nos países em desenvolvimento, ao longo do tempo (Kogevinas, Boffetta \& Pearce, 1994), tal como ocorreu nos países desenvolvidos. Deste modo, as diferenças nos níveis médios de exposição entre países industrializados e aqueles em desenvolvimento diminuíram, mas as diferenças relativas (isto é, a proporção dos níveis médios de exposição) têm geralmente aumentado. Além disso, o número de trabalhadores em algumas dessas indústrias está crescendo como resultado da transferência das indústrias de risco dos países industrializados para aqueles em desenvolvimento. Assim, embora os níveis médios de exposição estejam, de modo geral, diminuindo, a exposição total da mão-de-obra nos países em desenvolvimento é provavelmente maior do que em qualquer outra época.

\section{DIsCUSSÃO}

Ainda que as exposições ocupacionais não contribuam com uma fração significativa de casos de câncer, os carcinógenos ocupacionais são muito importantes em termos da saúde pública devido ao seu potencial de prevenção. Em princípio, exposições ocupacionais podem ser regulamentadas, minimizadas ou eliminadas de modo relativamente fácil se comparadas a fatores mais gerais de 'estilo de vida' como fumo, alimentação, práticas sexuais ou exposição à luz do sol. Além do mais, a prevenção das exposições ocupacionais leva, muitas vezes, à prevenção das exposições ambientais.

Deve-se enfatizar, no entanto, que, nos países industrializados, os maiores avanços na prevenção do câncer resultaram antes de mudanças econômicas e políticas do que da prevenção em nível individual. Por exemplo, os efeitos na saúde do tabagismo são conhecidos há várias décadas; enquanto as tentativas de prevenção fundamentadas no nível individual tiveram algum sucesso nos grupos de alta renda, em outros setores da comunidade tiveram 
pouco êxito. Medidas legislativas mais eficazes (como proibir a propaganda, aumentar o preço e limitar o fumo em locais públicos) foram adotadas nos últimos anos, embora ainda tendam a focalizar mais especificamente o consumo do cigarro do que o problema da produção de tabaco. Com isso, a indústria de cigarro transferiu suas atividades promocionais para os países em desenvolvimento (Tominaga, 1986), fazendo com que hoje um número maior de pessoas esteja exposto ao cigarro de tabaco. Na maior parte dos casos, os países em desenvolvimento não dispõem de força política e econômica necessária para impor restrições da natureza das que cada vez mais estão sendo adotadas nos países ocidentais. Por essa razão, as desigualdades na saúde entre os países industrializados e aqueles em desenvolvimento estão se intensificando.

Podem-se traçar alguns paralelos com referência a processos de produção envolvendo causas ocupacionais de câncer, que também estão sendo, de modo crescente, regulamentados nos países industrializados e, conseqüentemente, transferidos para paises em desenvolvimento. Também neste caso, o principal impacto decorre, provavelmente, do estabelecimento e da execução de ações de controle regularizador nacionais e internacionais, mas muitos países em desenvolvimento não possuem força econômica e política para impor tais controles. De fato, a presente crise da dívida do Terceiro Mundo e os programas de ajuste estrutural estão aumentando as pressões para que a indústria de risco seja transferida para os países em desenvolvimento.

Entretanto, houve algum progresso na prevenção do câncer ocupacional, mesmo no âmbito da presente situação internacional. Esforços em nível internacional têm-se concentrado no controle da transferência do lixo tóxico e da indústria de risco. Neste contexto, um paralelo pode ser estabelecido com a venda de armas, em relação à qual há um consenso global de que a nação industrializada tem responsabilidade, e um enfoque idêntico poderia ser buscado com relação às indústrias e substâncias químicas que foram proibidas nos países desenvolvidos por razões ambientais ou de saúde humana (Jeyaratnam, 1994). Por exemplo, a Convenção de Basel sobre Lixo Tóxico (Tolba \& El-Kholy, 1992) foi aprovada por 116 países e pela Comunidade Européia em 22 de março de 1989 , e recomendações similares foram desenvolvidas quanto à regulamentação da indústria de risco (por exemplo, as de Castleman \& Ziem, 
1991). Além disso, o Programa Ambiental das Nações Unidas (UNEP) ${ }^{2}$ fomentou a criação de um Registro Internacional de Substâncias Químicas Potencialmente Tóxicas (IRPTC), ${ }^{3}$ que visa a identificar todas as substâncias químicas proibidas ou severamente restringidas por cinco ou mais países e está, atualmente, elaborando diretrizes para o estabelecimento de uma legislação apropriada nos países em desenvolvimento.

A forma mais bem-sucedida de prevenção é nunca usar carcinógenos humanos reconhecidos no local de trabalho (Swerdlow, 1990). A segunda melhor opção é remover a substância pertinente, uma vez que se suspeite de sua carcinogenicidade. Em alguns casos, entretanto, a remoção completa de um carcinógeno é impossível (porque não estão disponiveis agentes alternativos), ou é vista como impraticável política ou economicamente (uma vez que os agentes alternativos são mais dispendiosos). Neste caso, a atenção se transfere para a redução dos níveis de exposição, por meio de alterações nos processos de produção e práticas de higiene industrial. Isto vem ocorrendo, nas últimas décadas, em alguns países em desenvolvimento e industrializados em relação a carcinógenos identificados como asbesto, níquel, arsênico, benzeno e radiação ionizante. Um exemplo interessante é o Registro Finlandês ASA, que tem como objetivos aumentar a consciência sobre os carcinógenos, avaliar a exposição em distintos locais de trabalho e estimular medidas preventivas (Alho, Kauppinen \& Sundquist, 1988). Ele contém informações tanto sobre locais de trabalho como acerca de trabalhadores expostos, e solicita-se a todos os empregadores que mantenham e atualizem suas fichas sobre empregados expostos a carcinógenos e forneçam a informação para o Registro. A cobertura da mão-de-obra sob exposição, segundo o Registro, parece abranger apenas cerca de um terço do total; no entanto, o sistema aparenta ter obtido sucesso, pelo menos parcialmente, na diminuição de exposições carcinogênicas no ambiente de trabalho. Embora o Registro ASA seja a única iniciativa nacional, vêm ocorrendo diversas ações locais interessantes, até mesmo nos países em desenvolvimento (Pearce \& Matos, 1994). Estas incluem a remoção de carcinógenos do processo de produção (Yin et al., 1987), bem como programas de fiscalização (Forget, 1991; McConnell, 1988; Noweir, 1986), de educa-

\footnotetext{
${ }^{2}$ United Nations Environment Programme.

${ }^{3}$ International Register of Potentially Toxic Chemicals.
} 
ção (Xue, 1987), de incentivo a melhorias gerais nas condições de vida e de trabalho (Yang et al., 1985) e melhorias na higiene industrial (Usewokunze, 1982).

Em suma, o conjunto de exposições ocupacionais carcinogênicas está aumentando nos países em desenvolvimento, tanto em conseqüência da transferência da indústria de risco como do estabelecimento da moderna indústria como parte do rápido processo global de industrialização. Essas crescentes exposições, junto com as mudanças demográficas, sugerem que a prevenção do câncer ocupacional será de importância cada vez maior nos países em desenvolvimento nas próximas décadas.

Muito poderia ser feito para prevenir ou minimizar a exposição a carcinógenos ocupacionais nos países em desenvolvimento, incluindo medidas internacionais para evitar ou controlar a transferência de indústrias e substâncias perigosas; regulamentação nacional e controle dos carcinógenos; melhorias na higiene industrial e nas condições gerais de vida e de trabalho. Entretanto, essas medidas têm de se defrontar com as limitações impostas pela crise da dívida externa e pelos programas de ajuste estrutural, o que significa que os problemas da saúde e do trabalho são considerados como secundários frente à luta diária pela sobrevivência. Desta forma, embora ainda exista muito a ser conseguido nas circunstâncias atuais, é mais provável que um progresso substancial na prevenção do câncer ocupacional nos países em desenvolvimento advenha de mudanças econômicas, incluindo alterações na relação entre países industrializados e em desenvolvimento, além de mudanças políticas e econômicas intrínsecas a esses países.

\section{REFERÊNCIAS BIBLIOGRÁFICAS}

ALHO, J.; KAUPPINEN, T. \& SUNDQUIST, E. Use of exposure registration in the prevention of occupational cancer in Finland. American Journal of Industrial Medicine, 13:581-592, 1988.

BALOYI, R. Exposure to Asbestos Among Chrysotile Miners, Millers and Mine Residents and Asbestosis in Zimbabwe. Helsink: Insitute of Occupational Health, 1989.

BOFFETTA, P. et al. Cancer. In: PEARCE, N. et al. (Ed.) Occupational Cancer in Developing Countries. Lyon: IARC, 1994. 
CASTLEMAN, B. I. \& ZIEM, G. E. Environmental review of industrial projects evaluated by developing countries. New Solutions, Summer:75-76, 1991.

EDWARDS, C. A. Agrochemicals as environmental pollutants. In: JOFSTEN, B. V. \& EKSTROM, G. (Ed.) Control of Pesticide Applications and Residues in Food: a guide and directory 1986. Uppsala: Swedish Science Press, 1986.

FASE. Exporting banned and hazardous pesticides, 1991 statistics. FASE Reports, 11:S1-S8, 1993.

FORGET, G. Pesticides and the third world. J Toxicol Environ Health, 32:11-31, 1991.

IARC WORKING GROUP ON THE EVALUATION OF CARCINOGENIC RISKS TO HUMANS. v. 53: Pesticides. Lyon: IARC, 1991.

JEYARATNAM, J. 1984 and occupational health in developing countries. Scandinavian Journal of Work Environmental Health, 11:229-234, 1985.

JEYARATNAM, J. Transfer of hazardous industry. In: PEARCE, N. et al. (Ed.) Occupational Cancer in Developing Countries. Lyon: IARC, 1994. p. 23-29.

KANJI, N. \& MANJI, F. From development to sustained crisis: structural adjustment, equity and health. Sociology Science Medical, 33:985-993, 1991.

KOGEVINAS, M.; BOFFETTA, P. \& PEARCE, N. Occupational exposure to carcinogens in developing countries. In: PEARCE, N. et al. (Ed.) Occupational Cancer in Developing Countries. Lyon: IARC, 1994.

MATOS, E. \& BOFFETTA, P. Other diseases. In: PEARCE, N. et al. (Ed.) Occupational Cancer in Developing Countries. Lyon: IARC, 1994.

MATOS, E. \& VAINIO, H. Survey of the situation in developing countries. In: PEARCE, N. et al. (Ed.) Occupational Cancer in Developing Countries. Lyon: IARC, 1994. p. 185-187.

MCCONNELL, R. Epidemiology and occupational health in developing countries: pesticides in Nicaragua. In: HOGSTEDT, C. \& REUTERWALL, C. (Ed.) Progress in Occupational Epidemiology. Amsterdan: Elsevier, 1988.

NOWEIR, M. H. Occupational health in developing countries with special reference to Egypt. American Journal of Industrial Medicine, 9:125-141, 1986.

PEARCE, N. \& MATOS, E. Strategies for the prevention of occupational cancer in developing countries. In: PEARCE, N. et al. (Ed.) Occupational Cancer in Developing Countries. Lyon: IARC, 1994.

PEARCE, N. et al. Industrialization and health. In: PEARCE, N. et al. (Ed.) Occupational Cancer in Developing Countries. Lyon: IARC, 1994. 
SACHS, W. On the archaelogy of the development idea. Ecologist, 20:42-43, 1990.

SWERDLOW, A. J. Effectiveness of primary prevention of occupational exposures on cancer risk. In: HAKAMA, M. et al. (Ed.) Evaluating Effectiveness of Primary Prevention of Cancer. (IARC Scientific Publications, $\mathrm{n}^{\circ}$ 103). Lyon: IARC, 1990.

TOLBA, M. K. \& EL-KHOLY, O. A. (Ed.) The World Environment 1972-1992: two decades of challenge. London: Chapman Hall, 1992.

TOMINAGA, S. Spread of smoking to the developing counties. In: ZARIDZE, D. \& PEARCE, N. (Ed.) Tobacco: a major international bealtb bazard. (IARC Scientific Publications, n"74). Lyon: IARC, 1986.

USEWOKUNZE, C. N. In: Proceedings of the World Symposium on Asbestos, Montreal, Canada, maio 1982.

VAINIO, H. et al. Occupational cancer in developing and newly industrialized countries. Ann Acad Med, 22:170-181, 1993.

WORLD RESOURCES 1986. A Report by the World Resources Institute and the International Institute for Environmental and Development. New York: Basic Books, 1986.

XUE, S. Health effects of pesticides: a review of epidemiologic research from the perspective of developing nations. American Journal of Industrial Medicine, 12:269279, 1987.

YANG, M. D. et al. Changes in health conditions in the Huainan coal mine in the past three decades., 11(suppl. 4):64-67, 1985.

YIN, S. N. et al. Occupational exposure to benzene in China. British Journal of Industrial Medicine, 44:192-195, 1987. 


\section{CÂNCER OCUPACIONAL \\ E MECANISMOS \\ CARCINOGÊNICOS*}

G. Thériault

As duas últimas décadas têm sido férteis em descobertas relativas aos mecanismos do câncer. Durante este tempo, muitos agentes químicos e físicos presentes no ambiente de trabalho vêm sendo apontados como fatores que determinam riscos elevados de câncer entre os trabalhadores expostos. Será que o conhecimento adquirido a respeito dos cânceres ocupacionais pode servir como chave no sentido de melhor compreensão futura do mecanismo da carcinogênese?

\section{INICIAÇÃO - PROMOÇÃO}

A primeira e, provavelmente, mais significativa observação já registrada em qualquer momento é a que afirma que o câncer se desenvolve em duas

\footnotetext{
• Tradução: Ronaldo A. de Souza \& Francisco Inácio Bastos
} 
etapas: iniciação e promoção. Iniciação é um dano permanente ao material genético da célula através de mutação. Este evento é essencial na geração do câncer. Sem ele, não haveria câncer. Entretanto, a iniciação não é suficiente para produzir o câncer por si só (embora existam exemplos no sentido contrário, de potentes substâncias químicas iniciadoras após exposição contínua). A iniciação deve ser seguida pela ação de um promotor. Este não causa câncer por si só, mas sua colaboração é essencial para permitir que a célula já iniciada torne-se um câncer. $O$ promotor permite a expressão do câncer.

O conceito de iniciação-promoção é proveniente de observações secundárias à experimentação animal. Descobriu-se que, pincelando a pele de um animal com uma substância carcinogênica como dimetilbenzantraceno (DMBA), um hidrocarboneto aromático polinuclear, não se estabelece um câncer. $O$ mesmo acontece com outro carcinógeno, o tetradecanoilforbol (TPA), que é um éster do forbol. Mas se o TPA é aplicado depois que o animal é pincelado com o DMBA, o câncer irá se desenvolver. O DMBA causa dano ao DNA da célula, e a partir daí o TPA permite que este dano se expresse sob a forma de um câncer. O DMBA é o iniciador, e o TPA é o promotor.

Este conceito teve imenso impacto na forma como os cientistas desenvolveram pesquisas subseqüentes sobre o câncer. Ele ainda constitui a linguagem mais comum hoje em uso.

\section{Proto-Oncogenes - Genes Supressores de Tumores}

As duas últimas décadas vêm testemunhando um desenvolvimento impressionante da biologia molecular e, com isto, maior compreensão da genética do câncer. Ao identificar a localização exata do gene em que a mutação carcinogênica tem lugar, os modernos biólogos moleculares nos estão trazendo para dentro do mundo do célula, onde somos postos em contato com uma série de eventos que devem constituir elementos do ambíguo mecanismo desta enfermidade (Alberts et al., 1994). 
Uma célula cancerosa é uma célula que entrou em estado de multiplicação incontrolável; em outras palavras, se torna 'louca'. Não mais responde às mensagens que lhe são enviadas por células vizinhas; comporta-se de forma egoísta; multiplica-se de uma maneira totalmente desordenada; é pobremente diferenciada, ainda que morra em decorrência disto; tem a capacidade de gerar seus próprios vasos nutrientes; pode destruir tecidos e se espalhar através de estruturas subjacentes; pode, ainda, invadir o sangue e vasos linfáticos e migrar para diferentes partes do corpo onde tem a capacidade de se aderir a tecidos e dar origem a metástases.

Esta definição de câncer indica que há muitos eventos envolvidos na carcinogenicidade, e muitos deles terão de ser devidamente explicados, de modo a possibilitar a compreensão do mecanismo do câncer.

Os cientistas descobriram que existem genes que estimulam o crescimento da célula e outros que o detêm. Entre os genes de crescimento, há alguns que, caso sofram mutação, irão servir de estopim a um crescimento ilimitado. Eles são denominados proto-oncogenes, que, uma vez ativados, tornam-se oncogenes. Essa ativação, passo essencial na carcinogênese de uma célula, por muito tempo foi considerada a marca registrada do câncer; entretanto, hoje parece ser insuficiente por si só para fazer com que uma célula se torne, de fato, cancerosa. A razão disto é que o crescimento de uma célula pode e é normalmente interrompido por outra série de genes, os supressores de tumores. Esses genes possuem a capacidade de interromper o crescimento de uma célula cancerosa; por este motivo, devem estar danificados (por mutação) para que uma célula possa crescer indefinidamente. Até o momento, não mais do que sessenta oncogenes foram identificados, e o número de novos genes supressores de tumores tem aumentado regularmente.

Em oposição a uma compreensão inicial de que um único gene em mutação era o marcador da célula cancerosa, os biólogos moleculares afirmam que deve haver muitos eventos mutacionais no interior de uma célula, tanto em proto-oncogenes como em genes supressores de tumores, antes que o crescimento de uma célula se torne incontrolável.

Um exemplo clássico desta concepção de multimutação na gênese do câncer é o de colo-retal humano. No homem, o câncer do cólon é conhecido por seu desenvolvimento crônico após a idade de 55 anos. Em sua história natural, apresenta-se, primeiro, como um pólipo benigno que se torna maligno 
com o decorrer do tempo. Os cientistas vêm analisando o material genético desse tumor em diferentes estágios de seu desenvolvimento. Através deste procedimento, eles puderam identificar sete diferentes genes mutantes, alguns deles proto-oncogenes e outros genes supressores de tumores. Ademais, essas mutações desenvolvem-se não de uma forma aleatória, mas segundo uma ordem cronológica, com algumas mutações aparecendo no início do processo, quando a célula é ainda bem diferenciada e apenas em estágio de ativa multiplicação normal (que corresponde à fase de pólipo do tumor), e outras aparecendo mais tarde, quando o tumor encontra-se em estágio avançado de carcinogenicidade. Este exemplo é utilizado como evidência de que a formação do câncer necessita de muitos eventos mutacionais antes de a célula tornar-se totalmente maligna.

A descoberta da proto-oncogênese e dos genes supressores de tumores e a observação de que cânceres 'maduros' contêm diversos genes mutantes deixaram pouca dúvida de que as mutações são essenciais ao desenvolvimento do câncer.

\section{A Especificidade da MutaÇão}

Pesquisa recente desdobrou os limites de nossa compreensão para ainda mais além. Observou-se que mineiros de urânio que desenvolveram câncer de pulmão, após exposição a produtos de derivados do radônio (radon daugbters) - radiação alfa -, apresentavam uma taxa extraordinariamente elevada (31\%) de mutação específica do códon 249 do gene P53, comparada a uma taxa de menos de $1 \%$ relativa aos demais pacientes com câncer de pulmão. Concluiu-se que a mutação do códon 249 deve ser um marcador do câncer de pulmão induzido pelo radônio (Taylor et al., 1994). Isto pode indicar que substâncias químicas carcinogênicas causariam uma alteração genética muito específica e que essas mutações devem ser utilizadas, no futuro, como marcadores confiáveis do agente causal que contribuiu para este determinado câncer. 


\section{GENOTOXICIDADE - EPIGENICIDADE}

Observações diárias do câncer levaram os cientistas a perceber que, no âmbito da iniciação/mutação e das fases promotoras da carcinogenicidade, há mais do que um único mecanismo envolvido. Por exemplo, ficou claro que a radiação ionizante causa câncer de forma muito mais direta do que o cloreto de vinil, e que a forma pela qual os hormônios estrogênios contribuem para a progressão do câncer de mama é muito diferente de como asbesto causa o câncer de pulmão. Para tentar explicar essas diferenças, a designação iniciação-promoção foi ampliada para o conceito mais descritivo de genotoxicidade-epigenicidade.

Genotoxicidade refere-se a eventos que causam danos ao material genético da célula (que constituem a marca registrada dos agentes iniciadores) e epigenicidade refere-se a eventos que têm lugar fora dos genes (onde se supõe atuar os agentes promotores).

Para tentar explicar os, aparentemente, diversos modos de ação que têm lugar sob estes dois conceitos obviamente amplos, Weisburger \& Williams (no prelo) propuseram uma nova classificação das substâncias químicas carcinogênicas (ver Quadro 1).

Eles dividiram as substâncias químicas genotóxicas em duas categorias: as que interagem diretamente com o DNA e as que necessitam de uma conversão por meio de mudanças metabólicas antes que possam causar dano ao DNA, as quais denominaram ativação-dependente. Na primeira categoria, eles incluem substâncias que agem através de potentes reações eletrofilicas como o etileno-imina, o éter bis (clorometil), os agentes alquilantes e aquelas que alteram a replicação de DNA, tais como o níquel e o cromo hexavalente. $\mathrm{Na}$ categoria ativação-dependente, eles incluem substâncias tais como o monômero de cloreto de vinil, o benzopireno, a 2-naftilamina e a 2-amino-3-metilimidazo(4,5)-quinolina dimetilnitrosamina, que necessitam de uma modificação metabólica tal como os dióis reativos, ou a transformação epóxida antes de danificar a célula de DNA.

As substâncias químicas carcinogênicas epigenéticas estão agrupadas sob seis categorias, que resultam de agudas observações clínicas. A primeira compreende substâncias químicas que derivam suas propriedades carcino- 
gênicas simplesmente de sua conformação física, tais como o asbesto, os polímeros ou as folhas laminadas. Os autores as denominam carcinógenos em estado-sólido. O mecanismo de sua ação permanece obscuro, mas possivelmente compreende um incremento do ciclo celular e geração de radicais 'hidroxi-'. Os hormônios constituem o segundo grupo. Sabe-se que estrogênios e a prolactina interagem com o câncer de mama feminino; sua presença acelera a progressão do câncer, e sua supressão é um adjuvante reconhecido em um tratamento bem-sucedido. Nesta categoria os autores incluem o estradiol, o dietilbestrol e o imitrole.

Tratamentos com imunossupressores se fazem acompanhar por um risco ampliado de câncer. Parece que drogas como a azatioprina, o soro antilinfocítico ou a ciclosporina $A$ estimulam neoplasias induzidas por vírus, transplantadas ou metastáticas. Elas constituem a terceira categoria dos carcinógenos epigenéticos. O quarto grupo inclui substâncias que aumentam a geração de radicais 'hidroxi-' ou sobrecarregam a defesa celular. Tais substâncias incluem o clofibrato e o dietil-hexilftalato. Elas são denominadas proliferadoras do peroxissomo.

No quinto grupo, os autores incluem substâncias que, em doses específicas, matam células, aumentam a regenetação e aceleram o ciclo celular. Elas são denominadas simplesmente citotoxinas e compreendem o hidroxinisol butilado, o nitrilotriacetato e o carbono tetracloreto. Finalmente, em sua última categoria, os autores incluem substâncias que reconhecidamente incrementam o efeito de substâncias químicas genotóxicas. Estas substâncias incluem os ésteres forbol, os fenóis, os ácidos biliares e a sacarina sódica, que freqüentemente aumentam a velocidade do ciclo celular e induzem a geração da enzima ornitina descarboxilase, um marcador da atividade de reparação do DNA. 


\section{Quadro 1-Carcinógenos ocupacionais conhecidos}

\begin{tabular}{|c|c|}
\hline Exposição ocupacional & Localização do câncer \\
\hline Asbestos & Pleura, peritônio, pulmão \\
\hline Aminas aromáticas & Bexiga urinária \\
B-naftalamina & \\
4-aminobifenil & \\
Benzidina & \\
Nitroaminas & \\
\hline Arsênico & \\
\hline Benzeno & Pulmão, pele \\
\hline Éter bis (clorometil) & Leucemia (ANLL) \\
\hline Crômio (hexavalente) & Pulmão (oat celh ${ }^{*}$ \\
\hline Radiação ionizante & Pulmão \\
\hline Óleos minerais & Pulmão \\
\hline Gás mostarda & Pele (escroto) \\
\hline Níquel (óxido de) & Pulmão \\
\hline Leucemia, outros (cérebro, pele) \\
\hline Hidrocarbonetos poliaromáticos (PAHs) & Pulmão, bexiga urinária \\
\hline Rádio & Ossos (sarcoma) \\
\hline Radônio & Pulmão \\
\hline Fuligem, alcatrão & Pele (escroto) \\
\hline Radiação ultravioleta & Pele \\
\hline Monômero de cloreto de vinil & Fígado (angiossarcoma) \\
\hline Feridas, cortes na pele & Pele \\
\hline Álcool & Garganta, laringe \\
\hline
\end{tabular}

* A denominação inglesa original é utilizada habitualmente. As células lembram a forma da aveia (oat). 


\section{A Causa de Mutação}

Mas o que causa as mutações? Propõem-se duas teorias. Alguns acreditam que as mutações são causadas por um agente físico ou químico que danifica o conteúdo de DNA de uma célula de forma direta e dá origem a gene ou genes causadores do câncer. Eles são os proponentes do que pode ser denominado como a teoria da mutação. Esta é a teoria mais difundida e corresponde adequadamente ao mecanismo hipotético do câncer secundário a uma exposição a carcinógenos potentes como as radiações ionizantes. Por outro lado, há quem acredite que o câncer é essencialmente decorrente de um evento fortuito que resulta de um grande número de mutações que, constantemente, tem lugar na célula, onde uma destas mutações dá origem a um oncogene ou a um gene supressor de tumor. Estes últimos podem ser denominados como os proponentes da teoria da mitogênese. Para eles, qualquer substância que estimula o crescimento celular aumenta a mutagenicidade $e, c o m$ isso, o risco de câncer.

Um defensor dessa teoria do acaso é Bruce Ames, o inventor do teste da carcinogenicidade, com base no poder mutagênico de substâncias químicas. No curso de suas pesquisas, Ames constatou que uma vasta proporção de substâncias químicas ambientais (estimadas em aproximadamente $50 \%$ ) eram carcinógenas para os roedores quando administradas aos animais em altas doses e que, surpreendentemente, ampla proporção de substâncias químicas reconhecidamente carcinogênicas (aproximadamente 40\%) não eram mutagênicas em testes realizados em placas de Petri. Isto aumentou a sua suspeita acerca do valor dos testes de mutagenicidade e carcinogenicidade. Ademais, ele observou que substâncias químicas endógenas formadas naturalmente durante os processos metabólicos normais não eram menos carcinogênicas do que substâncias químicas exógenas. E elas estão presentes no corpo em concentrações que são muito mais altas - por muitas ordens de magnitude do que os agentes exógenos. Ames sustenta que "as taxas endógenas de dano infligido ao DNA são deste modo tão altas que deve ser difícil para mutações exógenas aumentarem este dano de forma significativa, em níveis normais de exposição humana"(Ames \& Gold, 1990a).

Como um mecanismo alternativo, Ames propõe que o câncer é simplesmente a conseqüência lógica e esperada do simples acaso, em decorrência do grande incremento nos eventos mutacionais que ocorrem quando o cres- 
cimento da célula é posto em movimento por alguma agressão celular crônica ou de maior monta. Ele afirma que "testar animais com máximas doses toleradas (MTD) é equivalente a infligir-lhes injúrias de modo crônico, o que, através da divisão celular crônica, implica um alto risco de câncer" (Ames \& Gold, 1990a).

Mas quem está certo? Os proponentes da teoria da mutação ou aqueles que sustentam a teoria da mitogênese? É neste aspecto que os cânceres ocupacionais podem talvez oferecer algumas indicações úteis.

\section{O Que os CÂnCERES Ocupacionais ReVElam Sobre o MeCANismo de CARCINOGÊNESE}

O Quadro 2 lista os carcinógenos ocupacionais mais amplamente aceitos. Com relação a alguns deles, o mecanismo de ação parece relativamente óbvio, com relação a outros ele é suspeito e, quanto a muitos, completamente desconhecido. Esforçamo-nos em classificar esses câncercs de acordo com a teoria da mutação ou da mitogênese. 


\section{Quadro 2 - Classes de substâncias químicas carcinogênicas}

\begin{tabular}{|c|c|c|}
\hline Tipo & Modo de ação & Exemplo \\
\hline \multicolumn{3}{|l|}{ A. Genotóxico } \\
\hline 1. Ativaçăo-independente & $\begin{array}{l}\text { Elctrófilos, composto orgânico, } \\
\text { genotóxico, interagem com o DNA }\end{array}$ & $\begin{array}{l}\text { Imino etileno; éter bis (clorometil); } \\
\text { agentes alquilantes }\end{array}$ \\
\hline 2. $\Lambda$ tivação-dependente & $\begin{array}{l}\text { Requer conversão através da ativação } \\
\text { metabólica pelo hospedeiro ou in vitro } \\
\text { para o tipo } 1\end{array}$ & $\begin{array}{l}\text { Cloreto de vinil, benzo(a)pireno, } \\
\text { 2-naftilamina, 2-amino 3-metil- } \\
\text { imidazo[4,5-l quinolina, } \\
\text { dimetilnitrosamina }\end{array}$ \\
\hline $\begin{array}{l}\text { 3. Ativação-independente; } \\
\text { inorgânica }\end{array}$ & $\begin{array}{l}\text { Não diretamente genotóxico, leva a } \\
\text { mudanças no DN } \Lambda \text { por alterações } \\
\text { seletivas na fidelidade da replicação } \\
\text { do DNA }\end{array}$ & Níquel, cromo, cádmio \\
\hline \multicolumn{3}{|l|}{ B. Epigenético } \\
\hline $\begin{array}{l}\text { 1. Carcinógeno de estado } \\
\text { sólido }\end{array}$ & $\begin{array}{l}\text { Geralmente afeta somente células e } \\
\text { tecidos mesenquimais; forma fisica } \\
\text { tem papel vital; mecanismo exato } \\
\text { desconhecido, podendo aumentar o } \\
\text { ciclo celular e a geração de radicais } \\
\text { hidroxi- }\end{array}$ & $\begin{array}{l}\text { Polimeros ou folhas metálicas; } \\
\text { asbestos }\end{array}$ \\
\hline 2. Hormônio & $\begin{array}{l}\text { Altera principalmente o equilíbrio do } \\
\text { sistema endócrino e sua diferenciação; } \\
\text { freqüentemente atua como promotor; } \\
\text { habitualmente não é genotóxico }\end{array}$ & Estradiol, dictil-estilbestrol, amitrole \\
\hline 3. Imunossupressor & $\begin{array}{l}\text { Estimula principalmente neoplasmas } \\
\text { 'induzidos por vírus', transplantados } \\
\text { ou metastáticos; habitualmente não é } \\
\text { genotóxico }\end{array}$ & $\begin{array}{l}\text { Azatioprina, soro antilinfocítico, } \\
\text { ciclosporina } \Lambda\end{array}$ \\
\hline $\begin{array}{l}\text { 4. Indutor da proliferação } \\
\text { do petoxissoma }\end{array}$ & $\begin{array}{l}\text { Aumenta a produção de radicais } \\
\text { hidroxi-, sobrecarregando as defesas } \\
\text { celulares }\end{array}$ & Clofibrato, dietil-hexilftalato \\
\hline 5. Citotoxina & $\begin{array}{l}\text { Não é genotóxico ou carcinogênico; } \\
\text { acima de dosagens específicas, mata } \\
\text { células, aumenta a regeneração c o } \\
\text { ciclo celular; pode causar inflamação }\end{array}$ & $\begin{array}{l}\text { Hidroxianisol butilado; } \\
\text { nitrilotriacetato; tetracloreto de } \\
\text { carbono }\end{array}$ \\
\hline 6. Promotor & $\begin{array}{l}\text { Não é genotóxico ou carcinogênico, } \\
\text { mas aumenta o efeito de agentes do } \\
\text { tipo } 1 \text { ou do tipo } 2 \text {; freqüentemente } \\
\text { aumenta o ciclo celular; induz enzimas } \\
\text { como a omitina decarboxilase }\end{array}$ & $\begin{array}{l}\text { Ésteres de forbol, fenóis, ácidos } \\
\text { biliares, sacarina sódica }\end{array}$ \\
\hline
\end{tabular}

Fonte: Adaptada de Weisburger \& Williams (no prelo). 
Foi relativamente fácil pôr sob a rubrica 'mutação' alguns carcinógenos ocupacionais que podem agir diretamente no âmbito do DNA como a radiação ionizante, o rádio e o radônio. Foi igualmente fácil inserir sob a categoria mitogênese carcinógenos que impõem um dano direto às células e servem como estopim de uma resposta reparadora (curando e cicatrizando). Entre eles incluímos o asbesto, os ferimentos e o álcool. Mas, quanto aos outros carcinógenos listados, a classificação se torna mais difícil.

Os metais (crômio hexavalente, óxidos de níquel e, possivelmente, o arsênico) são propostos por Weisburger \& Williams como substâncias capazes de alterar a replicação de DNA e, portanto, alterar diretamente a expressão genética. Eles foram considerados por estes autores como genotóxicos. Entretanto, pode-se perceber que os trabalhadores para quem um risco ampliado foi relatado eram, em sua maioria, trabalhadores metalúrgicos expostos simultaneamente a uma mistura de contaminantes, muito freqüentemente ainda complementada pelo hábito de fumar. Isto pode indicar que essas substâncias químicas também agem por meio da alteração do ciclo celular e do crescimento da célula e, por este motivo, se enquadrariam no mecanismo da mitogênese.

As aminas aromáticas são potentes carcinógenos da bexiga urinária. Acredita-se que elas sejam mutágenos, através da ação de seus metabólitos eletrofillicos. Isto é amplamente aceito. Entretanto, há alguma possibilidade de que elas possam ser mitógenos. Trabalhadores que desenvolveram câncer de bexiga, após exposição a aminas aromáticas, muito freqüentemente trabalhavam em ambientes quentes, os quais acarretam transpiração intensa. Isto deve implicar o aumento de urinas concentradas altamente irritantes para a parede da bexiga e agressiva para suas camadas internas de células.

O mecanismo pelo qual o benzeno causa leucemia em baixas concentrações é desconhecido. Em elevadas doses, entretanto, o benzeno causa anemia aplástica, e é na fase regenerativa da hematopoiese que as leucemias aparecem. Isto coloca-se a favor de um mecanismo de mitogênese.

$O$ éter bis(clorometil) e os gases mostarda (agentes alquilantes) têm o potencial de interagir diretamente com o DNA através de reações eletrofilicas. Entre todas as substâncias químicas mutagênicas exógenas, elas são provavelmente as mais potentes. Todavia, o fato de que os casos de câncer de pulmão que aparecem depois da exposição aos gases mostarda ocorrem após 
exposições de grande intensidade pode indicar ainda, uma vez mais, que o mecanismo relevante implicado é o do reparo celular posterior a um dano celular severo.

Os cânceres de pele (na maior parte das vezes do saco escrotal) relatados após exposição a óleos minerais, fuligem e alcatrão são atribuídos aos hidrocarbonetos poliaromáticos (PAHs), componentes destes contaminantes. $\mathrm{O}$ mecanismo de ação dos $\mathrm{PAHs}$ é desconhecido. $\mathrm{Na}$ verdade, os $\mathrm{PAHs}$ não são uma única substância, mas uma ampla mistura de substâncias químicas, muitas delas já incluídas na listagem apresentada. De modo geral, as pessoas expostas a contaminantes que incluem os PAHs são marcadamente afetadas, tendo a pele impregnada pela exposição crônica nos seus locais de trabalho. É provável que essas substâncias químicas também atuem através da agressão celular crônica da pele (e dos pulmões).

A luz ultravioleta pode muito provavelmente atuar tanto como radiação ionizante, danificando o DNA diretamente, ou causando danos à pele exposta, forçando uma renovação celular acelerada, agindo, desse modo, como um mitógeno.

O monômero de cloreto de vinil foi incluído entre os mitógenos, e não entre os agentes mutagênicos. Isto porque sabe-se que o monômero de cloreto de vinil dá lugar a um potente metabólito eletrofilico, capaz de interagir com o DNA e provocar mutações. Entretanto, exames patológicos do fígado dos trabalhadores expostos ao cloreto de vinil que desenvolveram angiossarcomas revelaram órgãos profundamente danificados por cirroses e cicatrizes (Delorme \& Thériault, 1978). Além disso, muitos trabalhadores expostos ao cloreto de vinil desenvolveram cirrose, embora não houvesse angiossarcoma. Quando a carga de exposição foi reduzida, nenhum caso adicional de angiossarcoma foi relatado. Isto indica que esses cânceres são antes decorrentes da fase ativa do ciclo celular e da mitogênese do que da mutação direta produzida pelo cloreto de vinil. 


\section{CONCLUSÃO}

Nesta revisão dos carcinógenos ocupacionais conhecidos, do ponto de vista da mutagenicidade direta ou da mitogênese acelerada, procurou-se analisar o que os cânceres ocupacionais podem revelar sobre o mecanismo da carcinogenicidade. É espantoso perceber o quão freqüente, na grande maioria dos exemplos listados no Quadro 2, o mecanismo da mitogênese pode ser invocado, em algumas ocasiões, com muita certeza (asbesto, ferimentos, álcool), e em outras, com uma suspeita razoavelmente bem fundamentada (metais, benzeno, PAHs, luz ultravioleta, monômero de cloreto de vinil).

Os exemplos em que um mecanismo mutagênico pode ser identificado com grande certeza são mais raros (radiações ionizantes, rádio, radônio), e todos eles resultam de exposições a elementos físicos (radiações) exclusivos das substâncias químicas. Os outros exemplos permanecem ambíguos - aminas aromáticas, éter bis (clorometil), crômio hexavalente, gases mostarda.

Em sua defesa do mecanismo da mitogênese como explicação dos cânceres no homem, Ames \& Gold (1990b) escreveram: “Com relação às substâncias químicas associadas ao câncer ocupacional, a exposição de trabalhadores geralmente têm ocorrido em doses quase-tóxicas, que provavelmente causariam proliferação celular". Esta afirmação é certamente exagerada, mas devese reconhecer que, exceto para o câncer secundário às energias veiculadas pela radiação (e mesmo esta observação pode ser posta em questão), a maioria dos cânceres ocupacionais pode ser a expressão da agressão celular e da reparação celular subseqüente.

\section{REFERÊNCIAS BIBLIOGRÁFICAS}

ALBERTS, B. et al. Molecular Biology of the Cell. 3ed. Nova York/Londres: Garland Publishing Inc., 1994.

AMES, B. N. \& GOLD, L. S. Too many rodent carcinogens: mitogenesis increases mutagenesis. Science, 9701-1, 1990a. 
AMES, B. N. \& GOLD, L. S. Misconceptions on pollution and the causes of cancer. Angewandte Chemie International Ed. in English, 29:1.197-1.208, $1990 \mathrm{~b}$.

DELORME, F. \& THÉRIAULT, G. Ten cases of angiosarcoma of the liver in Shawinigan, Québec. Journal of Occupational Medicine, 20:338-340, 1978.

TAYLOR, J. A. et al. P53 Mutation hotspot in radon associated lung cancer. Lancet, 343:86-87, 1994.

WEISBURGER, J. H. \& WILLIAMS, J. M. Causes of cancer. In: MURPHY, G. P. \& LAUREN JR, W. (Ed.) American Cancer Society Textbook of Clinical Oncology. 2.ed. Atlanta: American Cancer Society. (No prelo) 


\section{EPIDEMIOLOGIA DA \\ VIOLENNCIA EM LOCAIS \\ DE TRABALHO NOS EUA*}

Dana P. Loomis

\section{INTRODUÇÃO}

Os programas para a proteção da saúde dos trabalhadores nos Estados Unidos têm, historicamente, focalizado exposição química e riscos associados à maquinaria industrial. Normas nacionais específicas desenvolvidas e reforçadas pela Occupational Safety and Health Administration (OSHA) estão, de fato, preocupadas quase exclusivamente com produtos químicos, detritos e radiação (Corn, 1992), enquanto muitos elementos prejudiciais que aumentam o risco de danos têm sido deixados para o controle voluntário por parte da indústria, ou regulados, caso a caso, a partir de regras gerais da Occupational Safety and Health Act. Pesquisas em epidemiologia ocupacional vêm, de modo similar, focalizando o câncer e outras doenças crônicas de longa latência, dando pouca atenção às injúrias até os anos 80 .

\footnotetext{
- Tradução: Ronaldo A. de Sonẓa \& Francisco Inácio Bastos
} 
De acordo com essa história, revelou-se uma surpresa para a comunidade da saúde ocupacional dos EUA aprender que ser assassinado no emprego constitui um sério problema na área. Pelo menos em dois estudos epidemiológicos pioneiros acerca de danos fatais ocupacionais, publicados nos início dos anos 80 , mencionaram-se as mortes de trabalho causadas por homicídios, além dos habituais riscos de quedas, problemas com maquinaria e vcículos motorizados (Baker ct al., 1982; MMWR, 1985). Todavia, a percepção de que a violência é uma questão da saúde ocupacional chamou a atenção de muitos pesquisadores, inicialmente em decorrência de dois artigos publicados na edição de outubro de 1987 do American Journal of Public Health (Davis, 1987; Kraus, 1987). Estes artigos apresentam pesquisas sobre dados de mortalidade da Califórnia e do Texas, no final dos anos 70 e no início dos 80 , mostrando um risco substancial de ser assassinado no trabalho, entre homens e mulheres envolvidos na venda de mercadorias e serviços ao público. Entre os homens, graves riscos se concentravam especialmente em diversos grupos profissionais de tamanho reduzido, incluindo motoristas de táxi, policiais e guardas. No cditorial em que foram apresentados os trabalhos, sinalizou-se a importância dos riscos, observando-se que as taxas referentes aos assassinatos de motoristas de táxi eram mais elevadas do que as encontradas entre prisioneiros, um grupo incontestavelmente de alto risco (Dietz \& Baker, 1987). Esses primeiros artigos também expressaram a magnitude potencial do problema $\mathrm{cm}$ termos de números absolutos de trabalhadores afetados. No Texas, assaltos violentos constituíram a principal causa de morte de mulheres trabalhadoras e, também, uma das principais causas entre os homens (Davis, Honchar \& Suarez, 1987; MMWR, 1985); padrões similares também foram observados em Maryland (Baker et al., 1982).

Quando sugerimos discutir os referidos artigos no nosso seminário semanal de Epidemiologia Ocupacional na Universidade da Carolina do Norte, pouco depois que ambos foram publicados, o grupo considerou as descobertas curiosidades interessantes, mas duvidou da real importância delas na saúde dos trabalhadores e, especialmente, da relação delas com as preocupações habituais da 'academia' quanto à epidemiologia ocupacional. Naquele momento, estávamos concentrados no estudo do câncer entre vários grupos de trabalhadores industriais e no desenvolvimento de métodos estatísticos para a análise de dados dos estudos das doenças crônicas. Nosso 
departamento era conhecido por seus estudos de câncer entre os que trabalham com borracha, asbesto e energia nuclear, mas poucos de nós tinham atribuído aos danos ocupacionais - muito menos aos assassinatos - mais do que uma reflexão passageira como objeto de pesquisa séria.

\section{A Situação Atual}

Atitudes em relação ao problema da violência no local de trabalho se alteraram desde 1987. A violência contra trabalhadores é agora reconhecida como importante questão no âmbito da saúde ocupacional. Em 1990, o National Institute for Occupational Safety and Health (NIOSH) promoveu uma conferência sobre homicídios no local de trabalho; em 1993, o instituto lançou um alerta, solicitando dedicação ao tema da prevenção do assassinato no emprego. $\mathrm{O}$ estado da Flórida estabeleceu medidas legais visando a reduzir a ameaça de roubo com violência contra trabalhadores em lojas varejistas, e os patrões passaram a externar preocupações crescentes com a segurança, a perda de produtividade e as obrigações legais (Purdy, 1994).

Sabe-se hoje, por meio dos estudos do NIOSH, com base na análise de um novo registro nacional de óbito, que os assassinatos no trabalho constituem a principal causa de acidente fatal entre mulheres trabalhadoras, em âmbito nacional, e a terceira causa principal entre trabalhadores do sexo masculino e no conjunto de trabalhadores (Jenkins et al., 1993). Além disso, o homicídio é a principal causa de morte em alguns setores da indústria que empregam grande número de pessoas, incluindo o comércio de atacado, comércio varejista, finanças, seguros, mercado imobiliário, serviços, transporte, comunicação e administração pública (Jenkins et al., 1993). Em suma, aproximadamente $1 / 8$ de todas as mortes dos trabalhadores de todas as indústrias é resultante de homicídio (NIOSH, 1993; Jenkins et al., 1993).

Poucos detalhes adicionais podem ser obtidos a partir dos estudos epidemiológicos nacionais e estaduais. Eles descrevem a população de trabalhadores sob risco de assassinato no emprego por idade, sexo, ocupação e ramo da indústria. Nacionalmente, a taxa global de homicídios é três vezes maior 
entre os homens do que entre as mulheres; as taxas são de, aproximadamente, 1,02 e 0,33 por cem mil, respectivamente (Tabela 1 ). No Texas e na Califórnia, todavia, as taxas parecem ser maiores, sendo clas intermediárias na Carolina do Norte; contudo, a razão entre as taxas rclativas a homens e mulheres parece ser quase a mesma $\mathrm{em}$ todas as árcas estudadas. Não fica claro se as diferenças geográficas nas taxas são reais ou artefatos de dados obtidos a partir do estudos diferentes; a Califórnia e o Sul têm altas taxas de homicídios, mas também é provável que a base de dados obtida a partir dos atestados de óbito do NIOSH deixe de incluir algumas mortes.

\section{Tabela 1 - Taxas de assassinato no local de trabalho de homens e mulheres nos Estados Unidos (por 100.000)}

\begin{tabular}{|l|c|c|}
\hline Região e anos & Homens & Mulheres \\
\hline EUA, 1980-89 & 1,02 & 0,33 \\
Texas, 1975-84 & 2,1 & 0,7 \\
Califórnia, 1979-81 & 2,2 & 0,5 \\
Carolina do Norte, 1977-91 & 1,6 & 0,3 \\
\hline
\end{tabular}

Trabalhadores com mais de 65 anos têm as mais altas taxas de homicídios, com índices de 1,2 c 6,5 por cem mil, entre mulheres e homens, respectivamente (Bell, 1991; NIOSH, 1993). Não há muita informação disponível sobre os riscos de diferentes grupos étnicos, mas, nacionalmente, a taxa de morte por homicídio no trabalho ć quase duas vezes maior para os afro-americanos do que para os outros grupos (NIOSH, 1993).

Tanto para homens como para mulheres, as firmas ligadas ao comércio varejista têm as maiores taxas de homicidio. Fsse setor industrial responde por $43 \%$ de todos os homicídios no emprego entre mulheres, em 48 estados americanos, durante um período de seis anos (Bell, 1991). Como sc observa na Tabela 2 , as taxas de mortalidade por homicídio entre homens no comércio varejista varia de 5,3 a 6,2 por cem mil trabalhadores, em diferentes áreas (Davis, 1987; Davis, Honchar \& Suarcz, 1987; Kraus, 1987), enquanto as taxas relativas a mulheres no comércio varejista têm-se situado entre $0,92 \mathrm{e}$ 
1,9 por cem mil trabalhadores (Bell, 1991; Davis, 1987; Davis, Honchar \& Suarez, 1987; Kraus, 1987). Em outros grupos ocupacionais de alto risco estão incluídos motoristas de táxi, outros trabalhadores na área de serviços e transportes e oficiais de segurança pública; as taxas de homicídio desses grupos variam entre dez e quarenta por cem mil em diversas regiões. É também inquestionável que as armas de fogo são utilizadas para cometer a grande maioria desses assassinatos, cerca de $3 / 4$ (NIOSH, 1993).

\section{Tabela 2 - Ocupações e ambientes de trabalho nos Estados Unidos com altas taxas de homicídio para homens e mulheres}

\begin{tabular}{|l|c|c|c|}
\hline Ambientes ou ocupação & Mulheres & Homens & $\begin{array}{c}\text { Todos os } \\
\text { trabalhadores }\end{array}$ \\
\hline Comércio varejista & $0,9-1,9$ & $5,3-6,2$ & - \\
$\quad$ Postos de gasolina & 13,3 & 14,2 & 5,6 \\
Lojas de comida & 3,6 & 11,9 & 3,6 \\
Restaurantes e bares & 2,6 & 7,0 & 1,5 \\
Lojas de bebidas alcoólicas & - & - & 8,0 \\
Serviços pessoais & $1,1-1,5$ & $4,1-4,3$ & - \\
Transportes e comunicação & $0,3-0,4$ & 2,0 & - \\
Negócios e serviços de reparos & 0,5 & 3,8 & - \\
Serviços de lazer e recreação & - & $1,6-5,1$ & - \\
Finanças, seguros e mercado imobiliário & $0,3-0,7$ & $1,0-2,4$ & - \\
Escritótios imobiliários & 1,7 & 2,4 & - \\
Administração pública & 0,5 & 4,5 & - \\
Oficiais da lei, guardas, detetives & - & $11-44$ & $4,9-9,3$ \\
Motoristas, choferes de táxi & - & $15-37$ & $3,6-6,7$ \\
Proprietários e supervisores de venda & 6,1 & $9,7-16$ & 2,8 \\
Vendedores & $0,8-1,1$ & 4,6 & - \\
Garçons, atendentes de bar e caixas de & 15,4 & 3,7 & 2,1 \\
lanchonetes & 20 & 11 & 3,1 \\
Pessoas que trabalham com cargas e embalagens & $0,5-3,0$ & $1,8-3,7$ & - \\
Gerentes e administradores & & & \\
\hline
\end{tabular}

Fonte: Compilada de Baker et al. Davis, 1987; Davis, Honchar \& Suarez, 1987; Kraus, 1987; Bell, 1991; NIOSH, 1993; Loomis et al., 1994. 
Sabe-se ainda menos sobre os assaltos não-fatais no trabalho. O National Crime Victimization Survey indica que, a cada ano, quase um milhão de pessoas nos EUA estão sujeitas a crimes violentos no trabalho, incluindo roubo, estupro e agressão, e que esses três atos violentos resultam em quase 160 mil registros anuais desses casos (Bachman, 1994). De modo geral, cerca de 15\% de todos os crimes violentos são cometidos contra pessoas que estão trabalhando.

Hales et al. (1988) estudaram tanto homicídios como injúrias ocupacionais não-fatais secundários à violência, utilizando dados de benefícios concedidos aos trabalhadores do estado de Ohio. Aproximadamente $20 \%$ dos requerimentos por injúrias devido à violência foram por homicídios, com taxas de cerca de 6,0 por cem mil para o conjunto de danos e 1,3 por cem mil por homicídio. Todavia, os locais de trabalho associados a riscos elevados foram os mesmos com altas taxas de homicídios e injúrias não-fatais devidos à violência, e similares àqueles observados em estudos anteriores.

Esses estudos de atos de violência não-fatais contra trabalhadores não fornecem informações sobre a distribuição de riscos por sexo e outras características dos trabalhadores. Contudo, os dados do National Crime Victimization Survey sugerem uma diferença entre os agressores que cometeram atos violentos contra mulheres trabalhadoras e os que cometeram atos violentos contra trabalhadores do sexo masculino. As mulheres foram atacadas mais freqüentemente por pessoas que conheciam, enquanto os crimes contra os homens foram cometidos principalmente por estranhos (Bachman, 1994). Além disso, os dados relativos a benefícios concedidos aos trabalhadores do estado de Ohio sugerem que as taxas globais de danos resultantes de violência são menores entre trabalhadores mais idosos, o que se contrapõe aos elevados índices de mortes por homicídios nos locais de trabalho nessa faixa etária (Hales et al., 1988).

Nem as certidões de óbito nem os registros de benefícios concedidos a trabalhadores fornecem qualquer informação sobre as circunstâncias ou causas das mortes de trabalhadores decorrentes de violência; conseqüentemente, quaisquer conclusões fundamentadas em dados são, por ora, especulativas. Com base na análise da natureza das ocupações das vítimas, o NIOSH e diversos pesquisadores observaram que o risco de os trabalhadores se tornarem vítimas da violência parece estar associado à exposição pública, ao intercâmbio de dinheiro, ao trabalho noturno ou em áreas com índices elevados de criminalidade e ao contato pessoal íntimo (NIOSH, 1993; Bell, 1991; Davis, 
Honchar \& Suarez, 1987; Kraus, 1987; Hales et al., 1988). Estas observações têm levado a especulações no sentido de que o roubo é freqüentemente um fator que contribui para o assassinato de trabalhadores, particularmente nos locais de comércio varejista e prestação de serviços (NIOSH, 1993). Além disso, sugeriu-se que eventos que ocorrem durante os assaltos, inclusive a resistência da vítima a solicitações, movimentos repentinos ou a entrada inesperada de um colega de trabalho ou freguês podem influenciar a possibilidade de ocorrer um assassinato (Crow \& Erickson, 1987).

Em decorrência dessas descobertas, várias recomendações no sentido de fazer com que os trabalhadores estejam mais protegidos contra a violência têm sido propostas pelo National Institute for Ocupational Safety and Health e por associações de comerciantes varejistas, além de oficiais de justiça. Essas recomendações propõem, geralmente, mudanças de natureza 'ambiental' focalizando principalmente os estabelecimentos de comércio varejista. Como exemplos, podem-se citar: melhorar a iluminação e a visibilidade do local de trabalho; reduzir a quantia de dinheiro à vista; instalar alarmes e câmeras de vigilância; instalar barreiras à prova de bala; fechar à noite; e patrulhamento mais freqüente por parte da polícia (NIOSH, 1993). Algumas mudanças comportamentais relativas ao trabalbador têm sido também sugeridas como possíveis intervenções. Elas incluem treinamento dos trabalhadores para resolver conflitos sem violência e não reagir durante o assalto.

A despeito do considerável progresso obtido na última década em relação ao reconhecimento, definição e prevenção da violência contra os trabalhadores, muito está para ser feito. É necessário saber mais sobre as causas de violência contra trabalhadores - especialmente a definição da importância do roubo como fator precipitante. Precisamos entender se as mulheres trabalhadoras são escolhidas como alvo de violência no trabalho, ou se a 'super-representação' delas, dentre as vítimas de homicídios, é simplesmente decorrente da natureza dos seus empregos. Do mesmo modo, deverse-ia saber se os trabalhadores idosos estão sob alto risco de violência no trabalho, na mesma proporção em que estão sob risco de morrer nele. Diversas intervenções voltadas para a prevenção da violência contra trabalhadores têm sido propostas, mas suas bases são bastante especulativas. É necessário desenvolver pesquisa para avaliar as intervenções propostas e também para desenvolver outras. 


\section{Pesquisas em Andamento na Carolina do Norte}

Visando a obter informação epidemiológica para responder a algumas dessas questões, estamos estudando o assassinato no emprego na Carolina do Norte, um grande estado sulista americano de base rural. A primeira fase da pesquisa incluiu um estudo epidemiológico descritivo das mortes de trabalhadores devidas a homicídio, entre 1977 e 1991; a segunda fase, ainda em curso, é um estudo prospectivo caso-controle de assassinatos no local de trabalho. Relatam-se, a seguir, alguns resultados preliminares da primeira fase do estudo.

\section{MÉTOdos}

Casos de assassinato ocorridos na ocasião em que a vítima estava no trabalho foram identificados por um sistema estadual de registros médicolegais. Esse sistema fornece uma extensa gama de informações, que incluem as causas de morte, codificadas segundo a $9^{a}$ Revisão da Classificação Internacional de Doenças (os códigos de 'causas externas' são utilizados para classificar os danos com morte), descrições das circunstâncias de morte e informação médica e toxicológica. Os dados assim obtidos são superiores em qualidade, abrangência e detalhe aos dados referentes às certidões de óbito habitualmente disponíveis nos cartórios estaduais.

Casos de danos ocupacionais foram selecionados do banco de dados central do escritório do Cbief Medical Examiner. Casos médico-legais registrados entre $1^{\circ}$ de janeiro de 1977 e 31 de dezembro de 1991 foram considerados elegíveis para o presente estudo caso indicassem que: a causa mortis era homicídio; o problema que levou à morte ocorreu enquanto o sujeito estava no local de trabalho na Carolina do Norte; e o intervalo entre lesão e morte foi de um ano ou período inferior. Revisaram-se, manualmente, registros em papel de todas as mortes ocorridas, e resumiram-se dados adicionais não disponíveis nos arquivos informatizados.

De modo a permitir o cálculo das taxas de mortalidade, estabeleceramse estimativas da força de trabalho, estratificadas por idade, sexo, raça, ocupação e ramo de atividade, a partir de amostras relativas aos censos nacionais de 
1980 e 1990 . A população de trabalhadores nos anos 'intercensitários' foi estimado empregando-se um modelo linear, e o número estimado de trabalhadores em cada estrato foi então totalizado por unidade de tempo, de modo a obter uma estimativa do número de pessoas/ano sob risco; as taxas foram estimadas por cem mil trabalhadores/ano. As taxas de mortalidade, ajustadas por idade, foram computadas utilizando-se ajustes diretos, tomando-se como padrão a distribuição de idade de toda a força de trabalho estadual. De modo geral, as taxas de mortalidade ajustadas e não-ajustadas foram idênticas, por isso apenas as taxas mais precisas não-ajustadas serão apresentadas.

\section{RESUlTADOS}

Um total de 355 mortes de trabalhadores por assassinato foram registradas durante os 15 anos do período de estudo, o que representa uma taxa de 0,8 homicídio por cem mil trabalhadores/ano. A maioria das vítimas (63\%) foi de homens de etnia euroamericana (Tabela 3). Contudo, a taxa de fatalidade foi maior entre os homens afro-americanos e mais baixa entre as mulheres brancas, com taxas de 1,6 e 0,3 por cem mil trabalhadores/ano, respectivamente (Tabela 1). Como em outras áreas, as taxas experimentavam incremento com a idade.

O número de mortes durante horas noturnas e nos fins de semana foi mais elevado do que em outros momentos do dia e em outros dias da semana, em contraste com as lesões ocupacionais fatais. Todavia, esse padrão é similar àquele relativo aos demais homicídios. Armas de fogo foram utilizadas em 3/4 de todos os homicídios de trabalhadores, e a grande maioria das armas eram revólveres.

O maior número de vítimas tinha ocupações relacionadas a vendas e administração e compunha-se de empregados em estabelecimentos que vendiam comida ou outras mercadorias (Tabela 4). Mas estes não foram os grupos que experimentaram as mais altas taxas de homicídios. Motoristas de táxi e guardas particulares apresentaram os riscos mais elevados, seguidos pelos trabalhadores empregados em vários tipos de negócios varejistas e oficiais de polícia (Tabela 2). 
Os resultados inéditos mais significativos estavam relacionados às circunstâncias nas quais os trabalhadores foram assassinados (Tabela 3). Mais da metade de todos os homicídios $(60 \%)$ tinham relação com roubo, como sugerido por estudos anteriores. Porém, outra proporção relevante, de cerca de $20 \%$ dos casos, resultou de conflitos entre o trabalhador e outra pessoa. Esses padrões se repetiram de modo quase idêntico para homens e mulheres. Além disso, $7 \%$ das vítimas (todas homens) eram oficiais de justiça mortos no cumprimento do dever, além de outras 40 mortes (11\%) secundárias a outras circunstâncias, ou circunstâncias desconhecidas.

Tabela 3 - Descrição das vítimas de homicídio no local de trabalho. Carolina do Norte - 1977-1991

\begin{tabular}{|l|c|c|}
\hline & Número & Percentual \\
\hline Homens & 291 & 82 \\
Mulheres & 64 & 18 \\
Europeus-americanos & 272 & 77 \\
Africanos-americanos & 75 & 21 \\
Outros & 7 & 2 \\
Idade (média 42,8) & & \\
$16-17$ & 4 & 1 \\
$18-24$ & 53 & 15 \\
$25-34$ & 74 & 21 \\
$35-44$ & 61 & 17 \\
$45-54$ & 62 & 17 \\
$55-64$ & 59 & 17 \\
$65-74$ & 34 & 10 \\
75 ou mais & 8 & 2 \\
\hline
\end{tabular}

Os homicidios relacionados a roubo ocorreram com maior freqüência no comércio varejista (67\%). A maior proporção desses homicídios (39\%) teve lugar em pequenos armazéns, e as vítimas de modo geral possuíam ou dirigiam tais negócios, ou vendiam mercadorias ou serviços ao público. Homicídios rela- 
cionados a conflitos ocorreram em grande variedade de lugares, incluindo fábricas, fazendas e escritórios, e as vítimas tinham diversas ocupações. $\mathrm{O}$ tipo de arma usada pelo assaltante também variava entre os diversos tipos de incidentes, observando-se um predomínio pouco expressivo de armas de fogo nos eventos relacionados a conflitos ou atividades, passíveis de apenação, relativas a roubo.

Embora a proporção de mortes resultantes de conflitos tenha sido essencialmente a mesma para homens e mulheres, a natureza das conflitos foi muito variada. Conflitos que resultaram na morte de homens estavam mais freqüentemente relacionados ao trabalho (Tabela 3). Por outro lado, a maioria dos conflitos com vítimas do sexo feminino era doméstica, e a violência era cometida por marido ou outros parceiros masculinos. Havia relacionamento anterior entre agressores e vítimas em 143 casos (40\%). A maioria dos homicídios relacionados a roubos em ambos os sexos era cometida por estranhos, enquanto os agressores em mortes secundárias a conflitos eram mais diversificados. Muitos dos agressores de vítimas do sexo feminino eram maridos ou parceiros; nenhum dos homens mortos em conflitos foi atacado por esposas ou parceiras, mas, em alguns casos, a vítima e o agressor tinham envolvimento com a mesma mulher. Ataques a homens foram perpetrados com maior freqüência por colegas de trabalho (incluindo empregados e empregadores) ou clientes, mas alguns dos agressores eram conhecidos mas não colegas de trabalho ou membros da família (Tabela 4).

\section{Tabela 4 - Locais de trabalho onde ocorrem homicídios}

\begin{tabular}{|l|c|c|}
\hline Tipo de ambiente & Número & Percentual \\
\hline Luja de conveniência & 67 & 19 \\
Outras lojas varejistas & 47 & 13 \\
Mercearia & 33 & 9 \\
Restaurante ou bar & 30 & 9 \\
Indústria manufatureira & 22 & 6 \\
Posto de auto-serviço & 18 & 5 \\
Táxi & 16 & 5 \\
Estrada ou rua & 10 & 3 \\
Residência privada & 10 & 3 \\
Hutel & 8 & 2 \\
Outros & 91 & 26 \\
Desconhecidos & 3 & 1 \\
ToTAL & 355 & 100 \\
\hline
\end{tabular}




\section{DISCUSSÃO}

Nosso estudo referente a 15 anos de homicídios de trabalhadores na Carolina do Norte demonstrou que a violência no local de trabalho não é um problema novo, mesmo em um estado sulista de base rural. Como em outras regiões, o problema é preocupante. Dispondo de informações acerca das circunstâncias dos homicídios em local de trabalho, dado não disponível nos estudos anteriores, fomos também capazes de avaliar mais diretamente a teoria segundo a qual a violência é resultado de roubo ou tentativa de roubo. Os resultados confirmam que roubo é de fato importante, estando relacionado a mais da metade dos homicídios contra trabalhadores. Porém, nossos achados relativos a trabalhadores mortos em conflitos mostram que o problema tem outras dimensões que se estendem tanto à esfera pessoal e familiar quanto ao local de trabalho.

As medidas propostas como intervenções para prevenir os trabalhadores de sofrerem injúria em decorrência da violência têm, grosso modo, focalizado lojas e restaurantes. Seu intento aparente é tornar esses lugares alvos menos atraentes para o roubo e proteger os trabalhadores de injúrias caso aconteçam os roubos. Essas metas seriam alcançadas através de mudanças físicas nos locais de trabalho ou modificações nos regulamentos relativos a horários de trabalho, procedimentos e comportamentos dos empregados. A despeito da relativa novidade da questão, essas propostas representam medidas clássicas em segurança ocupacional, nas quais se prioriza a mudança do desenho e da organização do local de trabalho ou o comportamento do trabalhador.

Embora não reste dúvida de que essas medidas parecem razoáveis e mostram-se de alguma valia, elas não têm sido avaliadas como meios de deter o roubo ou a violência. Por isso, não se sabe em que medida poderão prevenir injúrias perpetradas contra os trabalhadores e mortes.

Além do mais, não é provável que medidas tais como instalação de cofres e melhor iluminação ou redução do dinheiro à vista previnam a violência decorrente de conflitos, mesmo no comércio. Medidas de diferentes naturezas são provavelmente necessárias também em locais de trabalho cuja função não envolve venda para o público. 
A prevenção de muitos, se não da maioria, dos assassinatos de trabalhadores provavelmente exige medidas sociais mais amplas, para além da tradicional abrangência das intervenções em segurança ocupacional. Discussões relativas a esse nível de prevenção têm estado inteiramente ausentes da agenda de segurança ocupacional. Uma restrição drástica no acesso a revólveres ou qualquer tipo de pistola é uma medida que parece essencial a toda tentativa séria no sentido de obter uma redução no número de mortes e danos graves secundários à violência no local de trabalho e alhures. Intervenções destinadas a prevenir a violência contra mulheres por parte de seus parceiros poderia prevenir igualmente mortes entre trabalhadores, assim como entre as mulheres de modo geral. Para além de intervenções dessa natureza, situam-se os esforços mais amplos relativos às causas sociais fundamentais de roubo e violência interpessoal. Esse território pode ser pouco familiar aos profissionais que lidam com a questão da saúde ocupacional, mas demonstra o fato inescapável de que eventos no ambiente de trabalho têm vínculos estreitos com questões da sociedade como um todo.

\section{REFERÊNCIAS BIBLIOGRÁFICAS}

BACHMAN, R. National Crime Victimization Survey: violence and theft in theft workplace. Washington, D.C.: US Department of Justice (NCJ-148.199), 1994.

BELL, C. A. Female homicides in United States workplaces, 1980-1985. American Journal of Public Health, 81:729-732, 1991.

CROW, W. J. \& ERICKSON, R. The Store Safety Issues: facts for the future. Alexandria, VA: National Association of Convenience Stores, 1987.

DAVIS, H.; HONCHAR, P. A. \& SUAREZ, A. L. Fatal occupational injuries of women, Texas 1975-84. American Journal of Public Health, 77:1.524-1.527, 1987.

DAVIS, H. Workplace homicides of Texas males. American Journal of Public Health, 77:1.290-1.293, 1987.

DIETZ, P. E. \& BAKER, S. P. Murder at work. American Journal of Public Health, 77:1.273-1.274, 1987. 
HALES, T. et al. Occupational injuries due to violence. Journal of Occupational Medicine, 30:483-487, 1988.

JENKIS, E. L. et al. Fatal injuries to workers in the United States, 1980-1989: a decade of surveillance. U.S. Department of Health and Human Services (NIOSH). Pub. $n^{\circ}$ 93108S. Cincinnati, Ohio: National Institute for Occupational Safety and Health, 1993.

KRAUS, J. F. Homicide while at work: persons, industries, and occupations at high risk. American Journal of Public Health, 77:1.285-1.289, 1987.

NATIONAL INSTITUTE FOR OCCUPATIONAL SAFETY AND HEALTH (NIOSH). Alert: request for assistance in preventing bomicide in the workplace. (Pub. $\mathrm{n}^{\prime \prime}$ 93109). Cincinnati, Ohio: DHHS/NIOSH, 1993.

PURDY, M. Workplace homicides provoking negligence lawsuits and security. The New York Times, 14 feb. 1994. p. A1. 


\section{TRABALHO MATERNO E \\ NUTRIÇÃO INFANTIL: \\ SITUAÇÃO ATUAL E PERSPECTIVAS}

Luiz Augusto Faccbini

\section{INTRODUÇÃO}

$O$ interesse pela relação entre trabalho materno e bem-estar infantil parece estar em franco crescimento. As agências internacionais - Organização das Nações Unidas (ONU), Organização Mundial da Saúde (OMS) e Fundo das Nações Unidas para a Infância (UNICEF) - e os governos de muitos países têm realizado eventos e divulgado manifestos em que expressam intenções sobre os problemas decorrentes da crescente inserção da mulher no mercado de trabalho e da inadequação dos substitutos maternos no cuidado das crianças pequenas (Himes, Landers \& Leslie, 1992).

Esta questão é particularmente importante para o Terceiro Mundo, onde a gravidade da crise econômica pressiona de modo mais incisivo a participação feminina na força de trabalho, utilizada como importante alternativa familiar no enfrentamento da pobreza tornada crônica. Nesses países, os baixos investimentos sociais e a carência de infra-estrutura para o 
cuidado infantil sobrecarregam as famílias e principalmente as mulheres, que acabam respondendo tanto pelas atividades domésticas quanto pelas econômicas (Torres, 1993).

O objetivo central deste trabalho é situar as particularidades da temática e seus vínculos com as questões genéricas da epidemiologia. $\mathrm{Na}$ apresentação da situação atual do conhecimento sobre a relação trabalho materno e nutrição infantil, discutem-se os aspectos teórico-metodológicos dos estudos revisados, como época, local, amostra, enfoques e grupos sociais estudados. $\mathrm{Na}$ interseção das particularidades da determinação social do problema e das generalidades do método epidemiológico, procuram-se situar algumas perspectivas.

\section{Situação Atual e Perspectivas}

A revisão bibliográfica mostrou a relativa escassez de estudos publicados sobre a relação trabalho materno e nutrição infantil, apesar de sua atualidade e relevância. $\mathrm{Na}$ consulta aos periódicos de maior destaque na área de medicina, saúde pública e epidemiologia e a bases de dados disponíveis via on-line, como a Med-line, não se identificou um estudo sequer sobre a temática nos últimos 15 anos, o que parece evidenciar o caráter restrito de sua divulgação.

Foi possível, apesar disso, através de contatos com o Consultative Group on Early Childhood Care and Development do Fundo das Nações Unidas para a Infância (UNICEF), ter acesso a uma cuidadosa revisão, com mais de setenta referências sobre trabalho materno e bem-estar infantil, feita por Leslie (1989) em fontes bibliográficas alternativas e documentos de periodicidade irregular, livros, brochuras e relatórios de pesquisa, além de periódicos de países do Terceiro Mundo. Dessas referências, selecionamos 25 que, somadas às duas contribuições do Centro de Pesquisas Epidemiológicas do Departamento de Medicina Social da Universidade Federal de Pelotas (Olinto et al., 1993; Facchini, 1995), totalizaram 27 estudos sobre a relação do trabalho materno com o estado nutricional infantil. 


\section{Época, Local, Amostra e Resultados}

Os trabalhos analisados vão desde o início da década de 60 (Wray \& Aguirre, 1969) até meados dos anos 90 (Olinto et al., 1993; Facchini, 1995): um período de mais de trinta anos. Todos os estudos foram realizados em países do Terceiro Mundo, cobrindo vários continentes. Os países mais estudados foram Brasil, Jamaica, Índia, Haiti e Filipinas - com três trabalhos cada um -, seguidos da Colômbia, com dois. Os demais - Bolívia, Chile, Costa Rica, Gana, Guatemala, Indonćsia, Nicarágua, Panamá, Peru c San Vicente tiveram um estudo cada. Oito pesquisas referiam-se ao trabalho feminino na zona rural (Wray \& Aguirre, 1969; Ballweg, 1972; Grewal, Gopaldas \& Gadre, 1973; Rawson \& Valverde, 1976; Kumar, 1977; Popkin, 1983; Tripp, 1981; Shah, Walimbe \& Dhole, 1979), 14 ao trabalho feminino na zona urbana (Olinto et al., 1993; Facchini, 1995; Bailcy, 1981; Adelman, 1983; Bittencourt \& DiCicco, 1979; Greiner \& Latham, 1981; Zeitlan et al., 1978; Franklin, 1979; Powell \& Grantham-McGregor, 1985; Haggerty, 1981; Soekirman, 1985; Moreno-Black, 1983; Tucker \& Sanjur, 1988; Vial, Muchnik \& Mardones, 1986). Em cinco comparavam-se ambas as realidades (Engle, 1986; Popkin \& Solon, 1976; Marchione, 1980; Wolfe \& Behrman, 1982; Smith et al., 1983).

As amostras de 12 estudos eram inferiores a duzentas crianças (Ballweg, 1972; Grewal, Gopaldas \& Gadre, 1973; Rawson \& Valverde, 1976; Kumar, 1977; Tripp, 1981; Shah, Walimbe \& Dhole, 1979; Franklin, 1979; Haggerty, 1981; Moreno-Black, 1983; Tucker \& Sanjur, 1988; Marchione, 1980; Smith et al., 1983); em oito estudos variavam de duzentas a quinhentas crianças (Olinto et al., 1993; Facchini, 1995; Wray \& Aguirre, 1969; Adelman, 1983; Bittencourt \& DiCicco, 1979; Greiner \& Latham, 1981; Powell \& Grantham-McGregor, 1985; Soekirman, 1985) e nos sete restantes eram superiores a quinhentas crianças (Popkin, 1983; Bailey, 1981; Zeitlan ct al., 1978; Vial, Muchnik \& Mardones, 1986; Engle, 1986; Popkin \& Solon, 1976; Wolfe \& Behrman, 1982). Mctade dos trabalhos apresentava amostragem aleatória.

Quase um terço dos estudos observou pior estado nutricional nos filhos de mulheres empregadas, quando comparados às crianças de mães nãoempregadas (Wray \& Aguirre, 1969; Ballweg, 1972; Grewal, Gopaldas \& Gadre, 1973; Rawson \& Valverde, 1976; Shah, Walimbe \& Dhole, 1979; Adelman, 1983; Bittencourt \& DiCicco, 1979; Powell \& Grantham-McGregor, 1985). 
As diferenças no estado nutricional infantil não foram significativas em cerca de 25\% dos estudos (Popkin, 1983; Greiner \& Latham, 1981; Zeitlan et al., 1978; Franklin, 1979; Moreno-Black, 1983; Marchione, 1980; Smith et al., 1983). O efeito positivo (Olinto et al., 1993; Facchini, 1995; Bailey, 1981; Tucker \& Sanjur, 1988; Vial, Muchnik \& Mardones, 1986; Wolfe \& Behrman, 1982) e a modificação do efeito negativo em positivo (Kumar, 1977; Tripp, 1981; Haggerty, 1981; Soekirman, 1985; Engle, 1986; Popkin \& Solon, 1976) foram observados em cerca de $45 \%$ dos estudos. A modificação de efeito esteve na dependência principalmente da idade da criança (Haggerty, 1981; Engle, 1986), da renda familiar e/ou materna (Soekirman, 1985; Popkin \& Solon, 1976) e do tipo de trabalho materno (Kumar, 1977; Tripp, 1981; Soekirman, 1985).

\section{POPULAÇÃO}

Todas as pesquisas referiam-se a populações materno-infantis de baixa renda, vivendo em bairros da periferia urbana ou em vilas rurais. A idade das crianças variou amplamente, embora cerca de $60 \%$ dos estudos tenha enfocado crianças com idade máxima entre 4 e 7 anos. Esta tendência assinala a importância da temática para grupos populacionais muito particulares, os pobres da cidade e do campo, agricultores, operários e marginalizados sociais. Em função disso, estima-se que os futuros estudos continuarão privilegiando esse grupo sociodemográfico.

A seleção de grupos de comparação similares quanto a categorias-chave na determinação da nutrição infantil - como inserção de classe e idade das crianças (Victora, Barros \& Vaughan, 1988) - também ajuda a entender os contornos da opção materna pelo trabalho remunerado fora de casa e o seu impacto na nutrição infantil. Esse recorte favorece a sistematização das estratégias familiares de que a classe lança mão para garantir melhores condições de reprodução social. A restrição dos sujeitos elegíveis garante, ainda, melhor delimitação do objeto do estudo, tornando mais factível sua investigação (Kleinbaum, Kupper \& Morgenstern, 1982). 


\section{PRINCIPAis ENFodues}

Em termos gerais, identificaram-se duas abordagens mais correntes sobre o trabalho materno. Nos estudos da área de planejamento familiar, saúde e nutrição, houve certa ênfase na abordagem do trabalho materno na perspectiva da chamada 'nova economia doméstica'. Este enfoque valoriza mais o papel feminino na reprodução, ou seja, a mulher como mãe num sentido mais restrito, ligado à dedicação materna exclusiva ou quase aos cuidados infantis c familiares. Esses estudos tenderam a apresentar uma sociedade sem conflitos, fundada numa repartição equilibrada entre os gêneros e os membros do grupo familiar, cujos papéis, tarefas e espaços seriam mais complementares do que concorrentes. $\mathrm{O}$ enfoque considera a família um núcleo estável, imutável, protetor, altruísta, acima das formas mais instrumentais e políticas da sociedade. Nesta perspectiva, os membros do domicílio compartem as mesmas prioridades no uso dos recursos e do tempo no domicílio, havendo concordância consensual na distribuição da renda familiar e na alocação do tempo. A tomada de decisão no domicílio resultaria da simples combinação de vantagens para seus membros (Leslie, 1989; Pcrrot, 1988).

Boa parte dos estudos que utilizaram esse enfoque foi realizada entre fins da década de 70 e início da década de 80 e cnfatizou a maternidade como o papel feminino primordial, justificando, assim, a divisão sexual do trabalho na família e o efeito negativo do trabalho materno remunerado na nutrição infantil (Wray \& Aguirre, 1969; Grewal, Gopaldas \& Gadre, 1973; Popkin, 1983; Greiner \& Latham, 1981; Popkin \& Solon, 1976). Estes estudos enfocam, predominantemente, o balanço entre renda e tempo na tomada de decisão familiar. Geralmente ressaltam a esperada diminuição do tempo materno de cuidado dos filhos, em função de sua inserção no trabalho remuncrado. Popkin (1983), por exemplo, em um estudo em Laguna, nas Filipinas, registrou que os irmãos aumentavam seu tempo de cuidado infantil quando as mães trabalhavam, mas não o suficiente para compensar o efeito negativo da ausência materna. Os pais não aumentavam seu tempo de cuidado infantil, c a participação de avós, tias c vizinhas não foi discutida.

Principalmente a partir da década de 80 , foram realizados vários estudos que criticavam as interpretações da 'nova cconomia doméstica'. Os estudos com este enfoque crítico (Facchini, 1995; Tucker \& Sanjur, 1988; Vial, Muchnik \& 
Mardones, 1986; Engle, 1986; Wolfe \& Behrman, 1982) realçam o papel feminino na produção, ou seja, a mulher como agente social capaz de cartear recursos financeiros para a família de modo tão eficiente quanto o homem. $\mathrm{O}$ enfoque afirma que, na família, muitas vezes ocorrem padrões de desigualdade no uso dos recursos. Evidencia também que a desigualdade de direitos e obrigações na família está relacionada, dentre outros aspectos, à forma como os membros participam da constituição da renda familiar e às diferentes obrigações de homens e mulheres, dentro e fora do domicílio. Igualmente destaca que a decisão familiar sobre o uso dos recursos depende fortemente do poder econômico de barganha de cada um dos membros do domicílio. Revela que de modo crescente as mulheres têm assumido parcial ou totalmente a responsabilidade pelo sustento dos filhos e/ou de toda a família, o que, além da sobrecarga que acarreta, tem permitido maior participação materna nas decisões familiares.

Como contraponto ao enfoque da 'nova economia doméstica', os estudos com a abordagem crítica tenderam a reforçar um possível efeito protetor do trabalho materno remunerado na nutrição infantil. Tucker \& Sanjur (1988) ressaltam que crianças com mães empregadas tendem a ter ingesta dietética e níveis de hemoglobina aumentados e não diferem significativamente quanto às medidas antropométricas das crianças de mães donas de casa. Para as autoras, o esperado efeito negativo da menor presença materna no cuidado dos filhos e do domicílio não aparece quando os substitutos compensam adequadamente esse tempo. Neste caso, a renda do trabalho materno passaria a assumir uma importância-chave na relação com a nutrição infantil. Além disso, destacam que o trabalho expõe as mães a novas idéias e experiências, que aumentam sua habilidade para processar as informações. A mãe com essa diferenciação teria maior possibilidade de manter o emprego e obter maior salário. Nesta perspectiva, o aumento das oportunidades para as mulheres - tanto em termos de emprego e renda quanto em termos de educação e desenvolvimento pessoal - beneficiaria não apenas a mulher, mas também a criança. 


\section{Modelo Teórico}

A intrincada relação entre os diferentes aspectos da vida social, familiar e individual costuma dificultar a visão dos determinantes da nutrição infantil. Este problema esteve bem presente em boa parte dos estudos, principalmente nos mais antigos, que exploravam a relação entre trabalho materno e nutrição infantil de modo menos complexo. Autores que avaliaram mais cuidadosamente a literatura desta área têm sugerido que o efeito geral do trabalho materno na nutrição infantil pode ser mais bem entendido se variáveis secundárias ou intermediárias forem cada vez mais caracterizadas e de forma melhor (Himes, Landers \& Leslie, 1992; Leslie, 1989). Isto indica que a concepção global de mães trabalhadoras deve ser mais bem delimitada, especialmente quanto a aspectos mais específicos dos padrões de vida familiar e da inserção produtiva materna (Torres, 1993). A caracterização de importantes variáveis socioeconômicas e familiares, desconsideradas na maioria das pesquisas anteriores, atende a esse preceito.

Variáveis intermediárias, que dependem em boa parte do tipo de trabalho materno - como a participação da mãe na administração de alimento à criança, a disponibilidade de bens eletrodomésticos e de sanitário no domicilio e o estado nutricional infantil no início do estudo - também deverão ser mais bem caracterizadas. Nesta relação de variáveis intermediárias, também é importante lembrar outros processos, como por exemplo a rede de apoio familiar e extrafamiliar formada por parentes, vizinhos e amigos; a composição da renda familiar, incluindo recursos não-monetários; a participação materna na estrutura do gasto familiar; os gastos com alimentação, cuidados infantis, aquisição de bens; o tempo dedicado ao cuidado dos filhos e a qualidade do cuidado; a participação materna nas decisões da vida familiar e na qualidade das relações intrafamiliares. Também é recomendável explorar melhor a relação do trabalho materno e da nutrição infantil com variáveis como, por exemplo, tipo de família; renda familiar e materna; idade, escolaridade e estado civil maternos; chefia da família; morbidade materna e infantil e problemas familiares.

Desvendar essa rede, caracterizando-a, ainda que de modo parcial, possivelmente será uma das ênfases dos novos estudos. Nesta perspectiva, a elaboração de modelos teóricos, como o da Figura 1 (Facchini, 1995), deverá ter destaque crescente dentre os procedimentos utilizados para demonstrar a ar- 
ticulação entre processos selecionados e a nutrição infantil. Ainda assim, um modelo não deve ser entendido como uma estrutura fechada, acabada, tampouco como a agregação irracional de variáveis. É apenas um esforço para mudar o ponto de observação do epidemiologista, considerando as relações entre processos sociais não sob a ótica exclusiva da biologia ou da estatística, mas também a partir da lógica e do controle das ciências sociais.

FIGURA 1 - Trabalho materno e nutrição infantil: modelo teórico

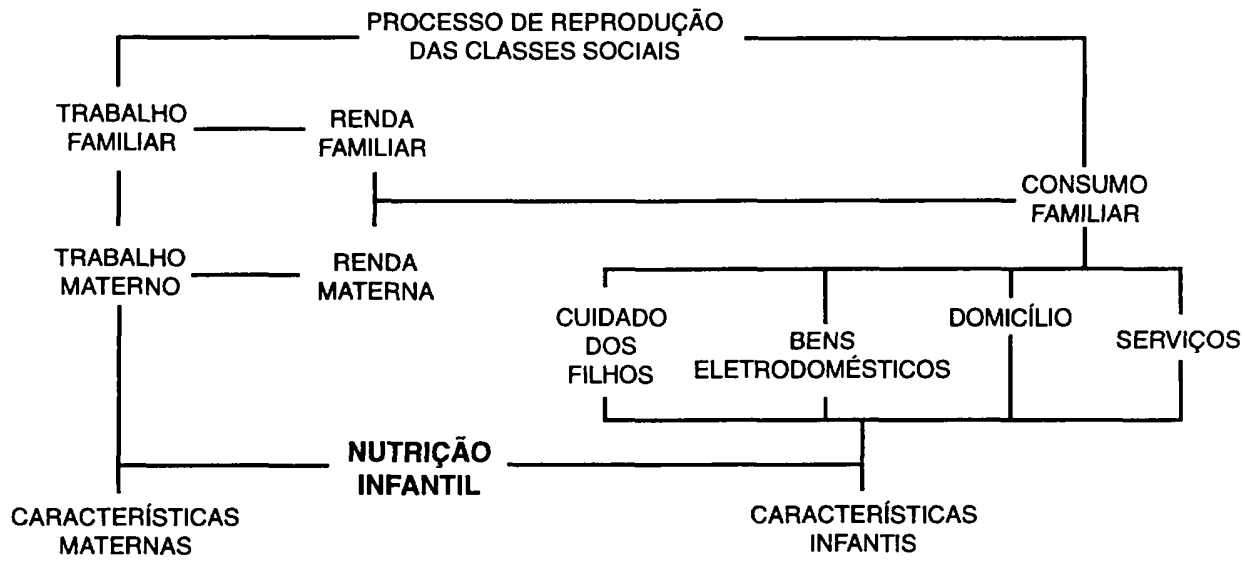

\section{METODOLOGIA}

A preocupação com a validade das medidas, evidenciada pelo maior rigor nos aspectos metodológicos e logísticos, mostrou-se uma tendência mais marcante nos estudos realizados nos últimos 15 anos (Olinto et al., 1993; Facchini, 1995; Tucker \& Sanjur, 1988; Vial, Muchnik \& Mardones, 1986; Engle, 1986). O treinamento dos auxiliares de pesquisa para a coleta de dados destaca-se como um aspecto a ser enfatizado pelos futuros estudos, visando à melhoria da validade das medidas. O exame das falhas metodológicas mais importantes dos estudos também deverá ser enfatizado nas futuras investigações sobre trabalho materno e nutrição infantil. 
Como o 'enviesamento' das medidas pode se manifestar mesmo com esses cuidados, a análise dos dados também será cada vez mais estratégica para a avaliação desse problema. Por exemplo: evidências de comportamento coerente dos tradicionais indicadores de estado nutricional - peso/idade, altura/idade e ganho de peso, medidos simultaneamente - em relação ao trabalho materno podem reforçar a validade das medidas estudadas, da mesma maneira que semelhanças com os achados de outros autores que estudaram as mesmas populações e/ou locais (Facchini, 1995).

\section{Delinenmento}

A grande maioria dos delineamentos foi de tipo transversal, havendo apenas quatro estudos longitudinais (Facchini, 1995; Bailey, 1981; Vial, Muchnik \& Mardones, 1986; Engle, 1986) e dois de tipo etnográfico (Grewal, Gopaldas \& Gadre, 1973; Rawson \& Valverde, 1976). Porém, o delineamento transversal não garante a anterioridade do trabalho materno em relação à nutrição infantil. Neste sentido, os estudos de coorte são vantajosos, pois proporcionam precisão no estabelecimento cronológico da exposição e de seu efeito (Leslie, 1989), superando o problema da causalidade reversa, muito freqüente nos estudos transversais (Rothman, 1986).

Entretanto, os custos e as dificuldades no acompanhamento da população por longos períodos são desvantagens importantes dos estudos longitudinais. Ainda assim, durante os priméiros seis anos de vida, o ganho e o déficit de peso para a idade revelam-se indicadores muito sensiveis da variabilidade do estado nutricional infantil (Facchini, 1995), mesmo em períodos curtos. Assim, coortes seguidas por aproximadamente seis meses poderão ser efetivas na observação do impacto do trabalho materno remunerado na nutrição infantil.

Por outro lado, as restrições do espaço social (bairros) e do período de acompanhamento, geralmente feitas por conveniência de amostragem e logística, também reduzem os custos do estudo e contribuem para a exeqüibilidade da seleção e da observação da coorte (Kleinbaum, Kupper \& Morgenstern, 1982). 


\section{Definiçño do Trabalho Materno}

A definição de trabalho materno é um dos aspectos mais cruciais dessa temática, pois se feita inadequadamente pode impedir a observação de diferenças e tendências entre grupos. Em $76 \%$ dos estudos, as mães foram categorizadas apenas em empregadas e não-empregadas. Em cerca de $40 \%$ dos estudos, também foi caracterizado o tempo materno dispendido com o trabalho remunerado. A subcategorização do trabalho materno remunerado foi enfocada por cerca de $30 \%$ dos estudos, enquanto apenas $16 \%$ das investigações avaliaram diferenças salariais e/ou da renda materna.

Uma caracterização mais complexa da inserção materna no trabalho remunerado e de suas atividades domésticas é extremamente importante para os futuros estudos. A constituição de três ou mais grupos de comparação também pode ser vantajosa, seja revelando um efeito dose-resposta, seja melhorando a capacidade de amostragem em apontar tendências estatisticamente significativas (Facchini, 1995).

\section{Avaliaçño do Estado Nutricional}

A grande maioria avaliou o estado nutricional infantil com medidas antropométricas ou dietéticas adequadas e referidas a padrões internacionais reconhecidos. Os déficits de peso para a idade e altura para a idade foram os indicadores nutricionais mais investigados, respectivamente em $76 \%$ e $40 \%$ dos estudos. Embora tenham sido identificados apenas dois estudos sobre ganho de peso (Facchini, 1995; Vial, Muchnik \& Mardones, 1986), futuros estudos deveriam utilizar mais este indicador, tanto pela relativa facilidade em sua obtenção quanto pela sua grande sensibilidade para evidenciar mudanças a curto prazo no estado nutricional infantil.

Aparentemente, a nutrição indica apenas uma dimensão física do desenvolvimento infantil, que possui importantes dimensões psicossociais e culturais. Entretanto, seu alcance poderá ser mais adequadamente apreciado relacionando-a a indicadores de desenvolvimento propriamente ditos, mas também com a morbidade comum, o uso de serviços da saúde e a cobertura vacinal. 


\section{Método de AnÁlise e Controle de Fatores de Confusão}

Considerando o período relativamente longo do levantamento bibliográfico, os métodos de análise utilizados mostraram um contraste marcante, identificando-se desde a simples descrição dos resultados até as mais sofisticadas técnicas estatísticas de regressão multivariada. Nove estudos exploraram a relação entre trabalho materno e nutrição infantil através de análise bivariada (Wray \& Aguirre, 1969; Ballweg, 1972; Grewal, Gopaldas \& Gadre, 1973; Rawson \& Valverde, 1976; Tripp, 1981; Shah, Walimbe \& Dhole, 1979; Bittencourt \& DiCicco, 1979; Haggerty, 1981; Moreno-Black, 1983), enquanto os 18 restantes o fizeram mediante análise multivariada. $O$ controle dos fatores de confusão foi um aspecto problemático em muitos estudos, embora cerca de $60 \%$ das investigações tenham adotado procedimentos com essa finalidade.

Os problemas relacionados aos métodos de análise dos dados são especialmente relevantes na discussão desta temática e podem ser ilustrados pelo estudo de Popkin (1983) nas Filipinas. Inicialmente, através de análise bivariada, ele identificou um efeito negativo do trabalho materno remunerado na nutrição infantil. Posteriormente, através da análise multivariada do mesmo banco de dados, observou uma modificação marcante de seus achados. Estas duas situações demonstram claramente tanto a complexidade da relação entre trabalho materno remunerado e nutrição infantil quanto o fato de que diferentes conclusões podem ser estabelecidas dos mesmos dados, dependendo do método de análise que se utilize.

Portanto, os futuros estudos precisarão tratar claramente desta questão. O aumento no número de variáveis estudadas pode ser uma estratégia importante no sentido de captar detalhes importantes da população sob estudo. Uma análise bivariada rigorosa, que explore a associação do trabalho materno e da nutrição infantil com cada uma das demais variáveis coletadas, também é essencial para a identificação de fatores de confusão. Da mesma forma, a seleção de maior número de variáveis para a análise multivariada, utilizando-se articuladamente um critério de associação mais amplo $(p<0,1)$ e um modelo de análise teoricamente embasado.

Estes procedimentos, aliados às restrições praticadas na seleção da população, deverão permitir um controle bastante efetivo dos fatores de confusão, 
reforçando a certeza de que as diferenças encontradas na nutrição infantil não são fruto de diferenças nos grupos de comparação, mas do efeito do trabalho materno remunerado. As restrições praticadas quanto à população, ao lugar e ao tempo deverão melhorar a comparabilidade dos grupos e a eficiência estatística dos testes selecionados (Kleinbaum, Kupper \& Morgenstern, 1982).

\section{Discutindo a Causalidade}

Os estudos publicados parecem revelar uma controvérsia importante a respeito do efeito do trabalho materno remunerado nas condições nutricionais das crianças. Autores que revisaram amiúde esta temática (Himes, Landers \& Leslie, 1992; Leslie, 1989) enfatizam vários problemas metodológicos que podem ter determinado boa parte das diferenças entre os achados. Entre os aspectos problemáticos, destacam-se as inadequações no tamanho das amostras, nos métodos de análise estatística e no controle de fatores de confusão, além da grande variedade de definições utilizadas para caracterizar o trabalho materno, mais do que a nutrição infantil. Em cerca de $50 \%$ dos estudos as amostras eram pequenas, com menos de duzentas crianças, dificultando a observação de diferenças significativas entre os grupos de comparação. Cerca de um terço dos estudos utilizou análise bivariada simples, e praticamente a metade das investigações não controlou adequadamente importantes fatores de confusão, tais como a idade das crianças, a idade de quem cuida delas, o tipo e o tempo de trabalho doméstico. O predomínio na categorização do trabalho materno em empregadas versus não-empregadas também evidencia marcante reducionismo na caracterização do problema e uma visão compartimentada dos papéis femininos e especialmente maternos.

As possibilidades de ambos os efeitos, negativo e positivo, do trabalho materno sobre as condições de saúde e nutrição infantis também são levantadas na explicação da inconsistência dos achados. Devido a suas altas necessidades nutricionais, decorrentes da combinação de efeitos do rápido crescimento e da alta prevalência de doenças infecciosas, bem como de sua incapacidade em consumir grandes quantidades de alimentos em uma única vez, as crianças, especialmente menores de seis anos de idade, necessitam freqüentemente de alimentos densos em nutrientes. As mães que não trabalham fora de 
casa podem ser mais capazes de assegurar refeições mais constantes aos filhos, mas as que trabalham remuneradamente podem ser mais capazes de produzir ou comprar alimentos mais caros, como óleos, legumes e produtos animais, proporcionar dietas mais ricas em proteínas e energia aos filhos (Himes, Landers \& Leslic, 1992) c, assim, melhorar-lhes a nutrição.

Apesar da complexidade do tema e dos conflitos entre os achados bibliográficos, os estudos que encontraram um efeito negativo do trabalho materno na nutrição infantil não permitem uma razoável confiança em sua generalização (Himes, Landers \& Leslie, 1992) para realidades urbanas industrializadas, pois referem-se principalmente a populações rurais e ao trabalho na agricultura. Além disso, são os mais antigos - realizados principalmente no transcurso dos anos $70-$, com maiores problemas metodológicos e sem o controle de uma série de importantes fatores de confusão (Leslie, 1989).

Também é preciso levar em conta a possibilidade de uma efetiva modificação do efeito ao longo do tempo. Na última década, verificaram-se grandes mudanças político-culturais em quase todo o mundo, com reflexos importantes na estrutura familiar e no mercado de trabalho, aliadas à persistência da crise econômica, ao achatamento da renda familiar da classe operária c ao alto preço dos alimentos (Himes, Landers \& Leslie, 1992; Leslie, 1989). Nos últimos trinta anos, também observou-se o incremento das tendências internacionais de aumento da urbanização, diminuição do tamanho da família, ampliação dos espaços sociais ocupados pelas mulheres e disponibilidade de serviços de apoio ao cuidado infantil como creches e pré-escolas. Estas condições parecem haver pressionado fortemente a mudança histórica do efeito do trabalho materno na nutrição infantil, pois a participação materna no orçamento familiar aumentou substancialmente nos últimos anos, passando a proporção de mulheres na força de trabalho paga dos países subdesenvolvidos de $28 \%$, em 1950, a $32 \%$, em 1985, e a $39 \%$, em 1991 (Torres, 1993; Sivard, 1987).

Nos estudos realizados nos últimos 15 anos em populações urbanas, a controvérsia e a dualidade do efeito cederam lugar a evidências de uma associação positiva e extremamente significativa entre trabalho materno remunerado e nutrição infantil e de uma melhoria desta última com o aumento da inserção materna no mercado de trabalho (efeito dose-resposta). Nesta perspectiva, mesmo com a contribuição materna para a nutrição 
infantil ocorrendo através da combinação dos efeitos da participação materna nos cuidados infantis e no trabalho remunerado, a preponderância foi deste último processo.

\section{Determinantes Básicos da Nutrição Infantil}

O mercado de trabalho reflete a vitalidade econômica do aparelho produtivo da sociedade capitalista. Quando há mais emprego, há mais desenvolvimento social, familiar e individual, existindo melhores condições de vida e de saúde. Assim, a reprodução social de uma dada formação, ao mesmo tempo que é dinamizada pela atividade produtiva, retroalimenta esta última, garantindo maior consumo, maior demanda de bens e serviços. Foi justamente num momento de maior oferta de empregos femininos (Facchini, 1995) que se observou um poderoso efeito do trabalho materno remunerado na nutrição infantil. Neste estudo, o trabalho materno remunerado destacou-se como o mais forte determinante de um aspecto essencial da sobrevivência infantil: o estado nutricional (Facchini, 1995).

Para entender melhor esta determinação, parece importante detalhar as análises sobre o impacto da renda familiar na nutrição infantil, considerando os processos de alocação de recursos no domicílio segundo o gênero do provedor. Neste caso, seria desejável detalhar as prioridades no gasto familiar, especificando o gênero dos contribuintes do orçamento doméstico e os graus de influência ou controle de diferentes aspectos da tomada de decisão segundo o sexo.

O detalhamento de aspectos relacionados à dieta e à ingesta alimentar infantis são igualmente prioritários para melhor conhecimento dos processos articulados em torno da relação trabalho materno versus nutrição infantil. De acordo com as recomendações de vários autores (Himes, Landers \& Leslie, 1992; Leslie, 1989; Olinto et al., 1993; Hawes \& Scotchmer, 1993), deve ser dado especial destaque à identificação da qualidade e da quantidade dos alimentos ingeridos pelas crianças e, assim, para os déficits em nutrientes.

Análises particularizadas sobre idade da criança (Haggerty, 1981; Engle, 1986), renda familiar e materna (Kumar, 1977; Soekirman, 1985; Popkin, 1976) 
e tipo de trabalho materno (Kumar, 1977; Tripp, 1981) também são essenciais, pois estas variáveis podem confundir ou modificar o efeito do trabalho materno. Em dois estudos (Haggerty, 1981; Engle, 1986), o estado nutricional dos filhos de mulheres empregadas era pior do que o das crianças de mulheres não-empregadas até um ano de idade e melhor após essa idade. Além disso, a idade do substituto materno no cuidado infantil, o tipo de família, o tipo de ocupação materna è o tempo de trabalho ou a duração da jornada também mostraram mudanças no efeito do trabalho materno na nutrição infantil. A idade da criança é essencial, não só porque as mais velhas facilitam a liberação materna para o trabalho remunerado, mas também porque as mais jovens ganham peso mais rapidamente.

$\mathrm{Na}$ ausência de uma retaguarda de serviços, especialmente públicos, a participação nos cuidados infantis de filhos mais velhos, pais e avós, dentre outros, revela-se fundamental, não só na melhor distribuição da carga de trabalho domiciliar entre os membros da família, mas também na liberação materna para a realização de atividades remuneradas que garantam melhor padrão de reprodução familiar. Assim, as famílias maiores podem representar uma facilidade na liberação materna para o mercado de trabalho, uma vez que os irmãos mais velhos, avós e parentes, vivendo na mesma casa ou no mesmo bairro, poderão participar dos cuidados infantis.

Familias maiores, entretanto, necessitam de mais recursos para satisfazer as necessidades básicas. Alguns autores situam, nesta encruzilhada, as razões da ocorrência de maiores taxas de pobreza entre crianças do que entre adultos (Perrot, 1988). Esta situação parece não depender do mecanismo mais direto - pais mais pobres tendo mais filhos -, mas decorrente da menor participação materna no trabalho remunerado e da maior demanda de gastos determinadas por maior número de crianças pequenas no domicílio, que resultaria na redução da renda familiar e, assim, no aumento da pobreza.

Por outro lado, a inserção materna no trabalho remunerado é maior entre as mulheres vivendo sem companheiro (solteiras ou separadas), justamente quando é pequena ou nula a participação dos pais no esquema familiar de cuidado dos filhos (Facchini, 1995). O efeito próprio dessas variáveis poderá ser mais bem investigado em estudos com amostras maiores e mais heterogêneas.

Devido a sua escassez, os serviços de apoio ao cuidado dos filhos precisam ser garantidos através de uma ação objetiva do Estado e do empresariado. 
Os sindicatos de trabalhadores devem incrementar a luta por esse direito e os maridos precisam participar mais efetivamente da criação dos filhos, compartindo mais com suas esposas as tarefas cotidianas. Caso contrário, a contradição das mulheres frente às demandas econômicas crescentes e a falta de alternativas no cuidado dos filhos irá aumentar, sobrecarregando-as ainda mais e promovendo o mal-estar de mães e filhos.

A infra-estrutura da família também mostrou-se como eixo fundamental, através do qual se processa o efeito do trabalho materno, com especial destaque para qualidade do bairro, disponibilidade domiciliar de água encana$\mathrm{da}$, sanitário e chuveiro e bens eletrodomésticos, principalmente aqueles relacionados à conservação e à preparação dos alimentos, como por exemplo geladeira e liquidificador. Acumulados ao longo do tempo, esses recursos apareceram como uma reserva ou poupança familiar capaz de garantir melhores condições de reprodução. $\mathrm{Na}$ classe operária, o número de adultos empregados na família é a base dessa acumulação.

Sabe-se que água encanada e equipamentos como, por exemplo, chuveiro elétrico e sanitário com descarga melhoram as condições de higiene familiar e infantil, diminuindo a ocorrência de diarréia e infecções e, assim, potencializando a nutrição infantil (Facchini, 1995). Estudos com amostras maiores poderão detalhar as relações dessas condições de conforto com a vulnerabilidade infantil à desnutrição. Neste caso, o dimensionamento da miséria e da desnutrição infantil poderia ser estimado, em termos nacionais e regionais, a partir de dados secundários, como os produzidos pela Pesquisa Nacional de Amostras Domiciliares (PNAD/IBGE) e dados coletados pelos serviços da saúde comunitária. Em outra perspectiva, os marcadores de conforto e nutrição poderiam ser utilizados no estabelecimento de ações prioritárias de promoção da saúde, a serem encaminhadas nos níveis municipal, estadual e federal. 


\section{CONCLUSÃO}

As inconsistências dos achados sobre a relação entre trabalho materno e nutrição infantil são atribuídas fundamentalmente às diferenças entre os estudos, principalmente quanto a definição e mensuração do trabalho materno, delineamento, variáveis estudadas e controladas, análise estatística e enfoque teórico (Leslie, 1989; Facchini, 1995; Tucker \& Sanjur, 1988).

A organização cronológica dos estudos revisados revelou, no entanto, certo movimento lógico, uma aparente tendência histórica nos achados. Nos trabalhos mais antigos, observou-se um predomínio do efeito negativo do trabalho materno remunerado na saúde e na nutrição infantis. No período intermediário, os estudos mostraram maior variabilidade, boa parte deles não evidenciando diferenças estatisticamente significativas, enquanto as pesquisas mais recentes já revelam clara tendência em direção a um efeito positivo do trabalho materno remunerado na nutrição das crianças.

A possível modificação do efeito do trabalho materno na nutrição infantil seria fruto das transformações nos padrões de reprodução familiar e de classe observadas nos últimos trinta anos nas diferentes sociedades. Embora os dados dos diferentes estudos não sejam diretamente comparáveis, são úteis para mostrar uma certa inversão de tendências históricas. Aquilo que era negativo passa a ser positivo para a saúde e principalmente para a nutrição infantil. Ou seja, com o tempo, parece que o efeito positivo do cuidado da criança pela mãe deixa de se sobrepor ao do trabalho materno remunerado, que ganha importância.

A realização de novas pesquisas, levando em conta os aspectos teóricometodológicos salientados, poderá confirmar esta tese. Para um exame mais completo deste objeto de conhecimento, seria desejável articular estudos quantitativos, sofisticados em termos de análise estatística, com estudos qualitativos, capazes de revelar a contribuição dos aspectos culturais na conformação das desigualdades no crescimento e no desenvolvimento infantis. Numa perspectiva interdisciplinar, seria vantajoso combinar a contribuição de especialistas das mais diversas áreas, como por exemplo economia, medicina, nutrição, antropologia e epidemiologia.

Para a incorporação deste conhecimento à cidadania, também é necessário que a população estude e discuta a questão, identificando estratégias 
sociais de diminuição dos custos do cuidado infantil e de liberação das mães para o trabalho remunerado. Com isso, o encaminhamento e o apoio de politicas públicas destinadas a esta problemática poderão ser mais eficazes.

\section{REFERÊNCIAS BiBLIOGRÁFICAS}

ADELMAN, C. An Analysis of the Effect of Maternal Care and Other Factors Affecting the Growth of Poor Cbildren in Lima, Peru, 1983. Thesis. Baltimore: Johns Hopkins University, School for Hygiene and Public Health.

BAILEY, W. Clinical undernutrition in the Kingston/St. Andrew metropolitan area: 1967-1976. Sociology Science Medical, 15:471-477, 1981.

BALLWEG, J. Family characteristics and nutrition problems of preschool children in Fond Parisien, Haiti. Environmental Cbild Health, 18:230-243, 1972.

BITTENCOURT, S. \& DICICCO, E. Child Care Needs of Low Income Women: urban Brazil. Washington, D.C.: Overseas Education Fund. of the League of Women Voters, 1979.

ENGLE, P. Child Care Strategies of Working and Non-Working Women in Rural and Urban Guatemala. Paper presented at the American Association for the Advancement of Science Meetings. Philadelphia, Pennsylvania, 1986.

FACCHINI, L. A. Trabalbo Materno e Ganbo de Peso Infantil. Pelotas: Editora Universitária, 1995.

FRANKLIN, D. L. Malnutrition and poverty: the role of mother's time and abilities. Paper prepared for the Research Triangle Institute, Economic Department (processed), 1979.

GREINER, T. \& LATHAM, M. C. Factors associated with nutritional status among young children in St. Vincent. Ecology of Food and Nutrition, 10:135-141, 1981.

GREWAL, T.; GOPALDAS, T. \& GADRE, V. J. Etiology of malnutrition in rural Indian preschool children (Madhya Pradesh). Environmental Child Health, 19:265-270, 1973.

HAGGERTY, P. A. Women's Work and Child Nutrition in Haiti. Thesis. Boston: Massachusetts Institute of Technology, 1981. 
HAWES, H. \& SCOTCHMER, C. (Ed.) Children for Health. Londres: Child-to-Child Trust, 1993.

HIMES, J. R.; LANDERS, C. \& LESLIE, J. Women, work and child care. In: INNOCENTI GLOBAL SEMINAR. Summary Report. Florença: Unicef, 1992.

KLEINBAUM, D. G.; KUPPER, L. L. \& MORGENSTERN, H. Epidemiologic Researcb: principles and quantitative methods. Nova York: Lifetime Learning Publ., 1982.

KUMAR, S. K. Role of the Housebold Economy in Determining Child Nutrition at Low Income Levels: a case study in Kerala. Ithaca, Nova York: Cornell University, Department of Agricultural Economics, Occasional Papers n" 95, 1977.

LESLIE, J. Women's work and child nutrition in the third world. In: LESLIE, J. \& PAOLISSO, M. (Ed.) Women, Work, and Child Welfare in the Third World. Colorado: Westview Press, 1989.

MARCHIONE, T. J. Factors associated with malnutrition in the children of western Jamaica. In: JEROME, N. W.; KANDEI,, R. F. \& PELTO, G. H. (Ed.) Nutritional Anthropology: contemporary approaches to diet and culture. Pleasantville, Nova York: Redgrave Publ. Co., 1980.

MORENO-BLACK, G. Dietary status and dietary diversity of native highland Bolivian children. Ecology of Food and Nutrition, 13:149-156, 1983.

OLINTO, M. T. A. et al. Determinantes da desnutrição infantil em uma população de baixa renda: um modelo de análise hierarquizado. Cadernos de Saúde Pública, 9 (sup.1):14-27, 1993

PERROT, M. Os Excluídos da História. São Paulo: Paz e Terra, 1988.

POPKIN, B. M. Rural women, work and child welfare in the Philippines. In: BUVINIC, M.; LYCETTE, M. \& MCGEEVEY, W. P. (Ed.) Women and Poverty in the Third World. Baltimore: Johns Hopkins University Press, 1983.

POPKIN, B. M. \& SOI.ON, F. S. Income, time, the working mother and child nutrition. Environment al Cbild Health, 22:156-166, 1976.

POWELL, C. A. \&'GRANTHAM-MCGREGOR, S. The ecology of nutritional status and development in young children in Kingston, Jamaica. American Journal Clinical Nutrition, 41:1.322-1.331, 1985.

RAWSON, I. G. \& VALVERDE, V. The etiology of malnutrition among preschool children in rural Costa Rica. Environmental Child Health, 22:12-17, 1976.

ROTHMAN, K. J. Modern Epidemiology. Boston: Little, Brown, 1986. 
SHAH, P. M.; WALIMBE, S. R. \& DHOLE, V. S. Wage-earning mothers, motherssubstitutes and care of the young children in rural Maharashtra. Indian Pediatrics, 16:167173, 1979.

SIVARD, R. L. Women: a world survey. Washington: World Priorities, 1987.

SMITH,. M. F. et al. Socioeconomic, education and health factors influencing growth of rural Haitian children. Ecology of Food and Nutrition, 13:99-108, 1983.

SOEKIRMAN. Women's Work and its Effect on Infants' Nutritional Status in Central Java, Indonesia. Paper presented at the $13^{\text {th }}$ International Congress of Nutrition. Brighton, England, 1985.

TORRES, S. Mulher chefia 20\% das casas do País. Folla de S. Paulo. 26 ago. 1993. Cotidiano: Terceiro Caderno, 3-1.

TRIPP, R. B. Farmers and traders: some economic determinants of nutritional status in Northern Ghana. Journal Tropical Pediatrics, 27:15-22, 1981.

TUCKER, K. \& SANJUR, D. Maternal employment and child nutrition in Panama. Sociology Science Medical, 26(6):605-612, 1988.

VIAL, I. V.; MUCHNIK, E. R. \& MARDONES, F. S. Women's Market Work, Infant Feeding and Infant Nutrition in a Low Income Urban Setting. Santiago: Institute of Nutrition and Food Technology, 1986.

VICTORA, C. G.; BARROS, F. C. \& VAUGHAN, J. P. Epidemiologia da Desigualdade. São Paulo: Hucitec, 1988.

WOLFE, B. L. \& BEHRMAN, J. R. Determinants of child mortality, health and nutrition in a developing country. Journal of Development Economics, 11:163-194, 1982.

WRAY, J. D. \& AGUIRRE, A. Protein-calorie malnutrition in Candelaria, Colombia: I. Prevalence, social and demographic causal factors. Journal of Tropical Pediatrics, 15:76-98, 1969.

ZEITLAN, M. et al. Breast feeding and nutritional status in depressed urban areas of greater Manila, Philippines. Ecology of Food and Nutrition, 7:103-113, 1978. 


\section{MORTALIDADE POR HOMICÍDIOS NA \\ DÉCADA DE 80: BRASIL E CAPITAIS \\ DE REGIÕES METROPOLITANAS}

Edinilsa Ramos de Souza

\section{INTRODUÇÃO}

A década de 80 apresentou-se para o Brasil como um período histórico no qual ocorreram várias transformações socioeconômicas e políticas. Em termos da saúde pública, obscrvou-se a intensificação das mortes por causas externas de lesões e envenenamentos ou, simplesmente, causas violentas (grupo constituído por todos os acidentes, inclusive os de trânsito, suicídios, homicídios e outras violências, sob os códigos E800 a E999 do capítulo XVII da Classificação Internacional de Doenças - nona revisão - (CID-9). Entre o início e o final da década, essas causas assumiram importância crescente, passando de quarto para segundo lugar na mortalidade geral do País. Em 1989, as mortes violentas perdem apenas para as doenças do aparelho circulatório (Minayo \& Souza, 1993).

O perfil da mortalidade por violência, no Brasil dos anos 80 , esteve basicamente composto pela violência no trânsito e pelos homicídios (Souza \& 
Minayo, 1995). Estes últimos foram os grandes vilões e principais responsáveis pelo maior impacto da violência na mortalidade da população brasileira.

Com expressões e significados bastante importantes, variados e controversos, o estudo dos homicídios apenas recentemente veio a ser contemplado pela saúde pública em nosso país. Lim nível mundial, os crescentes índices de homicídios fizcram com que essa problemática passasse a ser encarada como prioritária, assumindo características de pandemia (Edelman \& Satcher, 1993).

A preocupação de estudiosos como Agudelo (1989), Yunes (1993) e Minayo (1994) está, hoje, explicitada na elaboração de um Plano de Ação Regional (OPS, 1994), desencadeado pela Organização Pan-Americana da Saúde (OPS), que propõe conhecer e atuar sobre as causas da violência, buscando eliminá-las.

O precário conhecimento sobre os homicídios dificulta as políticas e as ações preventivas. Sabe-se que a maioria deles envolve o uso de armas de fogo c incide em grupos sociais cujo perfil socioeconômico é menos privilegiado do que o encontrado em outras causas violentas (Mello Jorge, 1988). Entretanto, a real prevalência é desconhecida e existem falhas consideráveis nas informações sobre incidência. Os dados não são fidedignos o suficiente para informar sobre o tipo de arma de fogo utilizada, as circunstâncias do evento, os agressores e outros fatores.

Nada se sabe sobre os custos dirctos e indiretos dessa forma específica de violência. Max \& Rice (1993), embora chamem de 'tiro no escuro' os custos com agravos por arma de fogo, estimaram-nos em 20,4 bilhões de dólares, nos Estados Unidos, em 1990. De acordo com estes autores, para cada agravo fatal deste tipo, há dois outros que requerem hospitalização e 5,4 não severos o suficiente para serem hospitalizados.

Miller, Cohen \& Rossman (1993) acrescentam aos custos econômicos os não-monetários como dor, sofrimento, medo c perda da qualidade de vida. Estes afetam tanto as vítimas diretas quanto as secundárias (membros familiares e aqueles cujas vidas são abaladas pelo crimc).

Este artigo vem, portanto, aprofundar o conhecimento sobre os homicídios em nosso país. Nele, cfetua-se uma análise em que se configuram a magnitude e as especificidades dessa causa de morte. Ao mesmo tempo, tenta-se desvendar as possíveis raízes do problema e apresentar propostas de atuação para enfrentá-lo. 


\section{Material e MÉtodo}

Analisam-se dados de mortalidade por causas externas em residentes, aprofundando a investigação dos homicídios. Os dados sobre os óbitos originam-se de listagens fornecidas pelo Ministério da Saúde e das estatísticas de mortalidade publicadas por essa instituição. As populações utilizadas nos denominadores das taxas foram estimadas por Beltrão \& Pereira (1994).

As informações são analisadas em termos de taxas e mortalidade proporcional, segundo sexos e faixas etárias. Apresentam-se tabelas e gráficos para o conjunto do País e para as capitais de regiões metropolitanas.

As mortes por causas externas em geral (códigos E800-E999) são situadas em relação às demais causas de óbitos, e os homicídios (códigos E960E969) são destacados e, por vezes, desdobrados em subgrupos, como os provocados por arma de fogo (código E965).

Por fim, discutem-se os resultados e apresentam-se propostas de encaminhamento para os problemas levantados.

\section{ApresentaÇÃo dos Resultados}

Conforme pode ser visto na Tabela 1, as causas violentas, em 1989, vitimaram 102 mil pessoas da população brasileira, entre as quais 84.391 homens e 64.104 mulheres. As demais 111 pessoas não foram identificadas quanto ao sexo. Isto significa que, em relação às demais causas, as violentas ocupam a segunda posição na mortalidade, com a proporção de $15,2 \%$, perdendo apenas para as doenças do aparelho circulatório. Essa proporção, em 1980 , era de $11,8 \%$, quando era a quarta causa. Em relação ao sexo masculino, as mortes violentas também estão em segundo lugar, com $21 \%$. Já no sexo feminino, situam-se entre as cinco principais causas, com $7 \%$ dos óbitos, ocupando a quarta posição, juntamente com as doenças infecciosas e parasitárias. 
Tabela 1 - Mortalidade proporcional ${ }^{*}$ por principais causas, segundo o sexo. Brasil - 1989

\begin{tabular}{|l|c|c|c|c|c|r|}
\hline \multirow{2}{*}{ Principais causas } & \multicolumn{2}{|c|}{ TOTAL } & \multicolumn{2}{c|}{ Masculino } & \multicolumn{2}{c|}{ Feminino } \\
\cline { 2 - 7 } & $(\mathrm{N})$ & $(\%)$ & $(\mathrm{N})$ & $(\%)$ & $(\mathrm{N})$ & $(\%)$ \\
\hline Aparelho circulatório & 228.432 & 34 & 122.997 & 31 & 105.236 & 39 \\
Causas externas & 102.000 & 15 & 84.391 & 21 & 64.104 & 7 \\
Neoplasias & 80.568 & 12 & 43.789 & 11 & 36.743 & 14 \\
Aparelho respiratório & 65.952 & 10 & 38.424 & 10 & 27.456 & 10 \\
Outras & 142.986 & 22 & 81.725 & 20 & 60.844 & 23 \\
\hline
\end{tabular}

* Excluem-se as causas mal-definidas.

Fonte: Cenepi/Ministério da Saúde.

O crescimento da importância das causas externas no perfil de mortalidade do País não se dá de modo homogêneo em relação aos sexos, nem às faixas etárias e, menos ainda, no que se refere às causas específicas de mortes violentas.

No estudo de Souza \& Minayo (1995), detecta-se que os acidentes de trânsito se mantêm com proporções elevadas ao longo da década de 80 , significando, em média, $28 \%$ dos óbitos por todas as causas externas. Em seguida a essa causa específica, surgem os homicídios com a proporção média de $22 \%$ daquelas mortes, no mesmo período. Essas duas formas de violência, a ocorrida no trânsito e a dos assassinatos, estabelecem o perfil do grande grupo das externas. Em 1980, os acidentes de trânsito e os homicídios eram responsáveis por $48,5 \%$ dos óbitos por todas as causas violentas; em 1988 , essa proporção já atinge mais da metade, com $54,3 \%$. Contudo, os acidentes de trânsito, apesar das mais elevadas proporções em relação aos homicídios, apresentaram um incremento percentual menor do que esses últimos. Enquanto os primeiros passaram de 28,4\% em 1980 para 29,3\% em 1988, crescendo 0,9 pontos percentuais, os homicídios apresentaram, nestes anos, proporções de $20,1 \%$ e $24,1 \%$, ou seja, um incremento de quatro pontos percentuais.

O comportamento das mortes por homicídios, ao longo do período estudado, pode ser visualizado melhor na Tabela 2. 
Tabela 2 - Taxas ${ }^{*}$ de mortalidade por homicídios. Brasil - 1980-1988

\begin{tabular}{|c|c|c|c|c|c|c|}
\hline \multirow{2}{*}{ Ano } & \multicolumn{2}{|c|}{ TOTAL } & \multicolumn{2}{c|}{ Masculino } & \multicolumn{2}{c|}{ Feminino } \\
\cline { 2 - 7 } & $(\mathbf{N})$ & Taxa & $(\mathbf{N})$ & Taxa & $(\mathrm{N})$ & Taxa \\
\hline 1980 & 13.910 & 11,70 & 12.534 & 21,22 & 1.353 & 2,26 \\
1981 & 15.231 & 12,57 & 13.703 & 22,78 & 1.487 & 2,44 \\
1982 & 15.550 & 12,63 & 14.035 & 22,99 & 1.497 & 2,41 \\
1983 & 17.408 & 13,87 & 15.697 & 25,25 & 1.700 & 2,69 \\
1984 & 19.767 & 15,46 & 18.003 & 28,44 & 1.736 & 2,69 \\
1985 & 19.747 & 15,13 & 17.965 & 27,82 & 1.766 & 2,68 \\
1986 & 20.479 & 15,40 & 18.657 & 28,35 & 1.798 & 2,68 \\
1987 & 23.087 & 17,02 & 21.136 & 31,53 & 1.935 & 2,82 \\
1988 & 23.357 & 16,88 & 21.316 & 31,19 & 2.025 & 2,89 \\
\hline TOTAL & 168.518 & & 153.046 & & 15.297 & \\
\hline
\end{tabular}

*Taxas por cem mil habitantes.

Fonte: Cenepi/Ministério da Saúde.

Conforme indicado na Tabela 2 , em termos absolutos ocorreram 168.518 homicídios no Brasil, entre 1980 e 1988. Destes, 153.046 ou $90,9 \%$ (excluídos 175 óbitos de sexo ignorado) foram de homens e apenas 9,1\% (15.297 óbitos) de mulheres. Isto significa uma freqüência dez vezes maior de assassinatos no sexo masculino. O total de homicídios representa 19,8\% dos 850.307 óbitos ocorridos na década por todas as causas violentas.

Em termos de taxas, quando se comparam os anos inicial e final do período investigado, nota-se que, em relação à população total, houve um crescimento de 1,44 vezes ou $44 \%$ nas taxas que passaram de 11,70 para 16,88 por cem mil habitantes; no sexo masculino as taxas cresceram de 21,22 para 31,19 , ou seja, 1,47 vezes ou $47 \%$. No que se refere ao sexo feminino, o crescimento foi de 1,28 ou $28 \%$.

Em relação aos sexos, os homens apresentaram um índice de sobremortalidade por causas violentas crescente ao longo do período. Deste modo, a população masculina - que em 1980 morria nove vezes mais que a feminina - passou, em 1988, a morrer numa razão de 11 homens para cada mulher. 
$\mathrm{Na}$ Tabela 3 podem ser observadas as taxas de mortalidade por homicídios, segundo sexo e faixas etárias, para o Brasil em 1988.

Tabela 3 - Taxas* de mortalidade por homicídios, segundo sexo e faixas etárias. Brasil - 1988

\begin{tabular}{|l|c|c|c|c|c|c|c|}
\hline \multirow{2}{*}{$\begin{array}{l}\text { Idade } \\
\text { (em anos) }\end{array}$} & \multicolumn{2}{|c|}{ TOTAL } & \multicolumn{2}{c|}{ Masculino } & \multicolumn{2}{c|}{ Feminino } & Índice \\
\cline { 2 - 8 } & $(\mathrm{N})$ & Taxa & $(\mathrm{N})$ & Taxa & $(\mathrm{N})$ & Taxa & $\mathrm{M} / \mathrm{F}$ \\
\hline $0-4$ & 136 & 0,82 & 65 & 0,78 & 71 & 0,87 & 1 \\
$5-9$ & 90 & 0,52 & 52 & 0,60 & 38 & 0,45 & 1 \\
$10-14$ & 265 & 1,69 & 209 & 2,66 & 56 & 0,71 & 4 \\
$15-19$ & 2.931 & 20,82 & 2.678 & 38,16 & 253 & 3,58 & 11 \\
$20-29$ & 8.843 & 35,08 & 8.197 & 66,14 & 645 & 5,03 & 13 \\
$30-39$ & 5.592 & 29,74 & 5.130 & 55,75 & 459 & 4,78 & 12 \\
$40-49$ & 2.723 & 21,64 & 2.481 & 40,14 & 241 & 3,76 & 11 \\
$50-59$ & 1.281 & 14,56 & 1.181 & 27,79 & 100 & 2,20 & 13 \\
60 e mais & 848 & 9,00 & 745 & 17,08 & 103 & 2,04 & 8 \\
\hline
\end{tabular}

* Taxas por cem mil habitantes.

Fonte: Cenepi/Ministério da Saúde.

Como pode-se perceber, as maiores taxas de mortalidade por homicídios concentram-se nas faixas de 20 a 29 e de 30 a 39 anos, tanto na população em geral como em ambos os sexos. Também é perceptível que no sexo masculino as taxas são bem maiores do que no feminino, com um risco que chega a ser 13 vezes maior nas faixas de 20 a 29 e de 50 a 59 anos de idade.

Quando se compara o ano de 1980 a 1988, nota-se que o crescimento percentual da mortalidade proporcional por homicídios variou entre os sexos e as faixas etárias. De acordo com o Gráfico 1, esse incremento, na população em geral, foi maior nas faixas de 10 a $14(79,5 \%)$ e de 15 a 19 anos $(45,3 \%)$. Essa intensificação dos homicídios - em faixas etárias mais jovens do que naquelas em que eles tradicionalmente são mais freqüentes - deve-se sobretudo às mortes masculinas, nas quais a faixa de 10 a 14 anos cresceu $93,3 \%$ e a de 15 a 19 anos aumentou em $43 \%$. Também entre o sexo feminino, a faixa de 10 a 14 anos teve um salto expressivo de $43,9 \%$. 


\section{Gráfico 1 - Incremento da mortalidade proporcional por homicídios, segundo faixas etárias. Brasil - 1980 e 1988}

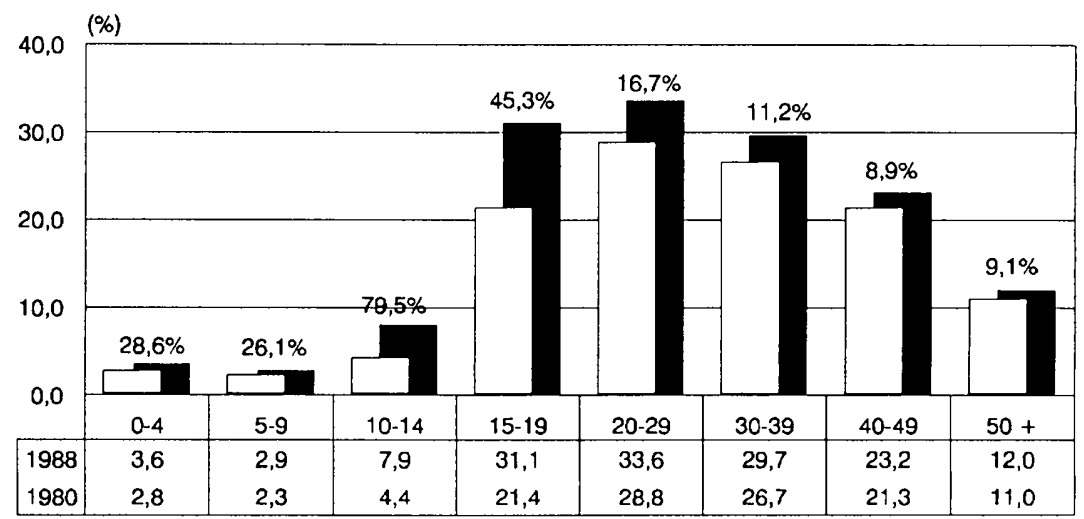

Fonte: Ministério da Saúde.

Esses dados mostram que, ao longo do período, cresceu a importância dos homicídios entre crianças e adolescentes, assim como entre mulheres, indicando um deslocamento, em termos de faixas etárias, e uma disseminação, em termos de sexos. Para as causas externas em geral, Souza \& Minayo (1995) apontam crescimentos de $16,9 \%$ na faixa de 10 a 14 anos e de $19 \%$ na de 15 a 19 anos. As autoras chamam a atenção para a faixa de 0 a 4 anos, na qual as proporções de mortes por causas externas, apesar da baixa freqüência, passam de $2,3 \%$ para $3,8 \%$, de 1980 a 1989 , significando um salto de $65,2 \%$.

A incidência das mortes por violência, em especial dos homicídios, em idades mais jovens reasseguram esse grupo como o principal responsável por Anos Potenciais de Vida Perdidos (APVP). Dados da OPS (1986) mostram que no Brasil, em 1983, os homicídios provocaram 544,5 APVP (de 1 a 64 anos) por cem mil habitantes, o que significa 33,0 APVP por morte. Nos Estados Unidos, esses valores foram 258,8 e 32,4 , respectivamente. Na população masculina de nosso país, essa mesma causa foi responsável por 489,9 APVP em cem mil habitantes, ou 32,7 APVP por morte. Esses valores também são maiores do que os observados nos EUA: 414,1 e 32,2, respectivamente. Tais dados indicam que, aqui, os homicídios são mais freqüentes e atingem pessoas mais jovens do que lá. 
As taxas de mortalidade por homicídios segundo capitais de regiões metropolitanas podem ser vistas nos Gráficos 2, 3, 4, 5 e 6 .

De acordo com o Gráfico 2 percebe-se que, na Região Norte, Belém permanece mais ou menos estável com taxas que oscilam em torno da média do País, sendo a capital que teve menor crescimento no período $(23,4 \%)$.

No Gráfico 3, da Região Nordeste, Recife destaca-se como a capital que vem apresentando as maiores taxas. Entre 1980 e 1989, essas taxas tiveram uma elevação de 193,9\%. Em Salvador verifica-se uma situação preocupante: teve um rápido e importante crescimento, na ordem de $1.046,7 \%$ entre o início e o final do período. Esta elevação se dá, sobretudo, a partir de 1987. Fortaleza, apesar de iniciar a série histórica investigada com a mais alta taxa da região, é superada por Recife, a partir de 1981, e termina o período com taxa semelhante à de 1980 , apresentando, em 1987, sua mais baixa taxa (14,8 por cem mil habitantes).

O Gráfico 4 apresenta as taxas de mortes por homicídios na Região Sudeste. Segundo ele, a capital de São Paulo, aparentemente, possui as maiores taxas, com um crescimento de $134 \%$ entre o início e o final do período. Nesta região, as taxas decresceram em Belo Horizonte (22,9\%) e no Rio de Janeiro (35,8\%). Entretanto, no caso específico desta última cidade, a diminuição das mortes por homicídios é artificial.

Gráfico 2 - Taxas de mortalidade por homicídios* segundo capitais de regiões metropolitanas e Brasil. 1980 e 1989

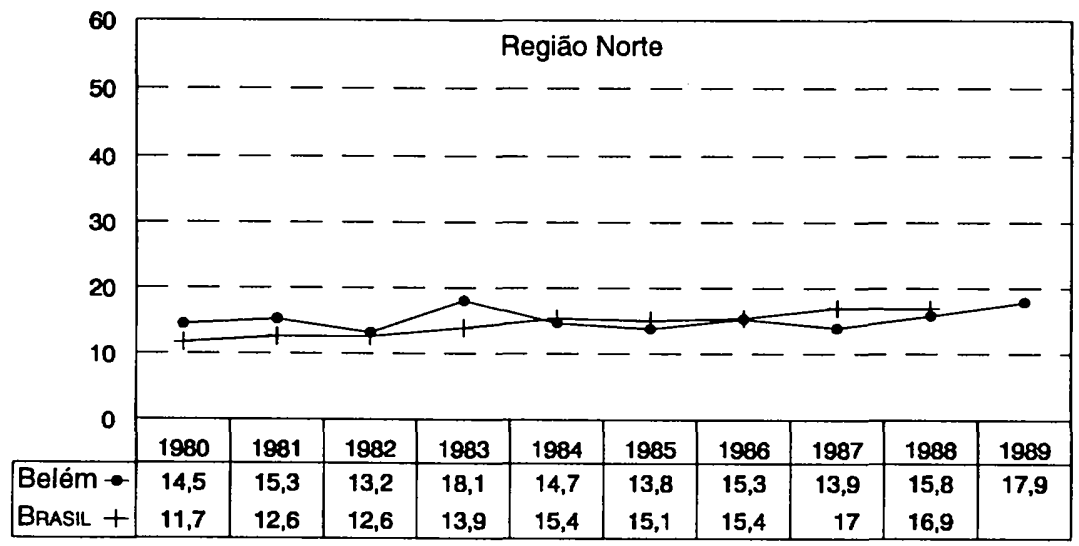

* Taxas por 100.000 habitantes.

Fonte: Ministério da Saúde. 
Gráfico 3 - Taxas de mortalidade por homicídios* segundo capitais de regiōes metropolitanas e Brasil. 1980 e 1989

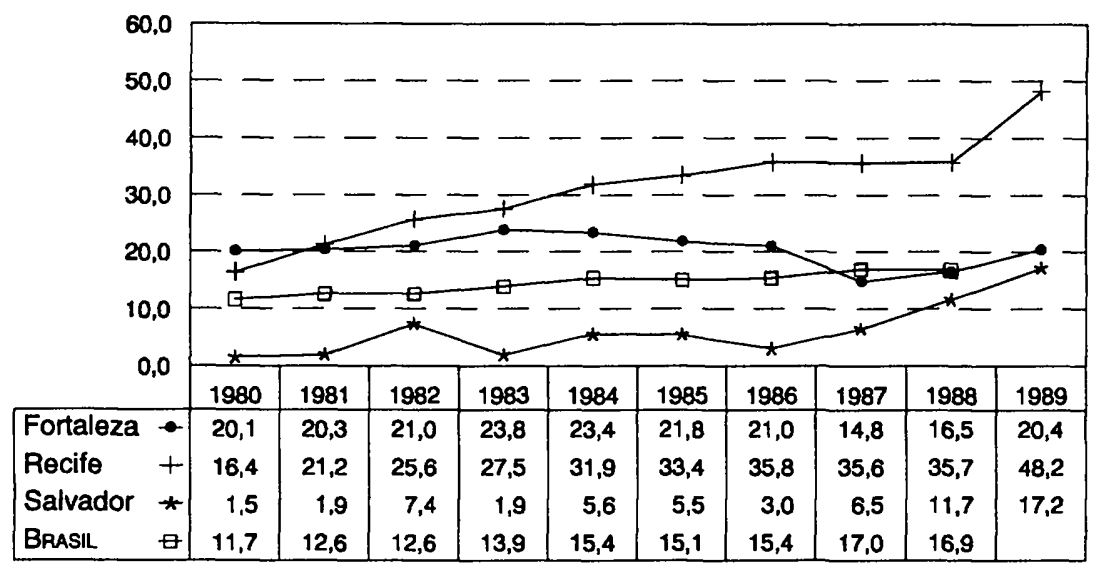

* Taxas por 100.000 habitantes.

Fonte: Ministério da Saúde.

Gráfico 4 - Taxas de mortalidade por homicidios* segundo capitais de regiões metropolitanas e Brasil. 1980 e 1989

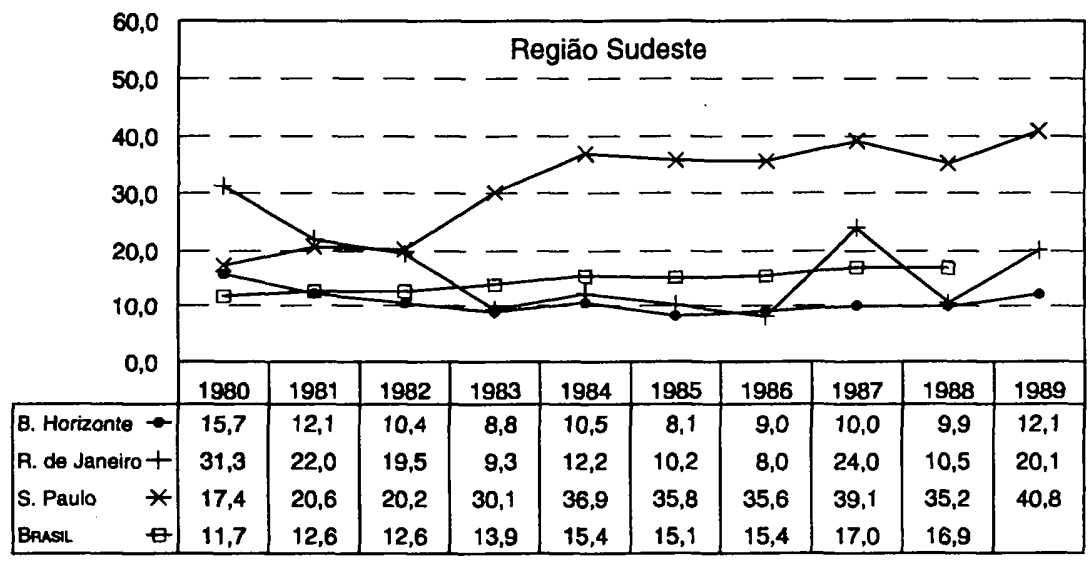

* Taxas por 100.000 habitantes.

Fonte: Ministério da Saúde. 
Sabe-se que uma parcela das mortes violentas não é adequadamente esclarecida quanto à causa básica do óbito. Desse modo, um grupo de mortes acaba sendo classificado no que se denomina simplificadamente de lesões ignoradas', ou seja, aquelas para as quais não se conseguiu identificar se foram acidental ou intencionalmente infligidas. Alguns autores, como Mello Jorge (1990), têm insistentemente ressaltado os problemas que essa falha na classificação acarreta, sendo o principal a subestimação das causas específicas de mortes violentas, como acidentes de trânsito, homicídios e suicídios.

Tal limitação na qualidade da informação pode ser constatada no Gráfico 5 , em que as taxas do Rio de Janeiro (com e sem a inclusão dos óbitos por armas de fogo que se ignoram se acidental ou intencionalmente infligidos - E985) assumem tendências opostas. Considerando a curva dos homicídios em que se incluem as lesões ignoradas por armas de fogo, observa-se que, na realidade, as taxas desse município são as mais altas em relação a todas as demais capitais do País, com um crescimento de $94,2 \%$ entre os anos de 1980 e 1989. Isto vem mostrar que ocorre uma falha na qualidade da informação. Esta afirmação pode ser feita a partir de estudos efetuados anteriormente nos quais se comprovou que a grande maioria das lesões por arma de fogo ignoradas é, na verdade, homicídio (Lait, 1992; Souza, 1992; Gonçalves \& Oliveira, 1992).

\section{Gráfico 5 - Taxas de mortalidade por homicídios. ${ }^{*}$ Rio de Janeiro (sem e com lesões ignoradas) e Brasil - 1980 e 1989}

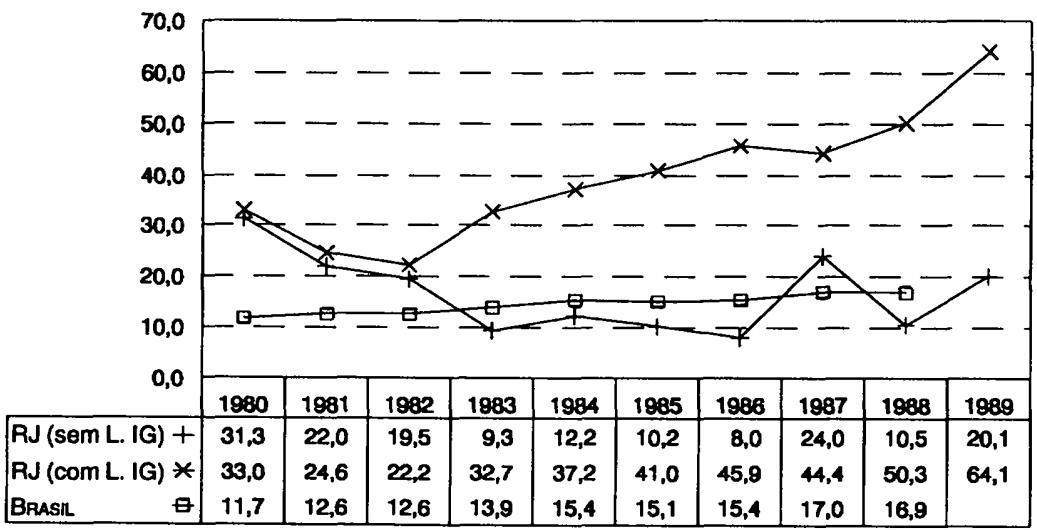

*Taxas por 100.000 habitantes.

Fonte: Ministério da Saúde. 
Quanto às taxas da Região Sul mostradas no Gráfico 6, destaca-se que, tanto em Curitiba como em Porto Alegre, elas são crescentes, embora permaneçam, na maior parte do período, abaixo da média do País. Entretanto, é preciso salientar que, nos dois últimos anos analisados, as taxas ultrapassam a dezena, e o crescimento em Porto Alegre foi o segundo maior entre as capitais, alcançando um percentual de 350,9\% de aumento, entre 1980 e 1989.

\section{Gráfico 6 - Taxas de mortalidade por homicídios*, segundo capitais de} regiões metropolitanas e Brasil. 1980 e 1989

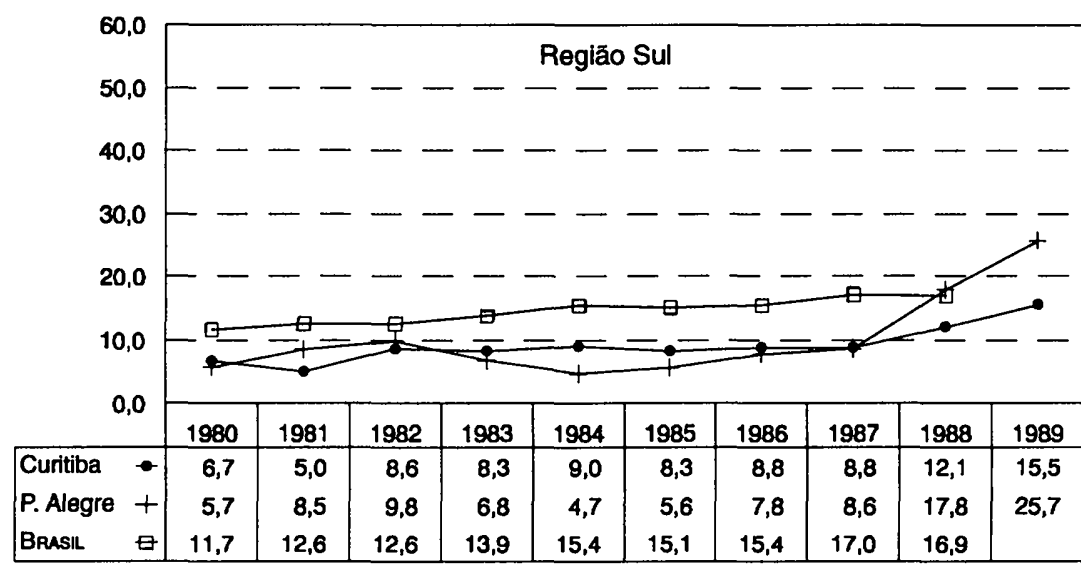

'Taxas por 100.000 habitantes.

Fonte: Ministério da Saúde.

Os homicídios que ocorreram no País ao longo da última década tiveram uma peculiaridade: a maioria foi perpetrada com armas de fogo.

$\mathrm{O}$ uso de armas de fogo não se restringe apenas aos homicídios. Esse tipo de arma é também utilizado nos suicídios, assim como produz vítimas acidentalmente. Deste modo, na Tabela 4 foram computadas as mortes violentas que envolveram armas de fogo em capitais brasileiras, nos anos de 1980 e 1989.

Pela Tabela 4, os óbitos que envolveram armas de fogo somaram 2.515 em 1980, representando $14,5 \%$ dos 17.305 óbitos por todas as causas externas, nas nove capitais. Em 1989, a contribuição dessas mortes foi de $26 \%$, ou seja, 6.265 das 24.095 mortes violentas. No Rio de Janeiro, quase metade 
$(46,8 \%)$ das pessoas mortas violentamente é alvejada por tiros de arma de fogo. É importante destacar que o maior crescimento das proporções de mortes envolvendo esse instrumento ocorreu em Recife, que passou de 19,7\% para $38,2 \%$, crescendo proporcionalmente $18,5 \%$; no Rio de Janeiro (18,3\%); em Salvador (16,3\%) e Porto Alegre (15,3\%).

Tabela 4 - Distribuição de óbitos* envolvendo armas de fogo em capitais de regiões metropolitanas do Brasil. 1980 e 1989

\begin{tabular}{|l|c|c|c|c|}
\hline \multirow{2}{*}{ Capitais } & \multicolumn{2}{|c|}{1980} & \multicolumn{2}{c|}{1989} \\
\cline { 2 - 5 } & No & $(\%)$ & No & $(\%)$ \\
\hline Belém & 101 & 13,6 & 132 & 20,0 \\
Fortaleza & 105 & 11,2 & 155 & 15,6 \\
Recife & 157 & 19,7 & 514 & 38,2 \\
Salvador & 69 & 7,2 & 358 & 23,5 \\
Belo Horizonte & 226 & 16,9 & 154 & 11,3 \\
Rio de Janeiro & 1.434 & 28,5 & 3.188 & 46,8 \\
São Paulo & 256 & 4,3 & 1.342 & 14,5 \\
Curitiba & 88 & 10,0 & 140 & 12,6 \\
Porto Alegre & 79 & 11,1 & 282 & 26,4 \\
\hline Total & 2.515 & - & 6.265 & - \\
\hline
\end{tabular}

• Inclui acidentes (E922), suicídios (E955), homicídios (E965), intervenções legais (E970) e lesões ignoradas (E985), todas por armas de fogo.

Fonte: Ministério da Saúde.

O fenômeno do aumento da freqüência de mortes envolvendo o uso de armas de fogo tem sido amplamente debatido nos Estados Unidos. Mercy et al. (1993) discutem essa questão mostrando que:

- cerca de 65\% dos mais de 24 mil homicídios ocorridos em 1990 nos Estados Unidos envolveram arma de fogo;

- esse instrumento tem um papel fundamental no crescimento das taxas de mortes violentas; 
- a presença de um revólver aumenta dramaticamente a probabilidade de que um ou mais participantes de um conflito sejam mortos;

- há evidência científica de que a posse de arma de fogo fornece um risco significante ao proprietário e sua familia (esse risco incrementa em cinco vezes os suicídios e em três vezes os homicídios).

Esses autores ainda advertem que, para cada vez que um revólver é usado para matar alguém em legítima defesa, ele é utilizado 43 vezes em suicídios, acidentes e assassinatos que não visam a preservar a própria vida.

\section{Comentários E Propostas de EnCAMINHAMENTo}

Refletir sobre a problemática dos homicídios no Brasil não é uma tarefa fácil, porque o fenômeno é por demais complexo. Também não se podem compreender os dados aqui mostrados sem contextualizá-los.

É verdade que, historicamente, o ser humano sempre se utilizou desse procedimento: matar pelos mais variados objetivos e em defesa das mais nobres ou espúrias causas. Entretanto, o que se observa nas sociedades contemporâneas não pode ser interpretado como ampliação e intensificação de um mesmo fenômeno que se repete ao longo da vida humana em sociedade. Se o evento em si é o mesmo, na atualidade ele assume expressões e significados diferentes, em relação a épocas passadas, e específicos, para espaços socioculturais distintos.

Se os homicídios que se observam hoje nos grandes centros urbanos do mundo têm algo em comum, também o têm de específico. É verdade que, no Brasil, eles apresentam semelhanças e diferenças que os aproximam e distinguem da problemática dos homicídios em Nova York, por exemplo. Entretanto, o conhecimento acumulado ainda não permite que se tenha clareza suficiente em relação a essas questões.

Sabe-se que em épocas remotas e ainda hoje, em alguns locais, existem homicídios legais (destinados ans condenados por crimes e aceitos pela soci- 
edade) e ilegais (não legitimados e mesmo reprovados pela sociedade, passíveis de punição legal).

Pensar sobre os homicídios no Brasil significa efetuar um exercício no qual mais se tem a indagar do que a responder. Algumas dessas perguntas poderiam ser feitas da seguinte forma: por que essa causa de morte está crescendo entre nós? Por que os nossos jovens, cada vez mais precocemente, estão sendo assassinados? Quem são os responsáveis pelas suas mortes? Sobretudo, por que os matam e em que circunstâncias? Estaria a sociedade brasileira conivente com esses crimes, realizados na ilegalidade, impunes na omissão e legitimados, por uma parcela da população, como forma de resolver os graves problemas sociais do País? Ou são esses jovens e a violência em meio à qual vivem as conseqüchncias desses problemas? Teriam eles de sacrificar suas vidas pcla falta de opção por uma sobrevivência digna e integrada a um projeto de nação? Ou inexiste esse projeto? Seriam eles os responsáveis pela falta de escolas, empregos, moradias e mesmo pela organização do crime em torno do tráfico de drogas, tendo que, por isso, ser condenados a se matarem uns aos outros em rituais bárbaros? Ou são eles o clo frágil de uma rede de violência tramada nos altos escalões do poder legal c ilegal para a qual são recrutados como mão-de-obra desqualificada e barata? Seriam eles que, no imaginário social, assumem o papel de vilões e, na realidade, armados até os dentes, ameaçam as elites e a classe média, contra os quais é preciso se defender de todas as formas? Ou são, antes, vítimas dessas elites que na década em questão se preocuparam em acumular riqueza, mais do que com qualquer outra coisa? Scria por mero acaso que as capitais onde mais cresceram os homicídios, Recife e Rio de Janeiro, foram as mesmas em que houve maior intensificação da concentração de renda na década?

As respostas para algumas dessas indagações parecem óbvias. Contudo, outras não podem ser facilmente desvendadas. Nos estudos de Minayo \& Souza (1993) e Souza \& Minayo (1995), já se explicitam alguns fatores que ajudam a compreender o tema em pauta. Segundo as autoras, "não se pode responder simplistamente a essas questões fundamentais, mas é importante reconhecer que elas estão na raiz da guerra surda cujos reflcxos se projetam no quadro de mortalidade por violência, com destaque para os homicídios, sendo estes uma expressão particular de violência interpessoal". 
Para essas pesquisadoras, em termos de conjuntura social da década de 80 , três fatos podem ser relacionados ao aumento das taxas de homicídios nas grandes regiões metropolitanas:

- a consolidação da organização do crime criando uma economia e um poder paralelos, assumindo o papel do Estado na assistência e na segurança e se confrontando, no imaginário social e na realidade das classes populares, com a segurança pública;

- a consolidação dos grupos de extermínio;

- o aumento da população vivendo e trabalhando nas ruas, sobretudo de uma população infantil e juvenil compelida ao trabalho pelo aumento da pobreza absoluta em todas as regiões metropolitanas na década (Sabóia, 1993) e pela falência das instituições 'totais' de assistência e recuperação de 'menores'.

Esses três fatores se inter-relacionam sinergicamente com a violência estrutural das extremas desigualdades e com as mudanças de valores e visão das novas gerações em relação às elites, à pobreza, à riqueza, aos bens de consumo e à própria felicidade.

A violência estrutural no País tem por determinantes o crescimento da desigualdade socioeconômica, baixos salários e renda familiar para a maioria da população, associados à inflação c à conseqüente perda do poder aquisitivo (Sabóia, 1993). Essa forma de violência é acompanhada da descrença e do afastamento da população em relação às instituições sociais que não realizam as funções às quais se destinam; da ausência de políticas públicas integradas e condizentes com as necessidades da população na conjuntura atual, em relação às áreas de assistência, educação, saúde, moradia e segurança; da priorização do desenvolvimento econômico (frustrado na década) e do endividamento externo, em detrimento do desenvolvimento social e às custas do sacrifício da população em geral, mas, sobretudo, com maior ônus para os pobres; do intenso apelo ao consumo, conflitando com o empobrccimento do País e a miserabilidade de metade da população.

Aqui se entende que a forma fundamental de violência é a 'estrutural', e é a partir dela que se pode analisar a criminalidade. 
Além do acirramento das contradições sociais, é necessário considerar que, no período, houve mudanças radicais no perfil de criminalidade do País: não só se tornaram mais visiveis os crimes de 'colarinho-branco', mas também o crime evoluiu, organizando-se em torno do narcotráfico e do 'narcoterrorismo'.

O mais problemático em relação à organização do crime é que ela se constitui em uma rede cuja trama principal se articula com as instituições mais 'respeitáveis' da sociedade, conforme tem sido estudado por autores como Pinheiro (1983), Zaluar (1986) e Batista (1990) e amplamente divulgado pela imprensa. Na medida em que nela estão envolvidos juízes, policiais, empresários e membros do governo, esse tipo de criminalidade apresenta-se difícil de ser combatido. Ou seja, há profundos interesses econômicos e de poder que os tornam legítimos cúmplices da organização da ilegalidade.

Em meio a essa conjuntura, alteraram-se as relações na vida cotidiana, com o medo e a desconfiança generalizados gerando saídas e precauções individualistas, com o enclausuramento e a posse de armas sendo usados como meios de proteção à propriedade privada e à vida.

Os princípios dessa 'gucrra civil' não declarada, segundo Minayo \& Souza (1993), parecem se fundamentar em uma ética perversa em que a sociedade, para se preservar, necessita promover a morte do novo (na figura de scus jovens). De um novo cuja relação real e simbólica com a propriedade, com as instituições, com a religião, com o consumo, com os valores tradicionais, enfim, não repete padrões anteriores. Pelo contrário, constitui-se em ameaça efetiva para a sociedade dominante que não dispõe, por sua vez, de nenhuma resposta, nenhum modelo ou projeto capaz de satisfazer a esses jovens. A exclusão social que gera em algum momento a escolha pela ilegalidade produz, em primeiro lugar, a morte política antes de eliminar fisicamente o 'novo' que se teme e que se quer banir à custa do extermínio em sentido amplo. É só nesses termos que se consegue compreender a ocorrência e a impunidade de tantos assassinatos, concluem as autoras.

Quanto às propostas na área da saúde pública, algumas lições podem ser retiradas das questões já formuladas por estudiosos de nossa realidade e da sociedade norte-americana.

Como descrevem Edelman \& Satcher (1993), a abordagem da saúde pública deve localizar a atenção na prevenção primária, mais do que simplesmente cuidar das conseqüências dos atos violentos. Isto significa observar 
padrões, fatores de risco e causas; desenhar e avaliar intervenções; implantar programas locais efetivos. Ela também deve integrar as contribuições de várias disciplinas, setores e grupos, conforme realizado nos Estados Unidos com grande sucesso na prevenção de mortes por acidentes de trânsito e na redução da taxa de consumo de tabaco. Ainda segundo os autores, os esforços na prevenção devem ser implementados em múltiplos níveis: individual, familiar, na comunidade e na sociedade. É preciso traçar imediatamente ações voltadas para os jovens, que os ajudem a adquirir habilidades para a vida e treinamento profissional que os prepare para assumir um local na sociedade como adultos; reforçar a regulação do uso de álcool e de armas de fogo entre os jovens; bem como fornecer ambientes físico e social para jovens em que os atos violentos tenham menor probabilidade de ocorrer entre eles.

Kellermann (1993), analisando os obstáculos à pesquisa sobre violência, ressalta o pouco conhecimento como conseqüência da falta de financiamento e de vontade política para encarar o problema. Alerta para a necessidade de aplicação de recursos; de desenvolvimento de pesquisas e programas; de envolvimento de instituições governamentais juntamente com a iniciativa privada; de treinamento e qualificação de pesquisadores e de promoção de um maior número de encontros, conferências e comitês interdisciplinares. $\mathrm{O}$ autor se refere ainda às limitações nos sistemas de informação acarretando subregistro da prevalência e da incidência e aos problemas metodológicos que a complexidade do tema enseja. Finalmente, sugere como estratégias:

- o relato sistemático dos eventos envolvendo armas de fogo;

- estimativas da incidência anual e do impacto do uso desse instrumento em eventos não-fatais, a partir da inclusão dessas questões nos registros institucionais;

- o monitoramento dessas ocorrências em emergências hospitalares.

Às propostas destes autores acrescenta-se a necessidade premente de estudos, intervenções e avaliação em capitais como Recife e Rio de Janeiro, cuja intensificação da violência aparece claramente nos dados aqui mostrados. Também é preciso dizer que alguns esforços já vêm sendo realizados em referência a algumas das propostas mencionadas. Entretanto, ainda há um longo caminho a ser trilhado para prevenir os homicídios e reduzir o seu impacto na saúde pública. 


\section{REFERÊNCIAS BIBLIOGRÁFICAS}

AGUDELO, S .F. Violência y/o Salud: elementos preliminares para pensarlas e actuar. PAHO/ OMS, 1989. (Mimeo.)

BATISTA, N. Punidos e Mal Pagos: violência, justifa, segurança pública e direitos bumanos no Brasil de boje. Rio de Janeiro: Revan, 1990.

EDELMAN, P. \& SATCHER, D. Violence prevention as a public health priority. Health Affairs, 12(4):123-125, 1993.

GONÇALVES, J. O. \& OLIVEIRA, R. Investigação de óbitos por causa externa, Sergipe, 1990-91. In: II CONGRESSO BRASILEIRO DE EPIDEMIOLOGIA, Belo Horizonte, 1992.

KELLERMANN, A. L. Obstacles to firearm and violence research. Health Affairs, 12(4):142-153, 1993.

LAIT, L. C. F. Estimativa da mortalidade por homicídios no Estado do Rio de Janeiro de 1979 a 1987 e 1989. In: II CONGRESSO BRASILEIRO DE EPIDEMIOLOGIA, Belo Horizonte, 1992. (Mimeo.)

MAX, W. \& RICE, D. P. Shooting in the dark: estimating the cost of firearm injuries. Health Affairs, 12(4):171-185, 1993.

MELLOJORGE, M. H. P. Investigafão Sobre a Mortalidade por Acidentes e Violências na Infância, 1988. Tese de Livre Docência, São Paulo: Faculdade de Saúde Pública de São Paulo.

MELLO JORGE, M. H. P. Situação atual das estatísticas oficiais relativas à mortalidade por causas externas. Revista de Saúde Pública, 24(3):217-223, 1990.

MERCY, J. A. et al. Public health policy for preventing violence. Health Affairs, 12(4):729, 1993.

MILLER, T. R.; COHEN, M. A. \& ROSSMAN, S. B. Victim costs of violent crime and resulting injuries. Health Affairs, 12(4):186-197, 1993.

MINAYO, M. C. S. (Coord.) Bibliografia comentada da produção cientifica brasileira sobre violência e saúde. Rio de Janeiro: SDE/Ensp/Fiocruz (Panorama Ensp 2), 1990.

MINAYO, M. C. S. Violência: uma agenda para a saúde pública. In: VIII CONGRESSO LATINOAMERICANO DE MEDICINA SOCIAL, Guadalajara, mar. 1994. (Mimeo.)

MINAYO, M. C. S. \& SOUZA, E. R. Violência para todos. Cadernos de Saúde Pública, $9(1): 65-78,1993$. 
ORGANIZACIÓN PANAMERICANA DE LA SALUD (OPS)/DIVISIÓN DE PROMOCIÓN Y PROTECCIÓN DE LA SALUD. Las condiciones de salud en las Américas. Publicación Científica n 500, v.1. Washington, D.C.,1986.

ORGANIZACIÓN PANAMERICANA DE LA SALUD (OPS)/DIVISIÓN DE PROMOCIÓN Y PROTECCIÓN DE LA SALUD. Salud y violencia: plan de acción regional. Washington, D.C., 1994.

PINHEIRO, P. S. (Org.) Crime, Violência e Poder. São Paulo: Brasiliense, 1983.

SABÓIA, J. Distribuição de renda e probreza metropolitanas no Brasil. In: MINAYO, M. C. S. (Org.) Os Limites da Exclusão Social: meninos e meninas de rua no Brasil. São Paulo: Hucitec, 1993.

SOUZA, E. R. O Reflexo da violência na mortalidade da Baixada Fluminense: Brasil. Relatório Final de Pesquisa, Rio de Janeiro: Fiocruz, 1992.

SOUZA, E. R. \& MINAYO, M. C. S. O impacto da violência social na saúde pública do Brasil: década de 80. In: MINAYO, M. C. S. (Org.) Os Muitos Brasis: saúde e populą̧ão na década de 80. São Paulo/Rio de Janeiro: Hucitec/Abrasco, 1995. 


\section{EPIDEMIOLOGIA DOS TRANSTORNOS \\ MENTAIS EM IDOSOS: UM ESTUDO \\ COMUNITÁRIO E HOSPITALAR}

Renato Veras, Evandro Coutinbo \& Cláudia Medina Coeli

\section{INTRODUÇÃO}

O Brasil atualmente desponta na América Latina por sua excelência acadêmica e liderança na área da saúde coletiva, em particular na epidemiologia. Isso o torna um dos países mais habilitados a investigar algumas hipóteses presentes na literatura do Primeiro Mundo, tidas como universais, embora ainda não avaliadas suficientemente em sociedades menos desenvolvidas.

Uma das discussões relevantes no campo da epidemiologia é a área de envelhecimento e da saúde mental. ${ }^{1}$ É sabido que a síndrome cerebral orgânica e a depressão são dois dos mais importantes distúrbios na comunidade entre aqueles indivíduos da terceira idade. São doenças que não se restringem ao campo da saúde e trazem importantes repercussões de ordem social. Já foi

\footnotetext{
' Com o crescimento populacional dos idosos que vem ocorrendo nos dias atuais, principalmente em países do terceiro mundo, vários projetos sobre envelhecimento estão sendo realizados.
} 
bastante descrita a correlação inversa entre nível socioeconômico e educacional com essas doenças nos países centrais. Esta afirmação, apesar de corrente e assumida como verdadeira em muitos países, mesmo naqueles onde estudos não foram realizados, precisa ser testada.

Outra afirmação presente nos países desenvolvidos refere-se ao crescente custo da hospitalização entre aqueles de mais de sessenta anos (Clark \& Spengler, 1980; Maguire, Taylor \& Stout, 1986). Uma das características dos idosos é que os problemas da saúde, além de serem de longa duração, requerem pessoal qualificado, equipe multidisciplinar, equipamentos e exames complementares de alto custo. De fato, tudo faz crer que os gastos da hospitalização sejam bastante elevados com os idosos, principalmente com as doenças mentais, já que para estas, quando ocorrem em qualquer faixa etária, a utilização do leito hospitalar é intensiva.

Este artigo se propõe avaliar o idoso, na comunidade e no hospital, com problemas na esfera da doença mental. Pretende-se, no estudo comunitário, verificar a possível correlação de aspectos socioeconômicos e educacionais a partir de dados obtidos no Rio de Janeiro (Veras, 1992, 1994) e verificar a hipótese de associações das variáveis sociais, educacionais, econômicas e demográficas com os casos de sindrome cerebral orgânica e depressão. $O$ interesse por este estudo se justifica pelas prevalências apresentadas no trabalho de um dos autores (Veras, 1992) em que, nas áreas de maior poder aquisitivo e de hábitos e nível educacional semelhantes aos de países ricos, os índices são de três a quatro vezes menores do que nas regiões pobres da cidade, usandose a mesma metodologia e a mesma equipe de aplicadores do instrumento. Resultados tão díspares merecem uma investigação mais cuidadosa, e esta é uma preocupação do artigo.

Por outro lado, a partir do Sistema de Informações Hospitalares do Sistema Único de Saúde (SIH-SUS), com base nos formulários de Autorização de Internação Hospitalar (AIH), pode-se obter um recorte da população idosa internada no Rio de Janeiro devido a doenças mentais. Deste modo, é possível precisar não só as freqüências e os diagnósticos, como também avaliar custos e demais indicadores relativos a esse grupo de internações. Apesar de disponível, esse banco de dados ainda é pouco utilizado, e o esforço de sistematização das internações entre os idosos permitirá um melhor quadro dos problemas psiquiátricos do referido grupo etário no Rio de Janeiro. Esse 
duplo esforço - no campo comunitário e hospitalar - tem como objetivo central ampliar e divulgar informações relativas à saúde mental do idoso, a fim de incentivar maior número de pesquisadores a se debruçar no estudo do envelhecimento.

\section{Transtornos Mentais na Comunidade}

A literatura tem mostrado que os diagnósticos mais encontrados na comunidade são a demência ou Síndrome Cerebral Orgânica (SCO) e a depressão. Compreende-se por SCO o comprometimento das funções corticais (incluindo memória), da capacidade de solucionar problemas cotidianos, da habilidade motora, da linguagem e da comunicação e do controle das reações emocionais. Não há turvação da consciência. A prevalência estimada de casos severos é de $5 \%$ acima de 65 anos e $20 \%$ acima de 80 anos (Jorm, Korten \& Henderson, 1987; Lindesay, Briggs \& Murphy, 1989). Tal diferença reflete o fato de a prevalência de SCO dobrar para cada cinco anos a mais de idade entre os idosos (WHO, 1986).

A depressão inclui as categorias nosológicas de depressão maior e distimia Sua prevalência total situa-se em torno de $15 \%$, sendo que na depressão maior é de cerca de 3\% (Lindesay, Briggs \& Murphy, 1989).

Os estudos de distúrbios mentais em populações idosas começaram há quarenta anos. Até o início dos anos 50, os dados de hospital eram os únicos disponíveis. O primeiro estudo de comunidade registrado neste campo foi realizado por Sheldon, em Wolverhampton, em 1948 (Blay, 1989). Houve um número substancial de estudos nos EUA e na Europa, mas muito poucos no Brasil. Os trabalhos brasileiros mais importantes neste campo foram realizados por Almeida Filho, Santana \& Pinho (1984), Blay, Ramos \& Mari (1988), Blay, Mari \& Ramos (1989) e Ramos (1986).

O estudo de Almeida Filho, Santana \& Pinho (1984), usando o questionário QMPA, entrevistou 1.549 pessoas com mais de 15 anos de idade. Selecionou-se uma subamostra de 139 pessoas com mais de 55 anos, com o propósito de obter a prevalência de problemas de saúde mental nesta última faixa. 
A fim de comparar este estudo com outros, os autores apresentaram os resultados em duas faixas etárias: uma de 95 pessoas com idade entre 55 e 65 anos, e a outra com 44 pessoas com mais de 65 anos. A prevalência de neuroses e de distúrbios psiquiátricos em geral foi mais alta do que a esperada. Para demência, observou-se uma prevalência de $3,1 \%$ na faixa de 55 a 65 anos e de $6,8 \%$ para a faixa acima de 65 anos.

Ramos (1986), em São Paulo, em 1985, usou uma versão brasileira do PSE, um questionário de 15 itens, planejado para detectar distúrbios psiquiátricos nos idosos no seu local de moradia (comunidade). Entre as 292 pessoas idosas envolvidas, 68 tiveram índices acima do ponto de coorte que indicava suspeição a anormalidades psiquiátricas, uma prevalência total estimada de $23 \%$. Contudo, os resultados obtidos no estudo de validação (Blay, Ramos \& Mari, 1988) sugerem uma prevalência real de $25 \%$, ligeiramente mais alta do que a estimada.

O outro estudo foi realizado por Blay (1989) usando 91 pessoas idosas da amostra do levantamento de Ramos (1986). Ele aplicou o Face-Hand Test (FHT), teste clínico planejado para detectar síndrome cerebral orgânica na população idosa. O índice do FHT foi comparado a uma avaliação psiquiátrica, usando-se o Clinical Interview Schedule. A prevalência obtida foi de 5,5\%, em um ponto de coorte de $0 / 1$, constatando-se que o coeficiente de validade foi alto e a taxa global de classificação errônea foi de 8\% (Blay, 1989).

Existem outros estudos brasileiros na comunidade de distúrbios mentais nos idosos, mas de metodologia insatisfatória, e poucos utilizam os dados de hospital (Blay, 1989; Cunha, Barros Jr. \& Siqueira, 1985).

Em face da carência de dados sobre a população de idosos no Brasil, realizou-se um estudo na cidade do Rio de Janeiro, nos anos de 1988 e 1989. Foram selecionados, aleatoriamente, 790 moradores com sessenta anos ou mais, residentes nos bairros de Copacabana, Méier e Santa Cruz, dos quais 738 foram entrevistados. A proporção de não-resposta (7\%) foi homogeneamente distribuída nas três áreas. O instrumento utilizado - o Brazilian Old Age Schedule (BOAS) - foi desenvolvido especialmente para o estudo. Uma de suas seções é composta pela versão em português do Short-Care, uma adaptação do questionário de Gurland et al. (1977), feita pelo grupo de Guy's Hospital and Age Concern Psychogeriatric Research Project. $\mathrm{O}$ instrumento apresentou bom desempenho, conforme os dados do estudo de confiabilidade e validade de- 
monstram (Tabela 1). A descrição detalhada da metodologia empregada encontra-se em vários outros artigos (Veras, Coutinho \& Ney Jr, 1990; Veras \& Coutinho, 1991, 1994; Veras \& Murphy, 1991; Veras, 1992, 1994).

\section{Tabela 1 - Validade e confiabilidade do BOAS (Padrão-Ouro: DSM-III)}

\begin{tabular}{|l|c|c|}
\hline & SCO* & Depressão** \\
\hline Sensibilidade & 1,00 & 0,80 \\
Especificidade & 0,91 & 0,84 \\
KAPPA teste/re-teste & 0,93 & 0,71 \\
KAPPA interavaliador & 1,00 & 0,80 \\
\hline
\end{tabular}

* Ponto de corte $2 / 3$.

** Ponto de corte $7 / 8$.

Entre os três bairros estudados, Copacabana tinha a população mais idosa e com maior nível de escolaridade e renda, enquanto Santa Cruz situou-se no outro extremo. As prevalências de SCO e depressão, assim como seus respectivos intervalos de confiança de $95 \%$, encontram-se na Tabela 2. Os idosos residentes em Santa Cruz não só apresentaram a mais alta prevalência de SCO como também esse valor se situou em um nivel bastante elevado, se comparado ao que se observa na literatura. Embora a Tabela 2 não apresente os dados estratificados por faixa etária, a prevalência de SCO aumentava de forma importante com a idade nas três áreas, para ambos os sexos.

Quanto ao diagnóstico de depressão, Copacabana e Méier apresentaram prevalências próximas, enquanto os idosos de Santa Cruz voltaram a mostrar os valores mais altos. As prevalências para as formas mais graves de depressão (ponto de corte 12/13) foram de 6,8\% em Copacabana, 4,5\% no Méier e 11,6\% em Santa Cruz. Ao contrário do que se observou para SCO, o diagnóstico de depressão não se associou de forma consistente à idade. 
Tabela 2 - Prevalência de SCO e depressão por bairro

\begin{tabular}{|l|c|c|}
\hline Bairro & SCO & Depressão \\
\hline Copacabana $(n=252)$ & $5,9 \pm 2,92$ & $22,6 \pm 5,17$ \\
Méier $(n=244)$ & $9,8 \pm 3,74$ & $19,7 \pm 4,99$ \\
Santa Cruz $(n=242)$ & $29,8 \pm 5,67$ & $35,1 \pm 6,01$ \\
\hline
\end{tabular}

A associação entre SCO, depressão e variáveis sociodemográficas foi inicialmente investigada pelo odds-ratio (OR) não-ajustado. $O$ intervalo de confiança de $95 \%$ foi estimado usando-se o método Cornifield (Kahn \& Sempos, 1989). Em seguida, foram estimados os OR ajustados por regressão logística, assim como seus respectivos intervalos de confiança de $95 \%$. O objetivo do ajuste foi eliminar efeito de 'confusão' que poderia ocorrer entre as associações de interesse, na medida em que a análise exploratória dos dados demonstrou não apenas a associação das variáveis sociodemográficas com a ocorrência dos transtornos mentais, mas também entre si.

A Tabela 3 mostra a prevalência de SCO e depressão segundo as categorias de oito variáveis sociodemográficas. Estas foram calculadas agrupando-se as amostras das três áreas, sem qualquer tipo de ponderação; portanto, não podem ser consideradas como estimativas para a cidade do Rio de Janeiro. O único objetivo de apresentar esses dados é fornecer informação adicional para os odds-ratio apresentados nas duas tabelas a seguir. É importante destacar a maior proporção de mulheres na amostra $(62 \%)$ e o pequeno número de indivíduos nas categorias solteiro $(8 \%)$ e divorciado (5\%). Deve-se acrescentar que não houve informação sobre renda em $32 \%$ da amostra.

$\mathrm{Na}$ Tabela 4 são apresentados os odds-ratio, intervalos de confiança de $95 \%$ e os níveis de significância estatística para as oito variáveis e SCO. $O$ valor 1 na primeira linha de cada variável significa que a categoria foi usada como referência para calcular o OR. Todas as variáveis estavam associadas à SCO quando nenhum ajuste para 'confusão' foi feito. Quando cada variável foi investigada, ajustando-se simultaneamente para os outros sete fatores, a força da associação reduziu-se e perdeu a significância estatística para sexo, estado civil e renda. Uma prevalência aumentada de SCO foi observada apenas para os idosos de 80 anos ou acima desta idade, 
analfabetas, residindo com cinco pessoas ou mais e para aquelas com má condição física. Copacabana foi a área com a menor prevalência dessa desordem. Nenhuma interação entre as variáveis foi encontrada.

\section{Tabela 3 - Prevalência de SCO e depressão segundo as variáveis sociodemográficas}

\begin{tabular}{|c|c|c|c|}
\hline Variável & $\mathrm{N}$ & $\operatorname{SCO}(\%)$ & Depressão(\%) \\
\hline \multicolumn{4}{|l|}{ Sexo } \\
\hline Masculino & 284 & 11,6 & 17,6 \\
\hline Feminino & 454 & 17,2 & 32,6 \\
\hline \multicolumn{4}{|l|}{ Idade } \\
\hline $60-69$ & 361 & 10,5 & 26,3 \\
\hline $70-79$ & 277 & 14,4 & 27,4 \\
\hline 80 ou mais & 100 & 33,0 & 27,0 \\
\hline \multicolumn{4}{|l|}{ Situação conjugal } \\
\hline solteiro & 58 & 12,1 & 29,3 \\
\hline casado & 376 & 10,9 & 20,7 \\
\hline viúvo & 270 & 22,2 & 33,0 \\
\hline divorciado & 34 & 8,8 & 41,2 \\
\hline \multicolumn{4}{|l|}{ Educação } \\
\hline analfabeto & 121 & 49,6 & 44,6 \\
\hline 1"grau incompleto & 135 & 16,3 & 32,6 \\
\hline 1"grau completo ou mais & 476 & 5,5 & 20,2 \\
\hline sem informação & 6 & - & - \\
\hline \multicolumn{4}{|l|}{ Número de pessoas } \\
\hline nenhuma & 86 & 16,3 & 30,2 \\
\hline $1-4$ & 544 & 11,6 & 22,8 \\
\hline 5 ou mais & 105 & 30,5 & 42,9 \\
\hline sem informação & 3 & - & - \\
\hline \multicolumn{4}{|l|}{ Renda (US\$) } \\
\hline até 150 & 150 & 22,0 & 32,0 \\
\hline $151-400$ & 133 & 12,8 & 21,1 \\
\hline 401 ou mais & 218 & 4,1 & 17,9 \\
\hline sem informação & 237 & - & - \\
\hline \multicolumn{4}{|l|}{ Área } \\
\hline Copacabana & 252 & 6,0 & 23,0 \\
\hline Méier & 244 & 9,8 & 20,9 \\
\hline Santa Cruz & 242 & 29,8 & 36,8 \\
\hline \multicolumn{4}{|l|}{ Saúde física } \\
\hline ruim & 129 & 30,2 & 60,5 \\
\hline boa & 609 & 11,8 & 19,7 \\
\hline
\end{tabular}


Tabela 4-Odds-rationão-ajustados $\left(\mathrm{OR}^{\mathrm{na}}\right)$ e ajustados $\left(\mathrm{OR}^{\mathrm{a}}\right)$ para SCO e variáveis sociodemográficas

\begin{tabular}{|c|c|c|c|c|}
\hline Variável & $\mathrm{OR}^{\mathrm{na}}$ & IC $95 \%$ & $\mathrm{OR}^{2}$ & IC $95 \%$ \\
\hline \multicolumn{5}{|l|}{ Sexo } \\
\hline Masculino & 1 & & 1 & \\
\hline Feminino & $2,39 * * *$ & $1,32-4,34$ & 1,37 & $0,57-3,26$ \\
\hline \multicolumn{5}{|l|}{ Idade } \\
\hline $60-69$ & 1 & & 1 & \\
\hline $70-79$ & 1,28 & $0,69-2,38$ & 1,01 & $0,43-2,38$ \\
\hline 80 ou mais & $3,50^{* * *}$ & $1,56-7,84$ & $5,05 * *$ & $1,42-17,96$ \\
\hline \multicolumn{5}{|l|}{ Situação conjugal } \\
\hline solteiro/casado/divorciado & 1 & & 1 & \\
\hline viúvo & $2,75^{* * *}$ & $1,56-4,85$ & 1,59 & $0,64-3,93$ \\
\hline \multicolumn{5}{|l|}{ Educação } \\
\hline analfabeto & 1 & & 1 & \\
\hline 1grau incompleto & $0,11^{* * *}$ & $0,05-0,25$ & $0,09 * * *$ & $0,03-0,24$ \\
\hline 1थgrau completo ou mais & $0,02^{* * *}$ & $0,01-0,05$ & $0,06^{* * *}$ & $0,02-0,16$ \\
\hline \multicolumn{5}{|l|}{ Número de pessoas } \\
\hline nenhuma & 1 & & 1 & \\
\hline $1-4$ & $0,51 *$ & $0,23-1,15$ & 1,22 & $0,37-3,94$ \\
\hline 5 ou mais & $3,65^{* * *}$ & $1,42-9,43$ & $4,48 * *$ & $1,10-18,28$ \\
\hline \multicolumn{5}{|l|}{ Renda (US\$) } \\
\hline até 150 & 1 & & 1 & \\
\hline $151-400$ & $0,48^{* *}$ & $0,25-0,94$ & 0,55 & $0,21-1,44$ \\
\hline 401 ou mais & $0,14^{* * *}$ & $0,06-0,30$ & 1,38 & $0,42-4,52$ \\
\hline \multicolumn{5}{|l|}{ Área } \\
\hline Copacabana & 1 & & 1 & \\
\hline Méier & $3,83^{* *}$ & $1,03-14,25$ & 2,09 & $0,44-9,82$ \\
\hline Santa Cruz & $22,75^{* * *}$ & $6,86-75,40$ & $12,65^{* * *}$ & $2,40-66,68$ \\
\hline \multicolumn{5}{|l|}{ Saúde física } \\
\hline ruim & 1 & & 1 & \\
\hline boa & $0,16^{* * *}$ & $0,08-0,32$ & $0,36^{* *}$ & $0,13-1,02$ \\
\hline
\end{tabular}

$* 0,10<\mathrm{p}<0,05$.

$* * 0,05>\mathrm{p}>0,01$.

$* * * \mathrm{p}<0,01$. 
Tabela 5 - Odds-ratio não-ajustados $\left(O R^{\text {na }}\right)$ e ajustados $\left(O R^{2}\right)$ para depressão e variáveis sociodemográficas

\begin{tabular}{|c|c|c|c|c|}
\hline Variável & $\mathrm{OR}^{\mathrm{na}}$ & IC $95 \%$ & $\mathrm{OR}^{\mathrm{a}}$ & IC $95 \%$ \\
\hline $\begin{array}{l}\text { Sexo } \\
\text { Masculino } \\
\text { Feminino } \\
\end{array}$ & $\begin{array}{l}1 \\
2,98^{* * * *} \\
\end{array}$ & $1,87-4,76$ & (I) & \\
\hline $\begin{array}{l}\text { Idade } \\
\begin{array}{l}60-69 \\
70-79 \\
80 \text { ou mais }\end{array}\end{array}$ & $\begin{array}{l}1 \\
0,79 \\
1,17 \\
\end{array}$ & $\begin{array}{l}0,50-1,25 \\
0,55-2,50 \\
\end{array}$ & $\begin{array}{l}1 \\
0,64 \\
0,89 \\
\end{array}$ & $\begin{array}{l}1 \\
0,36-1,11 \\
0,34-2,36 \\
\end{array}$ \\
\hline $\begin{array}{l}\text { Situação conjugal } \\
\text { solteiro/casado } \\
\text { viúvo/divorciado }\end{array}$ & $\begin{array}{l}1 \\
2,07^{* * *}\end{array}$ & $1,34-3,19$ & $\begin{array}{l}1 \\
1,29\end{array}$ & $0,73-2,30$ \\
\hline $\begin{array}{l}\text { Educação } \\
\text { analfabeto } \\
\text { 1^grau incompleto } \\
\text { 1grau completo ou mais }\end{array}$ & $\begin{array}{l}1 \\
0,30 * * * \\
0,16 * * *\end{array}$ & $\begin{array}{l}0,15-0,61 \\
0,09-0,30\end{array}$ & $\begin{array}{l}1 \\
0,31 * * * \\
0,27^{* * *}\end{array}$ & $\begin{array}{l}0,13-0,72 \\
0,12-0,60\end{array}$ \\
\hline $\begin{array}{l}\text { Número de pessoas } \\
\text { não } \\
1-4 \\
5 \text { ou mais }\end{array}$ & $\begin{array}{l}1 \\
0,57 * \\
2,09 *\end{array}$ & $\begin{array}{l}0,31-1,04 \\
0,90-4,50\end{array}$ & (I) & \\
\hline $\begin{array}{l}\text { Renda (US\$) } \\
\text { até } 150 \\
151-400 \\
401 \text { ou mais }\end{array}$ & $\begin{array}{l}1 \\
0,52^{* *} \\
0,40^{* * *}\end{array}$ & $\begin{array}{l}0,30-0,92 \\
0,24-0,66\end{array}$ & $\begin{array}{l}1 \\
0,51^{*} \\
0,74\end{array}$ & $\begin{array}{l}0,26-1,03 \\
0,35-1,56 \\
\end{array}$ \\
\hline $\begin{array}{l}\text { Área } \\
\text { Copacabana } \\
\text { Méier } \\
\text { Santa Cruz } \\
\end{array}$ & $\begin{array}{l}1 \\
1,08 \\
2,59 * * *\end{array}$ & $\begin{array}{l}0,61-1,89 \\
1,55-4,34 \\
\end{array}$ & $\begin{array}{l}1 \\
0,73 \\
1,14 \\
\end{array}$ & $\begin{array}{l}0,35-1,53 \\
0,49-2,67\end{array}$ \\
\hline $\begin{array}{l}\text { Saúde física } \\
\text { ruim } \\
\text { boa }\end{array}$ & $\begin{array}{l}1 \\
0,11 * * *\end{array}$ & $0,06-1,95$ & $\begin{array}{l}1 \\
0,14^{* *}\end{array}$ & $0,07-0,26$ \\
\hline
\end{tabular}

$* 0,10<\mathrm{p}<0,05$.

$* * 0,05>\mathrm{p}>0,01$.

$* * * \mathrm{p}<0,01$.

(I) Presença de interação. 
$\mathrm{Na}$ análise não-ajustada, todas as variáveis sociodemográficas, exceto idade, mostraram-se associadas ao diagnóstico de depressão pelo questionário BOAS (Tabela 5). No entanto, a maior presença de depressão entre viúvos $\mathrm{c}$ divorciados desapareceu quando se efetuou a análise multivariada. Idosos analfabetos, com renda inferior a US\$151 e com má saúde física apresentaram maior taxa de prevalência de depressão.

A presença de interação de sexo com o número de residentes na casa foi sugerida pelo modelo de regressão logística ( $L R S=5,55,2 \mathrm{df}, \mathrm{p}=0,06)$. A Tabela 6 mostra os OR e os intervalos de confiança de $95 \%$ para homens e mulheres, segundo o número de moradores no domicílio. É sugerido que a maior presença de depressão associada ao fato de se morar em uma casa superlotada é superior no caso dos idosos do sexo masculino, apenas.

\section{Tabela 6 - Odds-ratio e intervalos de confiança para interação entre sexo e número de moradores no domicílio}

\begin{tabular}{|l|c|c|}
\hline Número de pessoas & Masculino & Feminino \\
\hline mora só & 1 & $3,96(0,74-21,07)$ \\
$1-4$ & $1,04(0,20-5,45)$ & $3,79(0,79-18,06)$ \\
5 ou mais & $8,63(1,38-53,91)$ & $4,84(0,78-30,01)$ \\
\hline
\end{tabular}

LRS $=5,55,2 \mathrm{gl}, \mathrm{p}=0,06$.

\section{Discussão dos Resultados do Estudo Comunitário}

Alguns comentários gerais a partir dos resultados merecem ser feitos. Pelo fato de os dados apresentados serem de um estudo de prevalência, tivemos o cuidado de não utilizar a palavra risco, mas sim de mencionar que determinadas variáveis estão associadas com maior ou menor presença de doença. Em relação aos resultados obtidos, verifica-se que a idade associouse de modo importante à SCO, mas só a partir dos 80 anos. Isto é, não se observou aumento da prevalência ao se passar do grupo de 60-69 anos para o de 70-79 anos, conforme relatado em diversos estudos. Pode-se, assim, expli- 
car por que a associação entre $\mathrm{SCO}$ e sexo feminino desapareceu quando controlou-se por idade, pois as mulheres eram mais velhas do que os homens em nossa amostra. $\mathrm{O}$ mesmo pode ser dito em relação à perda da associação para viúvos, quando o controle para 'confusão' foi realizado.

Uma questão que merece maior aprofundamento refere-se ao instrumento. As prevalências de Santa Cruz mostraram-se atípicas, principalmente se levarmos em consideração que a mesma metodologia, o instrumento e os entrevistadores foram utilizados nas áreas estudadas. $O$ fato de Santa Cruz apresentar uma associação bastante forte com SCO, mesmo depois de ajustar os dados por idade, renda e escolaridade, precisa ser mais bem explorado, e a hipótese ligada ao problema do instrumento foi objeto de um artigo recente (Veras \& Coutinho, 1994). Assim, é possível que o instrumento de pesquisa utilizado para estabelecer o diagnóstico de SCO não seja adequado ao uso em determinados segmentos socioeconômicos, podendo apresentar resultados enganosos. Em tais áreas, caracterizadas pela carência de facilidades urbanas, de baixa escolaridade e renda entre os moradores (em particular os idosos), podem-se obter resultados distorcidos pela inadequação de instrumentos desenvolvidos em uma realidade social totalmente diversa. Apesar de todos os cuidados de tradução e do exaustivo treinamento da equipe de campo, algumas perguntas, talvez por não pertencerem ao universo cultural daquela população, levaram à obtenção de escores que acabaram por atribuir um grau de anormalidade a esses indivíduos. Por exemplo: não saber o endereço onde mora, o nome do presidente da República ou decorar três palavras do nome da instituição de pesquisa que está realizando a pesquisa ${ }^{2}$ são considerados valores de normalidade para um determinado contexto social e cultural, não devendo, assim, ser estendidos a todos os segmentos da população.

Ao contrário da SCO, o aumento da faixa etária não se associou à maior ocorrência de depressão. Este achado já foi descrito em outros estudos internacionais em que o pico de depressão situa-se em idade imediatamente anterior ao início da terceira idade. $O$ excesso de casos de depressão entre os idosos se deu entre os analfabetos e com renda inferior a US\$ 151.

\footnotetext{
${ }^{2} \mathrm{O}$ detalhamento dos itens perguntados e o percentual de acerto para Santa Cruz e demais áreas do estudo, bem como uma discussão mais aprofundada, são apresentados em artigo recentemente publicado (Veras \& Coutinho, 1994) e na tese de doutorado de um dos autores do artigo (Veras, 1992).
} 


\section{INTERNAÇÕES HOSPITALARES POR Transtornos MeNTAIS EM IDOSOS}

Poucos são os estudos em nosso meio que procuraram avaliar aspectos relativos às internações hospitalares no segmento de pacientes idosos, incluindo aquelas devidas a transtornos mentais. Este fato pode ser explicado tanto pelo número reduzido de trabalhos na área da terceira idade (Veras \& Alves, 1995) como pela dificuldade de acesso às fontes de dados sobre hospitalizações.

O Sistema de Informações Hospitalares do Sistema Único de Saúde (SIH-SUS), ${ }^{3}$ baseado nos formulários de Autorização de Internação Hospitalar (AIH), foi implantado há cerca de dez anos, inicialmente restrito aos serviços contratados privados e estendido posteriormente à rede filantrópica, universitária e, mais recentemente, ao restante da rede pública (MS/SES-RJ, 1990). Apesar disso, somente a partir de 1993 possibilitou-se o acesso amplo e ágil às bases de dados do SIH-SUS, através do serviço de correio eletrônico MS-BBS (MS/FNS/DATASUS/GTDB).

O SIH-SUS tem ampla cobertura nacional, abrangendo a totalidade da rede hospitalar pública (federal, municipal, estadual e universitária), além das redes privada contratada e filantrópica. É informatizado e trabalha com um conjunto variado de dados que permite avaliações que vão desde o perfil de morbidade hospitalar até a análise de procedimentos empregados durante a internação. Isto faz dele uma ferramenta potencial para a realização de estudos que tenham como objetivo a análise das internações em nosso meio.

Entretanto, algumas questões devem ser levantadas, com relação à acurácia dos dados registrados nos formulário AIH e, conseqüentemente, sobre a utilização do SIH-SUS com fins de avaliação. Embora o sistema de processamento eletrônico dos formulários AIH conte com algumas rotinas de tratamento de erros e com a obrigatoriedade do preenchimento de alguns campos, as primeiras não abrangem todo o escopo das variáveis, levando provavelmente ao preenchimento heterogêneo dos diferentes campos. Por outro lado, uma das grandes qualidades do SIH-SUS - abranger um número extenso de unidades da saúde pertencentes a diferentes redes - também pode contribuir

\footnotetext{
${ }^{3}$ Antigo Sistema de Assistência Médico-Hospitalar da Previdência Social (SAMHPS/AIH).
} 
para diferenças marcantes em relação à qualidade dos dados registrados pelas diferentes unidades da saúde, em função da maior ou da menor disponibilidade de recursos físicos e humanos para o processamento dos formulários $\mathrm{AIH}$. $O$ fato de este sistema raramente ser utilizado pelas unidades da saúde como fonte de informação deve trazer prejuizos adicionais, já que neste caso o acompanhamento contínuo da qualidade dos dados também não será implementado. Por fim, em se tratando de um sistema voltado para o faturamento, muitas distorções podem surgir, principalmente no que diz respeito ao registro dos serviços realizados. A experiência americana do financiamento prospectivo da assistência hospitalar, baseada nos Diagnosis Related Groups, ou DRGs (sistema de classificação de pacientes de acordo com o consumo de recursos durante a internação), apontou para algumas distorções, tais como a seleção de pacientes de maior rentabilidade e o aumento de altas precoces - 'mais rápido e mais doente' (Braga Neto, 1991; Fetter \& Thompson, 1992).

Travassos Veras \& Martins (1994) realizaram um estudo de confiabilidade dos dados dos formulários AIH preenchidos pelos hospitais privados, contratados da cidade do Rio de Janeiro durante o ano de 1986. Os resultados apontaram para uma grande variabilidade na qualidade dos dados entre as diferentes variáveis preenchidas, com as variáveis sexo, idade e tempo de permanência, apresentando alta confiabilidade, o mesmo não sendo verificado para o diagnóstico principal, para o qual as autoras recomendam a realização das análises, tomando por base as categorias mais agregadas (códigos de três dígitos) da Classificação Internacional de Doenças (CID-9). Por fim, apesar de a variável procedimento realizado ter apresentado boa confiabilidade, verificou-se que, em alta proporção dos casos discordantes, o procedimento registrado representava maior valor de reembolso para o hospital.

Levando em consideração todas estas restrições, buscamos traçar o perfil das internações por transtornos mentais na população idosa do município do Rio de Janeiro durante o ano de 1993 apor meio da análise da base de dados dos formulários AIH. Foram consideradas como internações por transtornos mentais todas aquelas cujo procedimento realizado pertencia ao grupo de procedimentos em psiquiatria (INAMPS - Tabela de Procedimentos - SIHSUS - Dígitos iniciais $=63$ ) e/ou que apresentavam como diagnóstico principal o código da CID-9, pertencente ao capítulo V (categorias 290 a 319). É importante ressaltar que, por limitações da base de dados disponível, empre- 
garam-se como unidade de análise as internações (formulários AIH-1) em vez do indivíduo, não sendo possível identificar, desta forma, a ocorrência de reinternações durante o período de estudo. Adicionalmente, para os registros dos AIH-1 que geraram um ou mais formulários complementares (AIH-5) apresentados para reembolso, tanto em 1993 como em 1994, procedeu-se à totalização das variáveis tempo de permanência e valor do reembolso.

Durante o ano de 1993 registrou-se um total de 348.858 formulários AIH-1, sendo $69.383(19,9 \%)$ no grupo etário acima de 60 anos. Do conjunto de internações entre a população idosa, 3.225 foram por transtornos mentais, correspondendo a 13,3\% do total das internações deste tipo. Quando se considera apenas o código da CID, pode ser verificado que as patologias do capítulo dos transtornos mentais ocupam o oitavo lugar das causas de internação na população idosa ao lado das patologias dos capítulos III (Doenças das Glândulas Endócrinas, da Nutrição e do Metabolismo e Transtornos Imunitários) e XVII (Lesões e Envenenamentos), o que representa uma proporção de $4,6 \%$ do total das internações neste grupo etário (Gráfico 1).

Gráfico 1- Distribuição das internações de idosos segundo os principais diagnósticos (capítulos da CID-9). Município do Rio de Janeiro - 1993

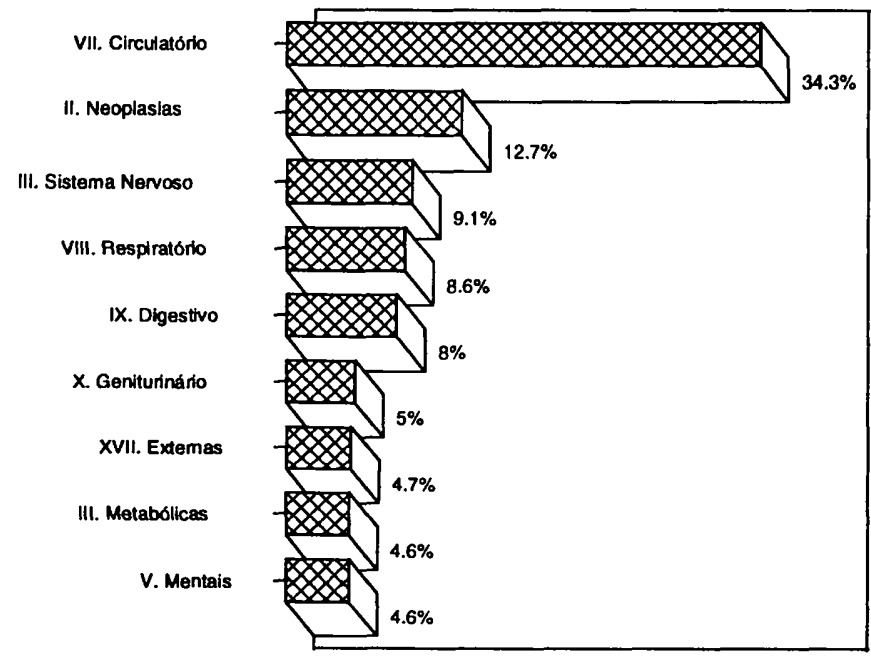


$\mathrm{Na}$ Tabela 7 é apresentada a distribuição das internações por transtornos mentais segundo a natureza do hospital, sendo observado um predomínio dessas internações $(52,1 \%)$ na rede privada contratada. Esse padrão também foi verificado nos anos de 1991 e 1992 por Queiroz (1993), sendo explicado pelo fato de a rede privada contratada responder por $64,4 \%$ dos leitos psiquiátricos cadastrados pelo SIH-SUS no município do Rio de Janeiro. A predominância de internações na rede privada foi observada em todas as faixas etárias, à exceção do grupo com 60 anos ou mais, em que a maior proporção dessas internações se deu na rede pública.

Já a análise da distribuição das admissões por transtornos mentais, levando-se em conta o sexo (Tabela 8), demonstrou maior proporção de internações para o sexo masculino. Entretanto, a análise estratificada, segundo grupo etário, evidenciou uma interessante modificação de padrão, com a predominância do sexo masculino, desaparecendo após os 60 anos - o que, por sua vez, deve ser explicado, ainda que parcialmente, pela maior proporção de mulheres idosas do que de homens idosos na composição populacional (Monteiro \& Alves, 1995).

\section{Tabela 7-Distribuição das internações por transtornos mentais segundo grupo etário e natureza do hospital. Município do Rio de Janeiro - 1993}

\begin{tabular}{|c|c|c|c|c|c|c|c|c|}
\hline \multirow{3}{*}{$\begin{array}{l}\text { Grupo } \\
\text { etário }\end{array}$} & \multicolumn{8}{|c|}{ Natureza do hospital } \\
\hline & \multicolumn{2}{|c|}{ contratado } & \multicolumn{2}{|r|}{ federal } & \multicolumn{2}{|c|}{ estadual } & \multicolumn{2}{|c|}{ outras } \\
\hline & $\mathbf{n}$ & $\begin{array}{c}\% \\
\text { (IC 95\%) }\end{array}$ & $n$ & $\begin{array}{c}\% \\
\text { (IC 95\%) }\end{array}$ & $\mathrm{n}$ & $\begin{array}{c}\% \\
\text { (IC 95\%) }\end{array}$ & n & $\begin{array}{c}\% \\
\text { (IC 95\%) }\end{array}$ \\
\hline 0219 & 373 & $\begin{array}{c}43,83 \% \\
(40,46-47,24)\end{array}$ & 323 & $\begin{array}{c}37,68 \% \\
(34,68-41,31)\end{array}$ & 103 & $\begin{array}{c}12,10 \% \\
(9,99-14,49)\end{array}$ & 52 & $\begin{array}{c}6,11 \% \\
(4,60-7,94)\end{array}$ \\
\hline $20 \times 59$ & 11.044 & $\begin{array}{c}55,10 \% \\
(54,41-55,79) \\
\end{array}$ & 4.105 & $\begin{array}{c}20,48 \% \\
(19,93-21,05) \\
\end{array}$ & 3.144 & $\begin{array}{c}15,69 \% \\
(15,19-16,20) \\
\end{array}$ & 1.749 & $\begin{array}{c}8,73 \% 11 \\
(8,34-9,13) \\
\end{array}$ \\
\hline 60 ou mais & 1.098 & $\begin{array}{c}34,05 \% \\
(32,41-35,71)\end{array}$ & 1.861 & $\begin{array}{c}57,71 \% \\
(55,98-59,42)\end{array}$ & 144 & $\begin{array}{c}4,47 \% 11 \\
(3,78-5,23)\end{array}$ & 122 & $\begin{array}{c}3,78 \% \\
(3,15-4,50)\end{array}$ \\
\hline ignorada & 122 & $\begin{array}{c}79,74 \% \\
(72,49-85,79)\end{array}$ & 7 & $\begin{array}{c}4,58 \% \\
(1,86-9,20)\end{array}$ & 10 & $\begin{array}{c}6,53 \% \\
(3,18-11,69)\end{array}$ & 14 & $\begin{array}{c}9,15 \% \\
(5,09-14,88)\end{array}$ \\
\hline TOTAL & 12.637 & $\begin{array}{c}50,95 \% \\
(50,32-51,38)\end{array}$ & 6.296 & $\begin{array}{c}25,94 \% \\
(24,50-25,39)\end{array}$ & 3.401 & $\begin{array}{c}14,01 \% \\
(13,58-14,45)\end{array}$ & 1.937 & $\begin{array}{c}7,98 \% \\
(7,64-8,33)\end{array}$ \\
\hline
\end{tabular}

Fonte: Base de dados dos formulários AIH (Brasil, 1990). 
Tabela 8 - Distribuição das internações por transtornos mentais segundo grupo etário e sexo. Município do Rio de Janeiro - 1993

\begin{tabular}{|c|c|c|c|c|c|c|}
\hline \multirow{3}{*}{ Grupo etário } & \multicolumn{6}{|c|}{ Sexo } \\
\hline & \multicolumn{2}{|c|}{ masculino } & \multicolumn{2}{|c|}{ feminino } & \multicolumn{2}{|c|}{ TOTAL } \\
\hline & $\mathrm{n}$ & $\begin{array}{c}\% \\
(\text { IC } 95 \%)\end{array}$ & $\mathrm{n}$ & $\begin{array}{c}\% \\
(\text { IC 95\%) }\end{array}$ & $\mathrm{n}$ & $\begin{array}{c}\% \\
\text { (IC 95\%) }\end{array}$ \\
\hline 0 a 19 & 578 & $\begin{array}{c}67,92 \% \\
(64,67-71,05)\end{array}$ & 273 & $\begin{array}{c}32,08 \% \\
(28,95-35,33)\end{array}$ & 851 & $\begin{array}{c}3,51 \% \\
(3,28-3,75)\end{array}$ \\
\hline 20 a 59 & 13.121 & $\begin{array}{c}65,48 \% \\
(64,81-66,13)\end{array}$ & 6.921 & $\begin{array}{c}34,53 \% \\
(33,87-35,19)\end{array}$ & 20.042 & $\begin{array}{c}82,57 \% \\
(82,09-83,05)\end{array}$ \\
\hline 60 ou mais & 1.454 & $\begin{array}{c}45,09 \% \\
(43,37-46,81)\end{array}$ & 1.771 & $\begin{array}{c}54,91 \% \\
(53,18-56,64)\end{array}$ & 3.225 & $\begin{array}{c}13,29 \% \\
(12,86-13,72)\end{array}$ \\
\hline ignorada & 54 & $\begin{array}{c}31,29 \% \\
(27,75-43,42)\end{array}$ & 94 & $\begin{array}{c}61,44 \% \\
(53,24-69,19)\end{array}$ & 153 & $\begin{array}{c}0,63 \% \\
(0,53-0,74)\end{array}$ \\
\hline TOTAL & 15.212 & $\begin{array}{c}62,67 \% \\
(62,06-63,28)\end{array}$ & 9.059 & $\begin{array}{c}37,33 \% \\
(36,71-37,93)\end{array}$ & 24.271 & $100 \%$ \\
\hline
\end{tabular}

Fonte: Base de dados dos formulários AIH (Brasil, 1990).

Travassos Veras (1992), estudando as internações realizadas em hospitais psiquiátricos privados, contratados do município do Rio de Janeiro durante o ano de 1986, evidenciou uma sub-representação dos idosos e das mulheres nas internações nesses hospitais. Nossos resultados confirmam este achado, como pode ser observado na Gráfico 2, em que há menor proporção de internações de idosos em hospitais privados contratados em relação aos demais grupos etários. Adicionalmente, verifica-se que, embora em todos os estratos etários a proporção de internações do sexo masculino seja maior do que a do sexo feminino, esta diferença se apresenta mais acentuadamente no grupo com mais de 60 anos, configurando uma situação de provável dificuldade de acesso a esses serviços pela população idosa, especialmente pela mulher. 
Gráfico 2 - Proporção das internações por transtornos mentais em hospitais privados contratados segundo grupo etário e sexo. Município do Rio de Janeiro - 1993

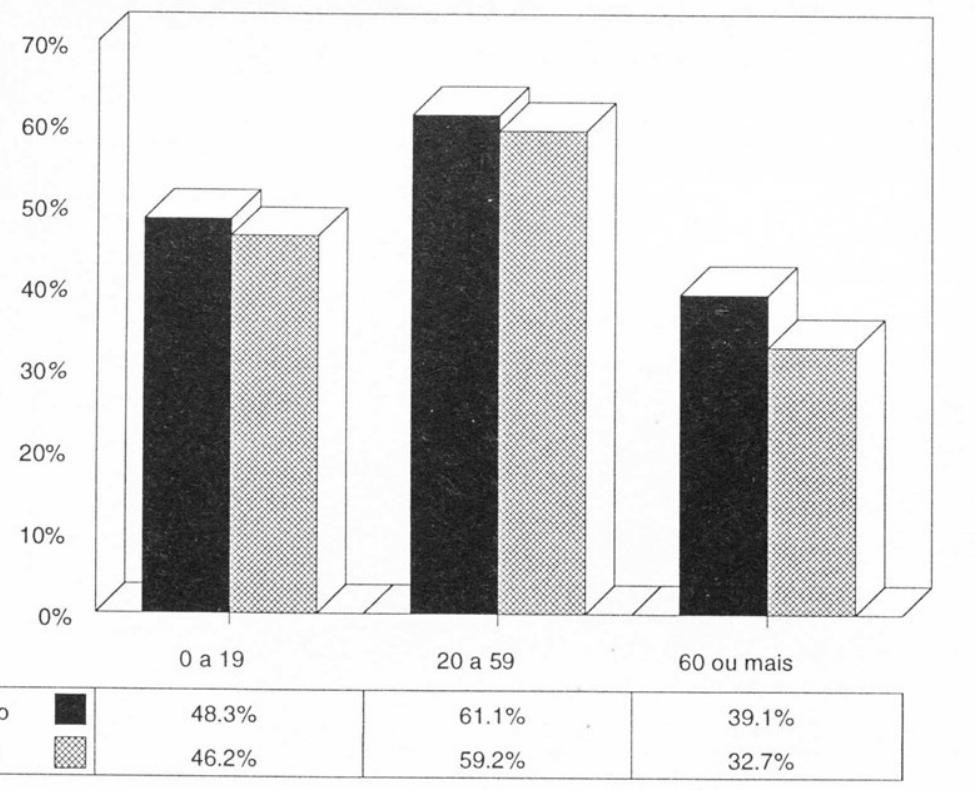

Com relação ao perfibnosológico, verifica-se que as psicoses esquizofrênicas (CID-9, categoria 295) representaram a principal causa de internação em todas as faixas etárias (Tabela 9). No entanto, a análise das subcategorias deste código revelou uma distribuição distinta dentro de cada faixa etária, a saber:

- 0 a 19 anos - predomínio dos códigos 295.9 (não-especificadas) e 295.3 (tipo paranóide) com $37,2 \%$ e $28,9 \%$ do total da categoria, respectivamente;

- 20 a 59 anos - predomínio dos códigos 295.3 (tipo paranóide), 295.6 (residual) e 295.9 (não-especificadas) com 35,2\%, 34,7\% e 19,4\% do total da categoria, respectivamente;

- 60 ou mais - predomínio dos códigos 295.6 (residual) e 295.3 (tipo paranóide) com $66,6 \%$ e $20,5 \%$ do total da categoria, respectivamente. 
Percebe-se, assim, o nítido aumento dos quadros residuais com o avançar da idade, fato este já descrito na literatura (Tavares Jr., 1994).

\section{Tabela 9 - Principais categorias diagnósticas (CID-9) nas internações por transtornos mentais segundo grupo etário. Município do Rio de Janeiro - 1993}

\begin{tabular}{|l|c|c|c|}
\hline Grupo etário/Categorias & $\mathrm{n}$ & $\%$ & I. C. de $95 \%$ \\
\hline 0 a 19 anos (Total = 851) & & & \\
Psicoses esquizofrênicas (295) & 253 & $29,73 \%$ & $26,27 \%$ a $32,95 \%$ \\
Outras psicoses não-orgânicas (298) & 223 & $26,20 \%$ & $23,28 \%$ a $29,30 \%$ \\
Outras oligofrenias especificadas (318) & 137 & $16,10 \%$ & $13,69 \%$ a $18,74 \%$ \\
Dependência de drogas (304) & 38 & $4,47 \%$ & $3,18 \%$ a $6,08 \%$ \\
Síndrome da dependência do álcool (303) & 29 & $3,41 \%$ & $2,29 \%$ a $4,86 \%$ \\
\hline 20 a 59 anos (Total = 20.042) & & & \\
Psicoses esquizofrênicas & 9.109 & $45,45 \%$ & $44,76 \%$ a $46,14 \%$ \\
Outras psicoses não-orgânicas (298) & 3.090 & $15,41 \%$ & $14,92 \%$ a $15,93 \%$ \\
Psicoses alcoúlicas (291) & 2.410 & $12,02 \%$ & $11,58 \%$ a $12,48 \%$ \\
Síndrome da dependência do álcool (303) & 1.646 & $8,21 \%$ & $7,84 \%$ a $8,60 \%$ \\
Psicoses afetivas (296) & 1.104 & $5,50 \%$ & $5,20 \%$ a 5,83\% \\
\hline 60 anos ou mais (Total = 3.225) & & & \\
Psicoses esquizofrênicas & 1.765 & $54,73 \%$ & $53,00 \%$ a $56,46 \%$ \\
Quadros psicóticos orgânicos senis e pré-senis (290) & 318 & $9,86 \%$ & $8,85 \%$ a $10,94 \%$ \\
Outras psicoses não-orgânicas (298) & 232 & $7,19 \%$ & $6,33 \%$ a $8,14 \%$ \\
Psicoses alcoólicas (291) & 184 & $5,71 \%$ & $4,93 \%$ a $6,56 \%$ \\
Psicoses afetivas (296) & 181 & $5,61 \%$ & $4,84 \%$ a $6,46 \%$ \\
\hline
\end{tabular}

Fonte: Base de dados dos formulários AIH (Brasil, 1990).

No grupo de crianças/adolescentes, as outras psicoses não-orgânicas (CID-9, categoria 298) foram o segundo diagnóstico mais freqüentemente observado, enquanto os quadros relacionados ao alcoolismo (CID-9, categorias 291 e 303) responderam pelo segundo lugar no grupo dos adultos. Entre os idosos, esta posição foi ocupada pelos quadros psicóticos orgânicos senis e pré-senis (CID-9, categoria 290) com predominância das subcategorias 290.0 (demência senil tipo simples), 290.8 (outros) e 290.4 (demência arterioscleró- 
tica), representando, respectivamente, $40,9 \%, 13,8 \%$ e $13,2 \%$ do total da categoria. As psicoses afetivas (CID-9, categoria 296) representaram o quinto diagnóstico mais freqüente no grupo dos idosos. Dentro desta categoria sobressaíram os códigos 296.9 (não-especificadas), 296.0 (psicose maníaco-depressiva, tipo maníaco), 296.1 (psicose maníaco-depressiva, tipo depressivo) e 296.4 (psicose maníaco-depressiva circular, tipo misto), representando, respectivamente, $37,6 \%, 21,5 \%, 19,9 \%$ e $11,0 \%$ do total da categoria.

A análise do perfil nosológico do grupo de idosos estratificados segundo faixa etária (Gráficos 3 e 4) revelou, para ambos os sexos, uma crescente importância relativa das demências como causa de internação psiquiátrica com $o$ avançar da idade.

Gráfico 3 - Proporção das principais categorias de internação por transtornos mentais em homens idosos segundo grupo etário. Município do Rio de Janeiro - 1993

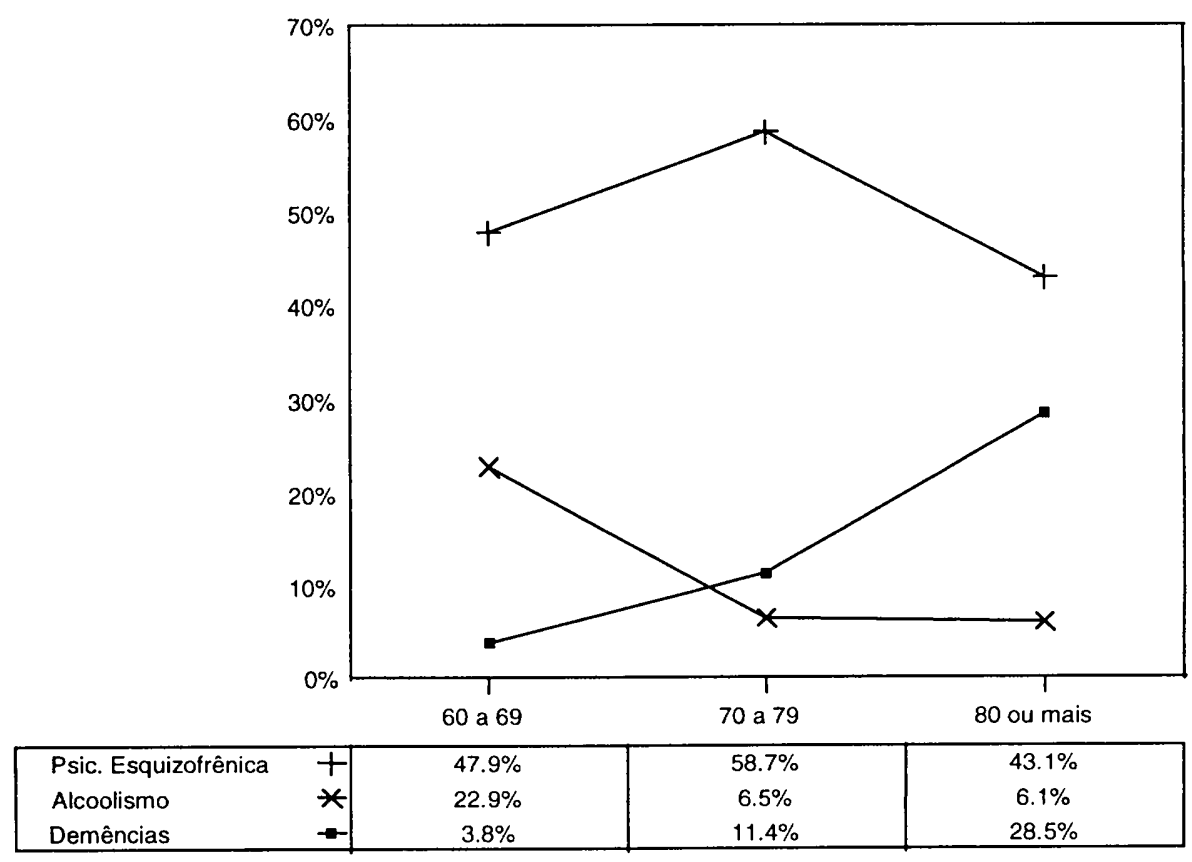


Gráfico 4 - Proporção das principais categorias de internação por transtornos mentais em mulheres idosas segundo grupo etário. Município do Rio de Janeiro - 1993

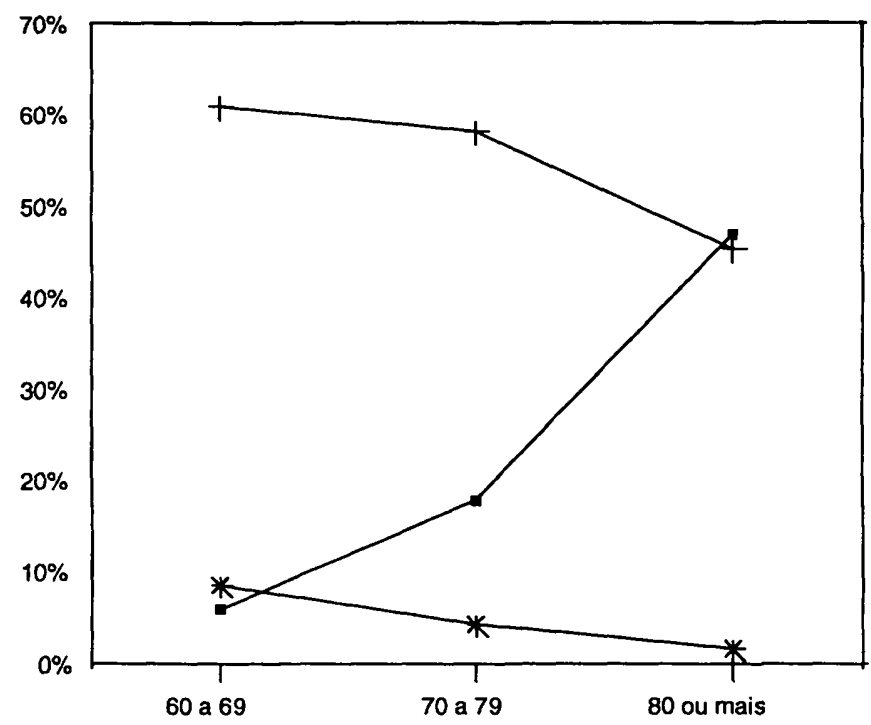

\begin{tabular}{|ll|c|c|c|}
\hline Psic. Esquizofrênica & + & $60.9 \%$ & $58.1 \%$ & $45.3 \%$ \\
Psic. Nao Orgânicas & $*$ & $8.5 \%$ & $4.2 \%$ & $1.6 \%$ \\
Deménéncias & - & $5.9 \%$ & $17.7 \%$ & $46.9 \%$ \\
\hline
\end{tabular}

Por fim, a análise relativa ao consumo de recursos mostra que as internações por transtornos mentais em idosos apresentaram valores de mediana ${ }^{4}, \tan$ to para o tempo de permanência como para o custo, que são aproximadamente o dobro daqueles observados para as outras faixas etárias (Tabela 10). Padrão semelhante foi verificado quando se consideraram todas as causas de internação em conjunto (Coeli, Camargo Jr. \& Veras, 1995), confirmando a vocação da população idosa como grande consumidora de recursos da saúde.

\footnotetext{
${ }^{4}$ Os valores de mediana foram apresentados no lugar das médias em função de as distribuições de tempo de permanência e custo apresentarem assimetria positiva.
} 
Tabela 10 - Valores dos quartis das distribuições de tempo de permanência e custo das internações por transtornos mentais segundo grupo etário. Município do Rio de Janeiro - 1993

\begin{tabular}{|l|c|c|c|c|c|c|}
\hline \multirow{2}{*}{$\begin{array}{l}\text { Grupo } \\
\text { etário }\end{array}$} & \multicolumn{3}{|c|}{ Tempo de permanência (dias) } & \multicolumn{3}{c|}{ Custo total (US\$) } \\
\cline { 2 - 7 } & 1 2 quartil & mediana & 3 9 quartil & 1 2 quartil & mediana & 3 2 quartil \\
\hline 0 a 19 & 9 & 28 & 85 & 81,00 & 248,50 & 774,00 \\
20 a 59 & 8 & 29 & 62 & 74,00 & 256,00 & 607,00 \\
60 ou mais & 29 & 60 & 183 & 148,00 & 552,00 & $1.126,00$ \\
\hline
\end{tabular}

Fonte: Base de dados dos formulários AIH (Brasil, 1990).

\section{Discussão dos Resultados do Estudo Hospitalar}

Como já foi mencionado, observa-se um quadro diferenciado entre o perfil da morbidade hospitalar por transtornos mentais na população idosa com relação àquele encontrado na comunidade. Apesar de as diferenças entre os sistemas de classificação dos diagnósticos empregados nos estudos na comunidade e hospitalar poderem responder parcialmente pelas discrepâncias observadas, outros fatores, provavelmente, estão envolvidos. Segundo Travassos Veras (1992), a chance de internação por um diagnóstico específico envolve não somente a prevalência da doença na população como também fatores relacionados à oferta de serviços e à organização da prática médica.

É interessante ressaltar, entretanto, que o grupo das demências (conjunto de diagnósticos relacionados ao rótulo $\mathrm{SCO}$ do estudo comunitário) apresentou uma crescente importância relativa como causa de internação com o avançar da idade. Por outro lado, a relevância da depressão não deve ser minimizada, pois, apesar de não ter aparecido no período estudado como causa importante de internação psiquiátrica, esta se apresenta fortemente associada aos problemas da saúde física (Veras, 1994), podendo tanto ser desencadeada por estes como desencadeá-los/agravá-los, possivelmente levando ao aumento da necessidade de internações hospitalares clínicas. Adicionalmente, já foi 
relatada uma alta prevalência de desordem depressiva entre idosos hospitalizados e a associação desta com o aumento do tempo de internação e da morbidade hospitalar (Koenig, 1990).

Os idosos apresentaram alto consumo de recursos da saúde nas internações por transtornos mentais. Cavalcanti \& Saad (1990), analisando os dados da Pesquisa Nacional por Amostra de Domicílios de 1981 (PNAD-81), relativos à Grande São Paulo, identificaram o grupo populacional dos idosos como aquele que apresentou o maior consumo de leitos hospitalares em função de múltiplas internações e do tempo de permanência prolongado. $\mathrm{O}$ tempo de permanência mediano nas internações por transtornos mentais de idosos (sessenta dias) foi bem superior ao parâmetro de 36,5 dias estipulado pela portaria 3.046 (MPAS, DOU, 1982) para os leitos psiquiátricos. Para Queiroz (1993), este perfil de internação prolongada apontaria para uma baixa qualidade do atendimento prestado, trazendo prejuízos para o paciente em função dos riscos implicados em um prolongamento da sua exclusão social.

Os resultados aqui analisados revelam a importância dos transtornos mentais para a população idosa em nosso meio, apontando para a necessidade de reconhecimento destes como um problema da saúde pública a ser enfrentado. Neste sentido, chama a atenção o resultado de um recente estudo (Roberts et al. 1994) realizado em uma amostra de pacientes idosos, assistidos em dois serviços geriátricos (hospital-dia) da Grã-Bretanha, que foram entrevistados com o objetivo de avaliar quais seriam os principais benefícios que eles esperavam obter através do atendimento nesses serviços. Uma melhora da saúde mental foi referida como o quarto item em importância, só sendo superado pelas expectativas em relação à redução das incapacidades, à melhora da qualidade de vida e à redução dos gastos com saúde. Embora as ações da saúde a serem implementadas devam ser orientadas no sentido de conseguir ao máximo a permanência dos idosos na comunidade, elas também devem buscar garantir o acesso à internação hospitalar quando for necessário. É inaceitável que, na vigência do princípio de universalização da atenção à saúde, continuem a operar mecanismos de seleção que dificultem o acesso aos serviços da saúde justamente pelo segmento da população que deles mais necessita. 


\section{CONCLUSÃO}

Diversos autores já chamaram a atenção para a existência de distintos padrões epidemiológicos, quando se investigam os transtornos mentais em populações hospitalares ou na comunidade (Dohrenwend \& Dohrenwend, 1982; Goldberg \& Huxley, 1992). Acesso aos serviços, gravidade da sintomatologia, grau de suporte familiar e social, entre outros fatores, estão intimamente relacionados à utilização dos serviços da saúde mental e serviços da saúde em geral. Enquanto a SCO e a depressão representam os principais problemas da saúde mental entre idosos na comunidade, a esquizofrenia é o principal diagnóstico desse grupo em hospitais psiquiátricos. Mesmo dentro do universo hospitalar, observamos padrões distintos quanto à distribuição, segundo o gênero dos idosos (predomínio masculino na rede privada contratada e feminino na rede pública). Porém, o que pode representar um problema quando se objetiva fazer uma epidemiologia dos transtornos mentais entre os idosos pode, também, ser ụm instrumento valioso na organização da atenção à terceira idade.

Identificar a população cujo nível de sofrimento psíquico ou falta de suporte familiar e social levou ao processo de internação, assim como seus principais problemas mentais, é fundamental como o primeiro passo no sentido da melhor organização do atendimento psiquiátrico à população idosa no Brasil.

\section{REFERÊNCIAS BIBLIOGRÁFICAS}

ALMEIDA FILHO, N.; SANTANA, V. S. \& PINHO, A. R. Estudo epidemiológico dos transtornos mentais em uma população de idosos da área urbana de SalvadorBA. Jornal Brasileiro de Psiquiatria, 33(2):114-120, 1984.

BLAY, S. L. Revisão e crítica da metodologia dos estudos sobre epidemiologia dos distúrbios psiquiátricos na população idosa. Revista da Associagão Brasileira de Psiquiatria, 11(1):1-9, 1989.

BLAY, S. L.; RAMOS, L. R. \& MARI, J. J. Validity of a Brazilian version of the Older Americans Resources and Services (OARS) Mental Health Screening Questionnaire. Journal of the American Geriatrics Society, 36(8):687-692, 1988. 
BLAY, S. L.; MARI, J. J. \& RAMOS, L. R. The use of the face-hand test to screen for organic brain syndromes: a pilot study. Revista de Saúde Pública, 23(5):395-400, 1989.

BRAGA NETO, F. C. Examinando Alternativas Para a Administrafão dos Hospitais: os modelos de gestão descentralizados e por linhas de producão, 1991. Dissertação de Mestrado, Rio de Janeiro: Escola Nacional de Saúde Pública/Fiocruz.

BRASIL. Ministério da Previdência Social. Portaria 3.046. Diário Oficial da Uniäo, Seção 1, p. 13.613-13.616, 22 jul. 1982.

BRASIL. Ministério da Saúde. Secretaria de Estado da Saúde do Rio de Janeiro. Sistema de Informagooes Hospitalares do Sistema Único de Saúde (AIH)-SIH/SUS. Manual de preencbimento e fluxo da AIH para hospitais públicos. Rio de Janeiro, 1990. (Mimeo.)

CAVALCANTI, M. G. P. H. \& SAAD, P. M. Os idosos no contexto da saúde pública. In: Fundação Sistema Estadual de Análise de Dados (SEADE). O Idoso na Grande São Paulo. São Paulo, 1990.

CLARK, R. L. \& SPENGLER, J. J. The Economics of Individual and Population Aging. Nova York: Cambridge University Press, 1980.

COELI, C. M.; CAMARGO JR., K. R. \& VERAS, R. P. O idoso internado: uma avaliação epidemiológica dos serviços de saúde do Município do Rio de Janeiro. In: III CONGRESSO BRASILEIRO DE EPIDEMIOLOGIA. Anais. Salvador, 1995.

CUNHA, U. G. V.;BARROS JR., O. R. \& SIQUEIRA, A.L. Levantamento epidemiológico psicogeriátrico em asilos. Jornal Brasileiro de Psiquiatria, 34(O):389-394, 1985.

DOHRENWEND, B. P. \& DOHRENWEND, B. S. Perspectives on the past and future of psychiatric epidemiology: the Rena Lapour Lecture. American Journal of Public Health, 72:1.271-1.279, 1982.

FETTER, R. B. \& THOMPSON, J.D. Inventors of DRGs look at PPS now. Hospitals, 66(13):136-138, 1992.

GOLDBERG, D. \& HUXLEY, P. Common Mental Disorders: a bio-social model. Londres: Routledge, 1992.

GURLAND, B. J. et al. The Comprehensive Assessment and Referral Evaluation (CARE): rationale, development and reliability. International Journal of Aging and Human Development, 8:9-42, 1977.

JORM, A. F; KORTEN, A. E. \& HENDERSON, A. S. The prevalence of dementia: a quantitative integration of the literature. Acta Psycbiatrica Scandinavica, 76:465-479, 1987. KAHN, H. A. \& SEMPOS, C. T. Statistical Methods in Epidemiology. Nova York: Oxford University Press, 1989. 
KOENIG, H. G. Depressive disorders in older medical inpatients. American Family Pbysician, 44(4):1.243-1.250, 1990.

LINDESAY, J.; BRIGGS, K. \& MURPHY, E. The Guy's/Age Concern survey: prevalence rates of cognitive impairment, depression and anxiety in an urban elderly community. British Journal of Psycbiatry, 155:317-329, 1989.

MAGUIRE, P. A.; TAYLOR, I. C. \& STOUT, R. W. Elderly patients in acute medical wards: factors predicting length of stay in hospital. British Medical Journal, 292:1.2511.253, maio 1986 .

MONTEIRO, M. F. G. \& ALVES, M. I. C. Aspectos demogtáficos da população idosa no Brasil. In: VERAS, R. P. (Org.) Terceira Idade: um envelbecimento digno para 0 cidadão do futuro. Rio de Janeiro: Relume-Dumará; UnATI/Uerj, 1995. p. 65-78.

QUEIROZ, E. M. C. Algumas Observafões Sobre Custos, Tempo Médio de Internafão e Qualidade de Atendimento em Saúde na Assistência Hospitalar a Transtornos Mentais' no Estado do Rio de Janeiro, 1993. Monografia de conclusão do Curso de Especialização em Psiquiatria Social, Rio de Janeiro: Escola Nacional de Saúde Pública/Fiocruz.

RAMOS, L. R. Growing Old in São Paulo, Brazil: assessment of bealth status and social support of elderly people from different socioeconomic strata living in the community, 1986. Tese de Doutorado. Londres: London School of Hygiene and Tropical Medicine/University of London.

ROTHMAN, K. Modern Epidemiology. Boston: Little, Brown and Co., 1986.

TAVARES JR., A. R. Enfermedades mentales. In: PEREZ, E. A. et al. La Atencion de los Ancianos: un desafio para los años noventa. OPS, Publicación científica $n^{\circ}$ 546:172-179. Washington, 1994.

TRAVASSOS VERAS, C. M. Equity in the Use of Private Hospitals Contracted by a Compulsory Insurance Scheme in the City of Rio de Janeiro, Brazil, in 1986, 1992. Tese de Doutorado, Londres: Departamento de Administração Pública, School of Economics and Political Science/University of London.

TRAVASSOS VERAS, C. M. \& MARTINS, M. S. Confiabilidade dos dados nos formulários de Autorização de Internação Hospitalar (AIH), Rio de Janeiro, Brasil. Cadernos de Saúde Pública, 10(3):339-355, 1994.

VERAS, R. P. A Survey of the Health of Elderly People in Rio de Janeiro, Brazil, 1992. Tese de Doutorado, Londres: Guy's Hospital/University of London.

VERAS, R. P. País Jovem com Cabelos Brancos: a saúde do idoso no Brasil. Rio de Janeiro: Relume-Dumará/Uerj, 1994. 
VERAS, R. P. \& COUTINHO, E. Estudo de prevalência de depressão e síndrome cerebral orgânica na população de idosos em três distritos da cidade do Rio de Janeiro. Revista de Saúde Pública, 25(3):209-217, 1991.

VERAS, R. P. \& COUTINHO, E. Prevalência da síndrome cerebral orgânica em população de idosos de área metropolitana da Região Sudeste do Brasil. Revista de Saúde Pública, 28(1):26-37, 1994.

VERAS, R. P.; COUTINHO, E. \& Ney Jr., G. População idosa no Rio de Janeiro (Brasil): estudo-piloto da confiabilidade e validação do segmento de saúde mental do questionário (BOAS). Revista de Saúde Pública, 24(2):156-163, 1990.

VERAS, R. P. \& ALVES, M. I. C. A população idosa no Brasil: considerações acerca do uso de indicadores de saúde. In: MINAYO, M. C. (Org.) Os Muitos Brasis: saúde e populafão na década de 80. Rio de Janeiro/São Paulo: Hucitec/Abrasco, 1995.

VERAS, R. P. \& MURPHY, E. The ageing of the third world: tackling the problems of community surveys - A community survey of the elderly population in Rio de Janeiro: a methodological approach (Part II). International Journal of Geriatric Psycbiatry, 6(9):629-637, 1991.

WORLD HEALTH ORGANIZATION (WHO). Dementia in Late Life: research and action. Report of a scientific group. Technical Report Series 730. WHO, 1986. 


\title{
TITULOS DA \\ SÉRIE EPIDEMTOLÓGICA
}

\begin{abstract}
VoLUME I
EQUUIDADE E SAÚDE: CONTRIBUIÇÕES DA EPIDEMIOLOGIA

Rita Barradas Barata, Masricio Lima Barreto,

Naomar de Almeida Filho \& Renato Peixoto Veras (Orgs), 1997.
\end{abstract}

\begin{abstract}
VoluME II
TeOrIa EpIDEmiológica Hoje: FundaMENTOS, INTERFACES E TENDÊNCIAS

Naomar de Almeida Fillbo, Maxricio Lima Barreto,

Renato Peixoto Veras \& Rita Barradas Barata (Orgs), 1998.
\end{abstract}

VOLUME III

Epidemiologia, Serviços E Tecnologias em SAúde

Mauricio Lima Barreto, Naomar de Almeida Filho,

Renato Peixoto Veras \& Rita Barradas Barata (Orgs), 1998.

VOLUME IV

EPIDEMTOLOGIA: CONTEXTOS E PLURALIDADE

Renato Peixoto Veras, Mauricio Lima Barreto,

Naomar de Almeida Filho \& Rita Barradas Barata (Orgs.), 1998.

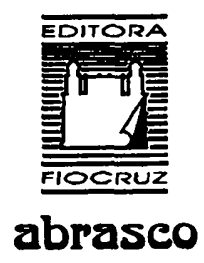




\section{OUTROS TÍTULOS DA EDITORA FIOCRUZ EM CATÁLOGO*}

- Estado sem Cidadãos: seguridade social na América Latina. Sônia Fleury, 1994. 249p.

- Saúde e Povos Indígenas. Ricardo Santos \& Carlos E. A. Coimbra (Orgs.), 1994. 251p.

- Saúde e Doenfa: um olhar antropológico. Paulo César Alves \& Maria Cecília de Souza Minayo (Orgs.), 1994. 174p. 1ª Reimpressão: 1998.

- Principais Mosquitos de Importância Sanitária no Brasil. Rotraut A. G. B. Consoli \& Ricardo Lourenço de Oliveira, 1994. 174p. $1^{\text {a }}$ Reimpressão: 1998.

- Filosofia, História e Sociologia das Ciências I: abordagens contemporâneas. Vera Portocarrero (Org.), 1994. 268p. $1^{2}$ Reimpressão: 1998.

- Psiquiatria Social e Reforma Psiquiátrica. Paulo Amarante (Org.), 1994. 202p. $1^{2}$ Reimpressão: 1998.

- O Controle da Esquastossomose. Segundo relatório do Comitê de Especialistas da OMS, 1994. 110p.

- Vigilância Alimentar e Nutricional: limitasōes e interfaces com a rede de saúde. Inês Rugani R. de Castro, 1995. 108p.

- Hanseniase: representafôes sobre a doenfa. Lenita B. Lorena Claro, 1995. 110p.

- Oswaldo Cruz: a construfão de um mito na ciência brasileira. Nara Britto, 1995. 111p.

- A Responsabilidade pela Saúde: aspectos jurídicos. Hélio Pereira Dias, 1995. 68p.

- Sistemas de Saúde: continuidades e mudanfas. Paulo M. Buss e Maria Eliana Labra (Orgs.), 1995. 259p. (co-edição com a Editora Hucitec)

- Só Rindo da Saúde. Catálogo de exposição itinerante de mesmo nome, 1995. 52p.

- Democracia Inconclusa: um estudo da Reforma Sanitária brasileira. Silvia Gerschman, 1995. 203p.

- Atlas Geográfico de las Malformaciones Congénitas en Sudamérica. Maria da Graça Dutra (Org.), 1995. 144p.

- Ciência e Saúde na Terra dos Bandeirantes: a trajetória do Instituto Pasteur de São Paulo no periodo 1903-1916. Luiz Antonio Teixeira, 1995. 187p.

- Profissões de Saxide: uma abordagem sociológica. Maria Helena Machado (Org.), 1995. 193p.

- Recursos Humanos em Saúde no Mercosul. Organização Pan-Americana da Saúde, 1995. 155p.

- Tópicos em Malacologia Médica. Frederico Simões Barbosa (Org.), 1995. 314p.

"por ordem de lançamento/ano. 
- Agir Comunicativo e Planejamento Social: uma critica ao enfoque estratégico. Francisco Javier Uribe Rivera, 1995. 213p.

- Metamorfoses do Corpo: uma pedagogia freudiana. Sherrine Njaine Borges, 1995. 197p.

- Politica de Saúde: o público e o privado. Catalina Eibenschutz (Org.), 1996. 364p.

- Formafãa de Pessoal de Nivel Médio para a Saride: desafios eperspectivas. Escola Politécnica de Saúde Joaquim Venâncio (Org.), 1996. 222p.

- Tributo a Vênus: a luta contra a sifilis no Brasil, da passagem do século aos anos 40. Sérgio Carrara, 1996.339p.

- O Homem e a Serpente: outras bistórias para a loucura e a psiquiatria. Paulo Amarante, 1996. 141p.

- Rafa, Ciência e Sociedade. Ricardo Ventura Santos \& Marcos Chor Maio (Orgs.), 1996. 252p. (co-edição com o Centro Cultural Banco do Brasil). $1^{\mathbf{3}}$ Reimpressão: 1998.

- Biosseguranfa: uma abordagem multidisciplinar. Pedro Teixeira \& Silvio Valle (Orgs.), 1996. 364p. 1' Reimpressão: 1998.

- VI Conferência Mundial sobre a Mulber. Série Conferências Mundiais das Nações Unidas, 1996. 352p.

- Prevención Primaria de los Defectos Congénitos. Eduardo E. Castilla, Jorge S. LopezCamelo, Joaquin E. Paz \& Iêda M. Orioli, 1996. 147p.

- Clínica e Terapêutica da Doenfa de Chagas: uma abordagem prática para o clinico geral. João Carlos Pinto Dias \& José Rodrigues Coura (Orgs.), 1997. 486p.

- Do Contágio à Transmissão: ciência e cultura na gênese do conbecimento epidemiológico. Dina Czeresnia, 1997. 120p.

- A Endemia Hansênica: uma perspectiva multidisciplinar. Marcos de Souza Queiroz \& Maria Angélica Puntel, 1997. 120p.

- Avaliaf̧ão em Saúde: dos modelos conceituais à prática na análise da implantafão de programas. Zulmira Maria de Araújo Hartz (Org.), 1997. 131p.

- Fome: uma (re)leitura de Josué de Castro. Rosana Magalhães, 1997. 87p.

- A Miragem da Pós-Modernidade: democracia e políticas sociais no contexto da globalizafão. Silvia Gerschman \& Maria Lucia Werneck Vianna (Orgs.), 1997. 226p.

- Os Diários de Langsdorff - v.1 (Rio de Janeiro e Minas Gerais, 08 de maio de 1824 a 17 de fev. de 1825) e v.2 (São Paulo, de 1825 a 22 de nov. de 1826). Danuzio Gil Bernardino da Silva (Org.), 1997. 400p. (v.1) e 333p. (v.2) (co-edição com a Associação Internacional de Estudos Langsdorff e Casa de Oswaldo Cruz) 
- Os Médicos no Brasil: um retrato da realidade. Maria Helena Machado (Coord.), 1997. 244p.

- Cronobiologia: princípios e aplicafões. Nelson Marques \& Luiz Menna-Barreto (Orgs.), 1997. 328p. (co-edição com a EdUSP)

- Saúde, Trabalho e Formagão Profissional. Antenor Amâncio Filho \& Maria Cecilia G. B. Moreira (Orgs.), 1997. 138p.

- Attas dos Vetores da Doenfa de Chagas nas Américas (v.1 - ed. bilíngüe). Rodolfo U. Carcavallo, Itamar Galíndez Girón, José Jurberg \& Herman Lent (Orgs.), 1997. 393p.

- Doenfa: um estudo filosófico. Leonidas Hegenberg, 1998. 137p.

- Epidemiologia da Imprecisão: processo saúde/ doenfa mental como objeto da epidemiologia. José Jackson Coelho Sampaio, 1998. 130p.

- Saúde Pública: uma complexidade anunciada. Mario Iván Tarride, 1998. 107p.

- Doenfa, Sofrimento, Perturbafão: perspectivas etnográficas. Luiz Fernando Dias Duarte \& Ondina Fachel Leal (Orgs.), 1998. 210p.

- Loucos pela Vida: a trajetória da reforma psiquiátrica no Brasil. Paulo Amarante (Coord.), 1998. ( 2 edição revista e ampliada)

- Textos de Apoio em Vigilanncia Epidemiológica. Série Trabalho e Formação em Saúde, 1. Escola Politécnica de Saúde Joaquim Venâncio (Org.), 1998. 149p. 
MPRESSÃO E ACABAMENTO

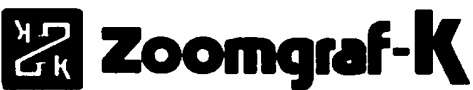

Av. Jansen de Mello, 403 - Niterói

CEP: 24030-020 - RJ - Brasil - 1998

Tels.: PABX (021) 620-2277

Fax: 620-5619 


